\title{
Strategising for Resilience
}

\author{
By
}

Simon Collins

A thesis submitted to the Victoria University of Wellington in fulfilment of the requirements for the degree of Doctor of Philosophy

Victoria University of Wellington 


\section{Abstract}

The term "resilience" is used to describe aspects of businesses that are able to withstand potentially destructive changes in the commercial environment in which they operate. Few studies have investigated the ability that some firms have not just to endure disturbance, but to buck market trends and improve, grow and capitalise on potentially destructive change. This thesis aims to elaborate our existing understanding by contributing empirical knowledge on resilient firms through the examination of the research questions: In the context of the New Zealand Manufacturing sector during the Global Financial Crisis, what contributes to resilience in firms? And, do dynamic capabilities play a role in the resilience of firms?

To address the identified gap in the literature, this research analysed the strategies of seventeen New Zealand manufacturing firms during the Global Financial Crisis utilising a qualitative, case study approach. Teece's (2007) Sensing, Seizing and Transformation dynamic capabilities framework was used to analyse and categorise the firms' actions. The findings confirm some, but also refute other, pre-existing assumptions and understandings regarding the resilience of firms that are offered by the prevailing literature.

This thesis contributes to the field of theory by offering evidence for five propositions that extend the existing resilience literature. These are: first, that the dynamic capabilities framework provides a useful means through which to examine the resilience of firms; second, resilient firms appear to have bundles of dynamic capabilities that provide resilience when present; third, certain capabilities appear to be necessary but not sufficient to create resilience; fourth, capabilities that enable firms to generate additional efficiency and margin appear to be among the most valuable in the creation of resilience, and fifth, capabilities that increase the 'volume' of knowledge, and improve the flow of, and access to, knowledge within a firm also appear to be among the most valuable for creating resilience. 
This examination of the concept of resilience presents new perspectives on why some firms perform better during crises, and how advantage is created and maintained when the environment generates barriers to performance. The results progress resilience as an emerging concept in the strategic management literature in two ways: first, the addition of empirical evidence extends and elaborates current theory regarding what constitutes resilient action in firms; and second, the results highlight the strengths and weaknesses of applying a dynamic capabilities framework to explore strategic management concepts. 


\section{Acknowledgements}

For: Annie and Louis Collins

Supervisors: Sally Davenport and Urs Daellenbach

Funded by: Industrial Research Limited

Advice and Encouragement: Stephen Cummings, Noelle Donnelly, Adam Weaver, Todd Bridgman, Jane Bryson.

Other PhD Students: Rebecca Bednarek, Terry Bowe, Andrea Dickens, Geoff Harrison, Maryam Mirzaei, Sarah Kimani, Sandra Goh.

Friends and Family: Graeme Scott, Linda Scott, Daniel Scott, Hadley Smith, Rose Collins \& Pete McDonald, David \& Siobhan Collins, Pearse Smyth \& Kate Collins, Rachael Swain.

Participants: Every manager who generously donated their time to talk. In particular, those who were so prepared to discuss what it was like to be 'non-resilient'. 


\section{Table of Contents}

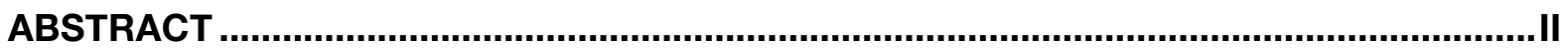

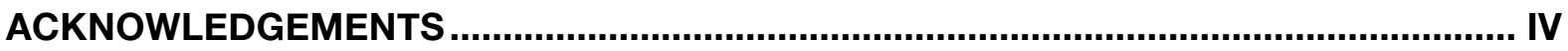

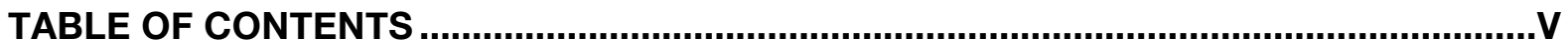

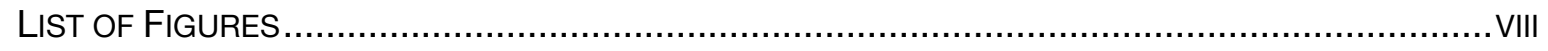

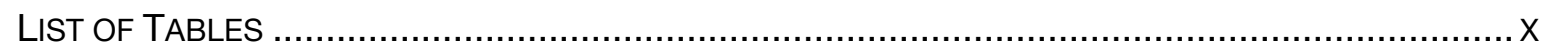

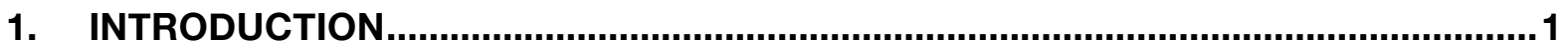

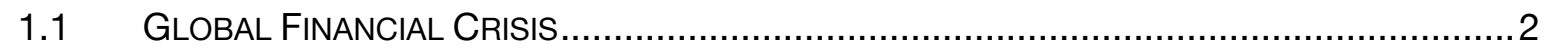

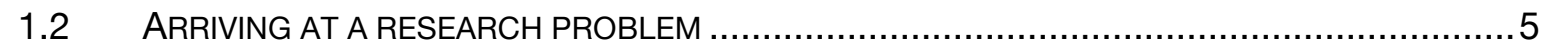

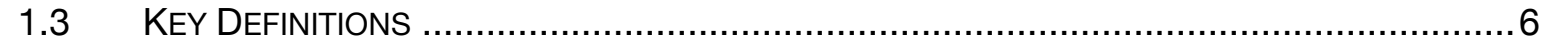

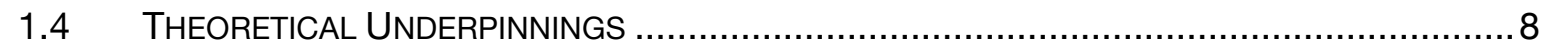

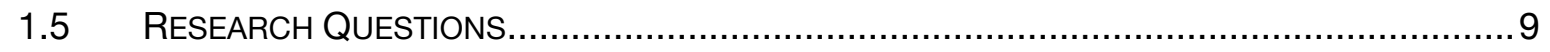

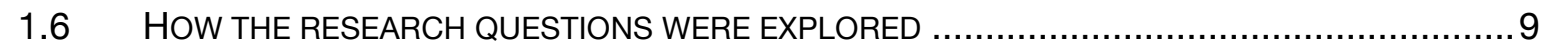

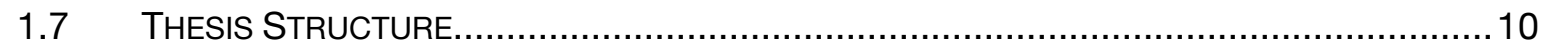

2 LITERATURE

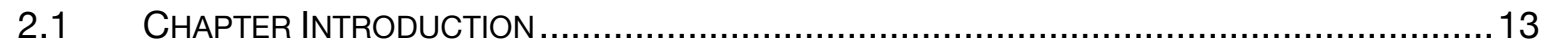

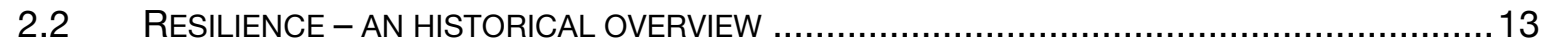

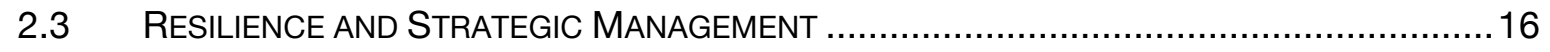

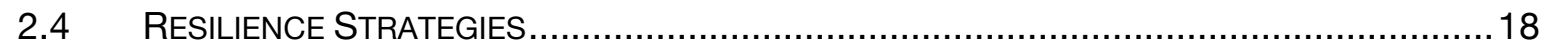

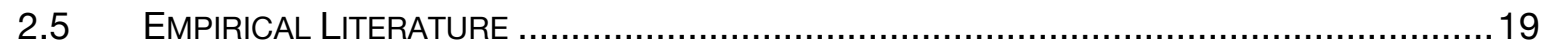

2.6 THEORETICAL RESILIENCE LITERATURE IN MANAGEMENT .......................................22

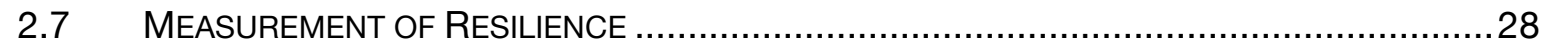

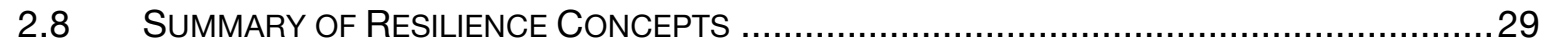

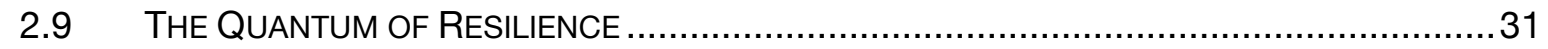

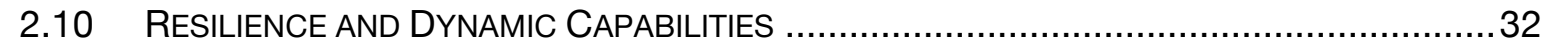

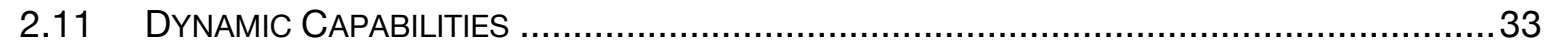

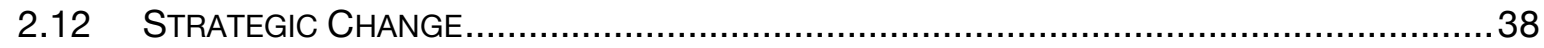

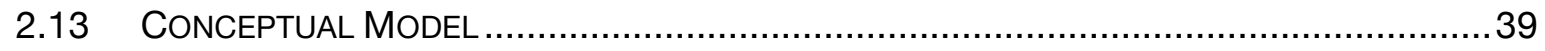

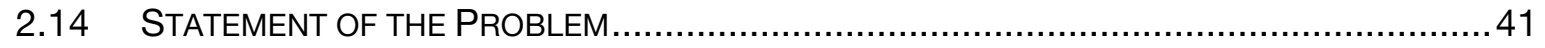

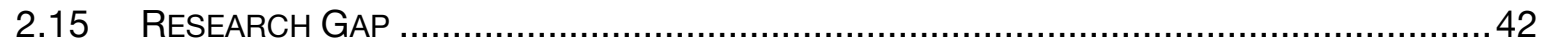

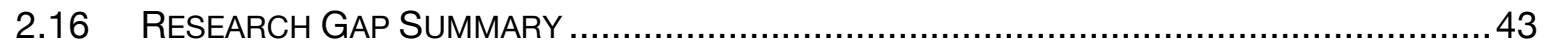

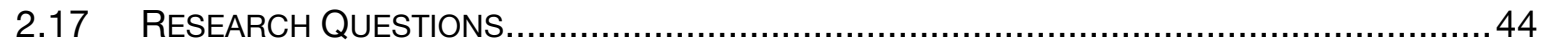

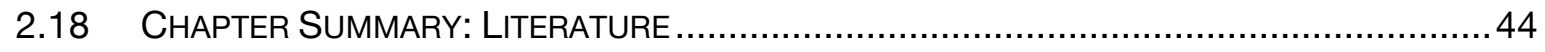




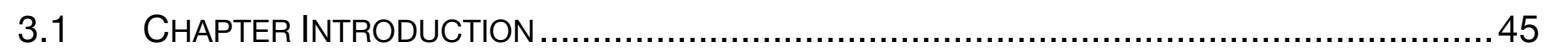

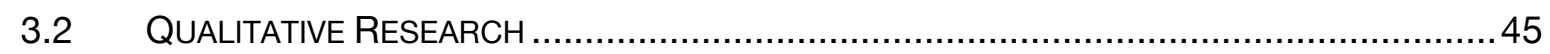

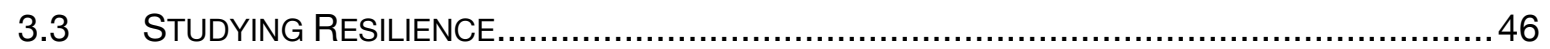

3.4 DYNAMIC CAPABILITIES AS AN ANALYTICAL FRAMEWORK ........................................... 48

3.5 USING INTERVIEWS TO COLLECT DATA.................................................................. 51

3.6 MANAGING THE CREDIBILITY AND RELIABILITY OF DATA ...........................................52

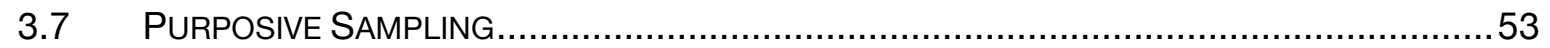

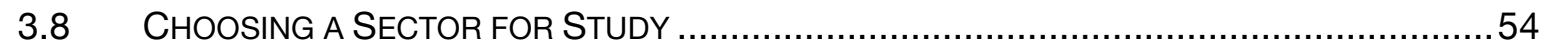

3.9 HUMAN ETHICS, ANONYMITY AND CONFIDENTIALITY ................................................ 61

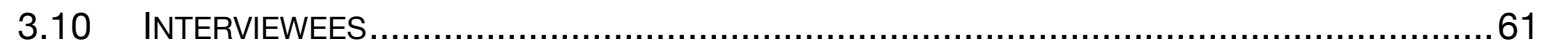

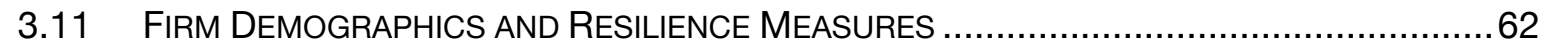

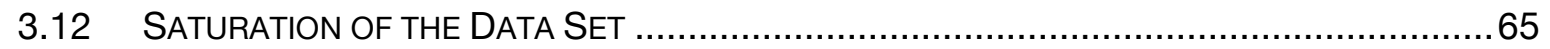

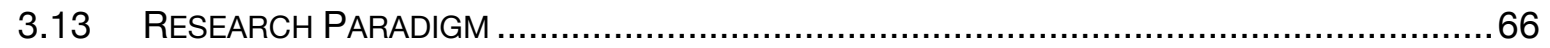

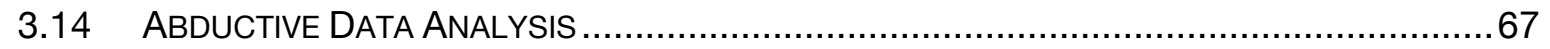

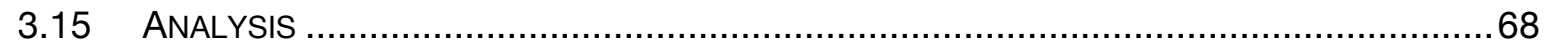

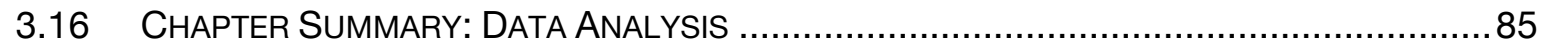

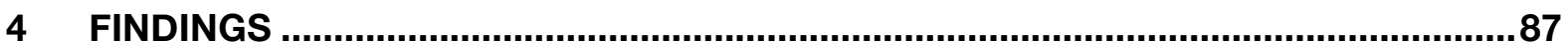

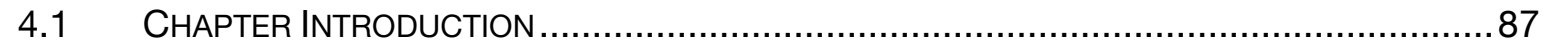

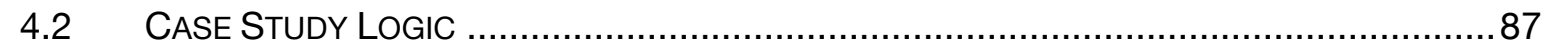

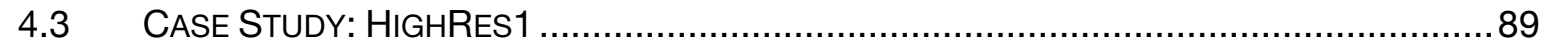

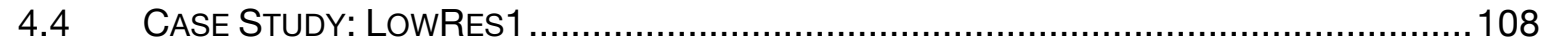

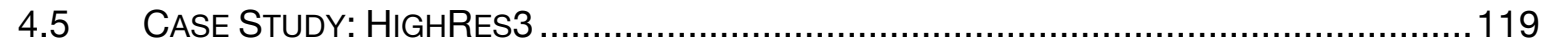

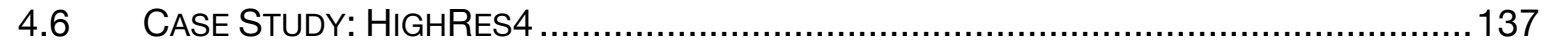

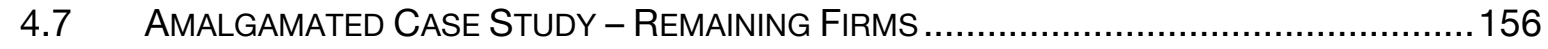

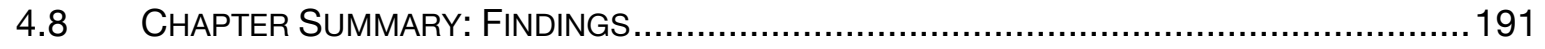

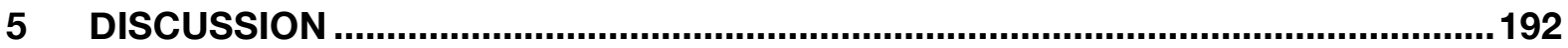

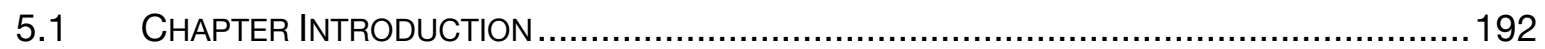

5.2 Discussion PART 1: REFLECTIONS ON TEECE'S FRAMEWORK ................................192

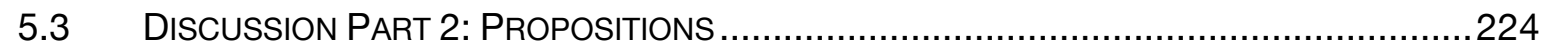

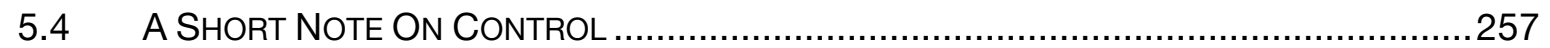

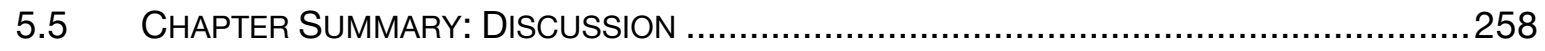

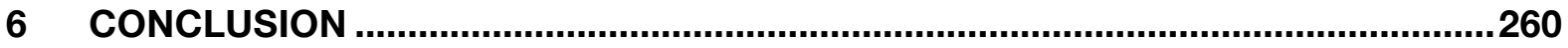

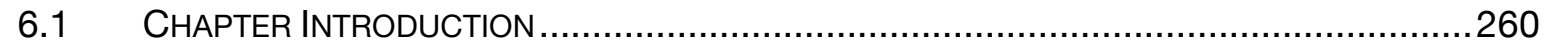




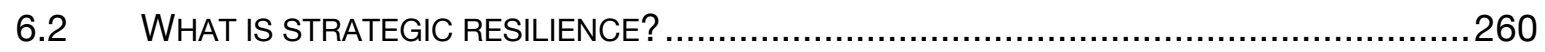

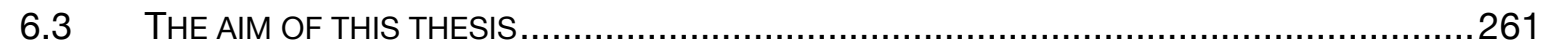

6.4 RESEARCH QUESTIONS, FINDINGS AND CONTRIBUTION..........................................262

6.5 NEW FINDINGS OF THIS THESIS THAT CONTRIBUTE TO RESILIENCE .............................268

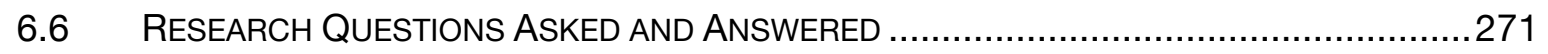

6.7 BROADER CONTRIBUTIONS TO LITERATURE........................................................273

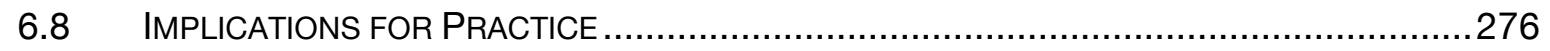

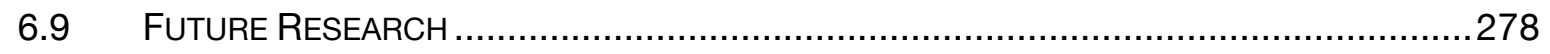

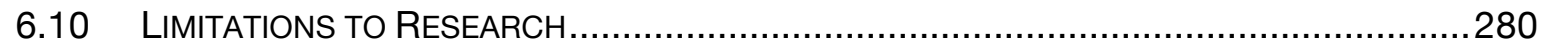

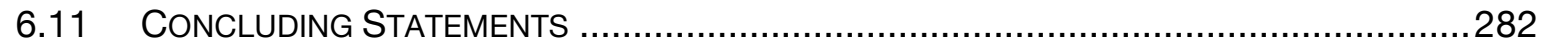

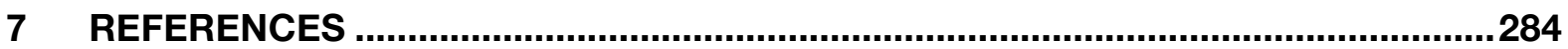

ApPendix 1: AlignMENT BetWEEN IDENTIFIED RESILIENCE AND DYNAMIC CAPABILITIES

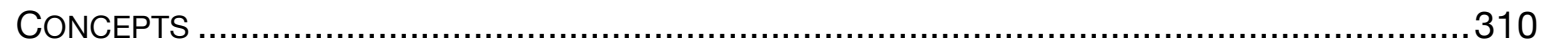

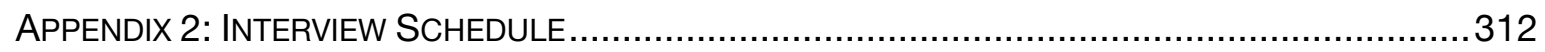

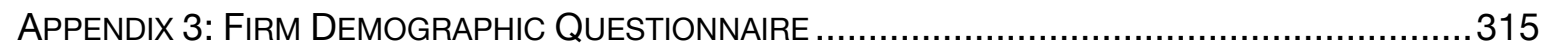

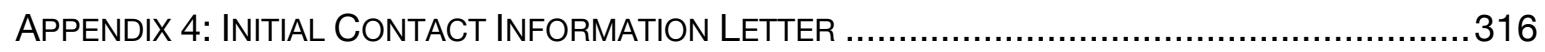




\section{List of Figures}

Figure 1: Business Failures in the US Manufacturing Sector (Dun \& Bradstreet, 2012)

Figure 2: References to Resilience (Google Scholar, 2011) ................................16

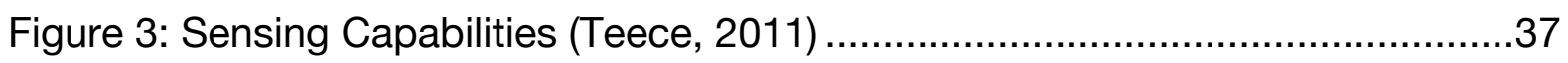

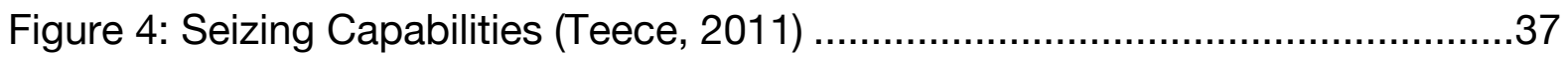

Figure 5: Transformation Capabilities (Teece, 2011)........................................38

Figure 6: Conceptual Schema Developed From Literature...................................40

Figure 7: Change in Real Value Added (June 2012 versus December 2007) in New Zealand Sectors (Captial Economics Limited, 2012) ................................55

Figure 8: Manufacturing output fails to recover from recession (Hosking, 2012) .....56

Figure 9: New Zealand Manufacturing Industry Employees (Statistics New Zealand, 2012) .57

Figure 10: New Zealand Manufacturing Enterprises 2000 - 2012 (Statistics New Zealand, 2012) .58

Figure 11: Hotspots in Discussion of Dynamic Capabilities .84

Figure 12: Select Case Study Firms Performance Over Time (indicative). .88

Figure 13: Sensing Totals 198

Figure 14: Seizing Totals 201

Figure 15: Delineating the Customer Solution \& Business Model Totals. 201

Figure 16: Seizing Capabilities that Contribute to Resilience 212

Figure 17: Managing Strategic Fit so that Asset Combinations are Value Enhancing 216

Figure 18: References to total Sensing, Seizing and Transformation by Firm, in Order of Resilience .223

Figure 19: Dynamic Capabilities as Resilience Contributors or Necessary but not Sufficient .230 
Figure 20: Processes to Tap Supplier and Complementor Innovations

Figure 21: Processes to Identify Target Market Segments, Changing Customer Needs and Customer Innovation 233

Figure 22: Curvilinear model of market diversity (Rumelt, 1982) 240

Figure 23: Resilience and the Continuum of Manufacturing Activities 242

Figure 24: Standard Value Chain Compared to Resilient Value Chain 243

Figure 25: Knowledge Management Dynamic Capabilities .245

Figure 26: Processes to Direct Internal R\&D Totals .249

Figure 27: Embracing Open Innovation Capabilities Relationship to Resilience ....251

Figure 28: Evidence supporting and refuting resilience concepts identified .263 


\section{List of Tables}

Table 1: Resilience Concepts, Definitions, and References 30

Table 2: Overlaps between identified resilience and dynamic capabilities concepts 32

Table 3: Core building blocks of dynamic capabilities and ordinary capabilities (Teece, 2014a) .35

Table 4: Empirical studies of resilience; key features 47

Table 5: Approach to Studying Resilience in this Thesis 48

Table 6: Case Study Approaches to Dynamic Capabilities .51

Table 7: Interview Questions and Related Resilience Concepts .52

Table 8: Characteristics of Participant Firms 60

Table 9: Qualitative Resilience Measures. .63

Table 10: Discriminating Evidence: Same year performance - Firms HighRes4 and MidRes1 .65

Table 11: Discriminating Evidence: Same year performance - Firms HighRes4 and MidRes1 .65

Table 12: Teece's $(2007,2011)$ Dynamic Capabilities Framework Operationalisation: Sensing Capabilities .72

Table 13: Teece's $(2007,2011)$ Dynamic Capabilities Framework Operationalisation: Seizing Capabilities: Delineating the Customer Solution and Business Model. 73 Table 14: Teece's $(2007,2011)$ Dynamic Capabilities Framework Operationalisation: Seizing Capabilities: Selecting Enterprise Boundaries to Manage Complements and 'Control' Platforms .73

Table 15: Teece's $(2007,2011)$ Dynamic Capabilities Framework Operationalisation: Seizing Capabilities: Selecting Decision Making Protocols .74

Table 16: Teece's $(2007,2011)$ Dynamic Capabilities Framework Operationalisation: Seizing Capabilities: Building Loyalty and Commitment .75 
Table 17: Teece's $(2007,2011)$ Dynamic Capabilities Framework Operationalisation: Transformation Capabilities: Achieving Decentralisation and Near Decomposability ......................................................................................

Table 18: Teece's $(2007,2011)$ Dynamic Capabilities Framework Operationalisation: Transformation Capabilities: Cospecialisation...............................................76

Table 19: Teece's $(2007,2011)$ Dynamic Capabilities Framework Operationalisation: Transformation Capabilities: Governance....................................................77

Table 20: Teece's $(2007,2011)$ Dynamic Capabilities Framework Operationalisation: Transformation Capabilities: Knowledge Management ....................................77

Table 21: Examples of Evidence for Dynamic Capabilities: Firm HighRes4 ............80

Table 22: Quantification of References to Dynamic Capabilities From Interviews ...82

Table 23: Variance of Firm Clusters - High Versus Low Resilience ..........................84

Table 24: Relative Firm Resilience Rankings on Objective Measures .....................88

Table 25: HighRes1: Dynamic Capabilities Heat Map ........................................106

Table 26: LowRes1: Dynamic Capabilities Heat Map .........................................116

Table 27: HighRes3: Dynamic Capabilities Heat Map ........................................134

Table 28: HighRes4: Dynamic Capabilities Heat Map ………............................153

Table 29: HighRes4: Dynamic Capabilities Heat Map Continued...........................154

Table 30: HighRes4: Dynamic Capabilities Heat Map Continued...........................155

Table 31: Amalgamated Case Dynamic Capability Heat Maps ..............................187

Table 32: Difference in proportion of references to dynamic capabilities in the most resilient compared to the least resilient firms.

Table 33: Selecting Decision Making Protocols Difference Between Top and Bottom

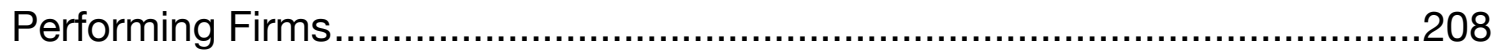

Table 34: Building Loyalty and Commitment Differences Between Top and Bottom Performing Firms 211 
Table 35: Decentralisation Differences Between Top And Bottom Performing Firms 213

Table 36: Managing Strategic Fit and Cospecialisation Differences Between Top And Bottom Performing Firms ......................................................................215

Table 37: Governance Capabilities Difference Between Top And Bottom Performing

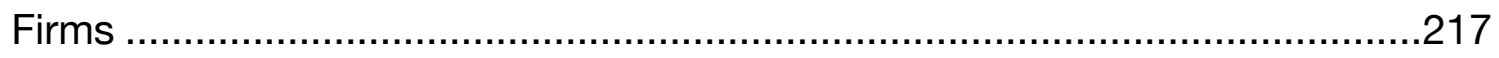

Table 38: Knowledge Management Capabilities Differences Between Top And

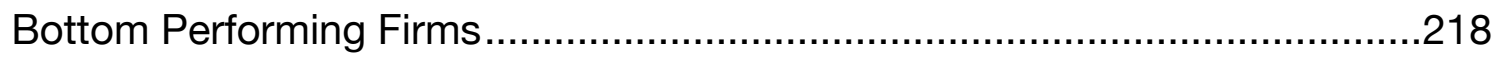

Table 39: Dynamic Capabilities Expressed by Most and Least Resilient Firms - Sorted

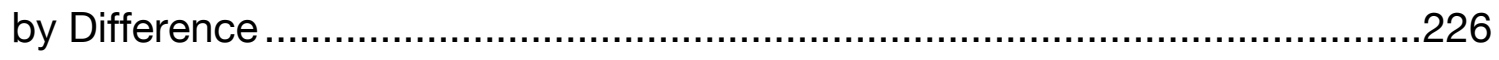

Table 40: Resilient compared to non-resilient firms percentage of discussion ......246

Table 41: Core Resilience Concepts Identified In Literature.................................265

Table 42: Research questions, position of literature and findings of this thesis.....272

Table 43: Research questions, position of literature and findings of this thesis.....273

Table 44: Research questions, position of literature and findings of this thesis.....273 


\section{Introduction}

'If you're going through hell, keep going'- Winston Churchill

This thesis aims to contribute empirical knowledge of resilience in firms in order to elaborate our existing understanding through the examination of the research questions: In the context of the New Zealand Manufacturing sector, during the GFC, what contributes to resilience in firms? And, do dynamic capabilities play a role in the resilience of firms? To address these questions, the study utilised the established dynamic capabilities framework as applied by many authors (cf. Augier \& Teece, 2009; Di Stefano, Peteraf, \& Verona, 2010; Easterby-Smith, Lyles, \& Peteraf, 2009; Helfat, Finkelstein, \& Mitchell, 2007; Helfat \& Peteraf, 2009) to examine the resilient actions (Rose, 2004) and capabilities (Birkie, Trucco, \& Kaulio, 2014; Vogus \& Sutcliffe, 2007). Dynamic capabilities focus on the creation, reconfiguration and renewal of a firm's assets to create competitive advantage. They are different from ordinary capabilities in that dynamic capabilities are unique to a firm. These capabilities are operationalised using Teece's (2007) framework that describes dynamic capabilities as being categorised as sensing, seizing or transformation processes. Understanding the resilience strategies of firms from this perspective has provided a new view of what enables a firm to continue to perform despite significant environmental disturbance.

Through a qualitative case analysis of seventeen firms in the New Zealand manufacturing sector, this thesis examines the influence of strategy and capability on the resilience of firms. The findings show that dynamic capabilities provide a useful framework through which to explore the resilience of firms, but also enables an understanding of how particular bundles of capabilities contribute to this resilience. Theoretical contributions are made to the resilience literature by applying the logic of dynamic capabilities to examine the resilience conceptual model identified in the literature review, and by confirming some, and disconfirming other, proffered 
resilience imbuing characteristics and attributes of firms. A further theoretical contribution is made to dynamic capabilities by elaborating how these capabilities are related to competitive advantage (Helfat \& Peteraf, 2009).

The following chapter outlines how the research gap was identified, what made up the existing basis in theory in the area of resilience, and the structure of the thesis.

\subsection{Global Financial Crisis}

The Global Financial Crisis (GFC) provides the context for the firms to be studied in this thesis. The GFC is described by some as the worst financial crisis since the great depression of the 1930sand resulted in government bailouts of banks, downturns in global stock exchanges as well as housing markets (Pendry, 2009). The crisis began in earnest in 2006 (Aizenman \& Jinjarak, 2009; Carmassi, Gros, \& Micossi, 2009) lasting a number of years, in New Zealand, until 2010 when positive GDP growth returned (Statistics New Zealand, 2010c).

In late 2010 a report published by the International Monetary Fund found there was no agreement between policy makers and researchers as to what caused the GFC (Merrouche \& Nier, 2010). Debate centres on whether accommodative financial policy, growing global imbalances in capital flows, or a combination of the two was the root cause of the crisis (Bernanke, 2010; Taylor, 2007; White, 2009). King (2010) suggests it was a combination of both influences stating: 'Capital flows provided the fuel which the developed world's inadequately designed and regulated financial system then ignited to produce a firestorm that engulfed us all' (p. 4).

Despite disagreement regarding the ultimate cause, the effect was not in doubt, they were wide ranging and far reaching (Blankenburg \& Palma, 2009; Economic and Social Commission for Western Asia, 2009; Elliot, 2011). A cascading collapse of investment banks and financial institutions created a catastrophic reduction in the availability of global credit. This was the event that tipped the world into recession, 
constraining the global supply of credit to retail banks and eventually to consumers (Crotty, 2009).

\subsubsection{Effect on businesses}

The World Bank (2012) predicted the GDP growth rate for a developed country in 2012 to be an average of 5.4 percent - the lowest in 10 years. Businesses bore the brunt of this economic contraction with global business failures increasing at an annual rate of 175\% during 2008 and 2009 (The Economist, 2011). Certain countries were particularly affected: Spain and Britain both saw large numbers of failures during this period. On a global scale the impact on businesses was far-reaching and often severe. In the United States more than 200,000 businesses failed due to the direct effects of the GFC (Figure 1) (Kavoussi, 2012), in the United Kingdom nearly 20,000 firms went out of business over the same period.

Figure 1: Business Failures in the US Manufacturing Sector (Dun \& Bradstreet, 2012)

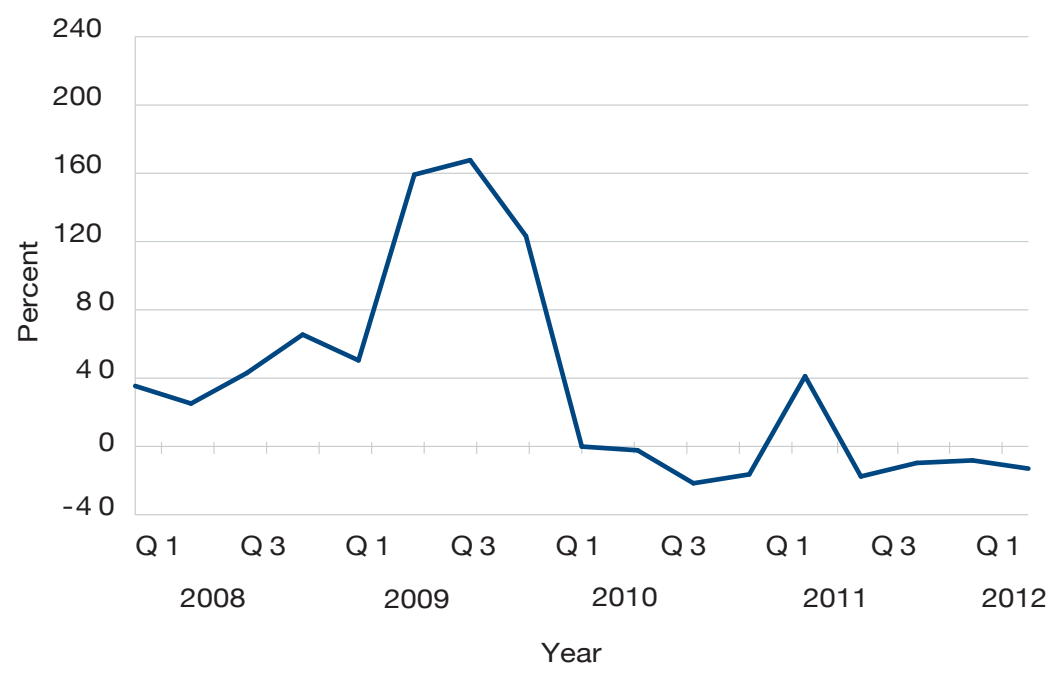

\subsubsection{Global Demand}

World-wide flows of trade declined by an average of twelve percent in 2009 (Schwartz, 2009). After a boom in commodity prices in preceding years, prices fell, particularly in developed countries (German, 2009). From its peak of demand, consumption of oil dropped by 3.7 million barrels per day. In consequence, the price of a barrel of oil 
dropped between 2008 and 2009 (British Petroleum, 2011) from a peak of more than $\$ U S 140$ to less than $\$$ US60 - a decline of 59 percent. Other commodities had historic increases in prices wiped out by the crisis. While oil had risen 800 percent since 2001, copper prices had increased by 700 percent and wheat 400 percent (Krauss, 2008). The slide in prices during 2008 saw nearly every major commodity lose half of the gains in prices made since 2001 (International Monetary Fund, 2012).

Consumer spending worldwide declined precipitously during the GFC, with rates of decline closely following the increasing instances of delinquency on mortgages, credit cards and car loans in the United States during this period (Barbaro \& Uchitelle, 2008). Retail spending in the US in 2009 decreased by 10.8 percent (Goldman, 2008). This level of depressed activity lasted into 2010 , which made this period the weakest two year period in the US since World War II (Kowalski, 2012). The weak trend in retail spending continued into 2012.

\subsubsection{Capital flows}

In the run-up to the GFC the U.S., Australia, Spain and the United Kingdom had been importing capital at higher than average rates (Backus \& Cooley, 2012) while Germany, Japan, China, Switzerland and the oil producing countries were exporting capital. This led to global imbalances that drove up asset prices, in particular in the U.S. but also in other developed countries. Before the GFC, the U.S. had become increasingly dependent on these capital inflows to finance an increasing trade deficit (Fratzscher, 2011). At that stage 1999 had seen the US post the largest imbalance in recorded history - US $\$ 316$ billion, or 3.7 percent of GDP. However the US current account deficit continued to grow, reaching more than six percent in 2006 which was once again the largest deficit in recorded history (Obstfeld \& Rogoff, 2005).

\subsubsection{The GFC in New Zealand}

There was little delay in the spread of money market friction from the US and Europe to New Zealand (Bollard \& Ng, 2009). New Zealand's economy was one of the first 
globally to enter recession in late 2008 (New Zealand Treasury, 2010) and despite being sixth equal shallowest at a cumulative loss of $3.3 \%$, it was also one of the longest in the crisis. Unemployment for the country more than doubled from 80,000 in 2007 to 160,000 in 2009 (Statistics New Zealand, 2010a). In 2009 business failures in New Zealand increased by $40 \%$ over the previous year (Slade, 2009). No sector in this country felt the GFC more so than that of manufacturing (Statistics New Zealand, 2012b).

\subsection{Arriving at a research problem}

'Call it the resilience gap. The world is becoming turbulent faster than organizations are becoming resilient.' (Hamel \& Valikangas, 2003, p. 1)

'In turbulent, surprising, continuously evolving marketplace environments only well-prepared, flexible, agile, and relentlessly dynamic organizations will thrive.' (Lengnick-Hall \& Beck, 2009, p. 3)

'Organizational resilience has been an increasingly important concept in the face of turbulence and uncertainties. However, there is still a lack of empirical research in measuring, understanding and developing organizational resilience.' ( $\mathrm{Ng}, 2013$, p. 81)

A number of concurrent threads coalesced to provide a strong direction for study when this project began in 2010. The GFC was strongly ensconced in the world's economic discourse and, despite beginning in earnest a number of years before (Merrouche \& Nier, 2010), it was continuing to wreak unexpected and significant impact across the global financial system (Nielsen, 2010). The term 'resilient' was emerging in discourse as a descriptor for firms that were managing to avoid the strongest effects and even perform well despite the GFC (Colebatch, 2009; Kruger, 2008; Rudd, 2009). 
Addressing this real world occurrence was the research agenda set out by Sutcliffe and Vogus (2007). They suggest that resilient firms have superior margins on products. Firms with better productivity as such can create larger margins and hence resilience. Further investigation into the resilience literature exposed its underdeveloped state, but also its raw potential for development through research. The calls for validation through evidence and theoretical development were clear (Carmeli \& Markman, 2011; Hamel \& Valikangas, 2003; Lengnick-Hall \& Beck, 2009; Reinmoeller \& van Baardwijk, 2005).

\subsection{Key Definitions}

\section{Resilience}

This thesis differentiates between the engineering, ecological and psychological definitions of resilience. Hard science definitions tend to emphasise the speed with which a system can return to a stable state after a disturbance as a measure of resilience (Bodin \& Wiman, 2004). This amounts to an emphasis on the efficiency of function (Holling, 1996). For example:

'[Resilience is] the speed with which a system returns to equilibrium state following a perturbation' (DeAngelis, 1980, p. 764)

Contrasting the efficiency emphasis of engineering definitions, authors from the field of ecology are more likely to discuss resilience as the capacity of a system to maintain continuity of function through the persistence of a stable state (Holling, 1996).

'The magnitude of disturbance that can be absorbed before the system changes its structure by changing the variables and processes that control behaviour' (Holling, 1996, p. 33) 
Definitions of resilience in psychology emphasise different attributes to that of other fields. Instead, a subject's capacity for adaptation to stress or trauma is the measurable attribute.

'[Resilience is] the ability to recover from setbacks, adapt well to change, and keep going in the face of adversity.' (Ovans, 2015, p. 1)

Economics, commerce and management definitions of resilience borrow readily from the range of definitions offered by other fields. Most consistently definitions resemble that of psychology and ecology, in that they refer to the firm's ability to adapt to change (Hamel \& Valikangas, 2003) but also to persist despite the presence of disturbance (Carmeli \& Markman, 2011). Such definitions include:

'[Resilience is] continually anticipating and adjusting to deep secular trends that can permanently impair the earning power of a core business' (Hamel \& Valikangas, 2003, p. 53)

'[Resilience involves] processes and dynamics that create or retain resources...that enable organisations to successfully cope with, and learn from the unexpected' (Birkie et al., 2014, p. 3419)

These definitions are particularly relevant in their fields. However, for application in strategic management they required further refinement. As such these various definitions represented a starting point for the development of a useful and operationalised characterisation of resilience for the strategy field. This thesis synthesises the above, and further characterisations of resilience, into a working definition in Chapter 2: Literature. 


\subsection{Theoretical Underpinnings}

This study is based in the dynamic capabilities literature, grounded in the field of strategic management (Teece, 2007; Teece \& Pisano, 1994). The research is designed to augment the developing field of resilience with the validity of the established dynamic capabilities theoretical perspective. The resilience literature predating this thesis was examined through the dynamic capabilities framework, to provide insight into the usefulness of existing theoretical offerings and the progress the understanding of how strategy affects the resilience of firms.

This study utilised a case approach to examine a number of firms in a sector significantly affected by the GFC. This provided a rich view of firms from the manufacturing sector, from various individual settings within that sector. The firms studied for this thesis were active in areas including medical and health (both animal and human), technology, food and beverage, plastics, and children's toys.

These firms experienced the GFC in various ways and as such created unique and particular approaches to manage the crisis. These approaches had various levels of success and as such provided a set of actions to compare the effectiveness of resource based resilience strategies (Rouse \& Daellenbach, 1999). The range of strategies offers insight into the types of responses to crises that create resilience in firms.

In addition, this thesis provides new insight into the dynamic capabilities framework. The dynamic capabilities view of strategic management has emerged as an area of intense interest over recent years (Barreto, 2010). The field emerged out of the resource based view of the firm in the 1990's (Teece \& Pisano, 1994). The literature on dynamic capabilities has also not extended the concept's application into different contexts (Zahra, Sapienza, \& Davidsson, 2006). Easterby-Smith et al. (2009) suggest that there is a need for more focused research into dynamic capabilities. This study provides a focus and empiricism through examining resilient action as a form or 
bundle of dynamic capabilities, extending the usefulness of the framework and providing a unique view into the link between dynamic capabilities and the performance of firms in dynamic and hypercompetitive environments (Teece, Pisano, \& Shuen, 1997).

\subsection{Research Questions}

This thesis aims to contribute to the understanding of resilience strategies through the following research questions which were examined in the context of the New Zealand Manufacturing sector during the GFC. The questions were as follows:

1. What contributes to resilience in firms?

a. What are the strategies, resources and capabilities that enabled resilient firms to continue to perform (or not) during environmental shocks?

b. What are the attributes and features of firms that enable resilience during environmental shocks?

2. Do dynamic capabilities play a role in the resilience of firms?

\subsection{How the research questions were explored}

Resilience is a highly contextual phenomenon. That is, the resilience of a firm, system, person or organism is unique to that subject, and situational to the disturbance (Block, 1993; Folke et al., 2004; Holling, 1973). As such any investigation into resilience is highly embedded in the context of that study. By categorising the strategies of firms using the dynamic capabilities framework, the generalizability of these highly contextual findings is improved. This thesis takes the approach of employing case studies of firms struggling with a crisis. The case method is contextually embedded by nature and has a particular strength in the elaboration of theory (Eisenhardt, 1989a; Graebner \& Eisenhardt, 2007; Yin, 2002). By studying resilience qualitatively, richer insights can also be gained (Yin, 2010). 
Because of the highly embedded nature of a resilience response, it was necessary to identify a disturbance that significantly and broadly affected the firms under study. The GFC provided this as a kind of natural experiment within which to explore the responses of firms to severe reductions in demand, access to capital, and a significant and persistent appreciation of the New Zealand exchange rate, among other effects (Bellamy Foster \& Magdoff, 2009; Bollard \& Ng, 2009). The New Zealand manufacturing sector was identified as a prime candidate for study within this context as it performed poorly relative to other New Zealand sectors during the period of the GFC (Pryor, 2012; Weir, 2012). Case firms selected from this sector had a range of levels of performance. These firms were compared in order to identify the particular dynamic capabilities that appeared to contribute to resilience.

In all, seventeen firms were studied using semi-structured interviews to collect data. The sample includes a mixture of large and small firms with performance that ranged from resilient and successful despite the disturbance through to non-resilient and eventual failures. The strategies of top and bottom performing firms were compared, while middle performing firms served to mediate the findings of this comparison (Rouse \& Daellenbach, 1999). The qualitative case studies were used to structure and elucidate these findings. Teece's $(2007,2011)$ dynamic capabilities was used as a framework to structure the findings from case firms.

\subsection{Thesis Structure}

This thesis contains six chapters, the introduction, literature review, research approach, findings, discussion and finally, conclusion. A brief outline of chapter content follows:

Chapter 2: Literature Review. This chapter identifies the way in which the concept of resilience has transitioned from engineering and science literature, through psychology and finally into commerce and management disciplines. The current state of resilience discussion in strategic management is identified and developed into a 
theoretical framework. This chapter also identifies the framework used for analysis dynamic capabilities. The chapter concludes with an identified research gap and the questions formulated to address it.

Chapter 3: Research Approach. This chapter describes how the research was conducted. First, by examining how both resilience and dynamic capabilities have been studied before, the chapter then outlines the reasoning behind the choice to use qualitative case studies to interpret findings. The GFC and sector selected for study are discussed and the reasoning elucidated. The chapter concludes by describing the process of analysis that was followed to produce the written cases presented in the Findings chapter.

Chapter 4: Findings. The outcomes of the analysis process are presented as findings. By first ranking the firms in terms of their resilience to the GFC, the logic for comparison is revealed. The findings identify that while dynamic capabilities may have been present in all firms, the suitability and particularities of dynamic capabilities appear to play a role in the resilience. Through the comparison of cases, the commonalities between the resilience responses of various firms emerged. The differences and similarities between cases are structured and elucidated.

Chapter 5: Discussion. The discussion integrates the findings of the thesis and the identified literature. The chapter approaches this by first exploring the utility of the dynamic capabilities framework as a means of analysing the resilience of firms, and second by offering four propositions for how firms that were more resilient to the GFC acted. These propositions were formed from the abstraction of the emergent themes that resulted from analysis.

Chapter 6: Conclusion. The contribution of the thesis is outlined in Chapter 6. This synthesises how the propositions, compare with the theoretical framework identified in the literature review. This chapter explains how the thesis contributes to the 
understanding of resilience and resilience strategy literature in the academic setting, as well as the implications for practice. Finally, the chapter identifies further areas for research that would capitalise on the findings as described previously. 


\section{Literature}

\subsection{Chapter Introduction}

This literature review identifies the emergence of the term 'resilience' across multiple fields over the past 150 years. This conceptual development is traced to the management literature, where the current thinking regarding the term is delineated. Potential gaps for new research in this understanding are identified and the research questions to address those gaps are posed.

\subsection{Resilience - an historical overview}

The term resilience has been used in engineering for decades to describe a characteristic of materials which designates how quickly they return to their previous configuration after the removal of a particular stressor (Glantz \& Johnson, 1999). The concept of resilience has since been applied in a range of fields, including: ecological and environmental sciences (Folke et al., 2004; Gunderson \& Holling, 2001; Holling, 1973; Walker \& Salt, 2006); psychology (J Block, 1950; Jack Block, 1993; Jack Block \& Kremen, 1996); systems theory (Berkes, Colding, \& Folke, 2002); information and communications technology (Sabherwal, Hirschheim, \& Goles, 2001); and strategic management (Carmeli \& Markman, 2011; Coutu, 2002; Hamel \& Valikangas, 2003). The essence of the term - that of the ability to cope with change is ubiquitous across fields. However often the nuances and terms of application vary. This section traces a brief history of the term in the natural and social sciences.

For the first century of its use, the term resilience was employed in piecemeal fashion. The earliest available full-text article that employs the term was from Professor Clerk Maxwell's (1865) investigation into electromagnetic fields. He discusses the retention of energy by bodies in a field for use in 'elastic resilience'. Resilience then makes its first appearance in the field of health science in a discussion of the properties of bone (Hulsen, 1896). In the early $20^{\text {th }}$ century the biological sciences began to employ the 
term. Drabble (1907) uses resilience to describe the capacity of cell walls to recover from changes in fluid pressure. The first mention of the resilience of ecosystems occurs in 1955 in a discussion of the fluctuation of animal populations (MacArthur, 1955). In psychology, the reason some individuals were able to emerge from significant risk experiences better than others had often been attributed to some form of internal hardiness (Bolig \& Weddle, 1988). Block (1950) introduced the concept of psychological resilience, which sought to address a disparity between observed and described phenomena by identifying the reason, attribute or ability that enabled some individuals to cope with trauma more effectively than others.

The end of the 1960's bought a significant increase in the pace and abundance of research into resilience. Redl (1969) further developed the concept in the field of psychology suggesting the Freudian structure of the ego is the source of resilience, as it is the basis of the psyche's ability to perceive and cope with negative pressure (Anthony \& Cohler, 1987). The definition of resilience that emerged in psychology deviated slightly from that of other sciences. The first use of resilience as an adaptive capacity emerged from the field of psychology, as did the notion that a resilience response may lead to positive outcomes, rather than the return to a previous state or level of function.

C. S. Holling's seminal 1973 paper: Resilience and Stability of Ecological Systems, established resilience as a construct in the field of ecology using a systemic view of ecosystems, rather than of single animal populations (Walker, Holling, Carpenter, \& Kinzig, 2004). This description of resilience was the first in the natural sciences to deviate from the engineering definition of the term and to acknowledge sets of independent but interacting variables. Hollings describes resilience as: 'a measure of the persistence of systems and of their ability to absorb change and disturbance and still maintain the same relationships between populations or state variables' (p. 14). This ecosystemic view of resilience expanded over time to include not just natural systems but human systems as well. The first article of this type examines the relationship of the ancient Mesopotamians to their environment (Adams, 1978), which 14 
described the way in which human settlements in marshlands were responsive and adaptable to their environment's cycles of alternatingly drying out and flooding again.

The concept of resilience began to emerge in business and economics during the 1990s in what amounts to a predictable jump from ecological sciences to environmental economics (Munasinghe, 1993). Studies tended to focus on systemic resilience such as that of economies (Franken, Le Fort, \& Parrado, 2004) and industry sectors (M. Muller, 1997). At the firm level, discussion of resilience at this time was often grounded in an operational context, with authors focusing on the resilience to shocks of supply chains (Hollis, 1996), and information systems (Benjamin, Gladman, \& Randell, 1998). It would take until the early 2000's for the concept of resilience to enter the field of strategic management.

Researchers associated with the Harvard Business School provide two of the first forays into examinations of the strategic resilience of firms or the resilience of their strategies (Coutu, 2002; Hamel \& Valikangas, 2003). This initial exploration did not include any empirical research into the nature of resilience; rather it provided an identification of possible resilience variables and introduced the need to study resilience in firms due to the risks of a turbulent operating environment. Risks identified by these articles include global terrorism, interruptions to supply and demand, and strong competition (Kendra \& Wachtendorf, 2003). Subsequent publications have driven the development of the concept of resilience, with authors exploring the antecedents to resilience (Sheffi, 2005; Valikangas, 2004), its related concepts (Lengnick-Hall \& Beck, 2005, 2009) and the types of organisations which can be described as resilient (Carmeli \& Markman, 2011). The content of the literature regarding resilience in the field of strategic management will be described in more detail in the following section.

Overall, the level of interest and discussion on the topic of resilience has steadily increased over time as the complexity of discussion of systems, individuals, 
organisations and societies has increased and the insights into their function and inner workings become more nuanced. While ecological sciences still see publications on the topic, other fields including engineering and business also show growth in the number of publications that refer to resilience as a core topic. Figure 2 shows the growth of the topic as entries in the Google Scholar publications database.

Figure 2: References to Resilience (Google Scholar, 2011)

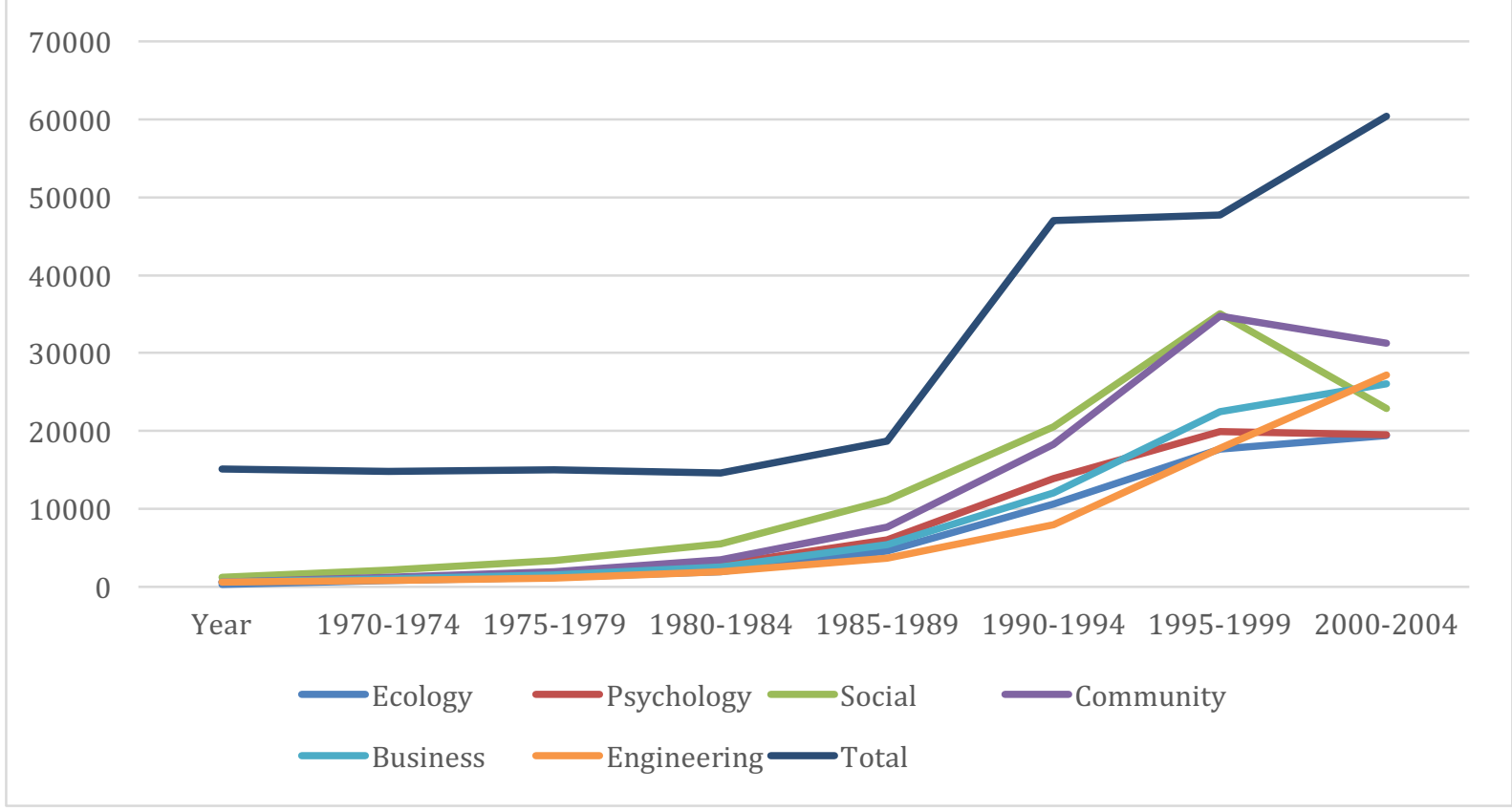

\subsection{Resilience and Strategic Management}

This thesis is grounded in the strategic management literature, where strategic management is defined as: the field of study that addresses how a firms intended and emergent initiatives and use of resources enhance performance with regard to its external environment (Keupp, Palmié, \& Gassmann, 2011; Nag, Hambrick, \& Chen, 2007). Rumelt (2011) characterises 'strategy' as an attempt to ride a wave of change which can be exploited to make money. The challenge of strategy is therefore not to forecast and predict the future, but to identify and assemble the patterns of change to allow for understanding of the forces that drive it. Understanding the resilience of firms is similarly concerned with the way organisations can manage such waves of 
change (Coutu, 2002; Hamel \& Valikangas, 2003; Weick, 1993), with specific regard to how firms manage disturbance. Rose (2004) suggests that it is important to identify resilient actions in firms, including those which would appear to violate established norms as doing so has the potential to enable firms to avoid further economic losses. This makes resilience a useful area of study in strategic management by understanding how firms can continue to enhance performance despite the impact of a dynamic environment. Resilience has been described as a set of capacities, routines, practices and processes, which a firm uses to orient itself, move forward, and 'create a setting of diversity and adjustable integration' (Hamel \& Valikangas, 2003, p. 3) during periods of disturbance. Lengnick-Hall, Beck and Lengnick-Hall (2010) suggest that resilience is the aggregation of the combined knowledge, skills, abilities and other attributes of the individuals who comprise the firm's human resources. Lengnick-Hall and Beck (2009) also refer to strategic resilience capacity as a construct which describes collective behaviours and attitudes of managers.

In short, there are a number of strands in current thinking about resilience in firms. These cover the firm's actions, strategies and activities (Hamel \& Valikangas, 2003); its orientation to its environment (Coutu, 2002) and the attributes and capabilities of its management and members (Lengnick-Hall \& Beck, 2009).

Webb and Schlemmer (2006) discuss resilience in terms consistent with the core capabilities literature (Prahalad \& Hamel, 1990). Their description of resilience as 'the capability to constantly renew and reorganise' is reflective of these capabilities; which allows a firm to gain advantage by developing or nurturing appropriate capabilities for a given product or market (Long \& Vickers-Koch, 1995). Hamel and Valikangas (2003) describe resilience capacity as a core capability based on innovation with respect to the organisational attributes that favour perpetuation. Lengnick-Hall, Beck and Lengnick-Hall (2010) discuss resilience as a capacity enabled by human resources policy. 
Sutcliffe and Vogus (2007) and Birkie, Trucco and Kaulio (2014), however, position resilience within the dynamic capabilities literature when they describe the concept as resulting from 'processes and dynamics that create or retain resources...that enable organisations to successfully cope with, and learn from the unexpected' (pp. 3419). Dynamic capabilities, in turn, are described as the abilities of managers that allow them to integrate, reconfigure, gain and release resources. As such, resilience would represent a specific type of dynamic capability that addresses a disturbance or shock. The current lack of coherence regarding the discussion of resilience is likely due to the early stage of its discussion in the management literature. However, the indications of a strong fit for the topic among strands of existing organisational research suggests there are opportunities to unite diverse viewpoints into a coherent whole.

\subsection{Resilience Strategies}

There are important distinctions to be made between the concepts of resilience capacity, strategic resilience, and resilience strategies (Coutu, 2002; Hamel \& Valikangas, 2003; Lengnick-Hall \& Beck, 2009; Sutcliffe \& Vogus, 2003). Resilience capacity is the latent potential for a firm to resile when encountering a disturbance. This is comprised of an organisation's set of cognitive, behavioural and contextual capabilities and routines (Lengnick-Hall et al., 2010). Strategic resilience is the extent to which a strategy initiative of the firm, either planned or emergent is capable of delivering its expected result despite the presence of environmental risk and change (Sheffi, 2005). Finally, a resilience strategy is a course of planned or emergent action, which is designed to enhance the performance of a firm despite the presence of increased risk in the form of environmental disturbance (Nag et al., 2007). LengnickHall \& Beck (2005) describe what they call 'a complex and varied action inventory', which is the ability of firms to create new actions upon the realisation that existing approaches lack efficacy in the new environment. The new actions - framed in this study as resilience strategies - are designed based on a constructive process to cope with the new operating conditions. The literature on this topic is segmented into empirical and theoretical in the following sections. 


\subsection{Empirical Literature}

There are two significant strands of empirical literature regarding resilience that make knowledge claims based on empirical evidence and those that anecdotally describe the phenomenon from the perspective of outsiders. In this study the empirical thread is addressed first, as it represents the most warranted claims of truth regarding resilience in strategic management. It is however, an extremely limited body of research (Birkie et al., 2014; Boin \& van Eeten, 2013; Vogus \& Sutcliffe, 2007), because the majority of publications in the field approach resilience and strategy from a theoretical perspective.

The empirical literature suggests that resilience in organisations would emerge from two broad categories of characteristics: 'change' and 'slack'. Change refers to the capacity of the organisation to adapt and self-renew. This includes the ability to be strategically flexible (Sheffi, 2005; Sheffi \& Rice, 2005), and having diverse innovation strategies (Reinmoeller \& van Baardwijk, 2005). Slack refers to the existence of redundancy in the form of relational and financial reserves (Gittell, Cameron, Lim, \& Rivas, 2006) as well as excess resources. Further explanation of these concepts continues below.

\subsubsection{Change}

Sheffi and Rice (2005) describe the resilience of an organisation as a function of its competitive position and the responsiveness of its supply chain. This function ultimately designates how quickly the firm can respond to a disruption in order to maintain or grow market share relative to competition. They suggest that redundancy and flexibility are the two ways in which supply chain responsiveness can be bolstered. However they go on to outline the ways in which redundancy may be detrimental to the organisation in other ways, including providing a limit to immediate response capacity, a loss of product quality and high inventory costs (Sheffi, 2005). The authors therefore are proponents of strategic flexibility as the ideal driver of resilience. 
Strategic flexibility is described as the ability of a firm to respond to uncertainties by adjusting objectives using its prior knowledge and capabilities, where 'capabilities' consist of people, processes, products and integrated systems (Lau, 1996). Strategic flexibility is also an ability to respond to substantial, uncertain and fast-occurring changes in a firm's environment (Aaker \& Mascarenhas, 1984). Sheffi and Rice suggest that investment in flexibility can be costly, but offset by the higher margins available to resilient market leaders who gain market share by capitalising on disruptions. Teece, Pisano and Shuen (1997) identify strategic flexibility as a component of dynamic capabilities - the ability of a firm to create, integrate and reconfigure competencies to cope with a dynamic environment (Teece, 2007).

Innovation is a process which allows an organisation to renew itself and adapt to change (Calantone, Cavusgil, \& Zhao, 2002; Johnson, Meyer, Berkowitz, Miller, \& Ethington, 1997). Identifying resilient firms by using measures including; book value per share, return on assets and sales growth, Reinmoeller and van Baardwijk (2005) found what they describe as a diverse but dynamic balance of emphasis on internal and external sources of ideas and resources for innovation. These authors also found that the resilient companies studied increased spending on innovation by an average of $235 \%$ over 20 years, and committed more to innovation during recessionary periods at the end of the 20 years (2002) than at the start of the period. Stated reasons for innovation in these firms ranged from retaining market leadership to being seen as a mechanism for renewal and a path to growth. In their study Webb and Schlemmer (2006) infer the value of a strategic resilience advantage which they describe as 'the capacity for continuous reconstruction' ( $p$. 181) by examining the way core competencies were employed by small IT firms.

The existing literature shows that resilient firms change in response to crises (Reinmoeller \& van Baardwijk, 2005; Sheffi, 2005; Webb \& Schlemmer, 2006). To create this resilience, these firms innovate in order to renew and reorganise the firm as a strategy to navigate rather than negate disturbance. Flexibility while costly, is a contributor to higher margins in resilient firms (Sheffi \& Rice, 2005). 


\subsubsection{Slack}

Meyer (1982) found that organisational slack acts as a buffer to environmental shocks. This proposition is reflected in more recent research on resilience. Gittell, Cameron, Lim and Rivas (2006) identified the need for what they describe as 'relational reserves' - the goodwill inherent in the relationship between the organisation and its employees as a source of resilience. Their study compared airlines that downsized due to a drop in demand following the September $11^{\text {th }}$ terror attacks in the United States, with those that did not. Their findings suggested that firms that downsized staff numbers - undermining the relationship with their employees and reducing relational reserves, were less resilient than those that maintained staff numbers.

Later, Gittell et al. (2006) analysed a case study of Southwest Airlines - a particularly resilient airline in the aftermath of September $11^{\text {th }} 2001$. Southwest Airlines has a 'no layoffs' policy enshrined in its corporate ideology and culture (Pfeffer \& Sutton, 2006), which has been in practice for decades (Kneale, 2009). While Gittell et al. control for the unit costs of airlines' operations, it does not acknowledge Southwest's on-going emphasis on reducing all other costs excepting those of wages and other employee costs (Gittell, 2005). Southwest Airlines has the fastest aircraft turnaround times in the United States airline industry and the highest labour and aircraft productivity. This has the effect of reducing the redundancy - a form of slack - in the system (Comfort, Boin, \& Demchak, 2010a). The suggestion is that while the firm cultivates certain forms of slack, it is active in reducing others and as such implies that the slack resilience relationship is a complicated one.

A report compiled by Ernst and Young (2010) suggests a strong correlate of resilience is the amount of working capital available to finance the organisation through a disturbance. Similarly, Gittell et al. (2006) describe financial reserves, which they defined as a low level of debt and high amounts of cash on hand, as providing flexibility during a disturbance. Combined with relational reserves as identified above 
and a viable business model this type of slack is identified as a strong component of resilience. Sutcliffe and Vogus (2007) identify margin as vital to the resilience of firms, they suggest that those which operate with too little are unable to respond to unexpected events. High levels of debt are associated with default risk, whether the operating environment is munificent or not (Farrell, 2011).

Sheffi and Rice (2005) state that redundancy is often considered 'sheer cost' ( $p .44)$ to an organisation and effectively amounts to an insurance policy. They also assert that maintenance of high levels of safety stock, backup sites and additional suppliers reduce reaction time to change and carry a related increase in risk. Longstaff (2005) and Longstaff et al. (2004) make the related point that redundancy can be counterproductive if it increases the complexity of the system, having the effect of reducing transparency and making operation more difficult. Redundancy may also lead to overconfidence in the ability of the system to absorb shocks and people may forget to watch for surprises (Perrow, 1984).

In short, the literature provides a range of views regarding the affect that slack, in various forms, can have on the resilience of firms. It appears that the ability of redundant resources to provide resilience is at best inconsistent with some authors suggesting it provides a buffer, but yet others proposing that it may be detrimental, creating barriers to change.

\subsection{Theoretical Resilience Literature in Management}

The literature that follows is not based on empirical research but provides a variety of theoretical perspectives on the resilience of organisations. While not strongly evidence-based, these publications offer a platform of discussion and set the scene for further research and validation of current thinking. Authors in this strand of literature refer to resilience as existing within three domains of the organisation: cognitive, behavioural and contextual resilience (Coutu, 2002; Hamel \& Valikangas, 
2003; Valikangas, 2004; Weick, 1993). Descriptions of these resilience characteristics are in the following sections.

\subsubsection{Strategic Resilience and Management Cognition}

There is a strong emphasis in this body of literature on the cognitive processes of managers in firms undergoing disturbance. Lengnick-Hall and Beck (2005), Weick (1993), Coutu (2002) and Beunza and Stark (2004) all make reference to cognitive concepts including sensemaking - the process of attributing meaning to experiences (Weick, 1995) - and ideology - sets of expectations and widely held beliefs (Rohan \& Zanna, n.d.) - as components of strategic resilience. Hamel and Valikangas (2003) suggest that firms that hope to be resilient against disturbance should have overcome what they describe as 'the cognitive challenge' which frees the firm from denial, nostalgia and arrogance. This allows the firm to consider objectively its environment and the ways in which change might affect it. Lengnick-Hall and Beck (2005) state that a strategic resilience capacity would encourage a firm to consider its environment in ways that improve its ability to determine the content and the duration of change. Starr, Newfrock and Delurey (2003) suggest that resilient organisations actively evaluate enterprise-wide risk dependencies. Sensing for changes in the environment, particularly in science and technology and in customers needs, and selecting decision making protocols, are identified by Teece $(2007,2011)$ as forms of dynamic capability.

Coutu (2002) claims that when coping responses are created using an appropriate understanding of the firm's environment, resilience results. Through her analysis of individuals and organisations she has deemed resilient, Coutu claims that those firms whose managers have a superior ability to understand the reality they operate in are better positioned to create appropriate responses. The formation of a strategic resilience response is, according to Hamel and Valikangas (2003) a cognitive process, as their description of the 'strategic challenge' suggests that the creation of strategic options for the firm must be linked to awareness of its environment. Strategically 
resilient organisations would therefore formulate responses that are situationally derived and specific.

The literature suggests that the conception and implementation of coping responses in strategically resilient organisations is guided by the ideology and values of the firm (Lengnick-Hall \& Beck, 2005). The core values and ideology of the firm are identified by several authors as beneficial to resilience, by helping to place events in context and within a frame of reference. According to Lengnick-Hall and Beck (2005) a pervasive ideological identity, which is derived from the firm's core values, creates a strong directive for choices made by the organisation following disturbance. Likewise Coutu (2002) suggests that organisations with strong values systems tend to be resilient. Values benefit resilience as they create meaning by giving the organisation ways to interpret events and then shape responses. For example, tobacco companies have strong values of 'adult choice', a neutral construct that is neither good nor bad but permeates how the firm conducts itself. If consistent across the organisation, values systems can be used as 'scaffolding' during times of turbulence.

Weick (1993) describes virtual role systems as the ability of organisation members to reconstruct missing components of a management structure in a shock. In instances where members must recreate a functioning organisation with these missing elements, a scaffolding of values provides guidance for action. Hamel and Valikangas (2003) also refer to the importance of a firm's ideology when they outline the ideological challenge. They describe ideals such as strategic variety, wide-scale experimentation, and rapid resource redeployment, which can be implemented across the organisation in employee training, performance metrics, and management processes as key to creating strategic resilience. In a study of hospitals during a physician strike, Myer (1982) found that an organisation's ideology exerts strong guiding forces during environmental jolts. 
Cognitive resilience regards how managers think about their environment and business and the contribution that their thought processes make to improved performance during disturbances (Coutu, 2002; Hamel \& Valikangas, 2003). Authors in this area suggest that manager's, (or collectives of managers) cognitive schemas, understanding and ability to make sense of their environment, options and strategies are strong contributors to resilience. This is because they improve a firm's ability to make better decisions and create courses of action that are better suited to the environment.

\subsubsection{The Role of Innovation in Resilience}

As described in the section on empirical research, innovation has been identified as component of resilience in organisations (Reinmoeller \& van Baardwijk, 2005). However, the conceptual and theoretical research also identifies innovation as a contributor of resilience in firms.

There is a strong normative sentiment in the literature regarding the role of innovation in creating a resilient firm. Firms that are active in innovation increase their adaptation capability. Thomke, von Hippel, \& Franke (1998) and Walker and Salt (2006) suggest that to build adaptive capacity, firms should embrace change, novelty and innovation as inevitable, instead of current approaches which provide incentives not to change (Allison \& Hobbs, 2004). Their assertion is that the dominant 'efficiency paradigm' values productivity or 'competitiveness' (Meyer \& Zucker, 1989, p. 24) which is derived by reducing the capacity for a system to change quickly and without great expense. Bricolage, as a technique to create novel approaches to manage change may drive innovation during a disturbance (Coutu, 2002).

Muller, Valikangas and Merlyn (2005) describe strategic exploration, a concept which they consider as going 'beyond experimentation and innovation' ( $p .57)$. They suggest that strategic resilience is benefited by discoveries, breakthroughs and opportunities that stem from combinations of different levels of introspective and opportunistic 
insights. Introspective insights are new insights into the company's own capabilities, i.e. self-discoveries, while opportunistic insights give insight into the firm's competitive realities, i.e. windows of opportunity. These can occur independently, or together as 'strategic breakthroughs'. Teece (2007) identifies sensing for new technologies both internally using development processes and externally by scanning the environment as forms of dynamic capabilities. Valikangas (2004) suggests that firms should devote 30 percent of capital expenditure to innovative strategies designed to augment a portfolio of innovative products.

Hamel and Valikangas (2003) suggest that firms that can expect to outperform others should have mastered three types of innovation: revolution, renewal and resilience. They also suggest that creating variety through formulating dozens of innovative 'stratlets' can benefit a firm's resilience, rather than making fewer 'large bets'. These authors state that firms that expect to last would have mastered innovation with respect to values, processes and behaviours that favour perpetuation, although they do not elaborate further regarding exactly what this entails. Lengnick-Hall and Beck's (2005) idea of a 'complex and varied action inventory' describes firms that have a broad repertoire of action alternatives are more capable of taking inventive action when their previous actions lose their effectiveness.

Weick (1993) and Coutu (2002) both identify bricolage - a form of institutionalised improvisation as a means of resilience response generation. Coutu suggests that when people are faced with adversity they generally revert to habitual ways of responding. Bricoleurs, however, are naturally creative under pressure because they act to create order from chaos on a regular basis. Then, when in the midst of a disturbance, a bricoleur can use the materials they have at hand to create and employ novel combinations to cope with adversity (Lévi-Strauss, 1996). Coutu would suggest that resilient organisations are full of bricoleurs to the point where it could be considered a core skill. Weick (1993) suggests that bricoleurs are effective in uncertain situations because they are used to operating under ambiguity. 
Bricolage, as the ability to create novel alternatives to usual courses of action, is reflective of innovation when defined as the creation of new products, processes and plans (Damanpour, 1991). Bricolage has been employed in the innovation literature in the past, including being used to explain divergent forms of technology development (Garud \& Karnøe, 2003) and to describe innovation under resource constraints (Baker \& Nelson, 2005). Gopalakrishnan \& Damanpour (1994) suggest that the products of bricolage are innovations in the sense that they represent the introduction of something new and potentially useful. Fuglsang \& Sorensen (2011) position bricolage in organisations as 'do-it-yourself' (p. 1) problem solving innovation. As such bricolage is referred to in literature as providing imperfect, but novel innovation solutions to a problem (Senyard, Baker, Davidson, \& Steffens, 2010).

\subsubsection{Behavioural Resilience and Resilience Context}

Resilience literature describes the behavioural content of a firm's coping response. Lengnick-Hall and Beck (2005) describe behavioural resilience as a property which allows a firm to learn more about a situation and to utilise its resources and capabilities through collaboration. It is comprised of a complex and varied action inventory and functional habits. This enables the firm to learn about the situation and utilise its resources through actions. The action inventory is the creation of new alternative actions, which are created upon learning that previous approaches have been rendered ineffective. Functional habits are a subset of routines, which open communication channels, creates interpersonal relationships and look for more sources of information (Lengnick-Hall \& Beck, 2005). Organisational routines are defined as the basic components of organisational behaviour (Becker, Lazaric, Nelson, \& Winter, 2005) and are 'repositories' for capabilities (Dosi, Nelson, \& Winter, 2000). They are also described as behavioural and cognitive regularities and recurrent patterns of interaction (Becker, 2004). Weick (1993) describes how the ability to reconstruct role systems after a disturbance is antecedent to resilience. This allows the continuation of organisational function despite the loss of communication with a management structure. 
The turbulence and complexity of a firm's environment (Comfort, Sungu, Johnson, \& Dunn, 2001), social capital, resource networks (Lengnick-Hall \& Beck, 2005) and business model (Hamel \& Valikangas, 2003) create the context for strategic resilience. Social capital is valuable in a disturbance as it reflects the level of trust in the connections the organisation has (Portes, 1998). The broad resource network of the firm relates to its ability to obtain resources, concessions and assistance that are not available to other organisations. Other authors have found that the sharing resource of networks has a positive effect on value creation (Tsai \& Ghoshal, 1998). Resilient organisations have an ability to get others to help them, and the ability to obtain resources externally can positively impact organisational slack (Bourgeois, 1981).

\subsection{Measurement of Resilience}

Because resilience has been applied in different ways in various fields of study (Brand \& Jax, 2007) operationalisation of the concept has not occurred in a cohesive manner (Carpenter, Walker, Anderies, \& Abel, 2001). Resilience has been applied as descriptive concept (Holling, 1973), a normative concept (Pickett, Cadenasso, \& Grove, 2004), and a hybrid concept (Folke et al., 2002) - in which the features of both the previous types are intermingled. Brand et al. (2007) assert that resilience has developed a shared vocabulary across the multiple disciplines in which it has been applied. They go on to suggest that this shared language is useful as a communication tool, but a hindrance to real understanding. Carpenter et al. (2001) suggest that to measure resilience, the properties of interest of the system, organisation or individual must be defined, as should the type of disturbance.

Some authors have approximated the resilience of organisations through the measurement of indicators. Concepts used in this manner include core competencies (Webb \& Schlemmer, 2006), planning and adaptive capacity (Stephenson, Seville, Vargo, \& Roger, 2010), fundamental performance indicators (Reinmoeller \& van Baardwijk, 2005) and persistence over time (Carmeli \& Markman, 2011). LengnickHall and Beck (2005) recommend this approach for their construct of resilience 
capacity. They outline a list of approaches they see as appropriate to measure sensemaking, ideology, action inventory, functional habits, social capital and resource networks. Their list includes respectively proxies such as: vocabulary in organisational documents, patterns of behaviour, competitive dynamics, organisational learning, the balanced scorecard (Kaplan \& Norton, 1996), social capital and social exchange theory. Their list of methods to measure these proxies includes content analysis, survey and observation.

Studies which have sought to evaluate the relationship of antecedent concept to the resilience of firms have adopted what is described here as a pragmatic definition of resilience (Gittell et al., 2006; Reinmoeller \& van Baardwijk, 2005). Under this approach, resilience is the sustained persistence and performance of a firm, despite the presence of unforeseeable disturbance. This definition eschews expressions of the nature of resilience, in favour of measurability. Other conceptualisations provide opportunity for measurement, such as the transformational definition's creation of new competencies (Jamrog et al., 2006) and the rebound conceptualisation's time taken to recover (Sutcliffe \& Vogus, 2003). However, using these models, comparison across organisations becomes problematic, due to the unique circumstance of each organisation to be studied. This definition is set out below in Section 2.7.

\subsection{Summary of Resilience Concepts}

This review of the literature has identified the set of antecedent concepts that authors consider as contributing to the resilience on firms. Table 1 summarises these concepts, their descriptions, and publications. 
Table 1: Resilience Concepts, Definitions, and References

\begin{tabular}{|c|c|c|}
\hline \multicolumn{3}{|c|}{ Core resilience concepts } \\
\hline Concept & Description & Key References \\
\hline $\begin{array}{l}\text { Diversity of } \\
\text { Innovation Strategy, } \\
\text { Strategic innovation, } \\
\text { Adaptive change }\end{array}$ & $\begin{array}{c}\text { Small bets on lots of technologies } \\
\text { (stratlets), strategic exploration, creating } \\
\text { new approaches to replace those } \\
\text { rendered ineffective }\end{array}$ & $\begin{array}{c}\text { Valikangas (2004), } \\
\text { Reinmoeller \& van } \\
\text { Baardwjick (2005), Muller } \\
\text { et al. (2005), Lengnick-Hall } \\
\text { \& Beck (2009), Lengnick- } \\
\text { Hall et al. (2010), }\end{array}$ \\
\hline Bricolage & Institutionalised innovation & Coutu (2002), Weick (1993) \\
\hline R\&D/Innovation & $\begin{array}{l}\text { Investment in R\&D, internal and external } \\
\text { searches for information }\end{array}$ & $\begin{array}{l}\text { Reinmoeller \& van } \\
\text { Baardwjick (2005) }\end{array}$ \\
\hline Strategic Flexibility & $\begin{array}{c}\text { The relationship between competitive } \\
\text { position and responsiveness of supply } \\
\text { chain }\end{array}$ & $\begin{array}{l}\text { Sheffi \& Rice (2005), Sheffi } \\
\text { (2005) }\end{array}$ \\
\hline $\begin{array}{l}\text { Renewal, } \\
\text { Reconstruction }\end{array}$ & $\begin{array}{l}\text { Resilient organisations have the capability } \\
\text { to renew and reconstruct themselves to } \\
\text { manage disturbance and to perpetuate }\end{array}$ & $\begin{array}{l}\text { Webb \& Schlemmer (2006) } \\
\text { Hamel \& Valikangas (2003) }\end{array}$ \\
\hline Margin & $\begin{array}{l}\text { High margins enable a firm to ride out } \\
\text { disruptions on lower volumes of sales }\end{array}$ & $\begin{array}{l}\text { Sutcliffe \& Vogus (2003), } \\
\text { Sheffi \& Rice (2005) }\end{array}$ \\
\hline Slack & $\begin{array}{l}\text { Redundancy (Supply chain), Reserves } \\
\text { (financial, relational) }\end{array}$ & $\begin{array}{l}\text { Gittell et al. (2006), Sheffi \& } \\
\text { Rice (2005), Ernst \& Young } \\
\text { (2010) }\end{array}$ \\
\hline $\begin{array}{l}\text { Governance and } \\
\text { capture strategy }\end{array}$ & $\begin{array}{l}\text { Capture new markets, assimilate, } \\
\text { dominate and defend new markets }\end{array}$ & Carmeli \& Markman (2011) \\
\hline Business Model & $\begin{array}{c}\text { How an organisation captures, retains and } \\
\text { delivers value }\end{array}$ & Hamel \& Valikangas (2003) \\
\hline Sense-making, & $\begin{array}{l}\text { Attributing meaning to experience. } \\
\text { Freedom from bias, denial and nostalgia, } \\
\text { awareness of the environment }\end{array}$ & $\begin{array}{l}\text { Weick (1993), Hamel \& } \\
\text { Valikangas (2003), } \\
\text { Lengnick-Hall \& Beck } \\
\text { (2005), Coutu (2002) }\end{array}$ \\
\hline Ideology & Mission, vision, values & $\begin{array}{l}\text { Coutu (2002), Hamel \& } \\
\quad \text { Valikangas (2003) }\end{array}$ \\
\hline $\begin{array}{l}\text { Connectivity, social } \\
\text { capital, resource } \\
\text { networks }\end{array}$ & $\begin{array}{c}\text { Number of connections to other } \\
\text { organisations, trust inherent in those } \\
\text { connections, access to resources others } \\
\text { do not have }\end{array}$ & $\begin{array}{l}\text { Lengnick-Hall \& Beck } \\
\qquad(2005)\end{array}$ \\
\hline
\end{tabular}




\subsection{The Quantum of Resilience}

Ultimately, the need to understand resilience necessitates its clear and implementable definition. On consolidation and reflection of the definitions to date the most consistent feature is that of the ability to change (Hamel \& Valikangas, 2003; Lengnick-Hall \& Beck, 2005, 2009; Lengnick-Hall et al., 2010; Muller, 1997; Sutcliffe \& Vogus, 2003; Webb \& Schlemmer, 2006; Weick, 1993), or to not change through the ability to return to a given state (Ash \& Newth, 2007; Comfort, Boin, \& Demchak, 2010b; Harrison, 1979; Holling, 1996). While the engineering and sciences definition of resilience as returning to a previous state is more traditional, the modern view of firms as dynamic entities and their strategies equally dynamic (Rumelt, 2011; Teece \& Pisano, 1994) necessitates a view of resilience that accounts for the need to change based on conditions. As such, the ability to change from one state to another forms the basis of the definition offered here. Many of the same authors implicitly assume that resilience is a positive change, despite the documented neutrality of the concept in other fields (Adger, 2000; Folke et al., 2002; Walker \& Salt, 2006). Despite the engineering or hard sciences definitions, resilience is widely accepted as a positive attribute in the psychology, sociological and organisational literatures (Block, 1993; Comfort et al., 2010). Combining these identified attributes, the suggestion of existing literature is that resilience is a positive change.

Resilience is a dynamic construct in that the resilience of an entity is relative to changes that are enforced upon it by external influences (Coutu, 2002; Folke, 2006; Hulsen, 1896). The ability of a system to remain within a threshold denotes the strength of its resilience, while the ability of an external influence to drive the system beyond that threshold and to force a change in state is the strength of disturbance (Walker \& Salt, 2006). The strength of resilience and of the disturbance are forces at which the interface is the threshold. 
This synthesis provides a useful definition of resilience that is both simple enough to operationalise and flexible enough that it can be applied in a range of contexts. That definition is:

Resilience is the ability of an organisation to develop and implement change that elicits positive effects in the face of disturbance.

\subsection{Resilience and Dynamic Capabilities}

Sutcliffe and Vogus (2007) and Birkie et. al (2014) suggest an opportunity for alignment between the emergent concept of resilience and the maturing notion of dynamic capabilities. They suggest that organisational learning and adaptation, high reliability organising, and dynamic capabilities are the areas of study most contributing to the understanding of resilience. A range of other authors' work outlined in this review of the literature on resilience identifies organisational attributes that are notably similar to those set out in the dynamic capabilities literature. Table 2 identifies these similarities in identified concepts.

Table 2: Overlaps between identified resilience and dynamic capabilities concepts

\begin{tabular}{|c|c|c|c|}
\hline \multicolumn{2}{|c|}{ Resilience } & \multicolumn{2}{|c|}{ Dynamic Capabilities } \\
\hline References & Concept & Concept & References \\
\hline $\begin{array}{c}\text { Webb \& Schlemmer } \\
\text { (2006) }\end{array}$ & Renew/Reorganise & $\begin{array}{l}\text { Reconfigure, } \\
\text { create, extend, } \\
\text { modify }\end{array}$ & $\begin{array}{l}\text { Sutcliffe \& Vogus (2007), } \\
\text { Teece (2007, 2011) Helfat } \\
\text { et al. (2007) }\end{array}$ \\
\hline $\begin{array}{l}\text { Hamel \& Valikangaas } \\
\text { (2003), Weick (1993), } \\
\text { Coutu (2002), Lengnick- } \\
\text { Hall \& Beck (2005) }\end{array}$ & Processes & $\begin{array}{l}\text { Processes to } \\
\text { select } \\
\text { innovations }\end{array}$ & $\begin{array}{l}\text { Zollo \& Winter (2002), } \\
\text { Teece (2007, 2011), } \\
\text { Eisenhardt \& Martin (2000) }\end{array}$ \\
\hline Sheffi \& Rice (2005) & Flexibility & $\begin{array}{l}\text { Competitive } \\
\text { Flexibility }\end{array}$ & $\begin{array}{c}\text { Teece, Pisano \& Shuen } \\
\text { (1997) }\end{array}$ \\
\hline Sheffi \& Rice (2005) & Prior Knowledge & $\begin{array}{l}\text { Knowledge, } \\
\text { know-how, }\end{array}$ & $\begin{array}{l}\text { Teece (2007), Zollo \& } \\
\text { Winter (2002) }\end{array}$ \\
\hline $\begin{array}{l}\text { Reinmoeller \& van } \\
\text { Baardwijk (2005) }\end{array}$ & Innovation & $\begin{array}{l}\text { Innovation } \\
\text { Capability }\end{array}$ & $\begin{array}{c}\text { Lawson \& Samson (2001), } \\
\text { Verona \& Ravasi (2003) }\end{array}$ \\
\hline
\end{tabular}


Potential exists then, to utilise the dynamic capabilities framework as set out by Teece (2009; 2007, 2011; 1997), Helfat (2007) and Eisenhardt and Martin (2000) to examine the resilience of firms.

\subsection{Dynamic Capabilities}

Having been identified as a theory that potentially holds explanatory power for what makes some firms resilient over others (Birkie et al., 2014; Vogus \& Sutcliffe, 2007), dynamic capabilities has been used in this thesis as an analytical framework. In this way it has been used to view the firm and its commercial ecosystem and as such requires introduction and elucidation here.

Introduced by David Teece and Gary Pisano in 1994, the dynamic capabilities approach has become an active area of research in strategic management literature (Di Stefano et al., 2010). Study of dynamic capabilities is concerned with how firms can create and sustain competitive advantage through interactions with, and creation of, environmental change (Helfat \& Peteraf, 2009). Closely associated with the resource-based view of the firm and its focus on capability and performance, dynamic capabilities are differentiated from this field by their focus on dynamic environments.

Much like in the resilience literature, the (relatively) new construct of dynamic capabilities has taken time to settle on a definition. Broadly categorised by Teece, Pisano and Shuen (1997) as 'the firm's ability to integrate, build, and reconfigure internal and external competences to address rapidly changing environments' ( $p$. 516). This definition leaves out the constituents these abilities, their attributes, and antecedents (Easterby-Smith et al., 2009; Eriksson, 2014). As such, other authors have forwarded their own views on definition of the concept. For some, dynamic capabilities represent organisational and strategic routines of managers which are 
antecedent to the development of strategic competitive advantage (Teece et al., 1997).

Dynamic capabilities are described as instrumental in the creation of advantage as managers' dynamic capabilities represent the ability to use resources to 'integrate, reconfigure, gain and release resources' (Helfat et al., 2007, p. 1107). They also refer to how valuable, rare, inimitable and non-substitutable resources can be created and current stocks of resources reconfigured (Ambrosini \& Bowman, 2009). It is important to note that many authors explicitly decouple dynamic capabilities from competitive advantage and/or identify the effect of mediating variables to affect advantage (Helfat \& Peteraf, 2009; Schilke, 2014). However despite this, proponents of this view suggest that without dynamic capabilities firms cannot exploit opportunities or neutralise threats using innovative or new forms of competitive advantage (LeonardBarton, 1992). Others define dynamic capabilities as processes which vary depending on the degree of market dynamism (Eisenhardt \& Martin, 2000).

More recently the following definition of dynamic capabilities has emerged: 'the capacity of an organization to purposefully create, extend, or modify its resource base' (Helfat et al., 2007, p. 4). This definition aims to improve the usability of the term by removing logical inconsistencies, tautological links and providing some means for measuring the effects of the construct (Easterby-Smith et al., 2009). Teece (2014a) differentiates dynamic capabilities from ordinary capabilities by contrasting the types of processes, positions (resources) and paths (strategy) that constitute ordinary capabilities from dynamic capabilities (Table 3). Ultimately, his claim is that dynamic capabilities are unique to the firms that possess them. 
Table 3: Core building blocks of dynamic capabilities and ordinary capabilities (Teece, 2014a)

\begin{tabular}{|c|c|c|c|}
\hline \multicolumn{4}{|c|}{ Weak and Strong Ordinary Capabilities Versus Dynamic Capabilities } \\
\hline Core building blocks & $\begin{array}{c}\text { Weak ordinary } \\
\text { capabilities }\end{array}$ & $\begin{array}{c}\text { Strong ordinary } \\
\text { capabilities }\end{array}$ & $\begin{array}{c}\text { Strong dynamic } \\
\text { capabilities }\end{array}$ \\
\hline Processes (routines) & Sub-par practices & Best practices & $\begin{array}{c}\text { Signature practices } \\
\text { and business models }\end{array}$ \\
\hline Positions (resources) & $\begin{array}{c}\text { Few ordinary } \\
\text { resources }\end{array}$ & $\begin{array}{c}\text { Munificent ordinary } \\
\text { resources }\end{array}$ & VRIN resources \\
\hline Paths (strategy) & Doing things poorly & Doing things right & $\begin{array}{c}\text { Doing the right things } \\
\text { (good strategy) }\end{array}$ \\
\hline
\end{tabular}

The dynamic capabilities framework suggests that firms are restricted in the capabilities they may develop due to the path dependence of prior decisions to develop a firm's domains of competence (Eisenhardt \& Martin, 2000; Teece et al., 1997). Teece et al. (1997) describe the resources attributable to a firm as 'sticky', meaning that, in the short run, firms are essentially stuck with the resources they have for three reasons: the complexity of resources, the fact that they are often difficult to trade (Teece, 1980) and the risk that little or no value will be derived from the resource once acquired by another firm. This path dependence, while restricting options, also contributes unique and inimitable capabilities to firms, imbuing them with a sustainable advantage.

The dynamic capabilities framework acknowledges the role of core capabilities as described by Leonard-Barton (1992). The capabilities of a firm are a key element in strategic management, allowing the appropriate adaptation, integration and reconfiguration of internal and external organisational skills, resources and competencies (Teece et al., 1997). These capabilities are dynamic by necessity, as the changing environment of the firm requires the adaptation and reconfiguration to ensure they are adequately matched to a changing competitive environment. Helfat, Finkelstein and Mitchell (2007) describe dynamic capabilities as being divisible into those which relate to the evolutionary fitness of the organisation and those of its 
technical fitness. Evolutionary fitness relates to the effectiveness of capabilities to create, extend and modify the resources of the organisation in order to create a better fit with its environment. The four dimensions that affect the evolutionary fitness of the firm are quality, cost, market demand and competition. Technical fitness relates to how well the capability is performed - enabling calculation of quality per unit of cost while the market demand and competition dimensions relate to the effectiveness of evolutionary fitness. Augier and Teece (2009) disaggregate dynamic capabilities into three subclasses;

- The capability to sense opportunities

- The capacity to seize opportunities

- The capacity to manage threats through combination, recombination, and reconfiguring of assets (either inside or outside a firm's boundaries)

Teece $(2007,2011)$ further develops this framework using headings of sensing, seizing and transformation to describe broad categorisations of the types of (dynamic) capabilities organisations need to develop and sustain advantage in dynamic environments.

Sensing relates a firm's processes for identifying innovations both internally and in the external environment and to identify target markets and to filter and shape the opportunities they present. depicts the specific capabilities that comprise sensing, as used by Teece (2007). 
Figure 3: Sensing Capabilities (Teece, 2011)

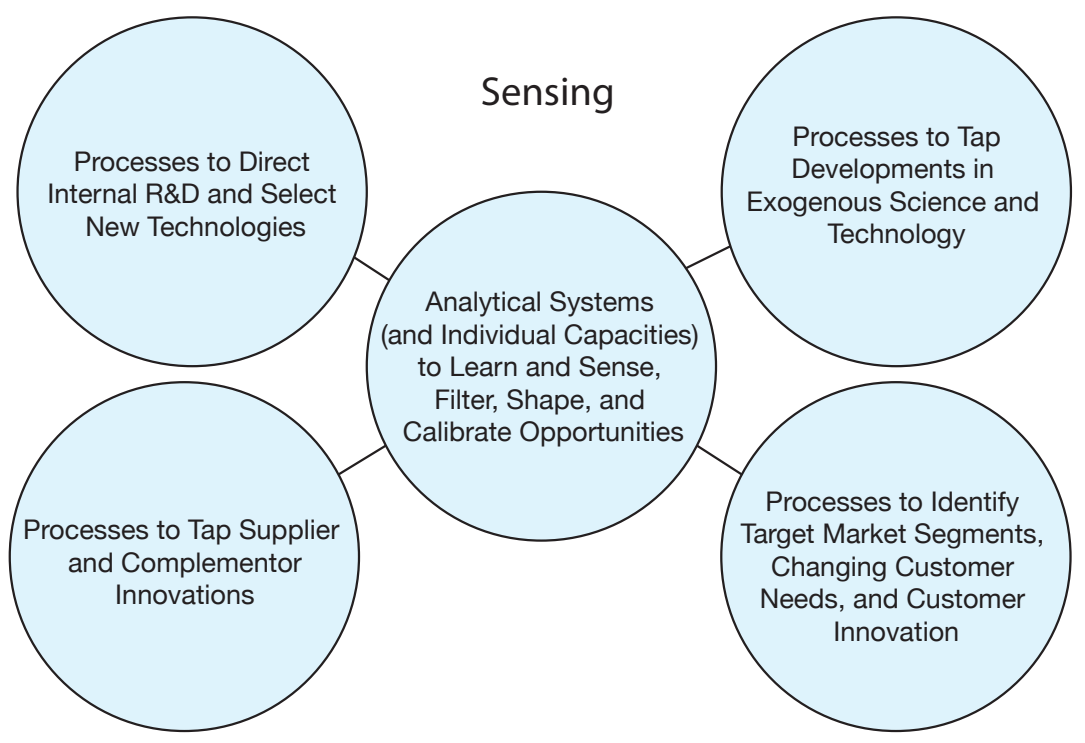

Seizing (Figure 4) is a firm's capability to define the business model and customer solutions, the boundaries of the enterprise and manage complements and control platforms, decision-making protocols and to build loyalty and commitment.

Figure 4: Seizing Capabilities (Teece, 2011)

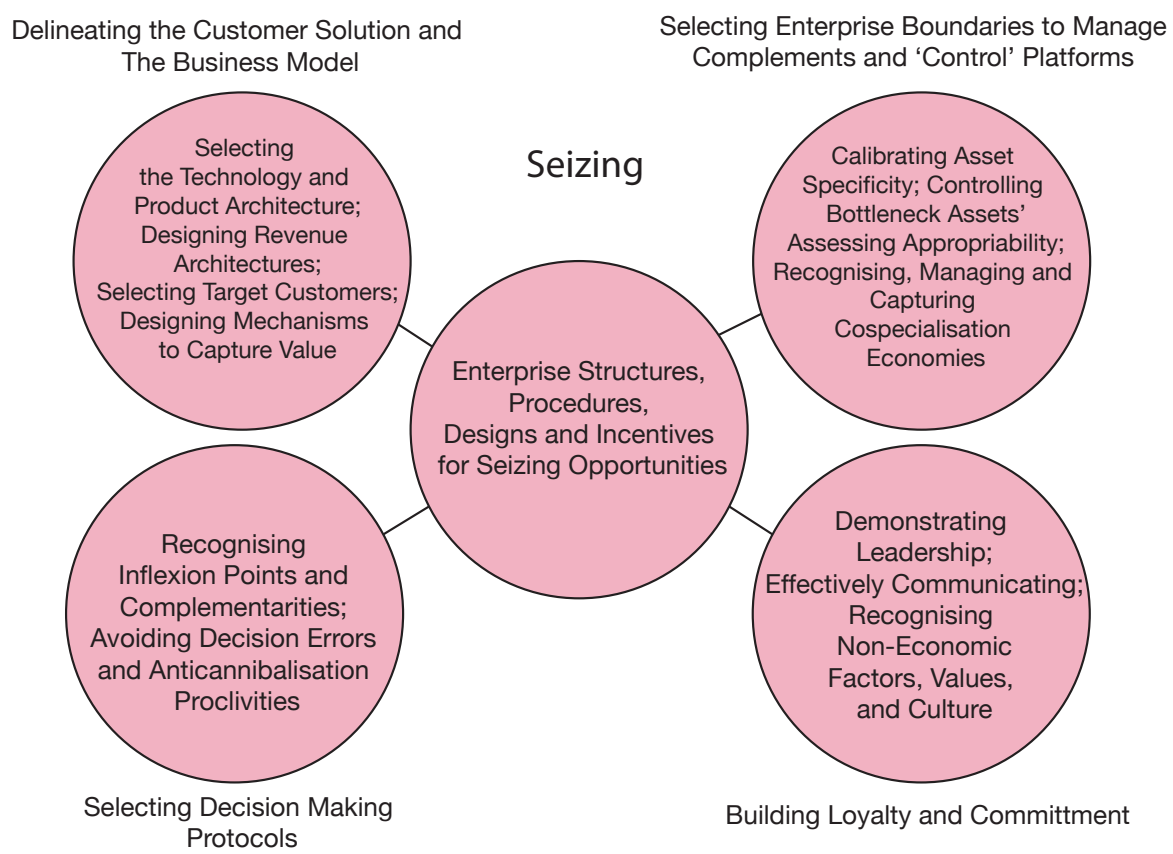


Transformation dynamic capabilities (Figure 5) regard the continuous alignment and realignment of tangible and intangible assets. This includes issues of decentralisation, co-specialisation, governance and knowledge management. More detail regarding these categories and their constituent sub-capabilities is provided in Chapter 3: Research Approach.

Figure 5: Transformation Capabilities (Teece, 2011)

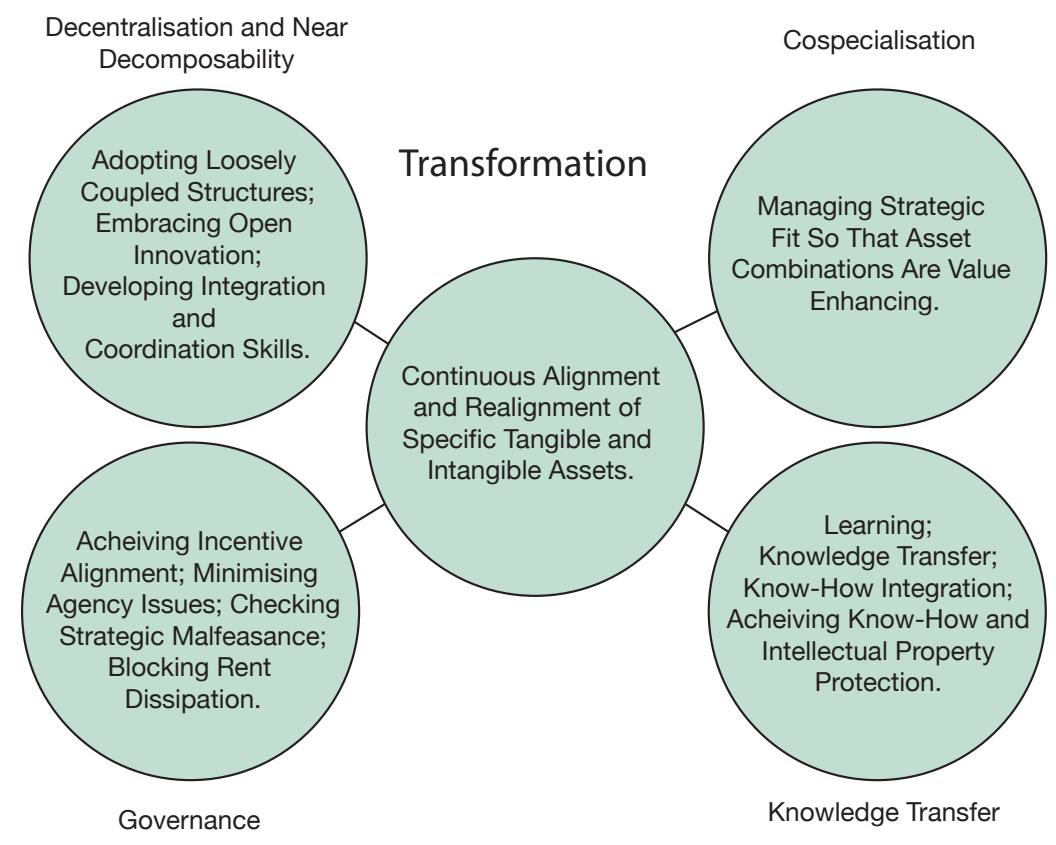

\subsection{Strategic Change}

Strategic change is a difference in the form, quality or state (Van de Ven \& Poole, 1995) in order for an organization to maintain its alignment with changes in technological and social environments through continual (or discontinuous) adjustment (Zajac, Kraatz, \& Bresser, 2000). These changes in alignment are embodied by changes in strategy content - that is scope, resources, advantage and synergies (Rajagopalan \& Spreitzer, 1997). strategic change looks to explain how change is enacted in firms as a process, but also what attributes of firms produce successful change outcomes. Resilience is not a topic currently discussed within this literature, however given the focus of strategic change on environmental fit and 
threats (Gioia \& Chittipeddi, 1991), resilience is positioned here as potentially relevant to the strategic change literature. That is, resilience is purposeful change to cope with particular, inherently negative, environmental change (Salenborg, Stålered, Sandberg, \& Hultén, 2013). What is of particular interest to this thesis is resilience as a second order change - that is the change to a new state of existence, as opposed to incremental change.

Strategic change is a significant body of theory, with far reaching implications for research (Rajagopalan \& Spreitzer, 1997). As such, it is necessary to delimit the position of this thesis within this field. This thesis is interested in resilience as a form of strategic change at the level of the entity - that of the firm, as opposed to the species, or industry level (Pettigrew, Thomas, \& Whittington, 2001). It is also interested in continuous change, in the form of teleological fit to the environment rather than discontinuous change. It also assumes that managers have a certain degree of agency to affect the firms fit with its environment in a dynamic fashion (Beckert, 2012).

\subsection{Conceptual Model}

The literature, while not well grounded in empirical research, at least provides a set of concepts that are likely to be related to the ability of a firm to strategize its way out of a shock. The schema below (Figure 6) shows how the current literature would suggest a resilience strategy is formed. 
Figure 6: Conceptual Schema Developed From Literature

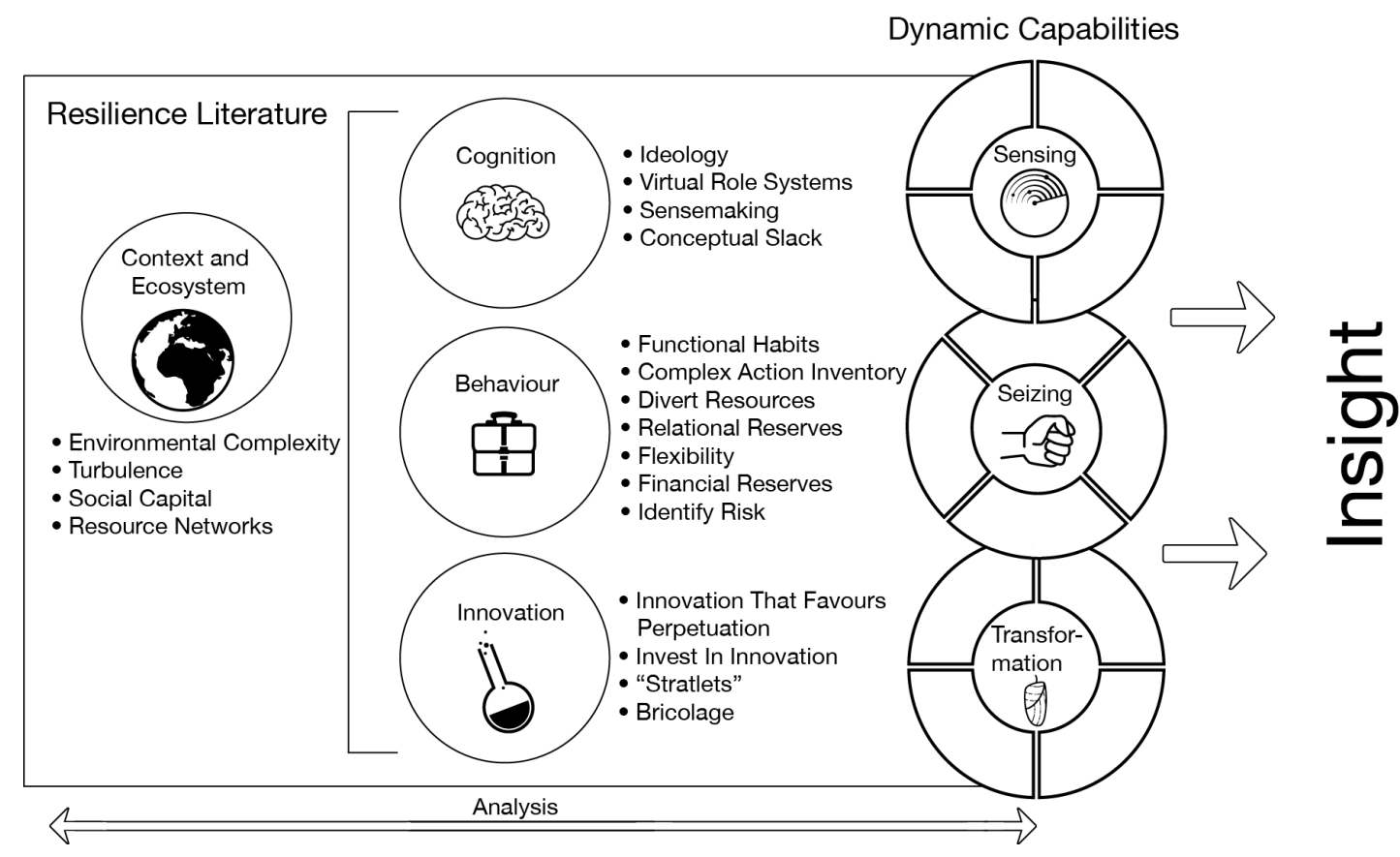

The conceptual schema in Figure 6 is derived from literature surveyed relating to the concept of resilience in strategic management. The literature and by extension the model, suggests that resilience strategies are different to day-to-day strategies of firms. These resilience strategies are formed first by a set of cognitive processes (sensemaking and bricolage) and guiding principles (ideology and values). Virtual role systems allow for reconstruction of hierarchies and draw on ideology to create actions. These conceptualised strategies are implemented through a set of processes that differ from the typical operating process of firms. The concepts of functional habits, diversion of resources, innovation, flexibility, organisational slack, and the relational reserves it has with its employees are unique behavioural processes and resource utilised to abate disturbance. These processes are instigated upon the realisation that old courses of action no longer work in the new environment (complex and varied action inventory). Resilience strategies and their relative success are anchored in the context of the organisation that relates to the firm's ability to implement these strategies. Identified from literature, concepts that constitute the resilience context of the organisation include complexity and turbulence of the 
environment and the shock being experienced, the level of social capital and networks of resources the firm has access to.

\subsection{Statement of the Problem}

This section aims to synthesize the literature into a statement of the problem to be addressed by the thesis. One issue in the study of resilience is the lack of empirical evidence in the literature. While a preponderance of theoretical and conceptual resilience publications has sought to identify the relevant concepts, there is, as stated by Sutcliffe and Vogus (2007); a dearth of empirical evidence in this area. Those publications that do employ empiricism to examine the resilience concept have focused on just a few areas, such as innovation strategy, industrial relations and flexibility of supply chains. Even fewer of the empirical studies utilise insider accounts to found their propositions of resilience capacity and behaviours, with the use of secondary sources of information to extrapolate the motivations and behaviours of firms. All of the identified empirical studies seek to test resilience antecedent concepts in isolation for the identification of simple cause and effect relationships.

Rose (2004) suggests that it is important to identify resilient actions, especially those that violate expected norms. While study has been undertaken in the area of strategic management, its focus has been on antecedent concepts such as resilience capacity, and the resilience of strategies themselves (Hamel \& Valikangas, 2003). As such, one area that lacks attention is that of the content of resilience strategies - the ex post examination of actions intended to create resilience to a disturbance. Birkie et. al. (2014), in their critical review of literature on resilience, identify a number of gaps in extant literature, these include:

- Understanding the relevance of core operational resilience functions

- A taxonomy of resilience capabilities and their related actors 
- Synergies and trade-offs between capabilities to deal with threats versus opportunities

- Operational resilience versus lean thinking.

Finally, innovation has been identified as a central concept in the study of organisational resilience by many of the conceptual and theoretical authors (Hamel \& Valikangas, 2003). It has also been addressed empirically in one study on resilient organisations (Reinmoeller \& van Baardwijk, 2005). However, as this study investigated the value of diversity of innovation strategies, it is not known how innovation contributes as a component of a wider company strategy during disturbance. Similarly, authors such as Hamel and Valikangas and Valikangas (2004) identify an orientation to innovation which is neither empirically founded nor related to the ability of an organisation to create resilience by innovating during a disturbance. The issue is therefore clearly defined as the need to understand the role of innovation during the context of a disturbance. Similarly, the concept of bricolage has been identified by authors as an important capacity in the creation of resilient responses by firms to environmental shocks (Coutu, 2002; Weick, 1993). However it has not been addressed empirically by research in the way innovation has, despite its close conceptual link (Baker \& Nelson, 2005; Fuglsang \& Sørensen, 2011). As such the role of bricolage as an innovative process would benefit from empirical study to investigate its value as a source of resilience.

\subsection{Research Gap}

As recently as 2007 Sutcliffe and Vogus (2007) described the empirical base on resilience as a 'dearth'. They suggest that the study of resilience in organisations is fragmented - that is, references to the topic emerge in a range of different subject areas, and show little systematic empirical work or individual attention. Birkie et. al. (2014) found just six examples of empirical research on the topic of resilience and strategic management as part of a systematic review. Bhamra, Dani and Burnard (2011) also identify a limited focus on empiricism contrasted with an overabundance 
of definition and theory building. The current stock of literature provides a useful platform for discussion and an initial foray into the types of attributes and characteristics of resilient firms. However, progression of the field of theory clearly requires empirical research to test, elaborate and extend the theory. This thesis seeks to address this need.

The literature offers a significant range of concepts that authors attribute to the creation of resilience in firms. Some of these are somewhat tautological, such as having large amounts of cash on hand (Ernst \& Young, 2010). Others are paradoxical, such as redundancy and slack being both beneficial and detrimental to resilience (Gittell et al., 2006; Sheffi, 2005d ). As discussed previously, these are not always asserted with evidence and analysis.

At the highest level, the goal of this thesis is to identify and elaborate the strategies that contribute resilience to firms. This is an extension of the existing literature which deals, so far, with the antecedents and attributes of firms that provide resilience (Birkie et al., 2014; Vogus \& Sutcliffe, 2007). The section that follows identifies how the study approached this goal, the methods that were employed to investigate this and the above noted goals.

\subsection{Research Gap Summary}

This review of literature has identified several features of the resilience literature that provide sufficient opportunity to perform research. This includes a preponderance of theoretical discussion and an espoused need for evidence to continue conceptual development (Birkie et al., 2014; Vogus \& Sutcliffe, 2007). The literature offers a range of concepts to be explored as resilience causing, so examination and elaboration of these concepts is a strong directive for research. 


\subsection{Research Questions}

The research questions have been developed to address the research gap and also the priorities of the study, which is to extend the literature into the identification of resilient action in firms (Rose, 2004). The research questions, examined in the context of the New Zealand manufacturing sector, during the GFC are:

1. What contributes to resilience in firms?

a. What are the strategies, resources and capabilities that enable resilient firms to continue to perform (or not) during environmental shocks?

b. What are the attributes and features of firms that enable resilience during environmental shocks?

2. Do dynamic capabilities play a role in the resilience of firms?

a. Is the dynamic capabilities framework useful to examine the resilience of firms?

\subsection{Chapter Summary: Literature}

This chapter has identified useful literature that provides clarity of the concepts relating to resilience as well as direction for further study to improve and develop the concept. The history of the concept was explored. The state of the literature and discussion of resilience in strategic management is reviewed, identifying two major strands of literature, empirical - evidenced and theoretical. The analytic framework dynamic capabilities and its apparent conceptual alignment with resilience core concepts is also examined. The chapter concludes by offering a conceptual framework and a research gap to be addressed by the thesis. 


\section{Research Approach}

\subsection{Chapter Introduction}

The research questions identified at the end of the literature review were operationalised and analysed using the approach outlined in this chapter. The research approach identifies the most appropriate sector within which to find participant firms, research paradigm, techniques, and analytic methodology. The research questions, which were examined in the context of the New Zealand manufacturing sector, during the GFC are:

1. What contributes to resilience in firms?

a. What are the strategies, resources and capabilities that enabled resilient firms to continue to perform (or not) during environmental shocks?

b. What are the attributes and features of firms that enable resilience during environmental shocks?

2. Do dynamic capabilities play a role in the resilience of firms?

a. Is the dynamic capabilities framework useful to examine the resilience of firms?

The research was conducted in a two-step process: First data was collected on the resilience of firms in the form of their relative performance and actions during the GFC. Second, the dynamic capabilities framework was applied to view this data.

\subsection{Qualitative Research}

The aim of this study is to build theory regarding the characteristics of firms that make them resilient. The existing literature has offered a range of potential attributes. However, the goal here is to extend this theory into the strategies, which potentially draw on these attributes, to create resilience. Qualitative research is useful for the elaboration of theory due to its ability to offer deep insights into the phenomena being studied (Given, 2008; Marshall \& Rossman, 2010). This type of approach enables an 
exploration of whether the expected characteristics are present, and to identify what is different or unexpected in the results (Hays \& Singh, 2011).

Qualitative research also enables the researcher to extract deep answers from participants by requiring them to be specific (Biklen \& Casella, 2007). The primary qualitative means of data collection, interviews and observation, result in more detailed and nuanced sets of data than quantitative methods, due to the in-depth methods and a smaller sample size (Strauss \& Corbin, 1998). This rich set of data can be used to probe the interesting differences and intricacies of the research sites. Multiple data points (where possible) within the firms studied enable the local verification of claims made by other respondents (Fink, 2000). This enables statements regarding the reliability of the data by exposing any inconsistencies in answers.

\subsection{Studying Resilience}

A number of authors have made forays into the empirical study of resilience in firms. Both qualitative and quantitative methods have been employed using a number of techniques. Reinmoeller and van Baardwijk (2005) utilised a secondary database of accounting figures to perform a quantitative study that cross-referenced resiliency in firms with their innovation practices. They sought to identify differences between resilient firms and less resilient firms in order to deduce the actions of resilient firms that were not present in others. Gittell et. al (2006) and Gittell (2005) also use secondary data sets to identify the resilience of sample firms. They used variables for analysis including stock price recovery, layoffs, debt/equity ratios, and cash on hand.

Sheffi and Rice (2005) approach the study of resilience using primarily qualitative methods, including interviews but also other mixed data sources, including publicly available statistics. They compiled case studies of firms from a range of industries, sectors and countries that had experienced disturbances and compared them with 
others which had not. As with Reinmoeller and van Baardwijk's (2005) approach, this enabled them to identify resilient actions by identifying those that were present in resilient firms, and not in others. Webb and Schlemmer (2006) also interview managers for their study of resilience by examining their data through the lens of core capabilities. However, this research found that these capabilities did not necessarily contribute any competitive advantage to firms. Table 4 depicts the various approaches to studying resilience employed to date.

Table 4: Empirical studies of resilience; key features

\begin{tabular}{|l|l|l|l|}
\hline Author(s) & Type & Approach & Measures \\
\hline $\begin{array}{l}\text { Reinmoeller and } \\
\text { van Baardwijk } \\
\text { (2005) }\end{array}$ & $\begin{array}{l}\text { Quantitative } \\
\text { (Secondary) }\end{array}$ & $\begin{array}{l}\text { Examine a database of firms } \\
\text { (publicly traded) over time, } \\
\text { compare and contrast resilient, } \\
\text { non-resilient to elucidate } \\
\text { differences. }\end{array}$ & $\begin{array}{l}\text { Accounting figures, } \\
\text { investment in innovation }\end{array}$ \\
\hline $\begin{array}{l}\text { Gittell (2005), \& } \\
\text { Gittell et. al (2006) }\end{array}$ & $\begin{array}{l}\text { Quantitative } \\
\text { (Secondary) }\end{array}$ & $\begin{array}{l}\text { Examine the difference between } \\
\text { pre and post crisis measures }\end{array}$ & $\begin{array}{l}\text { Recovery speed, number } \\
\text { of layoffs, financial } \\
\text { reserves, productivity }\end{array}$ \\
\hline Sheffi \& Rice (2005) & $\begin{array}{l}\text { Mixed } \\
\text { (Primary \& }\end{array}$ & $\begin{array}{l}\text { Case studies of firms from } \\
\text { sectors that had suffered a } \\
\text { disturbance compared with } \\
\text { others that had not. }\end{array}$ & $\begin{array}{l}\text { Interviews, publicly } \\
\text { available statistics }\end{array}$ \\
\hline $\begin{array}{l}\text { Webb \& } \\
\text { Schlemmer (2006) }\end{array}$ & $\begin{array}{l}\text { Qualitative } \\
\text { (Primary) }\end{array}$ & $\begin{array}{l}\text { Interviews with managers in firms } \\
\text { analysed through lens of core } \\
\text { capabilities }\end{array}$ & Interviews \\
\hline Weick (1993) & $\begin{array}{l}\text { Qualitative } \\
\text { (Secondary) }\end{array}$ & $\begin{array}{l}\text { Analyse the resilience of a group } \\
\text { of fire-fighters caught in a } \\
\text { disaster, identify key actions of } \\
\text { resilient individuals }\end{array}$ & Case Study \\
\hline
\end{tabular}

The small number of studies that have examined resilience empirically provide a precedent for research techniques. Both quantitative and qualitative data has been used as well as primary and secondary sources. The consistent approach in these studies has been the cross-comparison of high and low resiliency firms in order to eliminate variables that occur only in poor performers, while singling out those that are present in only resilient firms and assuming that these are resilience-contributing 
factors (Reinmoeller \& van Baardwijk, 2005). The research approach for this thesis has been designed to retain the strengths of these approaches while extending the knowledge base in a meaningful and useful direction.

The cross-comparison of firms either over time, or during a crisis, appears a natural and effective means of studying resilience (Reinmoeller \& van Baardwijk, 2005; Sheffi, 2005). However, when examining across numerous firms (as opposed to individual case studies) existing research has utilised participants from a range of industry sectors. This has lead to the comparison of firms with significant disparity in products, markets, practices and other variables. To address this the research performed here focused on a single sector to improve the inter-case comparability of firms. Another methodological development is the use of primary, qualitative data. As other studies have inferred practices in resilient firms from secondary sources, which tends to exacerbate the identification of key variables (Rouse \& Daellenbach, 1999), this study has sought to identify rich insights from managers through qualitative data collection to elucidate their experiences and gather more detail than secondary sources (Seidman, 1997). Table 5 outlines the approach of this research.

Table 5: Approach to Studying Resilience in this Thesis

\begin{tabular}{|l|l|c|c|}
\hline This Thesis & \multicolumn{1}{|c|}{ Type } & Approach & \multicolumn{1}{c|}{ Measures } \\
\cline { 2 - 4 } & Mixed & $\begin{array}{c}\text { Within a sector that has suffered a } \\
\text { disturbance, compare the } \\
\text { strategies of firms with different } \\
\text { performance levels using the } \\
\text { dynamic capabilities framework. }\end{array}$ & $\begin{array}{c}\text { Interviews, } \\
\text { demographic data } \\
\text { sourced from firms: } \\
\text { change in revenue, } \\
\text { company value, } \\
\text { employees, goals. }\end{array}$ \\
\hline
\end{tabular}

\subsection{Dynamic Capabilities as an analytical framework}

Dynamic capabilities has been identified as a potentially useful framework for the study of resilience in firms (Birkie et al., 2014; Vogus \& Sutcliffe, 2007) although, to date, no known studies have applied this framework to the study of resilience. The 
approach employed here, has been to apply the dynamic capabilities framework (Teece, 2007, 2011, 2014a, 2014b) to the interview data gathered about the resilience strategies of firms, so that it provides the structural basis for analysis. The dynamic capabilities view provides a comprehensive perspective of the firm (Augier \& Teece, 2009), including the multifaceted features of its strategy, structure, operation, tangible and intangible assets, and external environment. This appears to provide an encompassing categorisation of the firms under study.

While empirical research into dynamic capabilities has begun relatively recently (Wang \& Ahmed, 2007), qualitative research has been applied successfully to investigate this field of theory (Barreto, 2010; Bruni \& Verona, 2009; Grünbaum \& Stenger, 2014). The approach used in this thesis was to ask interviewees about their strategies using the resilience concepts as prompts. Their answers were categorised using the dynamic capabilities framework (Teece, 2007). This provided an independent means of highlighting the differences, similarities, and themes emergent in the testimony of respondents without introducing a potentially loaded set of questions, as dynamic capabilities are, by their very nature, positive (Helfat et al., 2007; Helfat \& Peteraf, 2009; Teece, 2014b). As such, asking neutrally about actions and then categorising them post-hoc avoids this issue.

The dynamic capabilities framework has been criticised for being difficult to use empirically (Easterby-Smith et al., 2009). However over recent years a number of inroads into the development of an evidence-based understanding of dynamic capabilities has emerged with both qualitative and quantitative methodologies providing alternative perspectives on the theory (Barreto, 2010; Wang \& Ahmed, 2007). Eriksson (2014) identifies a number of qualitative studies on dynamic capabilities, citing that the relative complexity and heterogeneity of the concept in each firm renders quantitative measures difficult to operationalise. 
A number of authors studying dynamic capabilities in firms have opted to use the approach outlined by Rouse and Daellenbach (1999) for the study of resource-based advantage. To study highly complex, imitable and firm specific advantages it is necessary to carefully select firms for study, cluster them by strategic variables, compare their performance, and then examine, through comparison, the highest and lowest performing firms in order to highlight the differences. This has become a consistent approach in the dynamic capabilities literature (cf. Ali, Peters, He, \& Lettice, 2010; Bowman \& Ambrosini, 2003; Breznik \& Lahovnik, 2014; Bruni \& Verona, 2009; Ljungquist, 2014; Pehrsson et al., 2015; Petricevic, 2013; Sirmon \& Hitt, 2009) and was applied in this thesis in order to undertake the comparison of the strategies of resilient and less resilient firms.

The use of qualitative case studies has emerged as a useful means of analysing dynamic capabilities (Wang \& Ahmed, 2007). Narayanan, Colwell and Douglas (2009) employ narrative based case studies to study dynamic capabilities as, in their words, 'one key advantage of the narrative method is that it allows much more context and detail to be reported than other qualitative methods' (p. 30). Newey and Zahra (2009) performed a process research case study based on longitudinal cases. Similarly Bruni and Verona (2009) undertook an exploratory, qualitative study of pharmaceutical companies using individual, in-depth, semi-structured interviews with top management. They used the case study method to investigate dynamic capabilities. Following these examples, this thesis employed a case study approach to examine resilience through the dynamic capabilities framework. Table 6 outlines the key characteristics of various dynamic capability case study research projects. 
Table 6: Case Study Approaches to Dynamic Capabilities

\begin{tabular}{|l|l|l|}
\hline Method & Authors & $\begin{array}{l}\text { Advantages of approach (according to } \\
\text { authors of research) }\end{array}$ \\
\hline $\begin{array}{l}\text { Case Studies } \\
\text { (Narrative) }\end{array}$ & $\begin{array}{l}\text { Narayanan, Colwell \& } \\
\text { Douglas 2009, }\end{array}$ & More context and detail can be reported \\
\hline $\begin{array}{l}\text { Case Studies } \\
\text { (Longitudinal) }\end{array}$ & Newey \& Zahra 2009 & $\begin{array}{l}\text { Identifies salient constructs and their } \\
\text { constituent components }\end{array}$ \\
\hline $\begin{array}{l}\text { Case Studies } \\
\text { (Extended) }\end{array}$ & Bruni \& Verona (2009) & $\begin{array}{l}\text { Enables the study of capabilities as } \\
\text { processes embedded in their context }\end{array}$ \\
\hline $\begin{array}{l}\text { Case Studies } \\
\text { (Multiple) }\end{array}$ & $\begin{array}{l}\text { Jantunen, Ellonen, \& } \\
\text { Johansson, 2012 }\end{array}$ & $\begin{array}{l}\text { Cross-case analysis helps to confirm, extend } \\
\text { and sharpen resulting theory }\end{array}$ \\
\hline $\begin{array}{l}\text { Case Studies } \\
\text { (Multiple) }\end{array}$ & Galunic \& Eisenhardt (2001) & $\begin{array}{l}\text { Subsequent cases test emerging theoretical } \\
\text { insights }\end{array}$ \\
\hline Case Study (Single) & Gilbert 2006 & Simplifies, reconnects and redirects theory \\
\hline Case Studies (Dual) & Rindova \& Kotha 2001 & $\begin{array}{l}\text { Compare and confirm/disconfirm based on } \\
\text { evidence from other case }\end{array}$ \\
\hline
\end{tabular}

\subsection{Using Interviews to Collect Data}

Semi-structured interviews were used to gather data with which to form case studies. Interviewing is an approach at the heart of qualitative research in that they enable participants to represent their experience through language (Seidman, 1997). Instead of testing and evaluating as in quantitative research (Creswell, 2009), interviews uncover the lived experience (albeit in retrospect) of the subject by asking them to impart their expert knowledge in the area (Flick, von Kardorff, \& Steinke, 2004).

Semi-structured interviews have the benefit of providing a loose framework to probe the discussion of identified concepts (Arksey \& Knight, 1999; Seidman, 1997), while not limiting the range of potential responses offered by participants or leading answers in such a manner that simply confirms the expected findings (Creswell, 2009; Hesse-Biber \& Leavy, 2010; Patton, 2001). Instead, semi-structured interviews enable the interviewee to discuss and elucidate topics they consider meaningful to them 
(Flick et al., 2004). This approach also enables the interviewer to follow up interesting strands that diverge from the expected direction of the discussion.

The interview schedule was developed from the conceptual model built from the review of the resilience literature (cf. Figure 6) The concepts and themes were operationalised through their constituent sub-concepts and questions were phrased to prompt discussion in these areas, rather than to test for their presence as in more structured interviews. Strategy content and dynamics were also operationalised as part of the interviews (Fahey \& Christensen, 1986; Montgomery, Wernerfelt, \& Balakrishnan, 1989; Rumelt, 2011; Rumelt, 1982). The aim was to develop an interview schedule that elucidated a view of what the firms did during the GFC to manage its effects. This took the form of asking what were the changes that the firms made to their strategy, which of these changes worked, and which did not. Questions included those in Table 7, while the entire interview schedule is Appendix 2.

Table 7: Interview Questions and Related Resilience Concepts

\begin{tabular}{|l|l|}
\hline (Selected) Interview Questions & Resilience Concept \\
\hline $\begin{array}{l}\text { In which areas were you looking to } \\
\text { innovate? }\end{array}$ & $\begin{array}{l}\text { Innovation (Hamel \& Valikangas, 2003; Reinmoeller } \\
\text { \& van Baardwijk, 2005; Valikangas, 2004) }\end{array}$ \\
\hline $\begin{array}{l}\text { What were the big changes (if any) you saw } \\
\text { in your environment during the crisis? }\end{array}$ & $\begin{array}{l}\text { Environmental Turbulence (Gittell, 2005; Sheffi, } \\
\text { 2005) }\end{array}$ \\
\hline $\begin{array}{l}\text { Were any changes your firm made during } \\
\text { this period particularly successful? }\end{array}$ & Renew, Reorganise (Webb \& Schlemmer, 2006) \\
\hline $\begin{array}{l}\text { How did you adapt your business to } \\
\text { function during this period? }\end{array}$ & Flexibility/Agility (Lengnick-Hall \& Beck, 2009) \\
\hline
\end{tabular}

\subsection{Managing the credibility and reliability of data}

Gray (2009) suggests that managing the validity and reliability of data are the two major concerns regarding the collection of credible interview data. Validity may be problematic with interviews, given that they depend on the direction of the answers 
given by interviewees and the inherent difficulty in procuring samples large enough to generalise to a population (Arksey \& Knight, 1999). Instead, insights from interviews are valuable contributors to knowledge by remaining anchored in their context (Guba \& Lincoln, 1994). To improve validity, the interviews in this project were semistructured to ensure interviewees have scope to express themselves. Interview schedules were piloted before being employed in the field.

The credibility of data is also affected by the recall and memory of managers (Huber \& Power, 1985). The risk of inaccurate responses stemming from myriad causes, including; perceptual and cognitive limitations, hindsight and attributional bias, a lack of information or knowledge, and poor elicitation procedures - the ability to draw out truth without communicating what is being sought - are acknowledged as limitations of this research (Miles \& Huberman, 1994). Interviews were conducted within two years of the end of the GFC (Statistics New Zealand, 2012b).

Reliability of data is supported when the instrument used to measure does so consistently (Gray, 2009). The interviews followed the same protocol; this includes reading questions as written, which may be repeated if asked by the respondent. Questions in which answers are refused were not be met with irritation or any other response. Probing and prompting of further answers was not carried out in a leading or directive manner (Oppenheim, 1994).

\subsection{Purposive Sampling}

Sampling for this thesis was carried out purposively. That is, firms were selected for particular attributes that they had which would benefit the study (Oliver, 2006). Employing purposive sampling is strategic in that the way potential participants are identified was based on their likely potential to add value to the proposed research (Given, 2008). 
The generalizability of the study is improved by the purposive selection of cases (Eisenhardt, 1989a). Similarities in the cases selected served to decrease the number of extraneous variables affecting the analysis (Graebner \& Eisenhardt, 2007; Yin, 2010). Selecting firms ensured firms shared as many similarities as possible, while the different conditions that each firm experiences enabled the exploration of the phenomenon of resilience.

\subsection{Choosing a Sector for Study}

The process of selecting a sector to study was approached systematically. The GFC provides a form of natural experiment within which to study how resilient firms cope with an undeniably significant and wide-ranging disturbance (Bedford, 2008; Elliot, 2011; Rudd, 2009). The field of potential industries was narrowed by examining a range of quantitative performance criteria. The summary statistics compiled by Statistics New Zealand for the Business Operations Survey (BOS) (Statistics New Zealand, 2010b) provided the basis for this narrowing. A description of the BOS is as follows (emphasis added).

'The Business Operations Survey is an integrated, modular business performance collection concentrating on measures of business performance and a range of practices and behaviours which may have some impact on that performance. It is an enterprise-based collection with a broad population, so data can be compared across a wide crosssection of NZ businesses' (Statistics New Zealand, 2010b, p. 1).

The survey collects data from private firms in 19 ANZSIC06 code sectors (Statistics New Zealand, 2010b). Business sizes range from small (six to 19 employees), to large (100 or more employees) and range in type from individual proprietorship, companies, and partnerships, among others. Firms included in the survey have a GST turnover of more than $\$ 30,000$ per year and have been operating for a year or more. 
The criteria for sector selection are listed below:

- Size (at least 300 firms in the total population)

- Low performance compared to other sectors

- The greatest (negative) change in sector performance

The first criterion is necessary to ensure that the sector being studied is sufficient in size to identify and sample a sufficient number of firms. The two performance criteria ensure that the sector under study provides the context of a significant disturbance for firms to require a resilient response. This should enable the comparison of high and low performing firms within the context of this disturbance to elucidate the differences in strategy between firms (Rouse \& Daellenbach, 1999). Figure 7 shows the change in real value added for a range of New Zealand sectors.

Figure 7: Change in Real Value Added (June 2012 versus December 2007) in New Zealand Sectors (Captial Economics Limited, 2012)

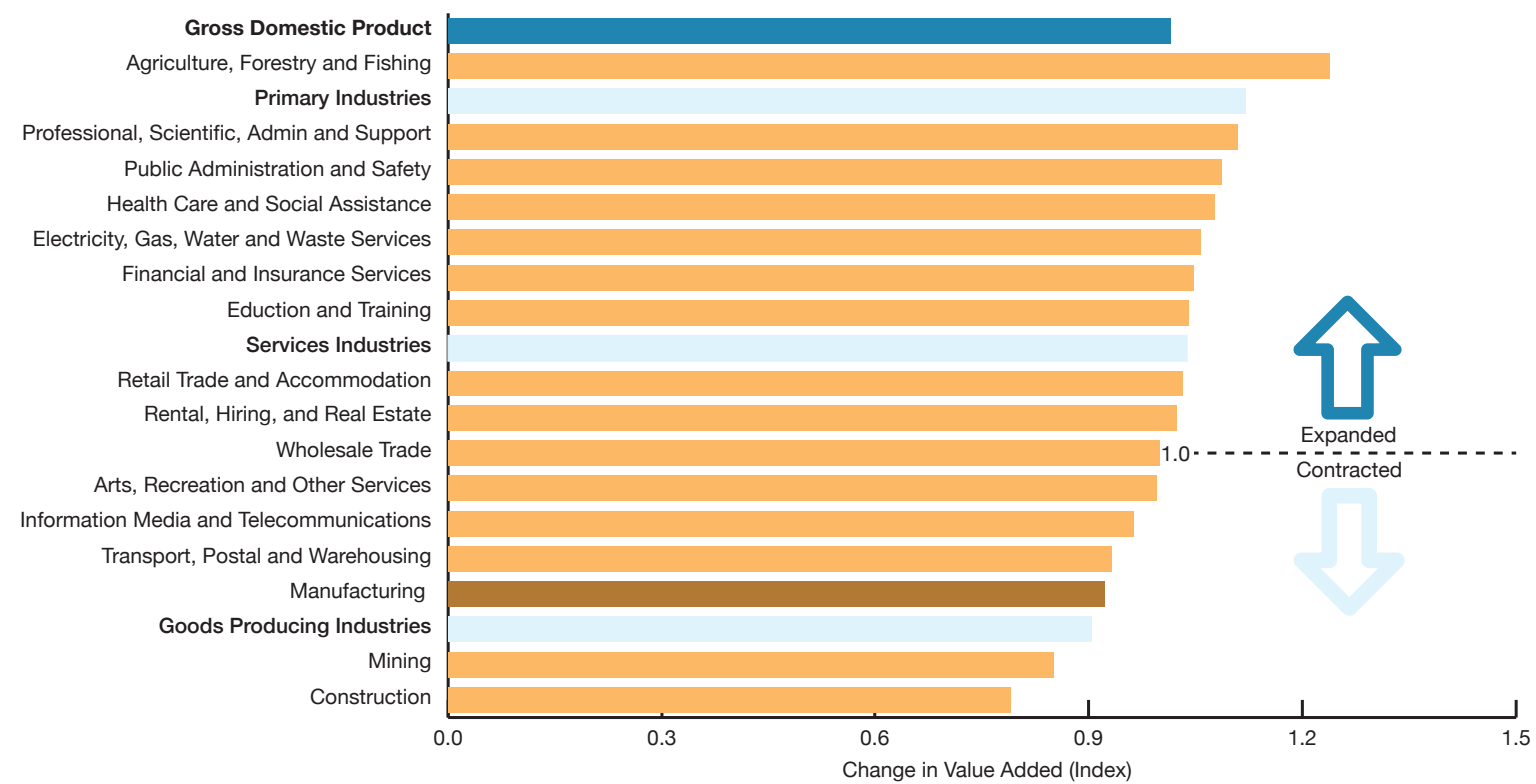

The manufacturing sector in New Zealand was one of six to show a contraction in real added value from December 2007 until June 2012 (Captial Economics Limited, 2012). Figure 7 compares a range of New Zealand industry sectors change in 
performance (as value added) in December 2007 versus June 2012. The BOS shows that the industry suffered declines in most sub-sectors - the only exceptions being the meat and dairy processing sub-sectors (Hosking, 2012; Statistics New Zealand, 2010b). Metal products, equipment and machinery have suffered the largest drops in output of any sub-sectors (see Figure 8). Some sectors such as chemical polymers and rubber have rebounded after bottoming out in 2011 (Statistics New Zealand, 2012b). However, at the time the research was conducted most still had not returned to pre-crisis levels of output (Figure 8). The manufacturing sector did not show consistent positive results until early 2013 (Beard, 2015). Reasons for the decline were attributed to a lack of demand or a lack of orders, or slowness in orders (Weir, 2012), or a global drop in demand and exchange rate pressure placed on the sector by the high value of the New Zealand dollar (Bollard \& Ng, 2009).

Figure 8: Manufacturing output fails to recover from recession (Hosking, 2012)

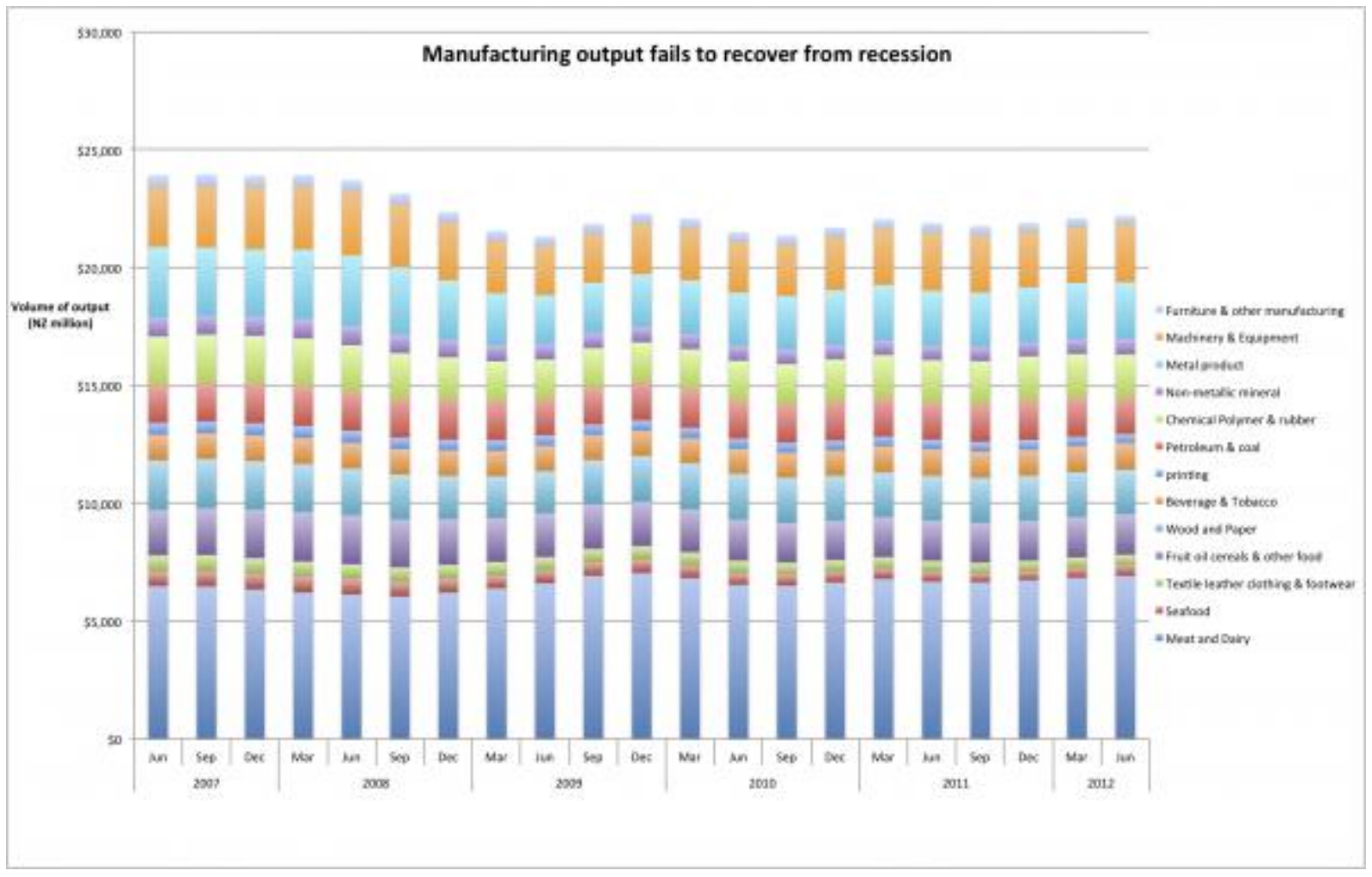

The data presented above show that sales for the manufacturing sector slumped significantly from a peak in early 2008 of $\$ 24$ billion in constant dollars to 
approximately $\$ 21.5$ billion in the first quarter of 2009 (Statistics New Zealand, 2012b). Removing the high performing meat and dairy sub-sectors from the figures, the remaining segments of the sector shed more than $\$ 4$ billion over the same period. In October of 2012 the New Zealand Manufacturers and Exporters association and the Engineering, Printing and Manufacturing Union identified what they called a manufacturing 'crisis' in New Zealand (Pryor, 2012). They reported that emergent conditions from the beginning of the GFC in 2007 had led to margin reductions of $50 \%$ for some firms while orders to manufacturing firms were the lowest in five years. Statistics New Zealand business demography statistics published in October 2012 (Figure 9) show that manufacturers shed 39,740 , or $15 \%$, of its total number of jobs in the period 2005 to 2012 (Statistics New Zealand, 2012a). The same figures show that there were 1964 (8.7\%) fewer firms operating in the manufacturing sector in 2012 since its peak number in 2006 (Figure 10).

Figure 9: New Zealand Manufacturing Industry Employees (Statistics New Zealand, 2012)

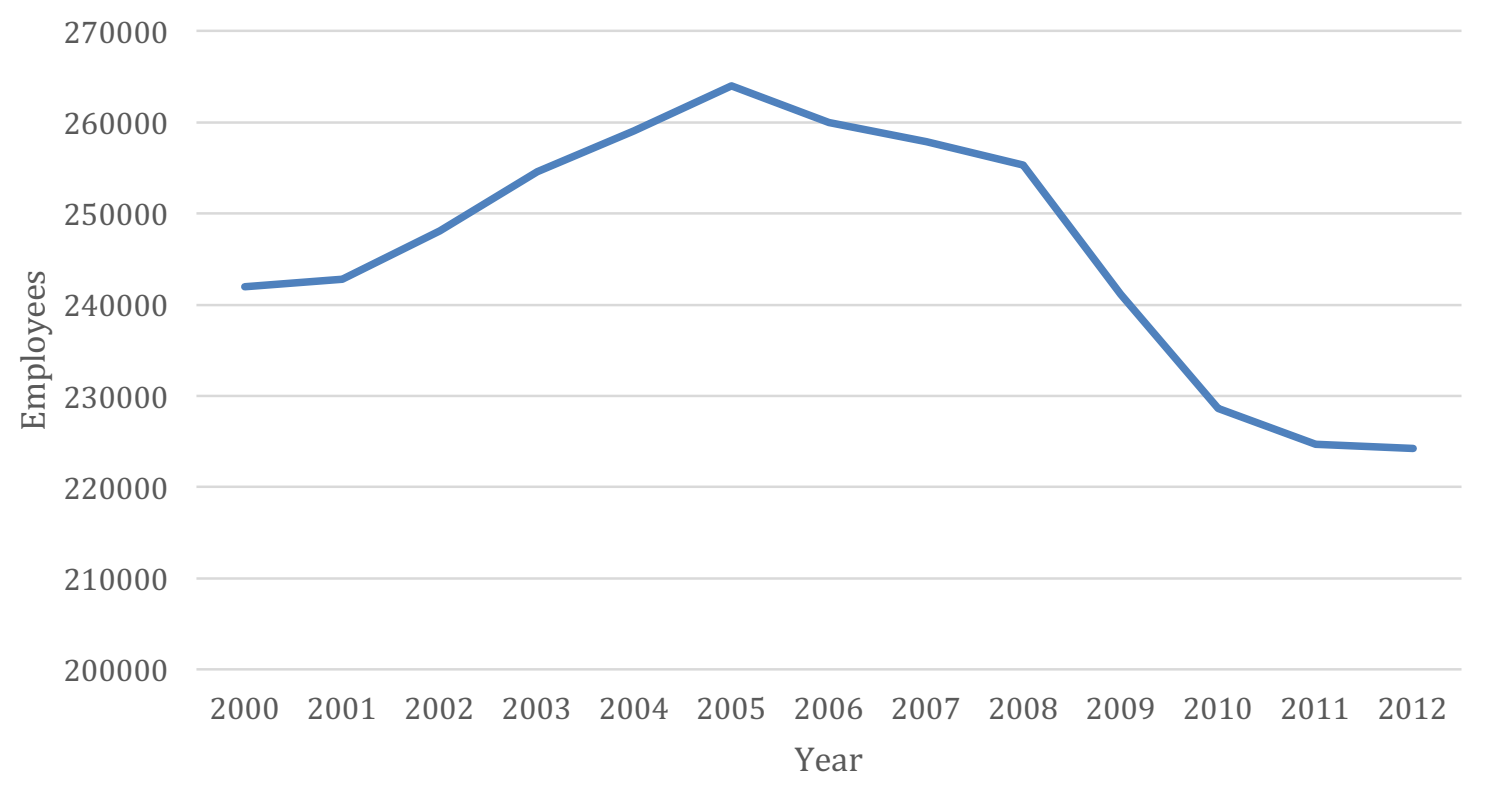


Figure 10: New Zealand Manufacturing Enterprises 2000 - 2012 (Statistics New Zealand, 2012)

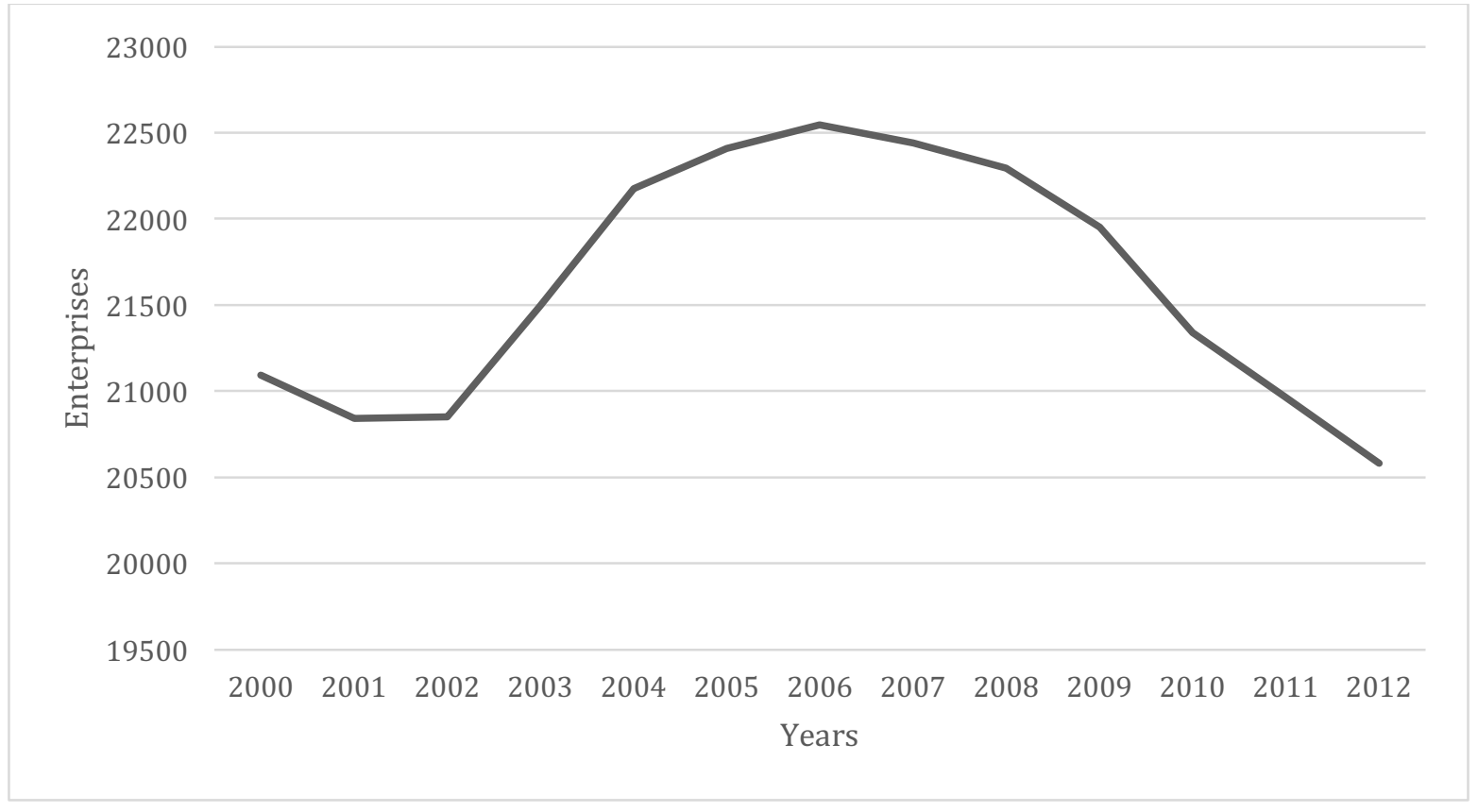

The impact of the GFC on the manufacturing sector, according to the statistics, was undeniable. The reduction in sales (Statistics New Zealand, 2012b), value added (Captial Economics Limited, 2012), output (Hosking, 2012), jobs, and the number of firms (Statistics New Zealand, 2012a) clearly shows a sector that struggled to deal with the effects of the global economic downturn. This made manufacturing the most appropriate sector to study the phenomenon of resilience within, in order to attempt to answer the research questions. The following sections will outline how the research was approached in order to study resilience in this selected context.

\subsubsection{Identifying Firms Within the Manufacturing Sector for Study}

Having arrived at a candidate sector, the next task was to identify potential firms from within that sector to study. These firms would form the research sites for the case studies (Eisenhardt, 1989a). In order to identify firms with a range of performance during the GFC, it was necessary to gain particular insight into their performance before approaching them. As such, potential participant firms were identified through four different channels: 
- news media searches,

- business development organisations and chambers of commerce,

- a published list of high performing manufacturing companies (TIN100) and,

- snowball sampling.

These sources each had the benefit that, while expressed in different ways, they offered a means of gaining insight and understanding regarding the performance of firms to aid the vetting of potential firms.

Individual firms were the unit of analysis for the study. This boundary enabled the selection of participants and the appropriate framing of interview questions. The dynamic capabilities framework uses the organisation (firm) as the unit of measure (Helfat et al., 2007; Helfat \& Peteraf, 2009; Teece, 2007; Teece \& Pisano, 1994) as do studies of resilience (Coutu, 2002; Hamel \& Valikangas, 2003; Rose, 2004; Sutcliffe \& Vogus, 2003; Valikangas, 2004).

Once potential firms were identified, a letter (Appendix ) was sent to initiate contact and gauge interest. Follow-up phone calls were placed to firms that did not respond to the letter. For firms that were interested in being involved, interview times were scheduled at the convenience of managers. Overall more than 170 firms were approached by mail and then telephone. Interviews were scheduled with twenty-two firms and carried out with nineteen. Ultimately, data from seventeen firms was used in the final analysis. The reasons for not carrying out scheduled interviews were:

- consistent cancellations,

- low availability of interviewees,

- finding on first contact that the firm is not truly manufacturing (e.g. one firm fitted out vehicles using exclusively $3^{\text {rd }}$ party products, making it essentially a services firm).

Data from two firms was not used in the final analysis as only one interview was conducted at the research site, despite reasonable attempts to conduct more. 
The seventeen firms that were used in the analysis were from a range of sub-sectors of manufacturing and a range of sizes, turnover and employees. These details are depicted in Table 8.

Table 8: Characteristics of Participant Firms

\begin{tabular}{|c|c|c|c|c|}
\hline Firm & $\begin{array}{l}\text { Manufacturing } \\
\text { Sub-Sector }\end{array}$ & $\begin{array}{l}\text { Revenue (when } \\
\text { interviewed) }\end{array}$ & $\begin{array}{l}\text { Number of } \\
\text { Interviews }\end{array}$ & $\begin{array}{c}\text { Participants } \\
\text { (Titles Provided) }\end{array}$ \\
\hline 1 & Healthcare & $\$ 500,000,001+$ & 2 & CEO, CFO \\
\hline 2 & Animal Health & $\$ 10,000,001-\$ 50,000,000$ & 2 & $\begin{array}{l}\text { Managing Director, } \\
\text { Head of Design }\end{array}$ \\
\hline 3 & $\begin{array}{l}\text { Electrical Power } \\
\text { Systems }\end{array}$ & $\$ 10,000,001-\$ 50,000,000$ & 2 & $\begin{array}{l}\text { Managing Director, } \\
\text { Operations Manager }\end{array}$ \\
\hline 4 & Animal Health & $\$ 50,000,001-\$ 100,000,000$ & 3 & $\begin{array}{c}\text { CEO, Financial } \\
\text { Controller, Production } \\
\text { Manager }\end{array}$ \\
\hline 5 & Children's Toys & $\$ 1,000,001-\$ 10,000,000$ & 2 & $\begin{array}{l}\text { Managing Director, } \\
\text { Head of Design }\end{array}$ \\
\hline 6 & Technology & $\$ 10,000,001-\$ 50,000,000$ & 3 & $\begin{array}{l}\text { Managing Director, } \\
\text { Finance Manager }\end{array}$ \\
\hline 7 & $\begin{array}{l}\text { Ventilation and } \\
\text { Air Quality } \\
\text { Technology }\end{array}$ & $\$ 10,000,001-\$ 50,000,000$ & 3 & $\begin{array}{c}\text { CEO, CFO, Head } \\
\text { Designer }\end{array}$ \\
\hline 8 & Human Health & $\$ 5,000,001-\$ 10,000,000$ & 2 & $\begin{array}{c}\text { CEO, Operations } \\
\text { Manager }\end{array}$ \\
\hline 9 & $\begin{array}{c}\text { Plastics } \\
\text { Manufacture }\end{array}$ & $\$ 5,000,001-\$ 10,000,000$ & 2 & CEO, CFO \\
\hline 10 & $\begin{array}{l}\text { Food and } \\
\text { Beverage }\end{array}$ & $\$ 5,000,001-\$ 10,000,000$ & 2 & CEO, Co-owner \\
\hline 11 & $\begin{array}{c}\text { Plastics } \\
\text { Manufacture }\end{array}$ & $\$ 50,000,001-\$ 100,000,000$ & 2 & $\begin{array}{l}\text { CFO, Innovation and } \\
\text { Operations Manager }\end{array}$ \\
\hline 12 & $\begin{array}{c}\text { Metal } \\
\text { Manufacture }\end{array}$ & $\$ 0-5,000,000$ & 3 & $\begin{array}{l}\text { Owner (outgoing) } \\
\text { Owner (incoming), } \\
\text { Floor Manager }\end{array}$ \\
\hline 13 & $\begin{array}{l}\text { Human Health } \\
\text { Technology }\end{array}$ & $\begin{array}{c}\$ 100,000,001- \\
\$ 500,000,000\end{array}$ & 3 & $\begin{array}{c}\text { CEO, CFO, Innovation } \\
\text { Manager }\end{array}$ \\
\hline 14 & Construction & $\$ 0-5,000,000$ & 3 & $\begin{array}{l}\text { Managing Director, } \\
\text { Head of Marketing, } \\
\text { Finance Manager }\end{array}$ \\
\hline 15 & $\begin{array}{l}\text { Health } \\
\text { Technology }\end{array}$ & $\$ 0-5,000,000$ & 2 & $\begin{array}{l}\text { Managing Director, } \\
\text { Head of Research and } \\
\text { Sales }\end{array}$ \\
\hline 16 & $\begin{array}{c}\text { Metal } \\
\text { Manufacture }\end{array}$ & $\$ 5,000,001-\$ 10,000,000$ & 3 & $\begin{array}{l}\text { Managing Director, } \\
\text { Finance Manager, } \\
\text { Operations Manager }\end{array}$ \\
\hline 17 & $\begin{array}{c}\text { Marine } \\
\text { Technology }\end{array}$ & $\$ 5,000,001-\$ 10,000,000$ & 2 & $\begin{array}{l}\text { Managing Director, } \\
\text { Financial Controller }\end{array}$ \\
\hline
\end{tabular}




\subsection{Human Ethics, Anonymity and Confidentiality}

The research performed for this thesis was subject to the guidelines of Victoria University of Wellington's Human Ethics Committee. For the protection of participants, both firms and individuals, the research was conducted and findings reproduced and articulated here, with the utmost consideration for anonymity and confidentiality. In order to protect the identities of participants, the unique identifiers assigned to firms and managers were stripped of identifying details. For example, in Table 8 (Page 60) the firms' area of operation has been generalised (health, technology, etc.), and revenue has been reported in a range. Other demographic data, while collected as part of the research, has not been reproduced in this thesis to ensure that no sufficient level of detail exists for firms to be identified. Where quotes from participants have been reproduced, as examples in this chapter and as evidence in Chapter 4: Findings (Page 87) names, companies, countries, types of customer and other identifying details respondents may have referred to by name have also been amended to preserve anonymity and confidentiality.

\subsection{Interviewees}

Multiple interviews were carried out in each firm; with either two or three interviews being carried out per site. Subjects were top and middle management employees including Owners, CEOs, CFOs, CTOs, other C-Level Executives, Managing Directors and Operations Managers. In understanding the extent of the reliability of data, individuals interviewed were chosen for their ability to corroborate or contradict the testimony of other interviewees within the firm. That is, interviewees were selected from cohorts within firms so that they similar access to, and influence over, information, decisions and strategy making for the firm during the GFC. Overall, forty interviews were carried out in participant firms. Further details of the breakdown by interview and firm are shown in Table 8. 


\subsection{Firm Demographics and Resilience Measures}

In order to analyse the data from the firms it was necessary to rank them for their resilience to the effects of the GFC. This provided the opportunity to analyse the inherent differences in strategy of resilient and non-resilient firms (Reinmoeller \& van Baardwijk, 2005; Sheffi, 2005; Sheffi \& Rice, 2005). In comparing the practices of firms from different clusters of performance the starkness of differences between the studied firms is highlighted (Rouse \& Daellenbach, 1999).

When resilience of what, to what varies from firm to firm (Carpenter et al., 2001), diagnosing an objective measure of that resilience to apply across firms requires a pragmatic approach. In order to score firms as resilient (or not) the method was to score firms on an as objective scale as possible. This approach has been used by others to diagnose the resilience of firms (cf. Gittell, Nordenflycht, \& Kochan, 2003; Reinmoeller \& van Baardwijk, 2005). The criteria used by these authors included fundamental performance indicators such as book value per share, return on assets and layoffs. However, for Gittell and others, and Reinmoeller and van Baardwijk, the firms they studied were publically listed, required by law to publish particular operating metrics. Due to the range of firm types, sizes and structures for this study, a set of measures that allowed for the lack of public data was required. The criteria also needed to measure the conceptualisation of resilience employed in this study, that of persistence and even performance in the face of undeniable disturbance (Carmeli \& Markman, 2011; Coutu, 2002). A best approximation of objective ranking and categorisation of the firms in terms of their resilience was necessary in order to enable cross comparison of the firms. Acknowledging the need to create a simple and yet objective measure of the resilience of firms, the criteria used (and applied with equal weighting) to rank the firms in this study were:

- growth - total value of firm (year on year change for the financial year that the interviews were conducted),

- stability of revenue during the GFC (year on year change), 
- resource base expansion (acquired or divested, expanded or contracted, capital expenditure, branches opened or closed, property, facilities, or intellectual property)

- goals - stated goals attained or not attained (as reported by managers)

These fundamental performance measures were scored on a three-point scale, from 1 to -1 , where 1 is positive change, -1 a negative change and 0 is no change. It is noted that the unique contexts, sizes, scales and other factors that differentiate firms' risks diminishing the potential to compare them. However, the similarities of sector and firm type should help outweigh the differences in specific context. To compile the required information for this list, specific questions in the interview schedule captured some of this data (goals, stock of assets changes), while a demographic questionnaire captured the financial measures. In the case of the three publicly traded companies in the sample, answers were verified where possible with third party sources of information.

Measures including revenue, and firm value, recorded in the demographic questionnaire were captured in retrospect across three points in time: 2007, 2009 and 2011. This enabled the calculation of percentage change across the period of what would widely be considered the GFC (Bollard \& Ng, 2009; Makhlouf, 2013; Statistics New Zealand, 2012a). The attainment of stated goals and extent of change in the size and stock of resources were addressed in the interview schedule. As such the answers were qualitatively derived.

Table 9: Qualitative Resilience Measures

\section{Goals Attained Or Not Attained}

'Interviewer: Before the crisis what were the goals [of your firm] ...

Interviewee: We were really focusing on [Country 2] and this new benching system...it's just not working the way it should be... because we've taken our eye off the ball in another sector.' (Managing Director, MidRes3) Score -1 (not attained) 
Table 9: Qualitative Resilience Measures Continued

'Interviewer: So what were your objectives during that period?

Interviewee: I'm trying to think of something more concrete and specific than restore viability... Improvements to the product range which were aimed at taking cost out that was essential, and also delivery of a product that was in accordance with increased safety standards. So there were essentially three products developments that we chased, two of which were successful and are now essentially the base of our product offering.' (Operations Manager, HighRes3) Score 1 (attained)

Resource Base Expansion

'Now we're looking at investment. We're going to expand this plant here significantly. We're going to expand our laboratory space in [City], double that. We're going to invest a significant amount of capital in IP development.' (Financial Controller, HighRes4) Score 1 (expanded)

'...a while ago we acquired a company which made [Complementary Product]. (CEO, HighRes1) Score 1 (expanded)

As is apparent in Table 24, the four-attribute, three-point resilience scale resulted in a number of firms attaining the same total score. In these instances, further qualitative evidence of performance differentiated the position on the resilience ranking. Two of the most conspicuous examples of this are the differentiation between those on the cusp of high and middling, and middling and low resilience. In those instances, both firms on the transition scored the same. However, further evidence from the interviews was used to discriminate the final positions of the firm in the ranking. The tied firms were considered on the same, emergent criteria that were typically answers to questions posed, but that did not fit into the demographic questions used develop the high level ranks. Below are examples of managers' testimony that was used as evidence in order to make these differentiations.

In the first example (Table 10) the quotes are illustrative of the managers' view of the performance of their firm over the same period. While HighRes 4 was recovering strongly, MidRes1 was still struggling with the effects of the GFC. 
Table 10: Discriminating Evidence: Same year performance - Firms HighRes4 and MidRes1

'...by the end of 2010 things were starting to come right. We were starting to come right second half of 2010 - we started trading out of it. 2011 and 12 were stellar.' (CEO HighRes4)

'I think in the last 12 to $18(2011-2012)$ months that we've seen some [negative] impact and it's just meant that we've had to operate a very lean business and make some calls around efficiency.' (Head Designer MidRes1)

In the table below, the managers of MidRes9 and LowRes 4 discuss which of the changes their firms made were particularly successful. The evidence shows that in MidRes9, managers considered their changes to be very successful. While in LowRes4 intended changes had not at that stage been realised, nor had their benefits.

Table 11: Discriminating Evidence: Same year performance - Firms HighRes4 and MidRes1

'Yeah, basically the supply chain changes we made were really successful. They were great. They helped us not only have a better way of managing our suppliers and partners but...that allowed us to manage those people better' (CEO MidRes9)

'l'd like to have changed our advertising - like to on TV. But at the moment we're working with this social media guy in [Country 2] and that's new, and working.' (Marketing Director LowRes4)

\subsection{Saturation of the Data Set}

Sample sizes for qualitative research projects are typically smaller than those of quantitative studies for a number of reasons (Mason, 2010). Small samples in qualitative research increase the researcher's familiarity with the respondent, and can enhance the validity of the granular inquiry (Crouch \& McKenzie, 2006). 'Saturation' is described by Mason as the point of diminishing returns for a qualitative sample, where another piece of data, does not necessarily provide further insight. Data 
collection that is stopped too early however may result in the creation of theory that is unbalanced or inaccurate (Given, 2008). In this study, saturation was signalled by the lack of emergence of new themes to attribute to instances of change or strategy in subsequent research sites (Guest, Bunce, \& Johnson, 2006).

As the collection of data progressed, the transcription, reading and analysis of research sites that had been completed were performed in parallel. The key themes and patterns emergent in the data were nascent. As further research sites were added these themes and patterns were readily identified in the data and as further research sites were added and analysed, an emerging pattern of a lack of confirmatory insight was apparent. For example, themes of efficiency, business model adjustment and innovation were present across the majority of firms. Signals that new insights were not emerging as readily from new research sites began to emerge between the $13^{\text {th }}$ and $15^{\text {th }}$ firms. Subsequent interviews and the concurrent analysis of transcripts further confirmed that the data set was becoming saturated.

\subsection{Research Paradigm}

\subsubsection{Postpositivism}

Creswell (2009) describes postpositivism as similar to positivism, with a key difference being that when studying a social reality, this philosophy acknowledges that the researcher cannot be completely assured about their knowledge claims. Instead, the researcher approximates reality through building evidence to support a theory, rather than the positivist notion of proving relationships (Hesse-Biber \& Leavy, 2010). While postpositivism recognises that the findings of research are conjectural, ultimately it acknowledges that there is an objective truth to be discovered through analysis and iteration (Robson, 2002).

Many authors discuss resilience as a factor of a number of systemic influences that imbue an entity with the ability to rebound (Bengtsson et al., 2003; Berkes \& Folke, 
1992; Carpenter et al., 2001; Walker \& Salt, 2006). An entity may be resilient to a particular stimulus, but not to another (Adger, 2000). The implication is that resiliency is a contextually defined attribute and is inherently embedded in its setting. Because of these features, postpositivism is a useful paradigm for the study of resilience. Postpositivism employs an encompassing model of causality described as mutual simultaneous shaping (Lincoln \& Guba, 1985), this means that the researcher is aware that circumstances are relative and that forces affecting subjects are dependent on their specific context.

Also useful in studying resilience is postpositivism's tolerance of multiple means of collecting data (Guba \& Lincoln, 1994). Through triangulation, post positivist research augments the claims that can be made by each data collection technique by extending, elaborating and further confirming or rebutting the insights generated (Phillips \& Burbules, 2000). Amounting to methodological flexibility, this allows for the use of objective measures of firm performance (to identify resilient/non-resilient firms) to be augmented by the strategies that firms employed during the GFC to create performance. This allows the diagnosis of resilient behaviours in firms through the elimination of non-resilient, common or marginal practices (Rouse \& Daellenbach, 1999).

\subsection{Abductive Data Analysis}

One of the techniques postpostivist research utilises is abductive data analysis (Borland, 1990). Abduction is the process of moving from an observation to a hypothesis through logical inference (Magnani, 2001). Abduction enables the creation of new knowledge as it allows a warranted description to be rendered in explanation of observed phenomena. As a contrast, deduction logically guarantees the validity of outcomes through falsification of hypotheses, and induction offers good evidence that an outcome will occur based on experience (Furman, 1990; Kolko, 2010). As such, abductive reasoning is the argument to best explanation, which is useful in this instance due to the highly contextual nature of the data. 
Abduction - as a warranted, best assertion (Letourneau \& Allen, 1999) - allows for the use of a framework like dynamic capabilities as it provides an encompassing view of the firm (Teece, 2007). The framework also provides a strong link back to the ecosystemic view of resilience (Berkes \& Folke, 1992; Folke et al., 2004), in that it considers both internal and external attributes and influences with regard to firm performance. As such, in the search for warranted assertability regarding what makes firms resilient, dynamic capabilities theory enables the categorisation of actions that a firm takes when reacting to a disturbance.

\subsection{Analysis}

The process of analysing the interviews was designed to gradually reduce the volume of the raw data gathered into manageable, meaningful fragments of text that each held all, or part of, the evidence for the presence of dynamic capabilities (Yin, 2010). This provided a view of a given firm's dynamic capabilities and, through intra-case analysis, enabled the identification of the capabilities that may contribute to resilience.

\subsubsection{Analysis of Interview Transcripts}

The interviews were transcribed as close as possible to the date of collection. Ensuring that the familiarity with the content was as high as possible, the transcription process was an opportunity to spend significant time immersed in the data. The transcripts were then read in their entirety and reread on a 'research site by research site' basis. This process was designed to create familiarity with the content of each case (Gill, Stewart, Treasure, \& Chadwick, 2008).

Following transcription, the analysis of interviews could proceed. The process was designed to follow Miles and Huberman's (1994) approach to the management of qualitative data. These authors describe a process of analysis consisting of three concurrent activities, that of data reduction, data display, and the drawing of 
conclusions and verification. These were performed over four phases of analysis. Data reduction regards the selection, focusing, simplification, abstraction and transformation of transcripts (Yin, 2010). This comprised phase one of analysis. Data display is the organisation; compression and assembly of information so that it is presented systematically and represented phase two. The drawing of conclusions is the attribution of meaning drawn from the regularities, patterns, configurations, and propositions of the data. These constituted phases three and four.

\subsubsection{Phase one - reduction of raw data}

The aim of reducing data is to isolate meaningful sections of the data from the complete data set (Miles \& Huberman, 1994). The reduction of data began with the reading and rereading of the transcripts for each firm. This provided an understanding of the case as a whole (Marshall \& Rossman, 2010) and contributed the understanding of what resilience responses and actions were and how firms had understood and managed their own uniquely circumstanced crisis (Guba \& Lincoln, 1994). This process included identifying and highlighting small passages of text where the firm made changes, experienced successes or failures and difficulties and other potentially valuable or interesting experiences. Transcripts were labelled for instances of changes and actions on the part of managers that explicitly dealt with the dynamic environment caused by the GFC. This labelling included the context of the discussion to ensure meaning of the snippets was retained. This approach of indexing ensured that the data was not categorised too early in the process of analysis (Miles \& Huberman, 1994; Yin, 2010).

\subsubsection{Phase two - initial coding and identifying dynamic capabilities}

Saldana (2009) describes initial coding as an open ended process including the ascription of short terms or phrases to interesting passages (Seidman, 1997). Marshall (1981) acknowledges that the researcher brings their sense of what is important to this process and that initial coding involves the ascription of this importance to meaningful extracts of transcripts. 
To approach initial coding, the indexed extracts of the transcripts from phase one were transferred into a spreadsheet for each firm. Each managers' responses were colour coded to ensure the individual voices of participants were retained as the data continued to be reduced (Miles \& Huberman, 1994). These extracts were then attributed initial codes from Teece's (2007) dynamic capabilities framework. Using rough codes such as Sensing, Seizing, Transformation, Innovation, and Change (as central tenets of dynamic capabilities, these initial categorisations allowed the retention of the context of the capabilities but reduced the overall volume of data being carried forward into subsequent stages. These segments of data were compiled into a spreadsheet for each firm with columns for data and for categories. This formed the basis for more detailed examination of the capabilities.

\subsubsection{Phase Three - case studies}

The third phase of analysis was designed to create understanding in granular detail of the capabilities that may contribute resilience to firms. By operationalizing Teece's $(2007,2011)$ dynamic capabilities framework, a comprehensive view of the firm and its capabilities was created.

Analysis of cases began by applying Teece's (2007) framework to the identified dynamic capabilities, serving to further refine the data from larger, more contextually rich segments, down to specific instances that constitute evidence for particular capabilities. This was performed by further developing the initial categories assigned in Phase 2 into segments of text that matched the descriptions of dynamic capabilities in the operationalisation of the framework.

Within the cases, themes of resilient action in firms (Rose, 2004) were identified and developed (e.g. integration, business model change). The data was arranged in a matrix (Verdinelli \& Scagnoli, 2013) for each research site across the dimensions of the framework. This categorisation provided the granular understanding of the 
dynamic capabilities of firms, the actions that comprised them and their likely effect on firm performance.

\subsubsection{Dynamic Capabilities: Terms used for Evidence.}

\section{Sensing Capabilities}

Sensing capabilities are those that embody searching for and identifying new knowledge by expanding search horizons, firms can glimpse opportunities, interpret and gauge new technologies and assess how they will evolve, and the likely responses of customers (Teece, 2007). Teece identifies four sub-categories of sensing dynamic capabilities, processes to:

- direct internal R\&D,

- tap development in exogenous science and technology,

- tap supplier and complementor innovations,

- identify target market segments, changing customer needs and customer innovations.

These categories are designed to provide a encompassing view of the areas that a firm may seek to create or identify new knowledge and subsequently destroy the status quo before moving to a new equilibrium (Teece, 2007). Table 12 through Table 18 below operationalises these capabilities using Teece's published articles for the key terms and phrases (cf. Augier \& Teece, 2009; Teece, 2007, 2011, 2014b) 
Table 12: Teece's $(2007,2011)$ Dynamic Capabilities Framework Operationalisation: Sensing Capabilities

\begin{tabular}{|c|c|}
\hline Capability & Terms, Themes and References \\
\hline $\begin{array}{l}\text { Processes to Direct Internal R\&D and Select New Technologies: } \\
\text { 'Discovery as grounded in organisational processes such as } \\
\text { research and development activity' (Teece, 2007, p. 1323). }\end{array}$ & $\begin{array}{l}\text { R\&D, Investment in R\&D, } \\
\text { change in R\&D direction and/or } \\
\text { focus, discussions of and } \\
\text { searches for new technologies, } \\
\text { products and processes. }\end{array}$ \\
\hline $\begin{array}{l}\text { Processes to Tap Developments in Exogenous Science and } \\
\text { Technology: } \\
\text { 'Organizational processes can be put in place... to garner } \\
\text { new technical information, tap developments in exogenous } \\
\text { science ' (Teece, 2007, p. 1323). }\end{array}$ & $\begin{array}{l}\text { Accessing developments by } \\
\text { universities and other research } \\
\text { institutions, research efforts by } \\
\text { others, scanning science and } \\
\text { technological developments. }\end{array}$ \\
\hline $\begin{array}{l}\text { Processes to Tap Supplier and Complementor Innovation: } \\
\text { 'One must accumulate and then filter information from } \\
\text { professional and social contacts' (Teece, 2007, p. 1323). }\end{array}$ & $\begin{array}{l}\text { New products and processes } \\
\text { from suppliers, supplier } \\
\text { responses to GFC effects, } \\
\text { information from professional } \\
\text { and social contacts, formal and } \\
\text { informal relationships with } \\
\text { suppliers. }\end{array}$ \\
\hline $\begin{array}{l}\text { Processes to Identify Target Market Segments, Changing } \\
\text { Customer Needs, and Customer Innovation: } \\
\text { 'This task involves scanning and monitoring internal and } \\
\text { external technological developments and assessing } \\
\text { customer needs, expressed and latent' (Teece, 2007, p. } \\
\text { 1324). }\end{array}$ & $\begin{array}{l}\text { New markets, Target } \\
\text { customers, Customer needs, } \\
\text { Changes to customer's product } \\
\text { and processes, probing } \\
\text { customer needs (overt and } \\
\text { latent), customer actions, } \\
\text { customer sentiment and } \\
\text { attitudes. }\end{array}$ \\
\hline
\end{tabular}

\section{Seizing Capabilities}

Following the identification of a new opportunity (or threat), Seizing capabilities regard the firm setting up new products, processes or services in order to capture its value (Teece, 2007). These capabilities are expressed across the areas of:

- Delineating the customer solution and business model,

- Selecting enterprise boundaries to manage complements and 'control' platforms,

- Selecting decision making protocols,

- Building loyalty and commitment. 
Teece (2007) suggests that the ability for a firm to create, refine and if necessary discard business models is key to dynamic capabilities.

Table 13: Teece's $(2007,2011)$ Dynamic Capabilities Framework Operationalisation: Seizing Capabilities: Delineating the Customer Solution and Business Model.

\begin{tabular}{|c|c|}
\hline Capability & $\begin{array}{l}\text { Terms, } \\
\text { References }\end{array}$ \\
\hline $\begin{array}{l}\text { Selecting the Technology and Product Architecture: } \\
\text { 'Reflect[s] management's hypothesis about what customers } \\
\text { want and how an enterprise can best meet those needs, and get } \\
\text { paid for doing so.' (Teece, 2007, p. 1329). }\end{array}$ & $\begin{array}{l}\text { New products, platforms, } \\
\text { technologies, product ranges, } \\
\text { product line extensions. }\end{array}$ \\
\hline $\begin{array}{l}\text { Designing Revenue Architectures: } \\
\text { 'The essence of the investment decision for the (strategic) } \\
\text { manager is that it involves estimating interdependent future } \\
\text { revenue streams and cost trajectories, and understanding a } \\
\text { panoply of continuous and interrelated cospecialised } \\
\text { investment issues' (Teece, 2007, p. 1329). }\end{array}$ & $\begin{array}{l}\text { Pricing structure, design of } \\
\text { revenue and cost structures, } \\
\text { revenue streams, and profit } \\
\text { potential. How is revenue } \\
\text { derived, what is the model by } \\
\text { which the firm proposes to invest } \\
\text { and derive revenue? }\end{array}$ \\
\hline $\begin{array}{l}\text { Selecting Target Customers: } \\
\text { 'Designing good business models is in part 'art.' However, the } \\
\text { chances of success are greater if enterprises... have a deep } \\
\text { understanding of user needs, [and]... understand just how to } \\
\text { deliver what the customer wants (Teece, 2007, p. 1330). }\end{array}$ & $\begin{array}{l}\text { Target customers and segments, } \\
\text { systems to identify target } \\
\text { opportunities and high value } \\
\text { markets, understanding user } \\
\text { needs, market research. }\end{array}$ \\
\hline $\begin{array}{l}\text { Designing Mechanisms to Capture Value: } \\
\text { 'However, the chances of success are greater if enterprises... } \\
\text { analyze the value chain thoroughly so as to understand just how } \\
\text { to deliver what the customer wants in a cost-effective and timely } \\
\text { fashion' (Teece, 2007, p. 1330). }\end{array}$ & $\begin{array}{l}\text { Efficiency, integration, value } \\
\text { chain decisions, supply chain } \\
\text { decisions, transaction cost } \\
\text { economics. }\end{array}$ \\
\hline
\end{tabular}

Table 14: Teece's $(2007,2011)$ Dynamic Capabilities Framework Operationalisation: Seizing Capabilities: Selecting Enterprise Boundaries to Manage Complements and 'Control' Platforms

\begin{tabular}{|c|c|}
\hline Capability & $\begin{array}{l}\text { Terms, Themes and } \\
\text { References }\end{array}$ \\
\hline $\begin{array}{l}\text { Calibrating Asset Specificity } \\
\text { 'Enterprise boundary decisions need to reflect... a company's } \\
\text { integration up-stream, downstream, as well as } \\
\text { externally...particularly when such capabilities [to integrate] are } \\
\text { not widely distributed in the industry' (Teece, 2007, p. 1331). }\end{array}$ & $\begin{array}{l}\text { Vertical and horizontal } \\
\text { Integration, Productive } \\
\text { capabilities of value chain } \\
\text { assets, Business scope. }\end{array}$ \\
\hline
\end{tabular}


Table 12: Selecting Enterprise Boundaries to Manage Complements and 'Control'

\section{Platforms Continued}

\section{Controlling Bottleneck Assets}

'The critical strategic element associated with capturing value from innovation is the ability of the innovating enterprise to identify and control the 'bottleneck assets' or 'choke points' in the value chain from invention through to market' (Teece, 2007, p. 1332).

\section{Assessing Appropriability}

'The amount of natural and legal protection afforded the innovation by the circumstances prevailing in the market' (Teece, 2007, p. 1331).

Bottlenecks, constraints.

Recognising, Managing and Capturing Cospecialisation Economies

Products are often systems. These systems consist of interdependent components resting on 'platforms.' There is strong functional interdependence amongst components of the system (Teece, 2007, p. 1332).

Value from vertical assets, acquisitions and divestments of vertical assets, asset combinations.

Table 15: Teece's $(2007,2011)$ Dynamic Capabilities Framework Operationalisation: Seizing Capabilities: Selecting Decision Making Protocols

\begin{tabular}{|l|c|}
\hline Capability & $\begin{array}{l}\text { Terms, Themes and } \\
\text { References }\end{array}$ \\
\hline $\begin{array}{l}\text { Recognising Inflexion Points and Complementarities } \\
\text { 'It implicitly recognizes inflexion points in technological and } \\
\text { market evolution. These inflexion points impact investment } \\
\text { requirements and strategic choices' (Teece, 2007, p. 1326). }\end{array}$ & $\begin{array}{c}\text { Product standards, } \\
\text { complementary products, } \\
\text { dominant designs, market } \\
\text { changes. }\end{array}$ \\
\hline $\begin{array}{l}\text { Avoiding Decision Errors and Anticannibalisation Proclivities } \\
\text { 'Overcoming biases almost always requires a cognitively } \\
\text { sophisticated and disciplined approach to decision making. } \\
\text { Being alert to the incentives of the decision-makers and to } \\
\text { possible information asymmetries is a case in point. Testing for } \\
\text { errors in logic is also essential' (Teece, 2007, p. 1333). }\end{array}$ & $\begin{array}{c}\text { Decision making frameworks, } \\
\text { decision criteria and logic, } \\
\text { information used to make } \\
\text { decisions. }\end{array}$ \\
\hline \multicolumn{2}{|c|}{} \\
\hline
\end{tabular}


Table 16: Teece's $(2007,2011)$ Dynamic Capabilities Framework Operationalisation: Seizing Capabilities: Building Loyalty and Commitment

\begin{tabular}{|c|c|}
\hline Capability & $\begin{array}{l}\text { Terms, Themes and } \\
\text { References }\end{array}$ \\
\hline \multicolumn{2}{|l|}{ Demonstrating Leadership } \\
\hline $\begin{array}{l}\text { 'There is an obvious role for leadership in making quality } \\
\text { decisions, communicating goals, values, and expectations, while } \\
\text { also motivating employees and other constituencies. } \\
\text { Organizational identification (and commitment, which is the } \\
\text { corollary) can dramatically augment enterprise performance' } \\
\text { (Teece, 2007, p. 1334). }\end{array}$ & $\begin{array}{l}\text { Leadership, manage, } \\
\text { managing, leading by example, } \\
\text { control, commitment, goals. }\end{array}$ \\
\hline \multicolumn{2}{|l|}{ Effectively Communicating } \\
\hline $\begin{array}{l}\text { 'Top management through its action and its communication has } \\
\text { a critical role to play in garnering loyalty and commitment and } \\
\text { achieving adherence to innovation and efficiency as important } \\
\text { goals' (Teece, 2007, p. 1334). }\end{array}$ & $\begin{array}{c}\text { Communication, channels of } \\
\text { communication. }\end{array}$ \\
\hline \multicolumn{2}{|l|}{ Recognising Non-Economic Factors, Values and Culture } \\
\hline $\begin{array}{l}\text { 'The ability of some enterprises to..., attract and retain more } \\
\text { committed talent, design reward systems, develop corporate } \\
\text { cultures, and blunt the formation of coalitions that extract quasi- } \\
\text { rents through threatening to withhold participation, is an } \\
\text { important managerial capacity' (Teece, 2007, p. 1340). }\end{array}$ & $\begin{array}{l}\text { Values, Organisational Culture } \\
\text { and Climate, Human Resource } \\
\text { Practice and Policy. }\end{array}$ \\
\hline
\end{tabular}

\section{Transformation Capabilities}

These capabilities regard the ability of the firm to recombine and reconfigure assets and structures to avoid unfavourable path dependencies (Teece, 2007). Radical change in technology or markets often requires revolutionary change in the structure of the firm. Transformation capabilities are expressed under the general headings of:

- Decentralisation,

- Cospecialisation,

- Governance,

- Knowledge management. 
These capabilities are operationalised as follows:

Table 17: Teece's $(2007,2011)$ Dynamic Capabilities Framework Operationalisation: Transformation Capabilities: Achieving Decentralisation and Near Decomposability

\begin{tabular}{|l|l|}
\hline Concept & $\begin{array}{l}\text { Terms, Themes and } \\
\text { References }\end{array}$ \\
\hline $\begin{array}{l}\text { Adopting Loosely Coupled Structures } \\
\text { 'With decentralized decision-making, different managers observe } \\
\text { different information and control different decisions... } \\
\begin{array}{l}\text { Decentralization must be pursued as enterprises expand, } \\
\text { otherwise flexibility and responsiveness will erode' (Teece, 2007, } \\
\text { p. 1336). }\end{array}\end{array}$ & $\begin{array}{c}\text { Business units, Businesses, } \\
\text { Offices in distributed locations. }\end{array}$ \\
\hline $\begin{array}{l}\text { Embracing Open Innovation } \\
\text { 'The open innovation model of Chesbrough (2003) also } \\
\text { recognizes the benefits of relying on a distributed model of } \\
\text { innovation where the enterprise reaches out beyond its own } \\
\text { boundaries to access and integrate technology developed by } \\
\text { others' (Teece, 2007, p. 1337). }\end{array}$ & $\begin{array}{c}\text { Open innovation, innovation } \\
\text { partners, changes in other } \\
\text { sectors and industries. }\end{array}$ \\
\hline $\begin{array}{l}\text { Developing Integration and Coordination Skills } \\
\text { 'integration capability'... was associated with positive enterprise } \\
\text { performance, again demonstrating the importance of knowledge } \\
\text { integration skills... organizational units must have considerable } \\
\text { autonomy... but remain connected to activities that must be } \\
\text { coordinated (Teece, 2007, p. 1337). }\end{array}$ & $\begin{array}{r}\text { Integration, value chain assets, } \\
\text { acquisitions. }\end{array}$ \\
\hline
\end{tabular}

Table 18: Teece's $(2007,2011)$ Dynamic Capabilities Framework Operationalisation: Transformation Capabilities: Cospecialisation

\begin{tabular}{|c|c|}
\hline Concept & $\begin{array}{l}\text { Terms, Themes and } \\
\text { References }\end{array}$ \\
\hline $\begin{array}{l}\text { Managing Strategic Fit So That Asset Combinations Are } \\
\text { Value Enhancing }\end{array}$ & \\
\hline $\begin{array}{l}\text { Cospecialisation can be of one asset to another, or of strategy to } \\
\text { structure, or of strategy to process. It is important to both seizing } \\
\text { and reconfiguration. In environments of rapid change, there is a } \\
\text { need for continuous or at least semi-continuous realignment } \\
\text { (Teece, } 1986,2007, \text { p. 1337). }\end{array}$ & $\begin{array}{l}\text { Strategic fit, asset configuration } \\
\text { and reconfiguration, } \\
\text { realignment. }\end{array}$ \\
\hline
\end{tabular}


Table 19: Teece's $(2007,2011)$ Dynamic Capabilities Framework Operationalisation: Transformation Capabilities: Governance

\begin{tabular}{|c|c|}
\hline Concept & Terms, Themes and References \\
\hline \multicolumn{2}{|l|}{ Achieving Incentive Alignment } \\
\hline $\begin{array}{l}\text { The microfoundations of incentive issues are embedded in an } \\
\text { understanding of agency and incentive design issues,... } \\
\text { separation of ownership from control creates interest alignment } \\
\text { problems, particularly around management compensation and } \\
\text { the allocation of corporate perquisites (Teece, 2007, p. 1339). }\end{array}$ & $\begin{array}{l}\text { Incentives, commissions, pay } \\
\text { and remuneration structures, } \\
\text { management checks and } \\
\text { balances. }\end{array}$ \\
\hline \multirow{2}{*}{$\begin{array}{l}\text { Minimising Agency Issues } \\
\text { The abuse of discretion and the use of corporate assets for } \\
\text { private purposes can occur absent appropriate } \\
\text { accountability/oversight (Teece, 2007, p. 1339). }\end{array}$} & \\
\hline & $\begin{array}{l}\text { Board of directors, } \\
\text { management, appointments, } \\
\text { minimising abuse of discretion, } \\
\text { interest alignment problems. }\end{array}$ \\
\hline \multirow{2}{*}{$\begin{array}{l}\text { Checking Strategic Malfeasance } \\
\text { 'Boards stacked with inexperienced 'independent' board } \\
\text { members may not have the requisite talents to properly diagnose } \\
\text { strategic 'malfeasance' and respond accordingly.' }\end{array}$} & Free-riding, manipulation, \\
\hline & $\begin{array}{l}\text { power broking, silos, deceptive } \\
\text { practice, failure to perform } \\
\text { (good sensing, seizing, } \\
\text { transformation). }\end{array}$ \\
\hline \multicolumn{2}{|l|}{ Blocking Rent Dissipation } \\
\hline $\begin{array}{l}\text { The ability of some enterprises to craft work specifications, attract } \\
\text { and retain more committed talent, design reward systems, } \\
\text { develop corporate cultures, and blunt the formation of coalitions } \\
\text { that extract quasi-rents through threatening to withhold } \\
\text { participation, is an important managerial capacity (Teece, 2007, } \\
\text { p. 1340). }\end{array}$ & $\begin{array}{l}\text { Protecting rents by managing } \\
\text { incentive structures and } \\
\text { coalitions. }\end{array}$ \\
\hline
\end{tabular}

Table 20: Teece's $(2007,2011)$ Dynamic Capabilities Framework Operationalisation: Transformation Capabilities: Knowledge Management

\begin{tabular}{|l|l|}
\hline Concept & $\begin{array}{l}\text { Terms, } \\
\text { References }\end{array}$ \\
\hline $\begin{array}{l}\text { Learning } \\
\text { 'Firms must dispel prejudices against technology from the } \\
\text { outside, and hone their absorptive capacity through learning } \\
\text { activities and skill accumulation. Enterprises may require alliance } \\
\text { arrangements to actively learn and upgrade relevant skills' } \\
\text { (Teece, 2007, p. 1332). }\end{array}$ & $\begin{array}{c}\text { Research \& Development } \\
\text { outcomes, New/upgraded skills, } \\
\text { new processes, experience. }\end{array}$ \\
\hline
\end{tabular}


Table 18: Knowledge Management Capabilities Continued

\begin{tabular}{|l|r|}
\hline $\begin{array}{l}\text { Knowledge Transfer } \\
\text { [E]nterprises develop governance procedures to monitor the } \\
\text { transfer of technology and intellectual property. Technology } \\
\text { transfer activities, which hitherto took place inside the } \\
\text { enterprise, increasingly take place across enterprise } \\
\text { boundaries. The development of governance mechanisms to } \\
\begin{array}{l}\text { assist the flow of technology... are foundational to dynamic } \\
\text { capabilities. }\end{array}\end{array}$ & $\begin{array}{c}\text { Implementing existing } \\
\text { knowledge in new areas, } \\
\text { Technology transfer, transfer } \\
\text { within and across firm } \\
\text { boundaries. }\end{array}$ \\
\hline $\begin{array}{l}\text { Knowhow Integration } \\
\text { 'The combination of know-how within the enterprise, and } \\
\text { between the enterprise and organizations external to it (e.g., } \\
\text { other enterprises, universities), is important' (Teece, 2007, p. } \\
\text { 1339). }\end{array}$ & $\begin{array}{l}\text { Applying knowledge across the } \\
\text { firm, skills applied to processes } \\
\text { and routines. }\end{array}$ \\
\hline $\begin{array}{l}\text { Achieving Knowhow and Intellectual Property Protection } \\
\text { 'Of equal importance are monitoring and managing the } \\
\text { 'leakage,' misappropriation, and misuse of know-how, trade } \\
\text { secrets, and other intellectual property' (Teece, 2007, p. 1339). }\end{array}$ & $\begin{array}{l}\text { Defence of patents, Intellectual } \\
\text { Property. }\end{array}$ \\
\hline
\end{tabular}

The operationalised framework was used to analyse the text identifying dynamic capabilities in order to categorise them as particular dynamic capabilities rather than as broadly defined dynamic capabilities. For example, the following quotes were indicative of capabilities that were reduced and categorised from antecedent data.

In the following quote, the manager describes how the firm has structured transferring knowledge from their R\&D processes to commercialisation in an example of knowledge transfer (transformation) capabilities. The manager discusses the theme of transferring technology across division of the firm to qualify it as an example of this capability.

'I can invent 10 things a day, but so what, what do you do with it? So what we are looking to do is we have an R\&D group which has the science part of it and an R\&D group that has the business part of it, and it's very very important to have that.' CEO HighRes4 
In the next example, the CEO of HighRes1 discusses how reconfiguring firm structures to access more cost effective labour and at the same time build geographic diversity into the value chain creating new assets and combines them with new and existing assets to create unique value to the firm through cospecialisation (a seizing capability) (Teece, 2007).

'We were really trying to take advantage of the currency situation by bringing forward large capex expenditure. But also we were trying to build some geographic diversity in our supply chain to improve disaster resistance and smooth out some issues we're having in recruitment, in particular low-wage workers.... we started planning to distribute some of these jobs to low-wage economies' CEO HighRes1 (Managing Cospecialisation Economies Capabilities).

In the final example, the manager invokes discussion of how the firm draws on their significant base of knowledge and experience that they keep codified and collated in a library to integrate this knowhow across the firm's various applications (Teece, 2007).

'Our drawing library, where all our intellectual property is, is very, very deep and strong so we can draw on a huge amount of knowledge we've built up and things we've captured properly over the last seven or eight years' CEO MidRes3 (Know-How Integration Capabilities).

The spreadsheets including the identified dynamic capabilities for each firm were treated in this manner to categorise the dynamic capabilities present in the firms. The spreadsheet for each firm was expanded to a second tab and the generic framework for Sensing, Seizing and Transformation (Teece, 2007) were populated with the text that evidenced those capabilities. An example of this approach to populating the spreadsheet is shown in Table 21. This enabled the complete overview of the expression of dynamic capabilities to be viewed for each firm. 
Table 21: Examples of Evidence for Dynamic Capabilities: Firm HighRes4

\begin{tabular}{|c|c|}
\hline Sensing Capabilities & \\
\hline $\begin{array}{l}\text { Processes to Direct } \\
\text { Internal R\&D }\end{array}$ & $\begin{array}{l}\text { Basically part of that strategic plan - one of the significant outcomes } \\
\text { is to have two R\&D groups if you like. One R\&D group is actually } \\
\text { technical people, the other R\&D group is business people. Because } \\
\text { the technical people, because we are busy inventing all sorts of } \\
\text { things, I can invent } 10 \text { things a day, but so what, what do you do with } \\
\text { it? So what we are looking to do is we have an R\&D group which has } \\
\text { the science part of it and an R\&D group that has the business part of } \\
\text { it, and it's very very important to have that and so it's probably quite } \\
\text { lacking in New Zealand. CEO } \\
\text { 'There are } 55 \text { scientists here; we want to double that. CEO }\end{array}$ \\
\hline $\begin{array}{l}\text { Processes to Tap } \\
\text { Exogenous Science \& } \\
\text { Technology }\end{array}$ & $\begin{array}{l}\text { '....and we also have another three scientists working out of } \\
\text { [University] doing R\&D in the [Country 3] market for us.' Financial } \\
\text { Controller }\end{array}$ \\
\hline $\begin{array}{l}\text { Processes to Tap } \\
\text { Supplier and } \\
\text { Complementor } \\
\text { Innovations }\end{array}$ & $\begin{array}{l}\text { 'We don't end up solely managing the development of their products } \\
\text { and different customers get involved in various degrees. We've got } \\
\text { one client who's based here for six months. They had four people } \\
\text { based here working through their program of a product that we're } \\
\text { launching in [Region] in April so they were very hands on involved.' } \\
\text { Financial Controller }\end{array}$ \\
\hline $\begin{array}{l}\text { Processes to Identify } \\
\text { Target Market } \\
\text { Segments, Changing } \\
\text { Customer Needs and } \\
\text { Customer Innovation }\end{array}$ & $\begin{array}{l}\text { These [Country 2] customers started going, 'Returns are down. We } \\
\text { can't afford that,' so they stopped ordering. And at the same time the } \\
\text { corporates had started unloading their inventories so bang: stopped } \\
\text { ordering. Then they order slower because the demand was lower. } \\
\text { Financial Controller } \\
\text { 'Then the other side is, well ok, at the moment we are using 3rd party } \\
\text { experience to guide the blue sky developing which is the IP } \\
\text { development and the idea there is to say - look, rather than wait for } \\
\text { somebody to come to us, let's look at all the different clients and see } \\
\text { what gaps they have in their product portfolio. Because each client } \\
\text { has got a different emphasis, which is really interesting.' Financial } \\
\text { Controller } \\
\text { Once we do that we'll be looking at segregating the markets, saying } \\
\text { where's the opportunity? Which clients have need in their portfolio, } \\
\text { which markets have growth opportunity in what products [HighRes4] } \\
\text { specialises in. Financial Controller }\end{array}$ \\
\hline
\end{tabular}

Augmenting the display of data and its quantification was the preparation of research site-specific pre-structured cases (Miles \& Huberman, 1994). The dynamic capabilities framework (Augier \& Teece, 2009; Teece, 2007) provided the major 
section headings for the cases. Each case site serves as a distinct experiment that emphasises the rich, real world context being studied (Eisenhardt, 1989a). The preparation of the case studies began once the all the data from an entire research site was available (Patton, 2001). This was followed by the construction of a case record, where the raw data was organised, classified, and edited. Finally, an ordered, descriptive full case study was prepared.

The case studies enabled the abstraction of the raw findings regarding expressed dynamic capabilities by identifying the motivations for actions, the expected and intended outcomes and underlying reasoning of managers for their strategies. Understanding strategy at the level of the individual cases provided the platform for further analysis across research sites (Graebner \& Eisenhardt, 2007).

\subsubsection{Phase Four - Inter-Case Analysis}

Eisenhardt (1989a) describes drawing conclusions from case studies as a highly iterative process of comparing the emergent frames of patterns, themes, concepts and relationships with evidence from each case. She notes that the iterations between theory and data are imperative in order to take full advantage of new insights available from the data. To achieve this, the thesis followed Miles and Huberman's (1994) four steps of:

1. Establishing discrete findings.

2. Relating findings to each other.

3. Naming patterns.

4. Identifying a corresponding construct.

Following intra-case analysis, a search for patterns and themes across cases was carried out (Yin, 2010). The approach to analysing across cases was that of Denzin's (1989) interpretive synthesis. That is, the organised data was amalgamated into a meta-matrix (Yin, 2010) that comprised the totality of the case data. 
Compiling the evidence for capabilities into a spreadsheet not only displayed data (Yin, 2010) but also enabled its quantification. By using the number of references to a particular dynamic capability as a proxy for emphasis, the areas that firms were focused on during the GFC were highlighted. These raw counts were then converted into a percentage of the total discussion of an individual dynamic capability. That is, a firm's total references to a particular dynamic capability were calculated as a percentage of all firm's references. This provided a means of identifying where firms were placing effort to create, build and reconfigure resources that others were not (Helfat et al., 2007).

Table 22: Quantification of References to Dynamic Capabilities From Interviews

\begin{tabular}{|c|c|c|c|}
\hline \multicolumn{2}{|c|}{$\begin{array}{c}\text { HighRes1 - Quantified References to Dynamic } \\
\text { Capabilities }\end{array}$} & HighRes1 & $\begin{array}{c}\text { Total } \\
\text { (of all Firms) }\end{array}$ \\
\hline $\begin{array}{c}\text { Processes to Direct } \\
\text { Internal R\&D }\end{array}$ & Count of references & 7 & 62 \\
\cline { 2 - 4 } & Percentage of references & 11.3 & 100 \\
\hline
\end{tabular}

Using the set of objective measures gathered (see section 0 ), the firms were arranged in order of their performance. The result was a ranking of firms from most, to least resilient. This enabled the cross-case analysis to highlight the effective resilience actions (Rose, 2004) through the comparison of higher and lower performing firms (Rouse \& Daellenbach, 1999). The complete list of firms is available in Table 24, Page 88.

Inter-case analysis was approached by initially utilising the quantified results as a means to identify areas where references to capabilities were relatively high. Conditional formatting in the analysis spreadsheets provided a means of highlighting the relatively high, through to relatively low scores of firms across the dynamic capabilities framework. The colours of cells were used as visual aids to begin the identification of key result areas, high scoring cells were coloured green, low scoring cells were coloured red, and scores in between dynamically assigned a relative colour 
on the spectrum between these extremes. Described as 'hot spots' of capabilities, where a hot spot was defined as areas of particularly high relative scores of the volumes of discussion of particular capabilities across a number of firms (Figure 11). These became priority areas for further investigation. By applying conditional formatting to the scores, these hot spots were highlighted by their relative difference in values across firms. Hot spots were identifiable as an area where:

1. Resilient firm's results contained high proportions of the total references to a particular dynamic capability and/or sets of dynamic capabilities.

2. Less resilient firm's results contained low proportions of the total references to a particular dynamic capability and/or sets of dynamic capabilities.

3. A lack of references to a particular dynamic capability or set of capabilities in resilient firms but high proportions in less resilient firms.

4. References to capabilities that were evenly distributed across firms.

Logically these results suggest that in the case of (1) and (2) above, that the dynamic capabilities represented in a hot spot contribute to the resilience of firms, while in the instance of (3) and (4) suggest that these capabilities may detract from, or not contribute to, the resilience of firms. 
Figure 11: Hotspots in Discussion of Dynamic Capabilities

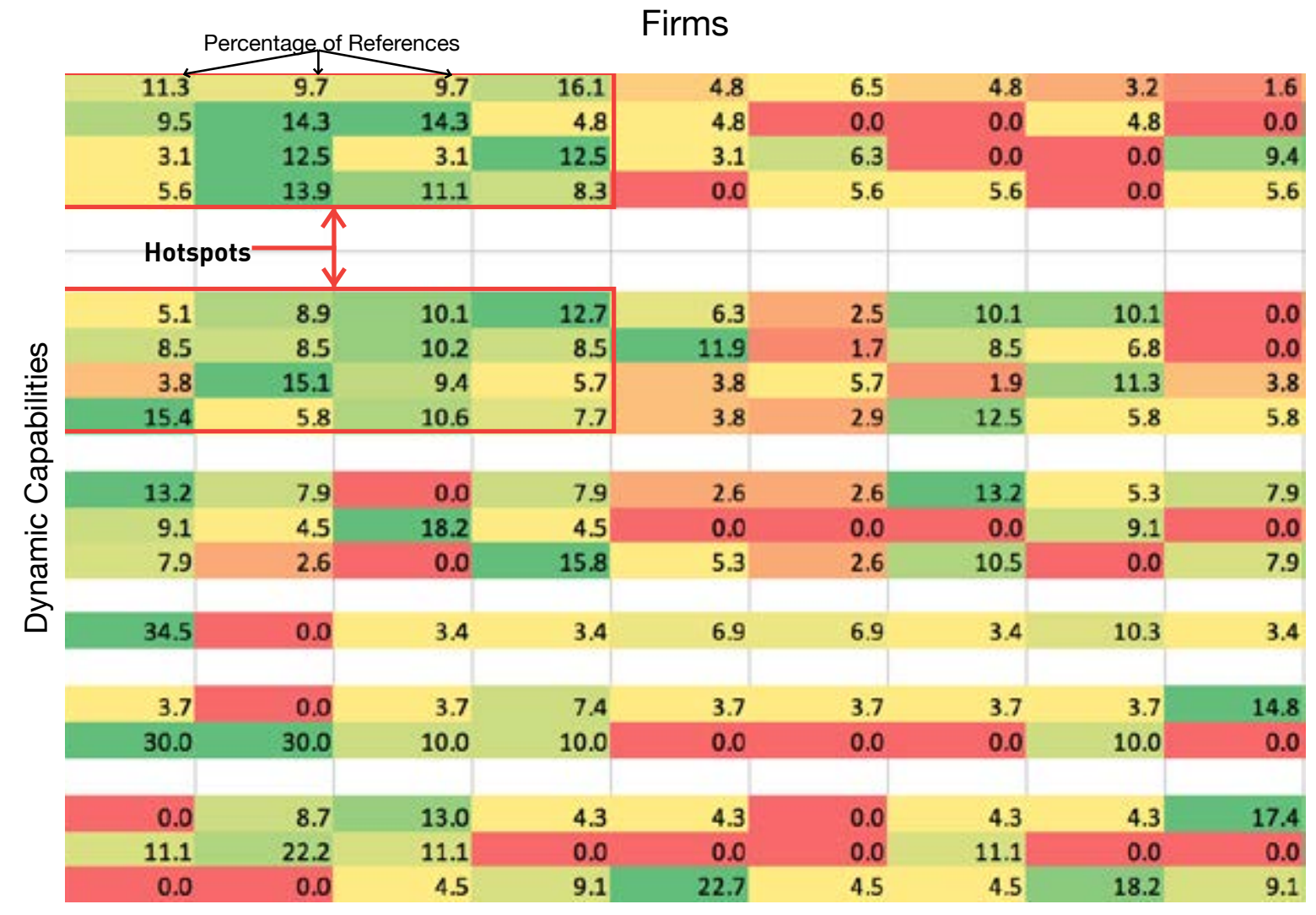

\begin{tabular}{|l|l|l|l|l|}
\hline \multirow{2}{*}{ Key } & Low Score & & & High Score \\
\hline
\end{tabular}

The ranked and quantified results were then used to contrast various subsets of firms to identify the highest variance between the dynamic capabilities expressed in resilient compared with less resilient firms, and vice versa.

Table 23: Variance of Firm Clusters - High Versus Low Resilience

\begin{tabular}{cccc}
\hline $\begin{array}{c}\text { Number of Firms } \\
\text { (Top vs Bottom) }\end{array}$ & $\begin{array}{c}\text { \% of Dynamic } \\
\text { Capabilities in } \\
\text { top firms }\end{array}$ & $\begin{array}{c}\text { \% of Dynamic } \\
\text { Capabilities in } \\
\text { bottom firms }\end{array}$ & Difference \\
\hline Top 3 Firms & 35.8 & 13.6 & 22.2 \\
Top 4 Firms & 38.9 & $\mathbf{1 4 . 0}$ & $\mathbf{2 4 . 7}$ \\
Top 5 Firms & 38.4 & 14.5 & 23.8 \\
\hline
\end{tabular}


The grouping of firms that show the highest discrepancy (accepting a likely margin of error due to the sample size) in the proportion of dynamic capabilities expressed was the top and bottom four firms (Table 23). For this reason, these were the firms used as the basis for comparison across levels of resilience. This enabled the crossreferencing of the types of capabilities expressed by resilient, and less resilient firms. For example, the hot spots of high concentrations of discussion of particular dynamic capabilities in resilient firms, contrasted with correspondingly cold spots in the same capabilities in less resilient firms would suggest the presence of resilience creating capabilities.

The inter-case analysis was conducted in this manner, with the differences between high resilience firms and low resilience firms providing the basis for comparison. The cases that constituted the remainder of the data set (nine out of the seventeen) were used to moderate the findings of the comparison between high and low resilience firms (Rouse \& Daellenbach, 1999). These were used to identify when capabilities that show considerable differences between the top and bottom firm are also present in the middle group they could be discounted as having particular influence. That is, they were used to identify when threshold levels of capabilities are found in these firms, they may not contribute to resilience, but may simply offset the chance of nonresilience.

\subsection{Chapter Summary: Data Analysis}

This chapter has outlined how the research project was carried out. By selecting New Zealand's lowest performing industry sector, a sample of firms that were undeniably affected by the GFC was accessible. By approaching the research from a postpostivist ontology, a small sample of firms with a range of performance provided a rich set of interview data that outlined the strategies of these firms in the context of the GFC. By applying the dynamic capabilities framework (Teece, 2007) an encompassing view of the firms were transposed into a case format. 
By structuring the data into case studies and analysing initially within those cases and then across them, the differences, patterns and themes nascent in the data were highlighted. The Findings chapter that follows offers the results of this analysis. 


\section{Findings}

\subsection{Chapter Introduction}

In this chapter, the testimony of managers is contextualised using the dynamic capabilities framework offered by Teece (2007) described in the previous chapter. This chapter has been organised to demonstrate the systematic application of the dynamic capabilities framework used here to view the data gathered in interviews. The chapter presents four case studies in an extended form for three resilient firms and the least resilient firm in the sample. Following these is a condensed case outlining the findings from the remaining thirteen case studies.

\subsection{Case Study Logic}

The justification for presenting these four particular cases in full was due to their diverse levels of performance, and so they offer a number of interesting variations on resilience. HighRes1 performed very well in spite of environmental disturbances. LowRes1 however suffered the most of all firms studied. HighRes3's position before the GFC was close to failure and the turnaround effort and subsequent return to profitability occurred in spite of the backdrop of economic hardship. HighRes4, as counterpoint to HighRes3's direct turnaround was highly performing until the GFC significantly impacted the firm, causing it to nearly fail before recovering (See Figure 12). 
Figure 12: Select Case Study Firms Performance Over Time (indicative)

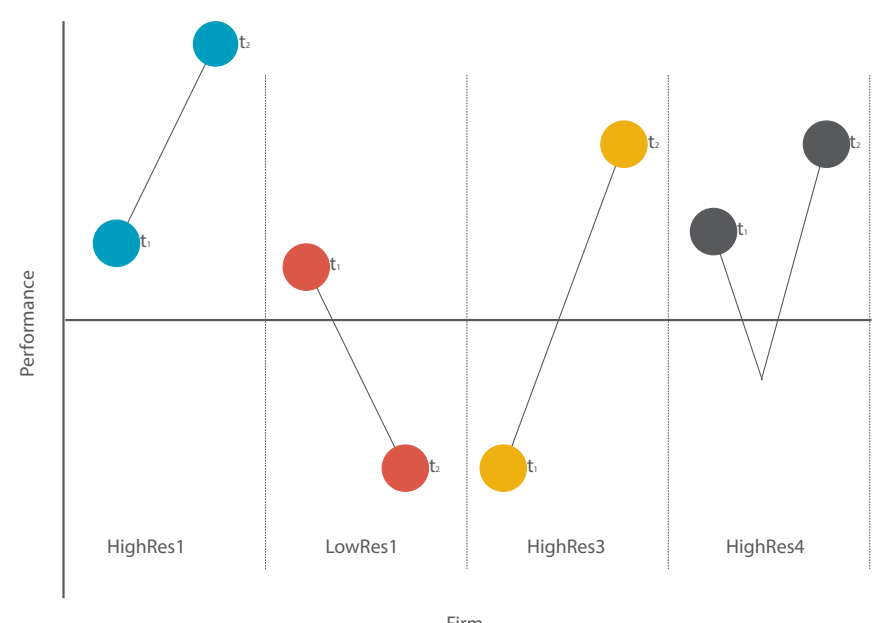

Table 24: Relative Firm Resilience Rankings on Objective Measures

\begin{tabular}{ccccccc} 
Rank & Firm \# & Growth & Stability & Assets & Goals & Total Score \\
\hline $\mathbf{1}$ & HighRes 1 & 1 & 1 & 1 & 1 & 4 \\
\hline $\mathbf{2}$ & HighRes2 & 1 & 1 & 1 & 1 & 4 \\
\hline $\mathbf{3}$ & HighRes3 & 1 & 0 & 1 & 1 & 3 \\
\hline $\mathbf{4}$ & HighRes4 & 1 & 1 & 0 & 1 & 3 \\
\hline $\mathbf{5}$ & MidRes1 & 1 & 1 & 0 & 1 & 3 \\
\hline $\mathbf{6}$ & MidRes2 & 1 & 0 & 1 & 1 & 3 \\
\hline $\mathbf{7}$ & MidRes3 & 1 & 0 & 1 & 0 & 2 \\
\hline $\mathbf{8}$ & MidRes4 & 0 & 1 & 0 & 0 & 1 \\
\hline $\mathbf{9}$ & MidRes5 & 0 & 1 & 0 & 0 & 1 \\
\hline $\mathbf{1 0}$ & MidRes6 & 0 & 1 & 1 & 0 & 2 \\
\hline $\mathbf{1 1}$ & MidRes7 & 0 & 0 & 1 & 0 & 1 \\
\hline $\mathbf{1 2}$ & MidRes8 & 0 & 1 & 0 & 0 & 1 \\
\hline $\mathbf{1 3}$ & MidRes9 & 0 & 0 & -1 & 0 & -1 \\
\hline $\mathbf{1 4}$ & LowRes4 & 0 & -1 & 0 & 0 & -1 \\
\hline $\mathbf{1 5}$ & LowRes3 & 0 & -1 & 0 & -1 & -3 \\
\hline $\mathbf{1 6}$ & LowRes2 & -1 & -1 & 0 & -1 & -1 \\
\hline $\mathbf{1 7}$ & LowRes1 & -1 & -1 & -1 & 0 & 2 \\
\hline
\end{tabular}


It is notable that a number of firms attained the same overall scores in the above table. In order to differentiate the performance of firms in order to provide a ranking, further information was considered to assign their final place in the table. For example, both HighRes3 and HighRes4 (among others) scored a total of 3. HighRes3 was elevated in the raking because of the strong recovery in performance compared to HighRes4's significant regression in performance prior to arresting the decline (See Figure 12)

Evidence for dynamic capabilities was identified in all 17 cases. However, both clear and subtle differences in the type and application of dynamic capabilities emerged across organisations. The analysis of these differences provided useful insight into the types of capabilities that create resilience in firms.

\subsection{Case Study: HighRes1}

Interviews: 2 (CEO, CFO)

HighRes 1 was the strongest performing firm in the study. A healthcare company, the firm grew at similar levels during the GFC as it did in preceding years. The firm was proactive during the GFC in making changes and investments that were materially beneficial to the continued performance of the firm.

\subsubsection{Sensing Capabilities}

\section{Processes To Direct Internal R\&D And Select New Technologies}

'We also grow our R\&D in terms of both capacity and as a percentage of revenue. Which is now approximately $18 \%$ of all of revenue' CEO

'I think that the R\&D from a product point of view we are starting to see good success because in the areas where new applications have been products - we're targeting new applications' CFO 


\section{Processes To Direct Internal R\&D And Select New Technologies Continued}

'Our rate of innovation has been steady but our R\&D capacity doubles every two years in the number of personnel doubles every few years. We currently run about 300 projects in parallel at any one time so our innovation rate is always increasing but it is relative to the size of the company.' CEO

'When we innovate we are looking for diversification across the medical field.' CEO

The focus of HighRes1's R\&D activities is the development and commercialisation of medical technology. The managers discuss increasing investment in R\&D in order to drive this. The total expenditure on R\&D was grown annually to keep the proportion of revenue invested constant at $18 \%$. The firm has invested in new facilities for R\&D including a new building during the GFC to facilitate discovery. While HighRes1 seeks to develop new technologies, it also seeks to find new applications for its existing technology platforms. These platforms are extended into new areas by banking on existing competencies using two of the following criteria: Same patient, same technology or same channel.

Processes to Tap Supplier and Complementor Innovation AND Processes to Tap Developments in Exogenous Science and Technology

'One of our key research partners is a hospital in [Country 3 City] because they work in [Medical Condition] is so closely aligned with us' CEO

'A while ago we acquired a company which made [Complementary Product].' CEO

HighRes1's managers discuss their information search as extending beyond the boundaries of the firm. In this instance the search for exogenous science and technology and their processes to tap the innovations of suppliers and complementors are expressed as the same relationship with a research hospital. This includes the CEO of HighRes1 who mentions that their research partnership with the hospital is due to its geographic location, and its expertise in the condition the firm treats through its products. When necessary the firm has found external sources of knowledge to augment its R\&D processes by making a small number of acquisitions in related businesses with innovations. 
Processes to Identify Target Market Segments, Changing Customer Needs, and Customer Innovation.

'One of the big things we noticed in our market was the way that consumers were deferring the diagnosis due to financial constraints.' CEO

'As you can imagine hospitals are forming multidisciplinary teams to look for cost savings' CFO

The managers interviewed at HighRes1 were aware that financial constraints for both end users and treatment partners such as hospitals drove changes to the needs of these customers during the GFC. They appear clearly to understand how customers reacted and changed as a response to their changing conditions.

\title{
4.3.2 Seizing Capabilities
}

\section{Delineating the Customer Solution \& Business Model}

\author{
Selecting the Technology \& Product Architecture \\ 'Well one thing l'll say on products.... You've got two avenues open, probably more than two; one \\ you want to make the product even better so it gives a better clinical result for the so they feel good, \\ get better quicker, more comfortable etc. Then you got the ergonomic design that you want to have: \\ it's easier to use, therefore less nursing time. It's delivering a better clinical outcome so that the \\ patient gets out of the hospital quicker.' CFO
}

'We do have superior technology. It's those kind of aspects of our business. One: superior product. Two: the type of product that we've got - it's fairly stable in both its volume and its price.' CFO

'It was very much more push another product out there, we will generate some revenue from it as opposed to worrying about the ancillary stuff.' CFO

'We have two main products the first one is hospital-based the other is home-based. One of the key attributes of the business is that a high proportion of our revenue is recurring, single use product, so not in the space of capital equipment such as [Competitor] and those companies which make [Product] and those type of things. They cost a lot of money and are a big commitment for a hospital and therefore they think very hard about those kind of decisions. As opposed to; we are more at the treatment end of a decision. If people are sick and require hospitalisation and they require some sort of support in the home the economics normally don't have much impact on that. In good times and bad times, the same person is likely to still be sick in most places in the world... have not stopped treating people.' CFO

Capabilities to select the product technology and architecture relate to deciding which technologies and features are embodied in the product (Teece, 2011). 
HighRes1's approach appears to be to leverage an evolving technology platform from which iterative products are derived. Product development is focused on improving the value delivered to consumers through improvements in this design. These changes are focused on improving both the product's ergonomics for the benefit of the user, but also the clinical results of use and the efficiency of those products to healthcare providers. The CFO also suggests that during the GFC, the firm's focus was on bringing new products to market quickly and effectively and with a level of technology that differentiated them from competitors. HighRes1's managers would appear to consider their high technology, the most advanced in their market, a key defensive attribute to their products.

\section{Selecting Revenue Architectures \\ 'While we drove growth very hard we have $15 \%$ gross [Revenue Growth] as a target and through finding new clinical applications for existing products and growing our value per patient. We have achieved that.' CEO}

'I guess our business is quite good in that it's pretty much like the Gillette model, you know, you sell them the razor and then you generate revenue in terms of various razorblades. So low value capital item, and then lots of revenue hopefully.' CFO

'I think it is back to the concept that we are treating patients. Three quarters of our revenue is treating patients. The prospect of treating patients so that in itself is a - well not guaranteed - but a more guaranteed revenue stream.' CFO

'A lot of our continued growth over the previous few years has been a higher than average contribution of currency hedging.' CEO

HighRes1's revenue model is described by the CFO as the 'Gillette model', that is, to sell customers a low cost capital item the use of which requires the customer to purchase consumables on an on-going basis. The product portfolio and platform structure appear to enable the firm to derive revenue from the end user at multiple stages of the treatment process. Continuing development of product design features enable the hospital and customer to save money between iterations but also for HighRes1 to continue to hone margin and build a continuing relationship with a customer after leaving hospital and continue the revenue stream. Through treating an ailment with increasing rates of occurrence, and building a model to lock consumers 
in, the firm has built a revenue platform with apparently solid volumes, prices and margins.

The managers of HighRes1 outline how the financial climate of the GFC provided an emergent stream of revenue - that of foreign exchange hedging. By increasing the foreign exchange cover they chose to take, the firm effectively created a new stream of revenue (or bolstered an existing one) that worked with the GFC's effects on the economy.

\section{Selecting Target Customers}

'We have been more focused about new product developments being in areas where we think that higher margins are achievable and I guess being far more focused about achieving those higher prices as opposed to kind of almost paying lip service to a degree.' CFO

'When we innovate we are looking for diversification across the medical field. We look to have two out of three of the following criteria when targeting a new area and that is: the patient, the same channel, or the same technology. That way we are safely banking on existing competencies.' CEO

'I guess the other thing I would say is that we are more focused on the - how would I describe this - more focused on the sales opportunities around patients for referral to different parts of the hospital. So the patient is being treated in one part of the hospital and we want to be generating revenue from them for more time that they are in the hospital rather than just in our traditional one part of the hospital.' CFO

HighRes1 appears to expresses dynamic capabilities to select target customers by identifying areas of potential application of its technologies. By utilising their current technologies, the managers suggest they are aiming to extract more revenue from new markets with lower cost of entry. They are also looking to drive demand for their products by changing the clinical practices in the situations in which they are used, further driving sales, but also creating lasting, consistent revenue streams. As such, the firms approach to selecting target customers is based on their understanding of how technologies can be implemented into new areas by either deepening engagement with existing markets, or making considered extensions into new ones. 


\section{Designing Mechanisms to Capture Value}

'We have been far more willing to invest in operational efficiencies and distribution and logistics efficiencies as well... you get good top line growth and you are getting efficiency out of the business, the result then becomes... it's not one plus one it's two times two - that kind of result.' CFO

'...we've already talked about the remodelling, redesigning how we are doing distribution... how we are going to a more direct sales model because that was kind of fundamental that we understood that it's just better: one you get the margin, and two you get the focus.' CFO

'I guess the other thing is that we have become far more focused through the GFC in terms of not only operating leverage - that is trying to expand our gross margin so where we can we have been far more proactive in terms of trying to get price increases.' CFO

'Our [Country 2] production plant has led to a reduction of costs by $25 \%$. Also changes to our operating leverage have saved us 5 or $6 \%$.' CEO

Designing mechanisms to capture value were a focus for HighRes1 during the GFC, encompassing a number of initiatives to derive and retain more value from the chain of activity. The unifying theme of these efforts was the emphasis on improving margin on products sold. This was achieved in a number of ways. Most crucially, moving to a direct sales model, including the purchase of a distribution company for a particular region, was designed to improve the margin for the firm by internalising and controlling those activities and streamlining distribution. This also captured the margin that would otherwise be retained by a third party. Similarly, the construction of a new manufacturing facility improved margins in two major ways. First, by situating the facility in a low cost economy the production costs were greatly reduced - by up to twenty-five percent. Second, the facility is also situated in close proximity to the firm's largest geographic market. This reduced the shipping costs of distribution. Product that was shipped previously via airfreight could now be driven by truck.

The firm also bought forward large capital expenditure programmes to exploit the financial climate. Including plans to extend its New Zealand operation and to expand manufacturing capacity overseas, this leveraged two effects of the GFC. First, the general economic slowdown put the firm in a strong negotiating position with contractors for the New Zealand-based expenditure. Secondly, the high New Zealand 
dollar gave it relatively high purchasing power for the international project(s). In both cases the firm paid significantly less in construction costs than it would have prior to the GFC.

\title{
4.3.2.1 Selecting Enterprise Boundaries to Manage Complements and "Control" Platforms
}

\author{
Calibrating Asset Specificity \\ 'We have moved to more of a direct model with our own distribution companies in various countries \\ around the world and trying to sell as much as you can directly into the market. So we've got 15 or \\ 16 direct sales companies all around the world. ' CFO,
}

\section{Calibrating Asset Specificity Continued}

'One of the more recent changes or things that have happened in the industry is we have set up manufacturing offshore. You might have talked about the manufacturing plant in [City]...because we were able to move some of our cost base into a low-cost location to try and offset some of the impacts of the higher dollar's effect on demand.' CFO

'We bought forward a couple of capital expenditure programmes including investing in the equipped acquisition of the [Country 3] distribution company but the big investment was in [Country 2] production facility.' CFO

'Interviewer: so except for products, what areas did you focus your innovation effort in?

Interviewee: new facilities especially that in [Country 2] lean manufacturing, logistics and distribution.' CFO

HighRes1 actively tuned the specificity of its various assets during the GFC. This included developing facilities such as the [Country 2] production facility, and the acquisition and development of logistical and distribution assets. The new manufacturing facility in [Country 2] was designed to build manufacturing capacity but as a side-effect lead to the firm reconfiguring the balance of manufacturing from New Zealand to [Country 4], leading the New Zealand facility to reduce its proportion of the firm's productive output and instead focus on R\&D. These two facilities are now more specific in their activities. The development of logistics and distribution assets included the acquisition and development of distribution structures in selected markets that were designed to focus on the sale of HighRes1 products. 


\section{Controlling Bottleneck Assets}

'...you get a [HighRes1] employee saying 'all right' and goes out there and sells [HighRes1] products compared to a distributor whose got some [HighRes1] products, products from [Company], products [Company], [Company] products who might get around selling some of our stuff one day.' CFO

'So traditionally I guess we have been like a lot of New Zealand businesses you have a manufacturing base here and try and sell their stock of products in various markets through an agent or a distributor or other manufacturers wherever it might be. We have moved to more of a direct model with our own distribution companies in various countries around the world and trying to sell as much as you can directly into the market.' CEO

Again, HighRes1's moves to a direct sales model in as many markets as possible was designed to alleviate what the firms considered were structural constraints to growth. By purchasing a distribution company in a large region and setting up and maintaining direct distribution in up to sixteen other individual markets, the firm reduced its reliance on agents and distributors that caused a bottleneck in sales. In addition, the firm reconfigured its manufacturing structure when its manufacturing facility's production capacity and cost structure was clearly favourable over the firm's original configuration. The new facility was promoted to the primary production centre, while the New Zealand facility became the backup capacity.

\section{Assessing Asset Appropriability \\ 'We believe [Country 2] has a less entrepreneurial society and therefore is less likely to shall we say... start competing against you, compared to the more entrepreneurial folk in [Region].' CFO}

'Certainly our technology and our R\&D which are best in market. Also our competitors are global and New Zealand is a low-cost place compared to other developed countries to do R\&D. That's why we have this huge campus here, R\&D personnel in New Zealand cost about $\$ 120,000$ per year that's compared to $\$ 2$ or $\$ 300,000$ in [Country 5] or the [Country 6].' CEO

'There are a few kind of smaller guys out there but we are number one and that is because we do have superior technology. It's those kind of aspects of our business. One; superior product two; the type of product that we've got - it's fairly stable in both its volume and its price.' CFO

HighRes1 appears to be active in assessing the appropriability of its assets. The managers interviewed clearly consider the firm's technology as a key competitive factor for the firm. In both their hospital and consumer treatment markets, they 
benchmark their technology as superior to competitors. The CFO also describes how when selecting locations for their manufacturing facility, the risk of imitation of products was a consideration. Likewise, the location of the management and R\&D centre in New Zealand was considered competitive. The managers describe the costs as being very competitive when considering the relative value and talent accessible in New Zealand, compared with the human resource costs of their competitors' locations.

\section{Reorganising Managing \& Capturing Cospecialisation Economies}

'We had a number of projects that we would have liked to have done but because the currency preGFC was relatively high. We thought, "Well, we can't afford the impact", at that point but now we have that opportunity we are going to do project a, b, c, d etc.... In the long term it has actually been paying dividends and we are probably growing in those markets.' CFO

'We also felt that coupling that with respective IP, we also found that given [Country 5] is still our largest single market it makes sense to be closer. You can drive a truck from [Country 2 City] to [Country 5 City] in about 15 minutes whereas if you are doing it in [Country 3] or [Country 6] we still have a very large Pacific Ocean that has to be travelled to get access to that market.' CFO

'So what we were going to do in [Country 2] is we are going to be extra capacity... What the GFC did, or the consequence of the GFC was, made us say; we're going to have to really think about that and effectively move [Country 2] to being closer to $24 / 7 \ldots$ and the spare capacity can be here, because we want that dollar saving more immediately.' CFO

'We were really trying to take advantage of the currency situation by bringing forward large capex expenditure. But also we were trying to build some geographic diversity the in our supply chain to improve disaster resistance and smooth out some issues we're having in recruitment... it was very difficult to get low-wage workers to work in factories here so we started planning to distribute some of these jobs to low-wage economies.' CEO

HighRes 1 is active in managing cospecialisation economies. Its drive for efficiencies during the GFC contributed a multiplier effect to the firm's position by adding to both the top and bottom line. The firm appears to have used the investment in capital to create assets that when combined with their stock of other intangible assets creates unique value. For example, investing in new facilities creates space for the growing $R \& D$ capacity of the firm. The new manufacturing facility in [Country 2] has also contributed to the management and capturing of cospecialisation economies by simultaneously reducing the costs of manufacturing, improving the margin on the 
firm's technologies and reducing distribution costs by being closer to the firm's largest market.

\section{Selecting Decision-Making Protocols}

\section{Recognising Inflexion Points}

'Also in [Country 5] the levels of capacity to diagnose [Medical Condition] is reasonably small and it was stalled during the crisis. There was also a lack of investment in new or refurbished hospitals as governments rationalised their spending. That has certainly slow sales of hardware.' CEO

'One of the big things we noticed in our market was the way that consumers were deferring the diagnosis due to financial constraints. So if you are unsure of your work situation and somebody tells you that you need to go to a laboratory to be tested for [Medical Condition] but that it is not urgent you might put that on the backburner for a while.' CEO

Inflexion points, the points in time at which a market or technology changes are the focus of these capabilities - that is, the ability to predict these changes and how they may interact. HighRes1 identified the change in its market that resulted from the GFC by noticing when hospitals it supplied began to suffer from a lack of investment by governments. Similarly, consumers of the product were deferring diagnosis of their condition. The firm took notice when the New Zealand currency sharply appreciated against others and identified this as an opportunity to bring forward a number of capital expenditure programmes to take advantage of the favourable financial situation.

\section{Avoiding Decision Errors \& Anticannibalisation Proclivities}

'We look to have two out of three of the following criteria when targeting a new area and that is: the same patient, the same channel, or the same technology. That way we are safely banking on existing competencies.' CEO

'The first was to get a tool I guess that enabled people to see what was happening in the business really and one of the things that we have now developed around the financial area for use in the business is a lot more constant currency reporting. Because when you have currency volatility it's very difficult to compare one year's results to the next.' CFO

Managers in HighRes1 utilise at least two frameworks to aid decision-making. The first is used when making product development and extension decisions. When 
expanding into a new area the firm looks to apply two of three things: the same channel, technology or customer. This ensures they are banking on existing competencies. The second framework is the use of constant currency reporting which enables the firm to look through currency volatility to compare performance across time periods with significant variability. These criteria appear to provide a framework for structured thinking regarding decisions that must be made under circumstances of significant ambiguity.

\subsubsection{Building Loyalty and Commitment}

\section{Effectively Communicating}

'making sure that best practice if you like is germinated throughout the organisation... over the last two or three years, more cases of where in a particular market we have been very successful in getting a new product well-established in a new hospital or in a state or whatever it is in, well, why is that? How can we transplant that to [Country 3] and get the same level of penetration?' CFO,

While there is little evidence for these capabilities in HighRes1, the CFO discusses the codification and global dissemination of an internal best practice. The firm used the highest performing sales people as a model to develop standard practice and then communicated it worldwide.

\subsubsection{Transformation}

\subsubsection{Decentralisation}

\section{Adopting Loosely Coupled Structures}

'I guess what we have done in terms of setting up the sales business that you need to be close to the markets, to drive sales, to be focused, to be close to your customers, to be there day-to-day, because it is difficult to be day-to-day if your salespeople are here. There is probably some logistics things you might change in terms of we where you have warehouses that kind of stuff, we're looking at those kinds of things' CFO

'As we continue to grow it's probably very unlikely that we are going to add manufacturing capability in New Zealand. It may be that we continue to add to [Country 4] CFO, 
HighRes1 was active during the period of the GFC in creating quasi-independent profit centres in geographic locations that were then able to focus on particular operational capability development. For instance, setting up a manufacturing facility in [Country 2] in order to leverage the significant cost and geographic benefits of the location also linked in with the strong medical manufacturing capability base in that area. The firm also set up distribution, sales and logistics capacity in the locations that provided better access to customers in order to reduce costs.

\section{Embracing Open Innovation}

'...in particular the ones who are geographically close and those that have particularly related interests to ours. For example, a lot of our plastics suppliers are within a 20-minute drive of this location. One of our key research partners is a hospital in [Country 3 City] because their work in [Medical Condition] is so closely aligned with us' CEO

HighRes1 is a very active innovator and invests a significant and increasing proportion of revenue into R\&D processes. The managers discuss some instances where the firm has forged links outside the boundaries of the organisation to access knowledge and technology from other organisations.

\section{Developing Integration and Coordination Skills}

'We bought forward a couple of capital expenditure programmes including investing in the acquisition of the [Country 4] distribution company. But the big investment was in [Country 2] production facility.' CEO

'[Innovation was focused on] ....new facilities especially that in [Country 2]... manufacturing, logistics and distribution.' CEO

HighRes1's acquired a number of other companies during the GFC. These included a distribution firm and a company that produced a complementary technology. These firms were integrated with varying success. Integration of these new resources was driven by the goal of increasing margin as well as the cross-fertilisation of medical manufacturing capability from the [Country 2] facility back to New Zealand. 


\subsubsection{Cospecialisation}

\begin{tabular}{|l|}
\hline Managing Strategic Fit So Asset Combinations Are Value Enhancing \\
\hline $\begin{array}{l}\text { 'That's why we have this huge campus here, R\&D personnel in New Zealand cost about } \$ 120,000 \\
\text { per year that's compared to } 2 \text { or } 300,000 \text { in [Country 5] or [Country 3]' CEO }\end{array}$ \\
\hline 'I guess one of the other things we did do... but when we did get into those high 80s [New Zealand \\
cents to United States dollar] they wanted an independent review... to see whether there is a better \\
way operationally to have the business set up... Our Finance Director thought about life as if you \\
are arriving from outer space and you had this idea that you were going to set up a medical devices \\
business such as ours where and how would you do it?' CFO
\end{tabular}

HighRes1's managers describe a number of processes that provide evidence of efforts to manage the fit of its assets. The CFO outlines a process through which the firm assessed whether New Zealand was the ideal location for its operations and whether its value chain was structured appropriately. While the firm's analysis suggested to the managers that it was appropriately positioned for R\&D efforts, the firm opted to adjust its manufacturing and distribution structures to reduce geographic risk and costs associated with manufacturing, transport, and shipping. As outlined above the firm rationalised and developed its structure, resources, and assets in such a way that it made the most out of the economic climate, in that it made capital expenditure relatively less expensive so the creation, reorganisation and recombination of those assets provided larger synergies. 


\subsubsection{Governance}

\section{Achieving Incentive Alignment and Minimising Agency Issues}

'I think from a financial point of view I would say you needs to have, and the following sounds contrite, sound long-term policies around protecting your revenue streams so be that if it's hedging, commodity hedging, whatever that might be, to avoid Boards [of Directors] tinkering with policy.' CFO

'The one thing I would say and this is something that I learned from the financial industry; as much as possible do not give banks security. Or give them as little as possible, because you need something almost as a rainy day store. For example, we're on this land, we own all the buildings on it, there is no direct security over all this from any bankers. So that if we got ourselves into strife we have got something that we, as opposed to they, can say in the first instance we are now happy to give you some security over our land' CFO

In order to hedge significantly more foreign exchange than the existing capital structure allowed for, the CEO and CFO compromised with the Board of Directors by being more conservative than usual in other areas. These processes are reflective of managing incentives as they regard application management of self-interests of various agents. Meanwhile the Board of Directors needed to be incentivised to unlock access to opportunities identified by managers.

The CFO describes a number of strategies employed to minimise the abuse of discretion. First, he discusses his active management of the board through policies that protect revenue streams. In particular, the managers were keen to ensure their higher than average returns from increased currency hedging were protected, despite the reluctance of the Board of Directors. Second, the firm ensures that external creditors do not gain security over assets, so that directives cannot be ordered over the firm during a particular crisis - such as a significant recall of products.

\section{Checking Strategic Malfeasance and Blocking Rent Dissipation}

'....we wanted to do more hedging but the board wouldn't let us because they were worried about a negative shareholder's funds kind of situation. What that meant was that we really assessed our capital structure going forward saying okay well we want to run a much more conservative balance sheet that covers when the opportunity is there rather than being really constrained...' CFO 


\section{Checking Strategic Malfeasance and Blocking Rent Dissipation Continued}

'But one of the things that our directors struggle with when they are new to the board is our treasury policy. Because they're used to businesses in New Zealand that are either typically commodity businesses; forestry, dairy, or meat and therefore your dividend programme is all based around seasons and pay-outs to your customers as opposed to taking a longer view that hopefully your customer is your customer for many years and you don't have the risk that the actual price of your good is going to be $50 \%$ less or $50 \%$ more from year to year' CFO

'I think from a financial point of view I would say you need to have, and the following sounds contrite, sound long-term policies around protecting your revenue streams, so that if it's hedging currency, hedging whatever that might be, to avoid Boards [of Directors] tinkering with policy.' CFO

The CFO of HighRes1 was particularly concerned with the ability of the Board of Directors to limit the strategic options of management during the GFC. $\mathrm{He}$ demonstrates his capability to manage the board which was in a sense functioning as a coalition (Teece, 2007). A compromise was established between management and the Board in order to unlock the set of options that the managers were seeking although the full extent of the desired currency hedging was curtailed. What the CFO suggests he learnt from the experience was that during a crisis his ability to create change through the subversion of the power of governing coalitions was dependent on the extent that policy legitimised the desired set of actions. As such policy should be set far in advance of a crisis, before such coalitions begin to act out of fear or conservatism.

\subsubsection{Knowledge Management}

\section{Learning}

'Our rate of innovation has been steady but our R\&D capacity doubles every two years in the number of personnel doubles every few years. We currently run about $300 \mathrm{R} \& \mathrm{D}$ projects in parallel at any one time so our innovation rate is always increasing but it is relative to the size of the company.' CEO

'I mean [Country 2] has been a roaring success in my mind that's just a given great cost savings fantastic people over there we are learning from them now that we are in [Country 2].' CFO 
The managers describe how the firm learns in a number of ways. First, through significant and increasing investments in R\&D. An activity that at a high rate relative to the size of the business. Designed to create new knowledge and technologies. Second, the CFO describes how the firm looks to understand how the best practices of actors within the firm are codified for dissemination across the organisation.

\begin{abstract}
Knowledge Transfer and Know-how Integration
'Thinking about the sales tools that each salesperson has, making sure that best practice if you like is germinated throughout the organisation. So there has been a bank, over the last two or three years, more cases of where in a particular market we have been very successful in getting a new product well-established in a new hospital or in a [Country] or whatever it is in well why is that how can we transplant that to [Country 3] and get the same level of penetration?' CFO
\end{abstract}

'When we innovate we are looking for diversification across the medical field. We look to have two out of three of the following criteria when targeting a new area and that is: the patient, the same channel, or the same technology. That way we are safely banking on existing competencies.' CEO

'When we innovate we are looking for diversification across the medical field.' CEO,

'I think that the R\&D from a product point of view we are starting to see good success because in the areas where new applications have been products - we're targeting new applications - we have seen revenue growth rates accelerate in those places.' CFO,

HighRes1 appears active in transferring knowledge across the organisation. Through the dissemination of (internal and hence unique) learned, best practices, the CFO discusses how the firm seeks to transplant successful sales techniques so that these successful processes are transposed into other markets. Similarly, the CEO identifies how they seek to apply existing competencies while diversifying across the medical field. This means applying existing technologies in new areas, to target new patients or channels (or a combination of these). Third, the firm taps the expertise from its global operations, funnelling the personnel and practice back to the New Zealand hub. This is performed by transplanting high performing individuals from the international facility. 


\subsubsection{Case Summary HighRes1}

This case study has contextualised the interview data gathered at HighRes1 into the dynamic capabilities framework, highlighting a number of thematic consistencies in the firm's approach to creating performance in spite of the GFC.

The firm looked to differentiate its markets by creating new technologies but also extended the application of existing technology into new areas. These developments were augmented by modifications to the firm's business model, structure and level of vertical integration. While the executive of the firm needed to develop strategies to work with the Board of Directors, other Transformation capabilities appeared to provide significant value, in particular the learning, integration and transfer of knowledge within the firm. This knowledge included that of the development and commercialisation of technologies but also the creation and integration of practical and processual knowledge.

Overall evidence suggests a significant variety of dynamic capabilities from across the Sensing, Seizing and Transformation framework. Particular capabilities were also applied in a variety of ways. For example, the firm designed mechanisms to capture value in a number of ways: including the development of its own distribution structure to retain margin otherwise absorbed by third parties, and taking opportunities of reduced capital expenditure costs during the GFC.

The heat map for HighRes1 is depicted in full in Table 25. What is clearly apparent in this table is both the consistent discussion of capabilities from across the framework, but also the relatively high levels of that discussion as a percentage of references by all firms. Only three capabilities featured no discussion by the managers of the firm, two of which were from the Building Loyalty and Commitment category. 
Table 25: HighRes1: Dynamic Capabilities Heat Map

\section{Sensing}

$\%$ of total

References

Processes to Direct Internal R\&D

Processes to Tap Exogenous Science \& Technology

Processes to Tap Supplier and Complementor Innovations

Processes to Identify Target Market Segments, Changing Customer Needs and Customer Innovation

\section{Seizing}

Delineating the Customer Solution \& Business Model

Selecting the Technology \& Product Architecture

Selecting Revenue Architectures

Selecting Target Customers

Designing Mechanisms to Capture Value

Selecting Enterprise Boundaries to manage Complements \& Control Platforms

Calibrating Asset Specificity

Controlling Bottleneck Assets

Assessing Asset Appropriability

Reorganising Managing \& Capturing Cospecialisation Economies

Reorganising Managing \& Capturing Cospecialisation Economies

\section{Selecting Decision Making Protocols}

Recognising Inflexion Points 
Table 23: HighRes1 Dynamic Capabilities Heat Map Continued

\section{Building Loyalty \& Commitment}

Demonstrating Leadership

Effectively Communicating

Recognising Non-economic Factors

\section{Transformation}

\section{Decentralisation}

Adopting Loosely Coupled Structures

Embracing Open Innovation

Developing Integration and Coordination Skills

\section{Cospecialisation}

Managing Strategic Fit so that Asset Combinations are Value Enhancing

\section{Governance}

Achieving Incentive Alignment

Minimising Agency Issues

Checking Strategic Malfeasance

Blocking Rent Dissipation

Knowledge Management

Learning

Knowledge Transfer

Knowhow Integration

Achieving Intellectual Property Protection 


\subsection{Case Study: LowRes1}

Interviews: 2 (CEO, CFO)

LowRes 1 are designers and manufacturers of marine electronics. The firm is family owned and operated and during the late 1990s and early 2000s grew strongly, eventually establishing a large international subsidiary in order to expand its business. The GFC appears to have had a severe impact on the firm and when the interviews were conducted in 2013, LowRes 1 had retrenched significantly from its peak in operations and revenue.

\subsubsection{Sensing Capabilities}

Processes to Direct Internal R\&D AND Processes to Tap Exogenous Science \& Technology

'We had innovation goals, unfortunately for the last three years.... I'm just thinking about the goals as opposed to.... It has been difficult to implement what we would have liked to have done and that has been not necessarily around money. It hasn't helped but it's also around the capabilities of our staff - we are stuck with the staff that we are and because they aren't particularly innovative, that has but a kibosh on our ability to be innovative ' CEO,

[CEO] loves change he really does so he was always looking at what is happening out there [In the Environment] What could we do? What were others up to? What are other people doing?' CFO, "

Compared to other firms, LowRes1 shows very little evidence for sensing capabilities. In the quotes above the two respondents outline that while management would have liked to engage in this type of process, the CEO considers the capabilities of staff of the firm to be the most significant barrier. This is despite, according to the CFO, that the CEO is interested in the developments others have made. Specific mechanisms to perform sensing process are not identified. 


\subsubsection{Seizing Capabilities}

\subsubsection{Delineating the Customer Solution \& Business Model}

\section{Selecting the Technology \& Product Architecture}

'The other aspect has been the decision to specifically concentrate on using [Company] products and moving away from engineering our own products' CEO,

'I think prior to, there was an element of service associated with us. We were doing installation work in [Country 2] not so much in New Zealand our strategy was get rid of completely the installation side and get rid of the other areas completely and focus on the design of the work and fit out of the boat and leave the people we were dealing with to carry out the labour-intensive work themselves.' CFO

'I think we've become a little bit more niche...we had industrial and we had Marine, and in Marine there's motorboats and sailing yachts and whatever and it is all really wonderful. After the GFC we've got some industrial clients but actually the competition was just so huge and we had nothing to offer that other people didn't.' CFO

The firm moved from manufacturing its own technologies to assembling those of a large international electronics supplier, making a decision to divest their own technology platform, in favour of one owned by a third party. The CFO describes how the firm has narrowed its focus to remove any notion of services as part of their offering. This relates to the firm becoming more niche oriented in its offering, choosing to exit its industrial business to focus on sailing vessels.

\section{Selecting Target Customers}

' $[C E O]$ could do three regattas - because he has to pay less than the price of one boat show. He decided to do that as a marketing tool. So you are on board, there are always functions, there are these other vessels, and there are owners, captains, engineers the people that really matter.' CFO

'We thought how are we going to meet the market? We will have to go to market, our specialty area, which is sailing boats within the Marine super yacht sector. It is a niche within a niche because sailing boats are only about $20 \%$ probably more like $15 \%$ of the total market. New Zealand is overrepresented with [Competitor] and others but there is a niche within a niche' CEO

These capabilities are expressed through the firms understanding of its customer's needs and willingness to pay for products and how to deliver what the customer wants. The CEO and CFO both reference the value the firm gained by changing focus 
from attending tradeshows to participating in regattas as key to building networks with customers. The aim was to take the firm from an 'unknown quantity' to an authority with key decision makers in the target customer firms and with individuals, rather than creating mass knowledge of the brand in target segments.

\section{Designing Mechanisms to Capture Value}

'We got rid of everything. Everything that was a cost. I used to run around in a Volvo, I sold it... other ways that we cut costs; wages and wage negotiations became so much easier for example we didn't reduce the wages but there was certainly no expectation that pay rises would be forthcoming. CEO'

'So we had to stop [Country 2] completely, we downsized in New Zealand, we made one person redundant and then another person left of their own accord and we just didn't replace people. We were probably fortunate in that we had had a full-time office manager in New Zealand and she resigned pretty much unexpectedly and only two weeks notice about Christmas 2008 so then we didn't replace her, so we sold everything - the company car, [CEO] went round in a van. CFO'

'So for the cost of doing one boat-show I can go to three regattas in [Region], and up in [Country], which I do. The costs associated with that are much reduced because the owner doesn't pick up the airfares to get there, but the other costs of accommodation, food and drink while you are there for three or four days.' CEO

LowRes1's predominant response to the GFC appeared to be redesigning and minimising their cost structure. The CEO and CFO both refer to significant costcutting exercises within the firm. These ranged from staff and vehicle costs through to the value for money the firm gets from attending regattas over tradeshows. The most significant cut the firm made was most likely shutting down its entire [Country 2] operation.

\subsubsection{Selecting Enterprise Boundaries to Manage Compliments and Control Platforms}

\section{Calibrating Asset Specificity}

'Prior to [The GFC] there was an element of service associated with us. We were doing installation work in [Country 2], not so much in New Zealand. Our strategy was completely get rid of the installation side, and get rid of the other areas completely, and focus on the design of the work and fit out of the boat and leave the people we were dealing with to carry out the labour-intensive work themselves.' CEO 
The CEO describes the process of narrowing down the firm's scope of operations to focus on its core competencies. This included exiting industrial operations and removing all ancillary services that formed parts of the firms offering, divesting these activities to third parties.

\title{
Controlling Bottleneck Assets
}

'So there were little things and then it was actually in January we got the December figures from [Country 2] and they have lost the entire year's profit in one month. So that was the beginning of just a terrible time really, terrible and although we had had some inkling it was truly shocking. We didn't think it was anything like how bad it was.' CFO

'In of February 2009 that was just before the end of the financial year so January/February we were all wrapped up we had wrapped up the whole thing [Country 2 operation] by next financial year. So once I knew I had to act pretty quickly' CEO

'So we had to stop [Country 2] completely, we downsized in New Zealand,' CFO

The managers discuss the financial constraints that the firm was under. They particularly focus discussion on the [Country 2] operation that was effectively a financial bottleneck, that losing money put significant constraints on the business as a whole. To address this the CEO's response was to shut the operation down as soon as possible, once the extent of the subsidiaries losses was realised.

\author{
Assessing Asset Appropriability \\ 'After the GFC we've got some industrial clients but actually the competition was just so huge and \\ we had nothing to offer that other people didn't.' CFO
}

The CFO discusses how the firm's retrenchment strategy gave consideration to the imitability of their products in particular markets. Their industrial operation appears not to have had any particular advantages when compared to competitors. As a result, the firm chose to withdraw from areas where they had no unique offerings. 


\section{Recognising, Managing and Capturing Cospecialisation Economies}

'So we had to stop [Country 2] completely, we downsized in New Zealand,' CFO

LowRes 1 struggled to maintain its stock of assets and in downsizing and reducing the asset base of the firm so significantly, they likely reduced their capability to cospecialise assets to create unique value from what remained. The CEO refers to focusing on the sailing boat market where the firm has significant knowledge, but the retrenchment the firm underwent likely reduced the value that could be derived from their knowledge by diminishing the areas in which it could be applied.

\subsubsection{Selecting Decision Making Protocols}

\section{Recognising Inflexion Points and Complementarities}

'The New Zealand Marine manufacturing market has been decimated by the exchange rate primarily' CEO

LowRes 1 recognised the effect that external stimulus was having on its market. The exchange rate 'headwind' that emerged as New Zealand's currency rose against others made LowRes1's products relatively more expensive. Another indicator for the firm was that clients were taking longer to pay bills. The CEO suggests that the major issues in their market have been caused by the New Zealand exchange rate appreciating significantly in recent years.

\subsubsection{Building Loyalty and Commitment}

\section{Demonstrating Leadership AND Recognising Non-Economic Factors}

'I think the things that we did have saved the company. Me getting rid of the [European Car] and driving around in a very old vehicle has sent the correct message - not only to our clients - but also the expectations of the staff and they saw that everything was being done.' CEO 


\section{Demonstrating Leadership AND Recognising Non-Economic Factors Continued}

'I would have liked by now to have had another key person in a role because I have been stuck with somebody who was unsuitable for far too long and they needed to be moved on a couple of years ago and we have not been in a position to do that.' CEO

Demonstrating leadership capabilities were exhibited in LowRes 1 through the actions of management during the GFC. The CEO describes his downsizing from a European company car to a delivery van as an example of signalling his staff regarding the firm's situation and that the firm was doing all it could to be cost effective. Both managers describe the negative effect a particular employee has had on the firm's organisational culture; however, proactive steps were not taken in order to remove or manage this employee, suggesting that the firm is inconsistent in applying these types of capability.

\subsubsection{Transformation}

\subsubsection{Decentralisation}

Adopting Loosely Coupled Structures and Developing Integration and Coordination Skills

'We closed down [Country 2] at the end of March' CFO

'In of February 2009 that was just before the end of the financial year so January/February we were all wrapped up we had wrapped up the whole thing [Country 2 operation] by next financial year. So once I knew I had to act pretty quickly' CEO

The managers describe their process of shutting down the [Country 2] subsidiary. This may be evidence that the firm was functionally reducing its decentralisation by removing the quasi-independent profit centre the subsidiary represented. Instead of developing loosely coupled structures as a positive expression of dynamic capabilities, it created a smaller, rigidly centralised structure. Relatedly, these actions suggest that because the subsidiary's manager managed to obfuscate the true state of affairs, that the firm showed poor integration and coordination skills by affording the subsidiary and its executive too much autonomy. 


\title{
4.4.3.2 Governance
}

\section{Achieving Incentive Alignment}

'So we sent our best person over there in 2000. Since then inevitably he started to build his own silos over there. He didn't have any ownership of the company - any flesh in the deal, skin in the game and didn't appear to want any but, was starting to become fiercely independent' CEO

'There was certainly no expectation [among staff] that pay rises would be forthcoming.' CEO

These capabilities affect the management of agency issues and are embodied in processes to manage potential interest alignment problems. According to the CFO, the firm appears to have been stuck with a manager in their [Country 2] business that was mismanaging subsidiary. The CEO suggests this manager had managed to obfuscate the details of the maladministration until it was too late to save the operation. The CEO goes on to insinuate that this manager's lack of shareholding as a form of incentive may have been a contributing factor to this manager's negligence. This manager's reluctance to assume any ownership stake is insinuated, suggesting that alignment between the objectives of the agent and principle actors was low.

\author{
Minimising Agency Issues \\ 'We couldn't change our manager in [Country 2]' CFO \\ 'I guess because we were having difficulties in New Zealand we didn't get to [Country 2] soon enough \\ and we didn't look deeply enough' CFO
}

LowRes1's managers appeared to fail to identify the freeriding, consolidation of power and mismanagement that the manager of their [Country 2] subsidiary engaged in. It was too late to remediate this situation by the time they did understand the extent of the issues. This suggests that the dynamic capabilities expressed by the firm to manage agency issues were not evolutionarily fit (Helfat \& Peteraf, 2009). 


\section{Checking Strategic Malfeasance}

'I guess because we were having difficulties in New Zealand we didn't get to [Country 2] soon enough and we didn't look deeply enough. So there were little things' CFO

It would appear that LowRes1 struggled to keep strategic malfeasance in check. The CEO and CFO both refer to the manager who was obfuscating and acting out of selfinterest in this operation. The CFO describes not being able to remove the manager and not looking 'deeply enough' at the financial situation of the business.

\section{Blocking Rent Dissipation}

'We closed down [Country 2] at the end of March and at that time our [Country 2]n manager basically was feathering his own nest,' CFO

...but [the manager] was starting to become fiercely independent and he started to obfuscate around the details so when it became obvious that I should go over and I did and within three weeks, I had shut the place down. CEO

'In the end he was the ones who made us fall over the and he didn't get that job so we are in New Zealand with money haemorrhaging' CFO

'I guess because we were having difficulties in New Zealand we didn't get to [Country 2] soon enough and we didn't look deeply enough. So there were little things and then it was actually in January we got the December figures from [Country 2] and they have lost the entire year's profit in one month. So that was the beginning of just a terrible time really, terrible and although we had had some inkling it was truly shocking we didn't think it was anything like how bad it was.' CFO

LowRes1's CFO references their failure to stop the financial mismanagement of the [Country 2] business as a source of lost rents and goes on to describe that by the time they realised the extent of the subsidiary's decline it was too late to rescue the operation. The evidence suggests that the capability of LowRes 1 to block the dissipation of rents was low.

\subsubsection{Knowledge Management}

The firm's managers did not appear to discuss any processes that could be considered Knowledge Management Capabilities. 


\subsubsection{LowRes1 Case Summary}

LowRes1 struggled to maintain solvency during the GFC. This was largely driven by the collapse of the international subsidiary but also due to structural market effects impacting the New Zealand operation. The attempts to arrest the decline appeared too late, or were insufficient, to avoid being significantly affected by the GFC. The main response of managers to the disturbance in this firm appeared to be retrenchment. The firm retrenched from international markets but also its business model - removing a service component to their offering. They also reduced efforts to innovate, and moved away from their own technolog(ies) in favour of third party offerings.

The heat map for LowRes1 is depicted in full in Table 26. What is clearly apparent in the heat map is the clear lack of discussion of dynamic capabilities when compared to other firms. The firm scores particularly low on discussion of Sensing and Knowledge Management capabilities. Similarly, the capabilities discussed are displayed in lower volumes than in other firms.

Table 26: LowRes1: Dynamic Capabilities Heat Map

\section{Sensing}

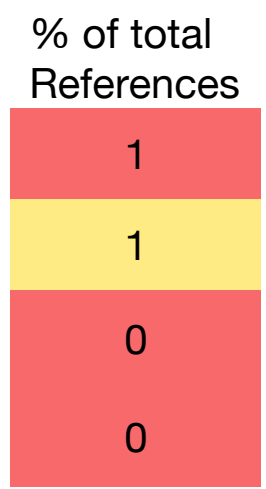


Table 24: LowRes2 Dynamic Capabilities Heat Map Continued

Seizing

$\%$ of total

References

Delineating the Customer Solution \& Business Model

Selecting the Technology \& Product Architecture

Selecting Revenue Architectures

0.0

Selecting Target Customers

5.7

Designing Mechanisms to Capture Value

5.8

\section{Selecting Enterprise Boundaries to manage}

Complements \& Control Platforms

Calibrating Asset Specificity

Controlling Bottleneck Assets

0.0

Assessing Asset Appropriability

15.8

Reorganising Managing \& Capturing Cospecialisation Economies

Reorganising Managing \& Capturing Cospecialisation Economies

\section{Selecting Decision Making Protocols}

Recognising Inflexion Points

7.4

Avoiding Decision Errors \& Anticannibalisation Proclivities

\section{Building Loyalty \& Commitment}

Demonstrating Leadership

4.3

Effectively Communicating

Recognising Non-economic Factors

4.5 
Table 24: LowRes2 Dynamic Capabilities Heat Map Continued

\section{Transformation}

\section{Decentralisation}

Adopting Loosely Coupled Structures

Embracing Open Innovation

Developing Integration and Coordination Skills

\section{Cospecialisation}

Managing Strategic Fit so that Asset Combinations are Value Enhancing

\section{Governance}

Achieving Incentive Alignment

Minimising Agency Issues

Checking Strategic Malfeasance

Blocking Rent Dissipation

\section{Knowledge Management}

Learning

Knowledge Transfer

Knowhow Integration

Achieving Intellectual Property Protection
$\%$ of total

References

7.1

0.0

2.6

0.0

5.6

0.0

0.0

0.0

0.0

0.0

0.0

0.0 


\subsection{Case Study: HighRes3}

Interviews: 2 (General Manager, Operations Manager)

HighRes3 are a manufacturer of industrial electric power systems with a 100-year history, much of it as a subsidy of various international parent firms. By the mid-00's the firm had been effectively stripped of assets and was left with a portfolio of legacy products. After being sold to a new owner, the firm began a process of renewal. This process was undertaken with the backdrop of the GFC, adding another set of challenges for management.

\subsubsection{Sensing}

\section{Processes to Direct Internal R\&D}

'So in the process we bundled together an R\&D team, and we separated the R\&D team from the factory and said "guys you are not responsible for what runs in the factory. What runs in the factory is the responsibility of factory guys" and so now they actually had time to do their jobs.' General Manager

'Yes we put a fixed percentage of our revenue into R\&D. That was both into the people and the tools to make those people productive so our R\&D department was made up of one and a half parttime people and between three and four full-time people plus another three quarters of a person who was about $80 \%$. So when you consider the small number of people that was a fairly substantial jump.' General Manager

As part of the drive to create new product technologies HighRes3 invested more resource in R\&D. This included both individuals in terms of manpower, but also a fixed proportion of revenue. These human and financial resource investments were tasked towards developing new platform that the firm could use to replace its aging technolog(ies).

\section{Processes to Tap Exogenous Science \& Technology}

'We got a [Country 3] company in to do some R\&D investigation and they came up with a mechanism and the idea was to create a usable system to create a completely new range of [Products]' General Manager 


\section{Processes to Tap Exogenous Science \& Technology Continued}

'R\&D, innovation we've had substantial contributions out of the New Zealand government to do $R \& D$ into our product development and certainly in the last two years we've certainly seen it show a little bit.' Operations Manager

HighRes3's managers describe how the firm utilised the services of external sources of technology to provide input into the process of developing their new technologies. This included engaging with government and private sector organisations to source funds and expertise to capture value from external developments in technology.

\section{Processes to Tap Supplier and Complementor Innovations}

'Yes. A lot of input from our suppliers... and some of them were instrumental in showing us that our drawings were wrong. Some of them were instrumental in asking why do you build it like this? Why don't you fabricate this like that and then build it like this? And they would show to us that by doing that it reduced their time and cost, which reduced our time and cost, and gave us a more reliable product' General Manager

The General Manager describes how involving suppliers in the innovation process has lead to the development of better products. By leveraging their expertise, the firm was able to reduce the time and cost that it took to develop their new platform technology as well as improving the overall quality of the product. As will be discussed later, the supply chain was significantly improved though innovative logistical distribution of materials.

\section{Processes to Identify Target Market Segments, Changing Customer Needs and Customer} Innovation

'We had changes in markets, so the whole focus was turned on its head and we said so what does the customer require, what does the customer pay for, what does the customer value?' General Manager

'In terms of customers, yes some of the good suggestions that were incorporated into improvements very definitely came from customers and sometimes from customers you had a major problem and yet in a way almost gave us the solution on a plate type thing.' General Manager 
'What has happened in the electricity industry is I think generally the utilities are moving away from period contracts and they are making far more project by project decisions. They are doing far more, if you like, unique engineering for specific sites which should be good for us because one of the aspects of our product is it's very much tailor-made for the customers.' Operations Manager

The firm was active in considering the needs of customers when developing products. The Operations Manager also suggests that the firm underwent a process of reorienting its offering on customers. He lists requirements and value as key considerations.

\subsubsection{Seizing}

\subsubsection{Delineating the Customer Solution \& Business Model}

\section{Selecting the Technology \& Product Architecture}

'The [new product] was the other major development that was done...put us back in the market in terms of competitiveness.' Operations Manager

'It will be inherently lower cost and simpler to use and it will be come compatible with the network engineering that is being done very, very widely all around the world.' Operations Manager

'[Effort in Innovation] went into the three projects that we have already talked about... we've kind of re-channelled that effort into a new horizontally designed [Product] because we think that has more potential to sell into our existing market.' Operations Manager '

The Operations Manager describes how the firm transitioned to a new technology platform developed in-house. This was designed as a horizontal extension to the existing product line. This new platform is lower cost to purchase and compatible with more complementary products in use by the firm's customers internationally. HighRes3 had previously developed another platform technology that the managers suggest didn't result in a viable product but instead created technical knowledge, that contributed to the other platform technology that did eventuate a marketable product. 


\section{Selecting Revenue Architectures}

'We were able to pick up period contracts and we had customers who at the end of the period contract said were you prepared to extend? And because of our improvement programme we were able to say yes as long as we agree on currency variations. So then we were able to improve our margins because we reduced our costs.' General Manager

'My personal goal would be $20 \%$ of sales coming from new products and by new products I define as something that was not sold three years prior. So something is only new for three years. $20 \%$ of your sales needs to come from that. That was the goal now at [HighRes3] we haven't got there.' General Manager

'Now in some cases the GFC was actually a boon for us because now actually people were saying "we cannot actually can go out and spend $\$ 35$ or $\$ 40,000$ on a new piece of [Equipment], can we refurbish this one and take all the modern advantages and add into this?" And we said "well of course you can." So in some cases we got more work through the refurbishment programme because we were able to do that. That was actually interesting enough that a couple of big companies started looking at it but by then we got actually huge jumps ahead in the market.' General Manager

Managers describe the firm's previous revenue model as to enter into service contracts for their products that last a number of years. Part of the return to profitability was to adjust these agreements to be more favourable to the firm, rather than offering particularly low prices in order to win work, often at poor or even negative margins, suggesting the firms was poor at costing their products. In changing the revenue model, the firm created revenues that were both more favourable to the firm in its terms and conditions.

A new stream of revenue also included the retrofitting and refit of existing hardware, including that of competitors' products with the new technology platform that was developed. This provided both a new stream of revenue and continuity of existing streams, but also served to take market share from competitors who could, or would not refit older product lines. 


\section{Selecting Target Customers}

'We are really starting to grow the industrial sector in [Country 2].' Operations Manager

'Growth in the markets internationally is a pretty big opportunity for us because we... supplied the main electricity infrastructure into a hell of a lot of [Region]. As a company we have been strong in [Region] although we haven't had a huge presence in the rest of the world, but there isn't another supplier of the legacy products. We've got huge opportunities in [Country 3] which is starting to come through. In the last two years the [Region] which has which is trickling in... We will crack [Country 4] but I think that will be next year.' Operations Manager

'We had changes in markets, so the whole focus was turned on its head and we said so what does the customer require, what does the customer pay for what does the customer value?' General Manager

The Operations Manager outlines how the firm approaches selecting customers. The firm primarily sells internationally to utilities companies but began seeking to develop their operations in the industrial sector. The firm appears to approach selecting markets geographically, with managers listing a number of specific regions as areas of interest. The firm targets extensions of product platforms into related use situations, driving the diversification from electricity infrastructure, to industrial power transmission. The General Manager suggests that these changes in markets have driven the firm to consider what these new customers are looking for in their products.

\section{Designing Mechanisms to Capture Value}

'[Country 4] suppliers for other component parts and he reckons that in the first, if you like, phase of our Asian sourcing initiative we knocked between 30 and $50 \%$ off our component costs so that's a huge difference.' Operations Manager

'In terms of getting a ready to manufacture and improving the quality of the output of the [Country 4] factory it's done very very impressive things so we've got some cost savings but we've also got a lot of efficiency in the assembly process.' Operations Manager

'Standardising. Some of that was what looking at what one person did and saying "that's clever" and give him a check list that allows anybody to do that. So we made a whole lot of, a lot of them were stupidly simple jigs, that they allow people to work not hard but smarter and far faster. So what happened now, instead of giving full five breakers off the line in the day, we could now get 20 or 30.' General Manager 
These types of capabilities appear to have been a significant focus for the firm. The Operations Manager discusses how the firm entered a process of sourcing components internationally, which went as far as setting up a distribution facility in a low cost location that integrated the components received from various sources. His account of the benefits suggest they have saved between 30 and $50 \%$ on the cost of components. The process has made manufacturing more efficient as components are packaged as required for individual production units. This enabled the firm to capture more value from existing sales volumes.

The General Manager describes the process of standardising practices across the firm. Creating a standard operating procedure for workers on the production line has alleviated a bottleneck in production that lead to significant improvements in the yield of the factory.

\subsubsection{Selecting Enterprise Boundaries to manage Complements \& Control Platforms}

\section{Calibrating Asset Specificity}

'[Owner] came in knowing the industry....and entered into a cost reduction exercise - sourcing parts out of [Country 4] rather than locally... that's the real mechanism that restored profitability here.' Operations Manager

'So [HighRes3] have a network of about 28 different suppliers in [Country 4]. But the thing that makes this different to a lot of organisations is that rather than just supplying boxes of bits from 28 factories, they are essentially centralizing on a single company who have a warehouse that's pretty much dedicated to parts for us... We work on the R\&D front with an international industry expert who has said that it is the most technologically advanced supply chain out of [Country 4] that he's seen in this industry.' Operations Manager

The firm made decisions regarding the integration and composition of its supply chain during the GFC, again, motivated by the need to reduce its costs. The firm migrated from a number of locally based suppliers, to develop its own logistics management company to integrate components from a number of suppliers. This saved costs in a number of ways, first by sourcing parts in a cheaper economy, and second by consolidating the logistics of procuring the supplies, and third by packaging the parts 
so that the different components for assembly were arranged together. This vertical integration also ensured the New Zealand operation could focus on the task of manufacture, while a specialised procurement operation could manage the supply chain.

\section{Controlling Bottleneck Assets}

'So what happened now instead of getting four or five breakers off the line in the day, we could now get twenty or thirty. Now you can start to sell. So our lead-time which used to be 32 weeks if you were lucky, started condensing down to 18 weeks and we were delivering on 18 weeks.' General Manager

'....and we then got the breakers to a point where they were consistent and stable, and now they could start to come off the production line whereas before five out of every ten breakers had to be reworked and all the time and cost and effort in that, we were now giving one in twenty that required adjustment. We begin now going back to our suppliers in saying this dimension is super critical.' General Manager

HighRes3 showed strong capabilities to relieve a constraint in their value chain. The process of manufacturing was inefficient and plagued high rates of costly errors. By standardising the roles of manufacturing staff and disseminating the best identified practices, the firm was able to reduce the rate of rejects and increase total throughput of the factory.

\section{Reorganising, Managing and Capturing Cospecialisation Economies}

'The safety standards on [Product] makes it a more attractive product and adds some cost so that when you combine that with work in [Country 4] to get the other components at a lower cost, basically that's what's restored market share.' Operations Manager

The capability to capture value from cospecialisation is apparent in the firm's efforts to build a technology platform and to extract higher margins from its production than the previous generation. The Operations Manager suggests that the combination of the new technology platform and the component sourcing operation in [Country 2] has driven the increase in market share that the firm has realised. While the new product platform is inherently more expensive, the reduction in manufacturing costs offsets this. 


\title{
4.5.2.3 Selecting Decision Making Protocols
}

\author{
Recognising Inflexion Points
}

'Man's appetite for electricity was not affected by the recession! ha ha ha ha. It's a bloody good industry because even in constrained financial times people have to do maintenance on that electricity distribution system. The expansion of it will slow down and certainly expand at times when you're putting in more industrial packs everywhere.' Operations Manager

The managers at HighRes3 appear to have a strong understanding of the pivot points for their markets. This includes how various segments of consumers were affected during the GFC and how their decisions were affected as a result. The Operations Manager recognised that while the GFC slowed the expansion of infrastructure deployment it did not diminish consumption of electricity. He suggests they are in a market that is itself resilient to global economic conditions. He also states that it is clear when an industrial customer is likely to need their products.

\section{Avoiding Decision Errors \& Anticannibalisation Proclivities}

'....and so we spend a lot of time getting the fundamental things right people, information, process, and then the products.' General Manager

The General Manager states that the firm considers the people, information, and process to be important to get right first before products. This ensures that the firm has the expertise, knowledge and process in place before beginning the development of new products.

\subsubsection{Building Loyalty and Commitment}

\section{Demonstrating Leadership}

'But absolutely its about leadership. It's about how do you expect people to interact together? And historically I think people took an approach "you are the boss I'll do what you say", and I'm saying "don't do what I say I don't know as much about what you do as you do!" ... And it takes time for people to get the confidence to do that when they haven't been working in that environment and I think we're really starting to make some progress there.' Operations Manager 


\section{Demonstrating Leadership Continued}

'We looked at the entire factory - the entire sourcing process and logistics - and we had a couple of people who had some quite good ideas, and sometimes you have to have a burning platform to force people to move. Change is uncomfortable and the normal reaction is resistance. "we've done it this way for a number of years, why do we have to change?"' General Manager

The General Manager and Operations Manager both suggest there were issues driving change in the organisation. Both see resistance as a normal response to change. The General Manager suggests that he used the idea of the 'burning platform' to motivate people to change. While the Operations Manager suggests that once people see results they are more likely to come on-board. Overcoming the status quo at the firm appears to be the major obstacle and that leadership was key to doing so.

\section{Effectively Communicating}

'My attitude, [General Manager]'s attitude and what people have started to do is that when they see it being done and delivering results, it's like when you start to see improvement and then you think, well and if we did that this way as well nobody says no you can't because this is what used to happen before [General Manager] and then before long people come out with their ideas.' Operations Manager

'I think the management philosophy of introducing new manufacturing and the cultural changes that go alongside that, which is about that breaking down silos, getting cross functional sharing of ideas and contribution accepting that people who do jobs have to know all about the jobs and therefore don't just tell them what to do - listen to their ideas because they are probably good.' Operations Manager

The managers interviewed suggest that an aspect of the firm's recovery was to remove a culture of compartmentalisation and power brokerage which diminished the capacity for communication across the organisation. The managers that had created silos and had consolidated power and control were removed (or exited), and this change facilitated the flow of ideas and improved communication. 


\section{Recognising Non-economic Factors}

'I think the management philosophy of introducing new manufacturing and the cultural changes that go alongside that which is about that breaking down silos, getting cross-functional sharing of ideas and contributions accepting that people who do jobs have to know all about the jobs and therefore don't just tell them what to do - listen to their ideas because they are probably good.' Operations Manager

'Prior to [Owner] there was very little encouragement of innovation as such, certainly not as a value that people within the organisation were recognised or rewarded for. It was about reputation - in this industry it's all about reputation. Having the confidence of the utilities and the industrial people in this business.' Operations Manager

The Operations manager acknowledges that valuing innovation and the reputation of the firm it had developed over a 100-year history were important to the firm in retaining and acquiring customers during the GFC. Similarly, the changes to the organisational culture which included more intra-organisational communication, sharing of ideas, and acknowledgement of long standing expertise were identified as positive developments by managers.

\subsubsection{Transformation}

\subsubsection{Decentralisation}

\section{Adopting Loosely Coupled Structures}

'[Subsidiary] now have a network of about 28 different suppliers in [Country 2] and mostly in the [City] region who are making bits for us' Operations Manager

'[Subsidiary] are essentially centralising on a single company who have a warehouse that's dedicated to parts for us and they are doing packaging and assembly. So that they send us a big box which has got all the different parts which are needed for our assembly line' Operations Manager

The firm decentralised its procurement by setting up a new subsidiary in [Country 2] to coordinate their network of suppliers. In doing so, the Operations Manager describes how the subsidiary focuses on managing the network of suppliers, so that the New Zealand operation can likewise focus on the development and 
manufacturing of products (or rather assembly with the specifically packaged components sent from [Country 2]).

\section{Embracing Open Innovation}

'We found that they had some... software that was for ballistic explosions and how do you contain them to protect people around them and I looked at this and I said, "Well this sounds exactly like what we are trying to do." 'General Manager

'So we we're able to use parts of the technology that was appropriate to us and we modelled the explosions and the ballistics guys were able to use Solidworks as an input to the system. They are able to tell us what the results would be so that we were able to keep changing the pre-sets until the physical test would show us the same results as the simulations would. Then we said, "Please add iterations." We would normally do six or seven iterations to get to the result that you're looking for so we were able to jump every third or fourth iteration because of the software, then do a physical test.' General Manager

The General Manager describes how the firm utilised processes and expertise from outside the firm and industry to use in the development of new products. The use of software explosion modelling saved the firm time and money in avoiding performing physical tests. By modelling explosions, they removed the need to perform 'every third or fourth test'.

\section{Developing Integration and Coordination Skills}

'[Owner] and [Owner of another manufacturer] basically went to [Country 2] to find potential parts suppliers....They made a partnership...with a company in [City] who specialize in coordinating [Country 2] supply chains to particularly New Zealand companies ' General Manager

'Well it hasn't delivered the dollar savings [Owner] was hoping for but in terms of getting a ready to manufacture and improving the quality of the output of the [Country 2] factory it's done very very impressive things so we've got some cost savings but we've also got a lot of efficiency in the assembly process.' Operations Manager

The development of the [Country 2] subsidiary is an example of HighRes3's efforts to create skills in integration and coordination of vertical supply chain assets. In sourcing components from a low cost economy, the firm stood to save on the cost of those inputs. However, to manage this new network of suppliers, the firm's subsidiary 
specialised in this activity. By integrating a new subsidiary that coordinated the various suppliers, HighRes 3 was able to attain both cost and efficiency benefits.

\subsubsection{Cospecialisation}

\section{Managing Strategic Fit so that Asset Combinations are Value Enhancing}

'The safety standards on the arc fault panel makes it a more attractive product and adds some cost so that when you combine that with work in [Country 2] to get the other components at a lower cost, basically that's what's restored market share.' Operations Manager

By bringing various resources to bear, namely a new technology, changes in the vertical integration of the firm as well as changes to sourcing and procurement, the firm was able to gain market share that had previously been eroded by competition. The Operations manager outlines these factors as balancing out when considering the higher cost of the new technology, but lower costs of sourcing.

\section{Achieving Incentive Alignment}

'I spent a lot of time I guess you could almost say in conflict with the prime shareholder because he and I just did not see eye to eye and the problem was there was no evidence for a solution. He had tried his way which had worked at other companies... and then found it was a costing a lot of money and giving him the jitters obviously because he had what he invested in there, and now there was this huge uncertainty.' General Manager

According to the General Manager the major shareholder in the firm understood and was prepared to invest in the firm's turnaround. However, the checks and balances of the General Manager's role appear to have been unclear and created some conflict between the agent and principals.

\section{Minimising Agency Issues}

'And in fairness to the shareholder and he took a deep breath and dared to go, and to keep going, and initially he was one of those guys who was very sceptical about it. But as he began to see what was happening he began to say, "Well actually this makes sense." General Manager 
The General Manager discusses how the shareholder was willing to accept the strategy to turn the business around despite initial scepticism. Ultimately the ownership of the business was required to relinquish control over the management of the firm and allow the executive to execute its plan to restore growth.

\section{Checking Strategic Malfeasance}

'My predecessor described it as - you hear about silos? This place was worse than that it was like machine-gun emplacements and people were sitting behind their armoured barrier and having a go at somebody else's gun slot and hoping that somebody in the other place would catch the bullet and do something useful with it. I think that's extreme but it's the truth - not a conducive environment to new ideas and one of the things that [General Manager] started doing was just beating that out of people, beating that out of the organisation.' Operations Manager.

Managers stated the firm has moved from being comprised of silos of consolidated powerbases, to one where two of these major powerbrokers had exited and the General Manager worked to remove this type of conduct from the firm.

\section{Blocking Rent Dissipation}

'Two of the principal powerbrokers exited the business as I said when we started - I am not aware of the precise circumstances of the exits but the people who are gone did act very much in that not only silos, but it was a very command and control type approach. As in they got all the work that was coming in their way gave it out almost on a task by task basis so that people in their groups and people going back to them for approval before it went anywhere else. That is such a stifling environment to work in it's not surprising that company wasn't doing very well.' Operations Manager

The Operations Manager suggests that the departure of two managers that were responsible for significant malfeasance was of benefit to the business's recovery. In their exit, the centralisation of power and authority was dismantled and the flows of information were improved. The extraction of quasi-rents on the part of powerbrokers was effectively dismantled. 


\subsubsection{Knowledge Management}

\section{Learning}

'I told you we were trying to contain this explosion? We were completely on the wrong track and you look back and you say, "Obvious isn't it?" But the time when your approach seems to be the right way, if you want to protect people what do you do? You build this thing like a safe. This actually doesn't work - how do you take a box of matches and turn it into an explosion? You constrain it. So how do you make a person safe? You don't constrain them - all the fireworks - you do exactly the opposite you take away all restrictions. It is counterintuitive but I guess that is part of the learning unless you make this stuff up at the beginning you couldn't understand that radical shift in direction.' General Manager

The evidence presented outlines two avenues of learning on the part of the firm. The General Manager describes how the firm employed an experimental approach to fundamentally rethinking their product line's safety features. According to the Operations Manager, the owner, on acquiring the firm, underwent a process of learning to understand the business and eventually how to improve the cost structure.

\section{Knowledge Transfer}

'[The Owner] came in knowing the industry but not knowing the products and pretty much toured the world to get to understand the marketplace and the product and the people and the movers and shakers and experts in the area and entered into a cost reduction enterprise - sourcing parts out of [Country 2] rather than locally' Operations Manager

'Standardising. Some of that was what looking at what one did and saying, "that's clever", and give him a check list that allows anybody to do that. So we made a whole lot of, a lot of them were stupidly simple jigs that they allow people to work not hard but smarter and far faster' General Manager

HighRes3 transferred knowledge across the organisation by standardising procedures. By examining the work practices of the highest performing staff, the General Manager suggests the others could work smarter and faster. The documented approach could be used to train employees faster and in a structured fashion. 


\section{Knowhow Integration}

'We started documenting and coming up with a standard operating procedure. We found the guy who did it the absolute best and then we then documented it, photographed it and now everybody does the same thing. Then when a new person comes on this is the person who does the training. People don't learn on the job they have a structured document which they work their way through' General Manager

'[Investment] went into the three projects that we have already talked about and we have moved from [Old Product Category] which essentially, while we will have got some benefit in terms of technical knowledge out of it, we haven't got a product out of it. We've kind of re-channelled that effort into a new horizontally designed [Product] because we think that has more potential to sell into our existing market.' Operations Manager

The firm's development of new products, even unsuccessful ones, appear to inform other developments. Technical knowledge not employed as intended has, according to the Operations Manager, been used to inform other products with more market potential.

\subsubsection{Summary Case 3}

HighRes3's challenge was to renew and rebuild its business while also being resilient to the GFC. These tasks affected all facets of the organisation. The firm looked to new markets, customers and technologies to drive growth in sales. Investments in improving the cost structure of the supply chain, the costs of manufacturing and reducing the lead times for customers retained more margin for the firm. Sourcing and manufacturing activities were significantly reconfigured. A new, extensible platform technology provided the basis of this more robust business model.

The firm also made significant changes to the management structure - removing underperformers, and managing the exits of powerbrokers and malfeasants who, under the prior regime had centralised power and information. Removing their silos while also uplifting the involvement and input of staff rounded out the response. 
Table 27 shows HighRes3's scores from across the dynamic capabilities framework. HighRes3's managers discuss processes that resemble dynamic capabilities that were particularly focussed on Sensing and Delineating the Customer Solution and Business Model. The firm appears to express capabilities consistently from across the framework.

Table 27: HighRes3: Dynamic Capabilities Heat Map

\section{Sensing}

Processes to Direct Internal R\&D

Processes to Tap Exogenous Science \& Technology

Processes to Tap Supplier and Complementor Innovations

Processes to Identify Target Market Segments, Changing Customer Needs and Customer Innovation

\begin{tabular}{c}
$\begin{array}{c}\% \text { of total } \\
\text { References }\end{array}$ \\
9.7 \\
14.3 \\
\hline 3.1 \\
\hline 11.1
\end{tabular}


Table 27: HighRes3 Dynamic Capabilities Heat Map Continued

\section{Seizing}

$\%$ of total

References

\section{Delineating the Customer Solution \& Business Model}

Selecting the Technology \& Product Architecture

Selecting Revenue Architectures

Selecting Target Customers

Designing Mechanisms to Capture Value

Selecting Enterprise Boundaries to manage

Complements \& Control Platforms

Calibrating Asset Specificity

Controlling Bottleneck Assets

Assessing Asset Appropriability

\section{Reorganising Managing \& Capturing Cospecialisation} Economies

Reorganising Managing \& Capturing Cospecialisation Economies

\section{Selecting Decision Making Protocols}

Recognising Inflexion Points

Avoiding Decision Errors \& Anticannibalisation Proclivities

\section{Building Loyalty \& Commitment}

Demonstrating Leadership

Effectively Communicating

Recognising Non-economic Factors 
Table 27: HighRes3 Dynamic Capabilities Heat Map Continued

\section{Transformation}

\section{Decentralisation}

Adopting Loosely Coupled Structures

Embracing Open Innovation

Developing Integration and Coordination Skills

Cospecialisation

Managing Strategic Fit so that Asset Combinations are Value Enhancing

\section{Governance}

Achieving Incentive Alignment

Minimising Agency Issues

Checking Strategic Malfeasance

Blocking Rent Dissipation

\section{Knowledge Management}

Learning

Knowledge Transfer

Knowhow Integration

Achieving Intellectual Property Protection

6.1

0.0
$\%$ of total

References

7.1

13.2

0.0

3.8

5.6

10.5

12.5

4.5 


\title{
4.6 Case Study: HighRes4
}

Interviews: 3 (CEO, Financial Controller, Production Manager)

HighRes4 was founded in the early 2000s from the remnants of an unprofitable iteration of a similar firm. The firm is a contract $R \& D$ provider and manufacturer focusing on animal health. Strong growth was curtailed heavily during the GFC and the firm had to take significant steps to remain viable. However, the strategies enacted have returned the firm to a strong growth trajectory.

\subsubsection{Sensing}

\begin{abstract}
Processes to Direct Internal R\&D
'Basically part of that strategic plan - one of the significant outcomes - is to have two R\&D groups if you like. One R\&D group is actually technical people; the other R\&D group is business people. Because the technical people, because we are busy inventing all sorts of things, I can invent 10 things a day, but so what, what do you do with it? So what we are looking to do is we have an R\&D group which has the science part of it and an R\&D group that has the business part of it, and it's very very important to have that.' CEO
\end{abstract}

'There are 55 scientists here; we want to double that.' CEO

HighRes4 have a structured approach to R\&D that emphasises first discovery and then commercialisation of those potential products. While the firm provides contract R\&D services to client organisations, they have also begun blue skies research processes to develop their own intellectual property, with a focus on bringing potentially lucrative discoveries to market. The CEO considers that commercialisation of sciences is a crucial, but lacking aspect, of business. The managers of the firm suggest they have invested and plan to continue investing in R\&D capacity to continue to grow this capability. 


\section{Processes to Tap Exogenous Science \& Technology}

'And we also have another three scientists working out of [City] University doing R\&D in market for us.' Financial Controller

'We don't end up solely managing the development of their products and different customers get involved in various degrees. We've got one client who's based here for six months. They had four people based here working through their program of a product that we're launching in [Region] in April so they were very hands on involved.' Financial Controller

'Then the other side is, well ok, at the moment we are using 3rd party experience to guide the blue sky development, which is the IP development. And the idea there is to say - look, rather than wait for somebody to come to us, let's look at all the different clients and see what gaps they have in their product portfolio, because each client has got a different emphasis, which is really interesting.' Financial Controller

HighRes4's business model is strongly integrated with developments in external science and technology. Their contract R\&D business utilises input from their client organisations, which due to their own individual focuses provides a breadth and depth of opportunity to explore developments. These avenues of access to information drive the firm's development processes in its own blue-sky research. The sources of external science and technology also extend to research institutes such as universities, with which the firm has formal research arrangements.

\section{Processes to Tap Supplier and Complementor Innovations}

'...these guys will then do a market assessment, bring in people from the industry and basically put together a case for them to take to this stage here, which is us. So we will do the R\&D and the manufacturing, so R\&D, R\&D and manufacturer, and then it goes over to the client who does the marketing.' CEO

The firm is heavily integrated with its suppliers and complementors, which includes its customers, who are integrated into the discovery and R\&D process. HighRes 4 acts as the outsourced R\&D and manufacturing divisions of client firms and as such, their clients become both supplier and complementors to HighRes4 and vice versa. 

do clients have need in their portfolio, which markets have growth opportunity in what products we specialised in. Financial Controller

The firm utilises a number of capabilities in this area. HighRes4 noticed a reduction in demand for its products during the GFC precipitated by its customers own financial difficulties. The firm takes a proactive approach to identifying its target segments and changing customer needs. That is, by looking at the gaps in potential client's portfolios and matching market growth and needs to a solution they can offer.

\subsubsection{Seizing}

\subsubsection{Delineating the Customer Solution \& Business Model}

\section{Selecting the Technology \& Product Architecture}

'It's a contract company to a large extent, so it's contract manufacturing and contract R\&D, all animal health, and on the whole, we don't own what we develop, on the whole. We develop a few platform technologies but we have no sales force. It's business to business. That's the model and mostly we don't own what we develop.' Production Manager

'So this is a - I guess a platform technology that we've developed and we are now extending into larger devices for different species. We are looking to take that into [Region].' CEO

As a contract research and manufacturer the firm often does not own the intellectual property they create on behalf of clients. However, HighRes4 has recently begun developing a small number of platform technologies and products. This allows them to extend the products into new areas and species cost effectively. HighRes4 approaches product platform development based on the likely requirements of a potential client. The platform can then be adapted depending on the client's specific needs. This serves to leverage the platform effectively across a range of applications multiplying the return on investment. 


\section{Selecting Revenue Architectures}

'So the idea is to have the fee for service and that brings in about [Dollars] a year in terms of revenue, and that's very high margins, half of it's profit, because it's very fickle. Manufacturing we are doing about [Range of Dollars] and that's about $15-20 \%$ margin if you're lucky. It goes up and down. So if you look at it the research side of the business contributes as much profit as the manufacturing side with far less utilisation of capital, and staff, and resource.' CEO

'We're trying to diversify our revenue sources, not just manufacturing but IP revenues and research revenues and clinical revenues. It's a multi level strategy of diversification.' Financial Controller

The respondents refer to revenue from two streams - contract research and contract manufacturing. The firm's research activities provide significant margin, while the manufacturing less so, however, the respondents refer to it being an essential part of the firm's value proposition for clients. The firm's strong capabilities to transition from research to manufacture has the effect of locking customers into the full range of services due to the likely cost of changing provider mid process.

During the GFC the firm sought to diversify the geographic distribution of its revenue due to the seasonality of its revenue streams. By targeting diverse geographies, the firm smoothed out not only the cyclicality of seasonal revenue, but also distributed the risk of environmental interference such as drought on the firms (customers) target customers - farmers.

\section{Selecting Target Customers}

'the idea there is to say - look, rather than wait for somebody to come to us, let's look at all the different clients and see what gaps they have in their product portfolio.' CEO

'They're still saying $5 \%, 6 \%$ growth in animal [Health].... [Region] is growing massively in terms of animal numbers...[Region] and [Region] are having trouble with resistivity and parasites so they're looking at new treatments to try and... the companion animal market's going through the roof.' Financial Controller

'I see the key as diversification. We used to be pretty dependent on weather in [Country] and New Zealand. So let's diversify and be dependent on weather in [Regions].' Financial Controller 
The CEO and Financial Controller outline a number of ways the firm selects clients and customers. The Financial Controller describes how the firm segments geographically, targeting countries and regions with specific features - growth in animal numbers or difficulties with disease and parasite resistivity. Their selection of clients and customers is also driven by the broad product category that the firm wishes to enter. The firm is looking to extend its product offering into companion animals, a market it sees as having significant growth potential. This was to create new target segments of both client organisations and end users.

\section{Designing Mechanisms to Capture Value}

'So the key thing is smart. And that raises pretty much every aspect of what we do, not just R\&D but also being smarter in manufacturing and smarter in ordering, smarter in negotiating contracts, the whole range.' Financial Controller

'We just jumped on a plane and visited the manufacturer and said ok, well why can't we just buy it from you. And well we did that, and guess what, the people in the supply in New Zealand are clipping us a million dollars for actually no service at all... So through delving into what goes on behind the scenes, we've actually been able to improve the cost of goods, but also not having the extra loop in the supply chain helps as well.' CEO

'The productivity base line is that which we put into our quotations, so if we start negatively impacting productivity through bad planning we start losing money. So you know we don't have glorious margins in manufacturing, so very very key, so planning is really important.' CEO

'So what we are trying to do is work out ways we can actually measure better.... We can actually tell what the margin is for that based on what we predict, and we have a feedback loop showing us what it actually is once we've made it.' CEO

The Financial Controller and the CEO describe the firm's approach to capturing value from their manufacturing operation. They suggest that having a capital intensive, high quality facility for manufacturing they aim to produce in high volumes at low margins. As such, the Financial Controller suggests they are careful in how they order, negotiate and manufacture. The CEO describes their focus on planning, which they see as the key to productivity. The CEO also describes how they monitor, at significant expense, the predicted versus actual margin achieved on manufacturing. 
The CEO also describes how the firm sought to move to purchasing direct from the manufacturers of materials. During a sourcing exercise, the firm identified that the local suppliers were marking up their products significantly for very little service. They have saved both time and money by removing these links from the value chain.

\subsubsection{Selecting Enterprise Boundaries to Manage Complements \& Control Platforms}

\section{Calibrating Asset Specificity}

'So buying the business was critical from two points of view, one: it was aligned to us because it was part of the value chain so we would invent and test, manufacturing would make, marketing would sell so it was quite an important part of the value bucket thing' CEO

'The interesting thing is [HighRes4] is highly vertically integrated if you look at the whole process from invention through to market, we do everything but discovery of the white powder - digging it out of the ground or whatever. We don't do the marketing but we do everything in between. So we are highly vertically integrated and that kind of been a long-term play.' CEO

The firm is highly vertically integrated according to the CEO. Prior to the GFC the firm purchased another firm, a [Country 2] based company to augment its offering in that market. The CEO sees the integration of the firm as long-term strategy.

\section{Controlling Bottleneck Assets}

'We've only just had the capacity. This time we've spent trying to fill up. We're now full. Then you go, 'Once you're full what do you do?' We're going to put some more capacity on, we're looking to buy capacity in [Country 2] but also we must have productivity gains if it can be generated. If you're not looking for them, you won't find them.' Financial Controller

'We have actually this year increased our capacity a lot. Actually, not capacity - we've increased our throughput a lot so there's been a lot more manufacturing work than there was last year.' CEO

The Financial Controller describes how the firm has struggled with limits to manufacturing capacity. The solution has been to improve productivity in New Zealand and to buy extra capacity on demand internationally. The firm's manufacturing business is structurally high cost and capital intensive, as the 
company was cash-strapped during the GFC, outsourcing enables the firm to dynamically scale the capacity of manufacturing.

\section{Assessing Asset Appropriability}

'Having the brains and the manufacturing is also an advantage in that transferring products from development into manufacturing is a very risky process but because we understand how it's developed; we can transfer it to manufacturing. A lot of companies have failed. There are a bunch of things but that's why I call us a research company and not a manufacturing company. I think it's about the smarts.' Financial Controller

Animal health plants that l've visited in [Country 2] are down here where they're not much more than a shed with people shovelling stuff into vats and drums. HighRes 4 in my view sits between the two standards [Of Human and Animal Health]. I haven't come across anything that's comparable. CEO

The CEO describes how the firm's facilities are closer to human health standard than a typical animal health operation. Because the asset base is already in place, it would be very costly for competitors to imitate the high standards of quality control, precision and cleanliness that HighRes4 offers its client organisations. Relatedly, the firm is highly skilled and experienced at transitioning an innovation though the stages of development and into manufacturing. The Financial Controller suggests the firm understands that this is an intangible advantage.

\section{Recognising Inflexion Points}

'Basically just a drop off in orders... Customers in [Country 3] stopped buying...' Financial Controller

'When the banks freaked out, because before the crisis we were growing quickly and we didn't have an understanding that you need to have of the business to survive hard times. We sailed into the crisis drinking Chardonnay basically and wondered why the hell the banks buggered off and the lots of horrific things were happening.' CEO

'These [Country 3] customers started going, 'Returns are down. We can't afford that,' so they stopped ordering. And at the same time the corporates had started unloading their inventories so bang: stopped ordering. Then they order slower because the demand was lower.' Financial Controller

The firm shows evidence of at least two means of identifying inflexion points. The Financial Controller describes a drop-off in orders as a signal that the market was 
entering a period of depressed demand. The CEO suggests that it took him a long time to recognise the signs of the same decline. However, the the availability of finance was main indicator that the economy was contracting.

\section{Avoiding Decision Errors \& Anticannibalisation Proclivities}

'I doubted my gut instinct for a short period of time and made some stupid decisions. So it's all very well to have a new person but if they tell you something that you know is not right tell them to get stuffed. Because I have hired a couple of people who have been absolutely freaking disasters and I sort of knew they would be but I did it anyway... I think the key thing was that I was doubting my gut instinct which was understandable because you went headlong into a crisis and didn't know what was coming.' CEO

'The team leader will then introduce the idea to myself, for example, and then it's assessing that based on: will it still meet our compliance needs? what are the positives in it? And then taking that through the approval process, which involves our own quality group. And if it impacts on a client then obviously client QA group also gets involved in those decisions.' Production Manager

'Well I suppose because it's contract R\&D you're working with the client so that at the end of the day the decision is made by the client. And you come up with the scope for the project, milestones - and as you reach each one you are reporting back to the client and depending on the outcome of that result as to when...the direction you take is decided between you and the owner of the project.' Production Manager

The CEO describes how during the GFC he made several decision errors, in particular around personnel. He suggests that rather than following instinct, he allowed himself to be pressured by outside influences. This suggests that the firm did not have strong capabilities to guide these decisions during the crisis. However, others within the firm discuss how decision processes are structured around a number of criteria including compliance, scope and milestones. The influence of clients is also factored into the decision making process. The suggestion is that at the strategic level, decisions may not be made based on structured thinking or decision rules, but at the operational level they may well be. 


\subsubsection{Building Loyalty and Commitment}

\section{Demonstrating Leadership}

'The dynamic leadership we have. It's a hard one to describe; the leadership that we've got has just been absolutely unbelievable. You feel like you do want to come back here tomorrow. And you can be having the hardest day ever - they make you actually feel as though you're a part of this anyway, even though there's no real financial gain or benefit for the rest of us they make you feel part of the whole company. And I think too that it's the loyalty behind everyone; everyone is so loyal.' Production Manager

'So becoming a leader would be a way of surviving. It was sort of significant that the new Chairman I got on board was really into this. He's quite a high-powered sort of character but he is a real scrapper - he's a [Customer] so he had a real passion for the business. But my strategy always was, "believe in the company and they won't let you down."' CEO

The CEO suggests the appointment of a new chairman to the board inspired and encouraged him to be a stronger leader during the crisis. The Production Manager suggests that the firm's leadership is dynamic and motivational during difficult times and that this has contributed to creating the strong loyalty within the firm.

\section{Effectively Communicating}

'It's building relationships with those multinationals' CEO

'.... That's the sort of thing that's been introduced to increase the level of communication here because you're getting to a certain size now where you just can't get around to everyone.' CEO

Managers in HighRes4 were aware that the standard of communication was poor prior to the GFC. However, efforts to increase the quality and volume of communication were successful and demonstrate the dynamic capability to effectively communicate. Relationships between the firm and their clients were also important to build and maintain due to the close integration between the firms. 


\section{Recognising Non-economic Factors}

'.. but also we are trying to build credibility with these multinationals whereby the innovations group is seen to be doing some pretty meaningful stuff and just get that credibility up because that helps maintain manufacturing relationships' CEO

'And just creating a team environment everywhere. Everyone works together, everyone thinks about everyone else, thinks about the company, and wants to.... I mean I would like to see a culture where everyone wants to see [HighRes4] be successful.' CEO

The CEO suggests that the firm has put significant efforts into building relationships with client organisations and creating credibility around their innovation efforts. This credibility in R\&D and innovation is then attributable to the manufacturing business. Interviewed managers also refer to culture as an area of importance in the creation of high performing individuals and teams, as well as in the creation of loyalty. Maintenance of the firm's positive culture is a focus for managers.

\subsubsection{Transformation}

\subsubsection{Decentralisation}

\section{Adopting Loosely Coupled Structures}

['HighRes4] then acquired [Subsidiary], which is a clinical research business in the [Country 2] to give themselves a [Country 2] platform and capability.' Financial Controller

'Basically it's important to understand that unlike other companies, we are a contract manufacturer and a contract researcher, so we don't market our own manufactured goods, ok? So we therefore rely on the marketing capabilities of our clients.' CEO

The firm acquired their [Country 2] business to provide a platform an entry point to that market. The geographic proximity of the subsidiary improves market access to the firm's largest geographic sales region, while also forming a distinct link in the value chain that increases the vertical integration of the conglomerate. 
HighRes4's business model is to become highly integrated with their clients throughout the process of development and manufacturing. Managers describe how the firm relies on its clients to discover the initial potential treatment and then to market the products that are co-developed by the two firms. In a sense HighRes4 adopts loosely coupled, impermanent or semi-permanent structures around a particular project with the client firm bookending HighRes4 by providing discovery and marketing, while HighRes4 itself performs R\&D, commercialisation and manufacturing. This structure disassembles upon completion of the project, but may continue for an indefinite time in the manufacturing stage.

\section{Embracing Open Innovation}

'We now have the capacity to go end to end in terms of the research offering. So once someone's come up with an idea, we don't create the molecules, once you get a molecule to commercialisation we can do end to end and that's opened up a new market for us and companies that are virtual drug companies, of which there are a number, continue to grow.' Financial Controller,

'We don't end up solely managing the development of their products and different customers get involved in various degrees.... We have other clients who are virtual clients who basically send across their molecules and specs. We're differently involved with clients on those innovations so if you come up with a new idea or a problem that you have to solve the client's going to be involved.' Financial Controller

By nature, HighRes4 engages in consistent, bidirectional open innovation. The firm has innovations flow across its boundaries from client organisations as discovered molecules and potential treatments, while HighRes4 passes those innovations back to client organisations as commercialised products with the respective IP accruing to those firms. The extent of external involvement in the various phases of development varies between the firm's clients. This enables a number of clients to remain 'virtual' companies that outsource all but their own core functions to HighRes4. 


\section{Developing Integration and Coordination Skills}

'And we're trying to work out how to integrate that company with what we've got here because they think of themselves as a completely different entity. They don't even think about [HighRes4]' CEO

'So it looks like there's going to be a fair bit of growth within that [Subsidiary] company and what we're looking at is how we integrate that so it's an end to end R\&D service because what that company offers is part of the R\&D continuum. What [HighRes4] offers is another piece of the R\&D continuum.' Production Manager

'So buying the business was critical from two points of view, one: it was aligned to us because it was part of the value chain so we would invent and test, manufacturing would make, marketing would sell, so it was quite an important part of the value bucket thing.' CEO,

Purchasing the [Country 2] business is likely evidence of the firm developing integration and coordination capabilities. The aim for the acquisition was to integrate clinical trialling services into the value chain. By assimilating the acquired firm into the set of activities, the firm was able to create a more integrated offering that was designed to be seamless from a customer's perspective, but leveraged the particular capabilities of each profit centre. Managers discuss the level of effort that the (parent) firm is putting into ensuring the integration of the subsidiary is consistent with their plan for a highly integrated offering.

\subsubsection{Cospecialisation}

\section{Managing Strategic Fit so that Asset Combinations are Value Enhancing \\ 'I think it [Key driver of success] was having research combined with manufacturing was critical - that is, really critical because if you have any issues we can assist you with troubleshooting so the whole combination of research and manufacturing.... So once you invent something almost always, in fact absolutely always, we end up being the manufacturer of the product.' CEO}

'So we have a large project at the moment on behalf of a [Country 2] based multinational. They have a really big $R \& D$ department, but this is over and above their capacity so they outsourced the whole project to us. The other kind of company that we work for are these almost virtual companies that have no facilities. They outsource everything and we are their R\&D engine.' Product Manager

So they do that in [Country 2\}, we have a tender into [Region] where we have a single person operating, it is actually a conduit to bring business back to [Country 2], so we sort of have relationships like that with key individuals in certain areas. CEO 
HighRes 4 appeared to be active in managing the fit of its assets to create value during the GFC. In particular, the firm was ensuring that it created a diverse and highly vertically integrated product offering including research, development, clinical trialling and manufacturing service. By acquiring an international subsidiary that provided a stronger presence in a key market and added another stage in the value chain, the firm has created a pipeline that is difficult or undesirable for clients to extricate themselves in order to transition to another provider for various stages of the process. This pipeline was leveraged by the firm in the development of their own platform technologies that can be extended and adapted for various applications. By using the firm's capabilities in research, development, clinical trialling and manufacturing, the firm captures value from every aspect of the development and sale of the product, instead of foregoing the intellectual property rights to its clients, as in its typical business model.

\subsubsection{Governance}

\section{Minimising Agency Issues AND Checking Strategic Malfeasance AND Blocking Rent Dissipation}

'I fired the board and started from scratch. I hired a new chairman who is bloody awesome and is still here today. I've made him a shareholder as a reward for his efforts but he sort of taught me... he taught me how much fun the whole financial side of things could be.' CEO,

'Yes, we changed the board. Understanding that there is actually a purpose for a board, but having a board to me was a pain in the neck... we had to beg on the bloody board. So it's really good so we changed our entire board aside from myself.' CEO

'We didn't have a good fix on the consequences of [The GFC], so I fired my best friend, my financial controller couldn't breathe. So I fired the board and started from scratch'. CEO

The good thing about the financial crisis to me was the bank just disappeared. They didn't want to know, because if they were at a board meeting and the company was failing it looks bad on their CV.' CEO

When the GFC's effects became apparent to the firm, those impacts were, according to the CEO, swift and particularly stressful and difficult to navigate for the firm's executive and governance. This led to conflict with their governance board, which constrained the CEO's options during the crisis. In order to minimise these agency 
issues the CEO, as a significant shareholder, removed the entire board of directors with the exception of himself replacing them with a new, handpicked, higher performing, and better experienced governance body. This removed the coalition that was constraining management options but also provided an opportunity to rationalise the incentives the Board of Directors was offered, with more Directors being allocated shares, in order to closer tie firm performance to remuneration. Removing the financiers from the Board also reduced the restrictions on management actions by removing a particularly conservative element from decision making.

\subsubsection{Knowledge Management}

\section{Learning}

'...so yeah essentially it was actually quite good as a training day for the company and now I think we can face anything. One of our clients... we sold some IP to them and they claim that we sold it for too much and they paid too much money, and I said, "Well you put the price on it, we put it out for tender you moron." and they said, "That's true but our capitalisation is quarter of a trillion, we will just sit on you until you stop breathing and you will die. I will pick up your company for stuff all." So these are the learnings you get which are fascinating.' CEO

'....all I did was I just listened and got mentored by some really really clever people and learnt a whole lot about, what - and basically how - you are supposed to do biotech.' CEO

'...so survival was the key driver, it wasn't in the least bit humorous or fun, it was quite awful so it was a great learning experience.' CEO

Learning a particularly experiential process in HighRes4. By facing the hasher realities of the GFC including financial difficulties and duplicitous behaviour of other actors, the managers suggest they learned particularly strong political lessons about how to navigate difficult operating environments.

The firm is also particularly active in learning as a process of technological development. The significant R\&D component of the business was focused on creating not only products for clients but also the development of extensible platforms the firm can retain ownership from. The firm's business model relies on the ability of the R\&D process to transition products from early development stages 
through to manufacturing and as such the firm has learned how to perform these activities but also how to ensure the process is run efficiently.

\begin{abstract}
Knowledge Transfer And Knowhow Integration
'...but essentially there is... a lot of knowledge on how to do things and when we first started, this knowledge was used poorly in the sense that they keep on changing things all the bloody time because they will find better ways to do it... if you have an idea, there's a process by which it can be assimilated but you can't just make the change.' CEO

'The majority of the R\&D work we do for third party clients. So they have an idea and they need that idea transformed into a commercial product, and we can take it from [HighRes4] to commercialisation.' Financial Controller

'That's what we do is commercialise ideas... [We are] Very very good at that and can do it probably faster than anybody else to the standards required. So we really understand what the standards are to the different markets around the world, we've got well across that.' CEO

'Well the key resource is the people's expertise. We have a management team of 7 people, 5 of which have over 2 decades' experience working in [Country 2] and [Region], and the reason for that is because New Zealanders don't have the experience required to service those markets in pharmaceuticals, and they've never worked there. So these are New Zealanders...[who] brought a lot of expertise.... So we need people that have actually done it in our client organisations to that very high standard, and we've actually imported them.' CEO
\end{abstract}

The firm has shown evidence for knowledge transfer capabilities in a number of ways. The Financial Controller described the firm's capability to develop an idea into a commercial product, requiring the transition of knowledge of the particular project details. This transition of new knowledge occurs across the value chain and is performed consistently as part of the business model. The Financial Controller suggested that the expertise inherent in the firm's personnel contributes to the firm's ability to deliver the newly developed product to each stage of the value chain.

The firm has been particularly active in recruiting internationally experienced talent. This has included a number of individuals whose experience gives the firm insight into how client organisations function. The firm has 'imported' employees with the appropriate knowledge in order to integrate those capabilities into the business. 


\section{Achieving Intellectual Property Protection}

'...so we've always got this IP and knowledge and know-how, so from a company value type thing that's kind of what we're trying to do is drive the value of the business through having our own IP and retaining it.' CEO

The CEO describes how the firm has sought to build a portfolio of intellectual property. During the company's early days, the focus was on developing on behalf of clients. This relieved the firm of the responsibility of defending intellectual property, while still retaining a portion of its value - though the fees paid for its initial development and for manufacturing products, which may have been ongoing. The responsibility for defending the intellectual property would ultimately fall to the owner and client firm.

However, as revenues increased, the firm was able to provide some resource to focus on the development of its own intellectual property. This is based on platforms that the firm considers high opportunities and has placed legal protection around.

\subsubsection{Case Summary HighRes4}

HighRes4 found itself significantly affected by the GFC. Its response was multifaceted; encompassing developments to the business model, revenue, and governance structures of the firm. By focusing on creating diversity in its portfolio of R\&D activities, markets, customers and products, the firm smoothed seasonal and geographic cyclicality of revenue. By building a stable of proprietary products (instead of its typical approach of developing and manufacturing on behalf), the firm captured more of the margin of the sale of the final product.

The firm also deepened its integration in the value chain and looked to both literally and figuratively position itself closer to customers by acquiring a client-facing subsidiary. Therefore, capturing more of the value of the process of development, commercialisation and manufacture and improving market access. This also enabled 
the firm to integrate more closely with organisations, including their client firms to enable the free transfer of knowledge across organisational boundaries.

Governance changes were sweeping and significant, including removing underperforming members of both the Board of Directors and the executive team. More seasoned and qualified replacements supplanted the exiting individuals. The firm also actively recruited highly experienced international talent to ensure the firm is internationally competitive.

Table 28 shows the capabilities the firm managers discussed. While the firm appears to show lower scores for Cospecialisation (both Seizing and Transformation), and Decentralisation capabilities, it otherwise displays dynamic capabilities from across the framework. The firm's managers often discuss processes that are consistent with Sensing, Delineating the Customer Solution and Business Model, and Selecting Enterprise Boundaries to Manage Complements and Control Platforms capabilities.

Table 28: HighRes4: Dynamic Capabilities Heat Map

\section{Sensing}

Processes to Direct Internal R\&D

Processes to Tap Exogenous Science \& Technology

Processes to Tap Supplier and Complementor Innovations

Processes to Identify Target Market Segments, Changing Customer Needs and Customer Innovation
$\%$ of total References

16.1

4.8

12.5

8.3 
Table 29: HighRes4: Dynamic Capabilities Heat Map Continued

Seizing

$\%$ of total

References

\section{Delineating the Customer Solution \& Business Model}

Selecting the Technology \& Product Architecture

Selecting Revenue Architectures

8.5

Selecting Target Customers

5.7

Designing Mechanisms to Capture Value

7.7

Selecting Enterprise Boundaries to manage

Complements \& Control Platforms

Calibrating Asset Specificity

Controlling Bottleneck Assets

4.5

Assessing Asset Appropriability

Table 28: HighRes4 Dynamic Capabilities Heat Map Continued

\section{Reorganising Managing \& Capturing Cospecialisation Economies}

Reorganising Managing \& Capturing Cospecialisation Economies

\section{Selecting Decision Making Protocols}

Recognising Inflexion Points

Avoiding Decision Errors \& Anticannibalisation Proclivities

\section{Building Loyalty \& Commitment}

Demonstrating Leadership

Effectively Communicating

Recognising Non-economic Factors

9.1 
Table 30: HighRes4: Dynamic Capabilities Heat Map Continued

\section{Transformation}

$\%$ of total

References

\section{Decentralisation}

Adopting Loosely Coupled Structures

Embracing Open Innovation

Developing Integration and Coordination Skills

\section{Cospecialisation}

Managing Strategic Fit so that Asset Combinations are Value Enhancing

\section{Governance}

Achieving Incentive Alignment

Minimising Agency Issues

Checking Strategic Malfeasance

Blocking Rent Dissipation

Table 28: HighRes4 Dynamic Capabilities Heat Map Continued

\section{Knowledge Management}

Learning

Knowledge Transfer

Knowhow Integration

Achieving Intellectual Property Protection 


\subsection{Amalgamated Case Study - Remaining Firms}

While the four preceding case studies offer significant and unique insight regarding the type and effectiveness of different resilience strategies, the thirteen remaining cases were also valuable, comprising a number of resilient and less resilient firms, but also the full set of moderating firms that scored in the middle of the resilience scale. As such, they have been summarised here as an amalgamated case record that highlights the particularly interesting evidence for dynamic capabilities these firms expressed during the GFC as part of these strategies. The evidence selected for representation shows the breadth of these capabilities. While the aim of this combined case is to identify the dynamic capabilities of firms in the study, the reason for inclusion in this manner is to highlight relevant data, retain its richness and ensure the transparency in communication of the data.

\subsubsection{Sensing}

\section{Processes to Direct Internal R\&D}

'That's how [MidRes7] differentiates itself in the market, that's one of its key strategies to go forward is to use innovation and R\&D to develop new products to maintain shareholder value.' Operations Manager MidRes7

'We have a group, part of our R\&D team, who actually focused on the ' $R$ ' science, so the technology group, and their job is to investigate new technologies that may be relevant to us to a point where they're de-risked such that we could pick them up and use them in a development.' CEO MidRes9

'Our R\&D spend has been in between ten and twelve percent of revenue compared to the average New Zealand company which is about zero. But in my view you cannot create margin without innovation - it's impossible.' CEO HighRes2

'So I will try and create a product that delivers all of that functionality and value of that stuff but it's still going to be different and has to be different otherwise it's just a "me too" product.' Head Designer MidRes1

'So we make products and we have this overriding idea for our business... we make one product and it replaces three or four others in the market.' Managing Director MidRes1

These dynamic capabilities were expressed by firms in a number of ways. Certain firms looked to invest more in R\&D in order to create new technologies, while others 
utilised existing resources but looked to extend efforts into new areas of application, markets and customers in pursuit of new streams of revenue.

Managers in a number of firms describe how during the GFC, those firms sought to improve on technologies and products offered by other firms. A number of firms looked to improve products already offered by the market. Another driver of R\&D described by managers was the need to address the needs of customers. While a number of firms sought to improve on offerings from other firms, MidRes7 worked to improve on the technologies its parent company offered, but was forced to pay for, due to the requirements of an intra-organisational economy. The firm sought then to develop its own technology that it could in turn offer to its parent.

Managers interviewed in MidRes7, HighRes2 and MidRes2 discussed directing their $R \& D$ processes into creating efficiencies. The managing director from HighRes2 describes how efforts to develop margin through innovation was a focus at the company. MidRes7 and MidRes2 sought to develop manufacturing processes to increase the efficiency of output.

MidRes6's managers describe how the firm sought to alleviate constraints to their business through R\&D in at least two ways. Firstly, when the firm did not have the required facilities to mass-produce a product, they circumvented this need by developing a product that did not require the missing equipment. In the second instance, the firm sought to smooth the cyclicality of their revenue by creating a product that would appeal to consumers during summer months.

MidRes1's process of development appears to be guided by the firm's strongly held values. When approaching the development of products, the Head Designer describes how espoused values such as durability, quality, and the necessity that a 
product combined several other products into one were all driving factors when engaging in development activities.

One of the managers interviewed at MidRes 9 describes how the firm focuses its R\&D efforts on replacing an aging technology platform at risk of obsolescence. The firm actively develops potential technologies, but also works to ensure they are sufficiently de-risked before pursuing their commercialisation.

\section{Processes to tap developments in exogenous science and technology}

'Well I've given a project to [Research Institute] to help coming up with a new [Product].' General Manager MidRes5,

'We identified some technology that [Research Institute\} had developed with [University]. They were getting really good clinical results but it was sitting on the shelf and it was not doing much and we decided we should take it up and try to promotionalise [sic] it.' CEO LowRes3

'Well, we have a close relationship with a number of [External Companies] and so we say, 'We're trying to develop this product' and send them whatever we want and they come up with flavours and so on. We do have a close relationship with them'. Co-owner. MidRes6

'This new product is a partnership with a [Food] company from the UK - they collect their used containers and we recycle those and turn them into our products which are made from recycled plastic.' Head Designer MidRes1

'Our [Country 3] strategy is in their utility sector, we're involved with an interoperability and comarketing arrangement with [Company].' CFO MidRes8

A number of firms show evidence for having utilised external search processes to sense for technologies and opportunities in their business ecosystem. In particular, firms appear to have formed mutually beneficial engagements with both public and private organisations. The firms that engaged with public institutions (MidRes5 and LowRes3) utilised the same one - a publicly owned manufacturing research institution. This organisation was effectively used to buy in capability and capacity to develop defined products and technologies. 
The private partnerships for both MidRes1 and MidRes8 appeared to be mutually beneficial for both partnering firms. MidRes1's arrangement with a related firm was to recycle post-consumer products and repurposing them as production materials. MidRes8 integrated with a software provider operating in the same market. By improving the interoperability of their products, the selling proposition to customers was augmented.

\section{Processes to Tap Supplier and Complementor Innovations}

'Yeah. Well, we have a close relationship with a number of flavour houses and so we say, "We're trying to develop this product." and send them whatever we want and they come up with flavours, and so on. We do have a close relationship with them.' Owner MidRes6

'l've got a distributor in [Country] and one in [Country], and [l'm] trying to set somebody up in the Philippines and Indonesia, all emerging markets in our sector... [Country] has just brought their first lot of standards in which are similar to ours [In New Zealand] at a lower level so our products fit comfortably there.' CEO MidRes3

'We're going to bring all our suppliers in and... say, "This is what we're doing. Is there anything we're not doing that we need to be doing that you can help us with to make this better?" Our suppliers get involved generally right at the outset. 'This is what we're thinking of: How can we do this?' CEO MidRes3

'With our partners both on the supply and customer ends we have an intention to be very close to them. But we don't really engage with them around that innovation.' Managing Director MidRes1

Comparatively few firms display evidence for processes that look to tap supplier and complementor innovation(s). Instead, there are an equal number of firms that either avoid, or show no interest in engaging with suppliers and complementors for the purposes of innovation. This is most apparent in low and middling resilience firms including LowRes2, LowRes3, and LowRes4.

MidRes3 utilised two forms of process to tap supplier and complementor innovations. The firm had entered into a new geographic market following changes in legislation, which made the use of the firm's category of products a requirement for potential customers. In other instances, the firm has leveraged close relationships with its suppliers to obtain help in the development of new products. 
Counterfactually, MidRes2 actively supresses engaging with suppliers when researching and developing products. The managing director describes how in his experience when suppliers are involved they will inflate prices to exploit the opportunity. MidRes1's managers describe how they do not have any particular motivation to engage with suppliers or others regarding innovation.

\section{Processes to Identify Target Market Segments, Changing Customer Needs and Customer} Innovation

'What they're finding in the market, which is one of our bigger challenges too, is that the customer is demanding not only more colours but also smaller runs.' CFO MidRes7

'That forced us to go through a process of learning and understanding some of the research around not just the end user but others in the value chain back from them - between us and the end user and we could understand the things that might distort or pervert the natural flow of innovation or things like that.' CEO MidRes9,

'Then on the other side of things with our customers...if we can develop a close relationship with them, then we can not only give them what they want, but refine it and they can give us ideas in how we could actually improve the product.' Co-owner MidRes6

'But it's not always about new products. It is often about new techniques that you can use on your existing gear so that anything that enables a customer to innovate or the customer to incorporate into designs.' Managing Director LowRes2

A number of firms describe having strong relationships with customers or other intermediaries that provide them a conduit to enable understanding of how user needs are developing. LowRes3 is active in understanding the customer's journey through the medical system and targets them where the firm's intervention is needed. MidRes6 courts close relationships with its retail customers in order to gather feedback about how their products are being consumed. 


\title{
4.7.2 Seizing
}

\section{Delineating the Customer Solution and Business Model}

\author{
Selecting the Technology and Product Architecture \\ 'Since [MidRes7], starting to expand into areas that don't involve [Firm's Traditional Product] .... \\ different formats on the same concept. [Products] that are generally a little more high-tech...we're \\ dealing with products that are multi layered, have ...features and have features that people start to \\ recognise as important on packaging.' CFO MidRes7
}

'...we've been going through a lot of redevelopment, with consideration to platforms, to make the product a better product for our customers but also much cheaper and easier to maintain down the track.' CFO MidRes9

'We are adding high-tech manufacturing to the [Industry].' MD MidRes2

'We identified some technology that [Research Institute] had developed with [University]. They were getting really good clinical results but it was sitting on the shelf and it was not doing much and we decided we should take it up and try to promotionalise [sic] it. CEO LowRes3

'The changes to the strategy was to be more focused on these innovative drugs that are being developed with more recent patents being applied.' Head Designer HighRes2

'It's where our timing has been right with partnering with these companies, as they have bought new science into drugs and we have provided, not just a traditional delivery device, but something quite innovative.' Head Designer HighRes2

'We have gone from a company making proprietary products just the same as everybody else to really developing solutions for our major customers.' Managing Director HighRes2

'We believe in buying quality for the long-term, and so when we came through with this product, we were conscious that our brand needed to express these values, that we believed was going to be really important in a recession, that of anti-consumption.... And we wanted something that lasts and continues, and might even be there for the next generation, and we wanted to express that value in a recessionary environment.' Managing Director MidRes1

When examining the interview data, a clear pattern of behaviour emerges in firm response to the reduction of demand for products. Almost all firms show efforts to change their product offerings to suit the change in the operating environment.

More resilient firms (HighRes1, MidRes2, Midres3) appear to be particularly active in managing their business models by making changes to the way they deliver value to customers. This often took the form of introducing new streams of revenue around 
the firm's products, such as ancillary services, but also by adding functionality and diversifying the applicability of the product(s).

A number of the firms studied occupy niches within their markets. The features of which appear to influence the development of products and technologies. These niches include medical testing, packaging, metalworking, children's toys, food and beverage, and laboratory equipment. In targeting these niches, the firms have developed products and technologies with attributes suited to the needs and preferences of users.

MidRes1 and MidRes6 occupy premium niches in the food and beverage, and children's toy markets respectively. The managers at MidRes6 describe quality as a key attribute of their value proposition. The owners previously had significant experience in the production of beverage concentrates. This approach to the distribution of beverages now forms a central tenet of the current firm's ultra premium product. MidRes1's niche was also described by the interviewed managers as a premium or quality niche. They describe the materials used in production as being particularly suited to their targeted customers and as such, seek to develop products using materials that appeal to particular geographies.

Mangers at a number of firms outline how they see their products' value as being derived from properties embedded through design. Head Designer from HighRes2 describes how the ergonomics of their products improve the value derived by users. MidRes1 also places significant emphasis on the design of products, looking to ensure they are 'transformational' in that the products both 'transform' literally and transform the way users, and indeed the families of users, behave.

Evidence for the migration to new product and technology platforms was apparent in a number of the firms. MidRes9's CFO describes how significant development effort 
had gone into creating new platform technologies to replace current ones that were becoming obsolete in the face of new developments by competition. The new technologies improve existing functionality but also collect data from the user, augmenting the functionality and informing future development. MidRes7 also improved the technology used in their products. The Operations Manager describes moving from plastic films, to films with barrier properties that improve the value of the product to customers.

MidRes3 also developed a platform technology. This product is a customisable installation, but in all cases retains the same core features. The firm found that evolutionarily development of the product was beneficial to its volume of sales. As such, the CEO sees improving its technology platforms as the key to making progress in its overseas markets. He also considers development of technology as a critical success factor, as others in their market have struggled due to their lack of innovation in technology.

A number of firm managers described how they have sought to expand their product lines. MidRes3 introduced a range of upgrades that were applicable to all products in their category as well as other new energy saving products. MidRes2's Managing Director describes how the firm's product line is based on introducing high technology products to an industry that has been traditionally low technology.

\section{Designing Revenue Architectures}

'We innovate in the sense that the way we do our processes, being refined to maximise profitability. That's the end result.' Operations Manager MidRes4

'[End users] might pay an annual subscription or a fee subscription to have the ability to understand what's happening with [Product] and provide remote diagnosis, etc.... It may be a little like a Sky TV model for example, where you've got an upfront cost for your decoder and then you pay a subscription.' CFO MidRes9

'In the last few years as everyone's been tightening their belts so that's created quite a significant pressure on our business and it has been somewhat of a catalyst...to produce consistent, rather than one off revenue streams.' CFO MidRes9 


\section{Designing Revenue Architectures Continued}

'We saved $\$ 100,000$ on one order and that was pipe fittings - it's not as if someone could have huge margins on that.' Managing Director MidRes2

'In terms of channels to the market there is no simple channel to provide stuff to people with [IIIness] so we're kind of halfway between a distribution model where we would distribute to institutions and a retail model where we would sell to individuals.' Manager LowRes3

'Hence the reason we then looked at going into [Country2] markets, maybe we can spread those lumps [in revenue] out a little bit. Flatten it out by going to other markets.' CEO MidRes3

'What we need is increased revenue. How do we get that without increasing units sold? And without bumping up the retail price?... Remove the people from the chain and pocket that margin ourselves.' Managing Director MidRes1

These capabilities underpin the firm's ability to derive revenue or change their cost structure. Removing costs from the value chain was a focus for a number of firms. MidRes7's CFO suggested that the firm's sales team were adamant that the firm needed to reduce its pricing to compete with others in the market. As such the firm entered a cost reduction exercise in order to achieve lower prices. MidRes2, HighRes2 and MidRes3's managers describe how these firms looked to reduce the cost of inputs by sourcing from overseas. In particular, the firms looked to international suppliers to find these less expensive inputs. MidRes6 found that over the duration of the GFC their relative purchasing power increased, as the New Zealand dollar appreciated significantly against other currencies. As such the firm sought to leverage their newfound buying power. MidRes4's managers outlined an initiative to increase the efficiency of manufacturing processes in order to improve margins.

A number of firms looked to improve margins and manage risk by taking control of the distribution of their products. Managers suggest this was designed to improve margins and revenue by either claiming a larger share of the total sales prices of products, as in the case of firms HighRes2 and MidRes1. MidRes1 had seen themselves as simply a manufacturer prior to the GFC. As such, they have taken more 
control of the manufacturing but also of the distribution and retailing of their products to ensure they captured the largest slice of the margin per unit.

MidRes9's managers describe how the firm changed distributors who were not adding sufficient value to their top line. A manager at LowRes3 outlined how the firm had both direct and indirect channels to market.

Firms MidRes6, MidRes3 and LowRes4 looked to develop sales volumes in new and existing markets in order to grow their top line. MidRes6 traditionally suffered a drop in sales during the summer months and as such, the managers describe how the firm looked to create new products that fit consumer's tastes during warmer months in order to reduce this cyclicality in revenue. MidRes3's managers describe extending its existing product line into new geographic markets in Asia. LowRes4s CFO describes how the firm sells licences to manufacture its products to joint venture partners in countries into which the firm wishes to extend sales.

HighRes2 underwent a significant business model restructure during the GFC. PreGFC, the firm speculatively developed products designed to have broad applicability. The renewed model involved collaborating with clients during their drug discovery phase and developing customised drug delivery systems that maximise usability, efficiency and efficacy of the device and drug. This was designed, according to the managers, not only to reduce the risk of speculatively developing products, but also to lock the client into a supply of bespoke product.

The managers of MidRes9 describe how the firm divested a revenue stream during the GFC. Their contract manufacturing business was the first indication that there was a significant change in the firms operating environment, and had become an uneconomical proposition. As such, the decision was made to divest these activities and focus on the firm's own product line. The CFO of the firm also described how a 
new range of products introduced a new revenue stream through a subscription model that augments the user experience.

\begin{abstract}
Selecting Target Customers
'Really, we're looking at consolidating our existing customers, existing markets, or trying to steal from competitors to bring them across... We really recognise the need to start working with customers for future roadmaps, understanding their roadmaps for product development.' CFO MidRes9

'Go after the ones that you are screwing things together and you're there making all these fancy bits because that's where the money is. But it's about knowing where you need to compete and we don't need to compete. Use those economies to your benefit.' Managing Director MidRes2

'So we have always been investing and expanding...our customer base really across all manufacturing levels.' Managing Director MidRes2

'We see our market as a very niche product. We think that the right place for New Zealand business is, especially ours anyway, at a high price point in a premium position, and the easiest way to hold that position is not to limit ourselves in terms of country markets.' Managing Director MidRes1
\end{abstract}

A number of firms have targeted emerging Asian markets during the GFC as an alternative to their traditional western markets that contracted during the crisis. Countries with strong economic growth rates (despite the GFC) provided an opportunity for many of the studied firms to grow sales by taking a small share of growing markets. A number of firm managers chose to describe their markets geographically.

MidRes4's managers suggest that [a large geographic area] has been their largest growing market during the GFC. MidRes9 distributes widely around the world, but the majority of the listed markets are in the developed, English speaking world and [Asia]. MidRes6 identifies potential country markets as a basis for expansion using particular attributes to categorise and choose markets.

The managers eventually settled on a country market with the most potential. LowRes4s CFO also targets countries using criteria based on their perceived potential for sales by the company. Particular regions were identified in particular for 
their potential to smooth out revenue. MidRes1's Managing Director suggests the firm tries not to limit itself in terms of country markets through the integrated distribution system it has developed.

MidRes9's managers describe how the firm was seeking to consolidate existing customers and to acquire customers from competitors during the GFC. Similarly, MidRes5's Managing Director describes how the firm was aiming to broaden their customer base during the GFC. While the Managing Director describes his aim to diversify customers across a broad range of segments, he goes on to outline how he looks to target high value customers for which the firm does not find itself competing with other manufacturers in developing countries. LowRes3 created a new market with its products. It targeted a subset of consumers that were not previously addressed by the health system.

\section{Designing Mechanisms to Capture Value \\ 'We've got capital expenditure; it's a lever to make sure we are increasing in productivity, we've got the latest machinery, we're minimizing our downtime, those sorts of things. So trying to take costs out of our process.' Operations Manger MidRes7}

'That's not as easy thing to change quickly but we have looked at how we can be more efficient in our manufacturing, be more efficient in our sourcing, look at component changes, reengineer our products sorts of things' CFO MidRes9

'How can we do what we are doing better, more efficiently? A big part of that is getting equipment in the right place. It's simple: staff and equipment in the right place for the market. The right people running it is first by 800 miles.' Managing Director MidRes5

'I mean we've got a really slick machine - which we run which all it is, is a sausage factory which just pumps out efficient sausages. So now we can scale up or down however, we like you know? It is extremely efficient and we are constantly tweaking, improving and developing it to make it run smoother.' Managing Director MidRes2

'The goal l've got down at the factory now, which is shifting business to an assembly process, is something l've had around for a long time so that's just come to fruition.' CEO MidRes3

'I talked about margin and I talked about staffing discipline, I talked about technology to bring that into the business and in a way the overarching umbrella principle is productivity. So maximize margin per unit, maximize activity per staff member, you know this efficiency has to be it. Managing Director MidRes1 
A number of the firms studied made changes to their business models that were designed to capture efficiencies from the process of manufacturing and distributing products. These changes included a number of different strategies to reduce costs and improve the operating margin on manufacturing activities.

A number of the firms sought to approach the reduction in demand by reorganising for efficiency. In a number of cases this was gained by removing redundancy from their systems, while in other firms the approach was to implement more efficient systems. In all cases, the ultimate goal was to create enough operating margin to either retain or reduce current pricing structures, despite lower levels of demand.

The managers at MidRes7 describe how the firm entered a cost reduction exercise when their sales staff suggested the market was signalling their products were relatively too expensive. As such, the CFO describes how the firm expected to remove cost from the manufacturing process. MidRes5's Managing Director tried to maintain their prices in the face of competition while removing cost out of manufacturing. MidRes3's Managing Director described how the firm sought to reduce costs from suppliers.

A number of firms sought to integrate both up and downstream activities into their processes in order to capture more margin from the value chain and/or to build efficiency in the manufacturing process. HighRes2 sought to reduce costs by sourcing manufacturing services in low cost locations. The Managing Director suggests while this was a difficult undertaking, he suggests it has it has delivered significant annual savings.

MidRes3 has moved from manufacturing the entirety of their product to outsourcing as much manufacturing as possible and assembling products at their factory. This was designed to reduce cost and overhead as well as helping to standardise their products for overseas markets. 
Firms approached improving efficiency in a number of ways. This was generally achieved through creating more efficient processes and systems, and minimising waste and mistakes. Firms MidRes7 and MidRes4's managers describe how they sought to drive efficiency into manufacturing processes. MidRes7's Operations Manager describes how they ran two manufacturing processes in-line with each other to remove a step. MidRes3's Managing Director suggests the move to an assembly process instead of in-house manufacturing was designed to reduce costs and improve the efficiency of manufacturing.

A number of firms looked to improve the efficiency of manufacturing by minimising waste from the value chain. MidRes7's managers describe how the firm looked to minimise waste from manufacturing. As did HighRes2 through the implementation of ISO 9000 quality standards. MidRes8's managers describe how they created and implemented an in-house system, making all staff 'quality inspectors'. The process reduced the rate of rejects in the firm.

Sourcing was another way firms looked to capture value out of the manufacturing process. MidRes7's manager described how it looked to improve its logistics and sourcing processes. In particular, the CFO outlines using sea freight instead of airfreight to ship products combined with processes to find new sources of inputs. HighRes2's Managing Director describes how the firm entered an encompassing process of sourcing from overseas rather than locally in order to reduce costs.

\subsubsection{Selecting Enterprise Boundaries to Manage Complements and 'Control' Platforms}

\section{Calibrating Asset Specificity}

'The other thing with the business is we've moved to a point where we subcontract what we need rather than have a whole bunch of staff sitting around. If we need a design person we hire a design person. If we need a marketing person, we'll call them in... our whole moral is not to have people sitting around waiting for things to happen.' CTO LowRes3 


\section{Calibrating Asset Specificity Continued}

'They [Competitors] manufacture everything in-house. Our business model is not to do that we have our manufacturing sites located where they should be and we buy product in.' Managing Director HighRes2

'We're trying to further outsource more of our processes and put more value into our designs which then means we don't have to do so much manufacturing.' CEO MidRes3

'So we are forever apart from growing the range of products we have always looked at acquiring other companies. We are in the process of possibly acquiring a small business in Auckland because we don't have an office or we don't have a sales engineer. Basically or we are either going to acquire this business or have an office in Auckland.' CFO MidRes3

'What we also did during this time was we took back distribution...so we are effectively able to eliminate them which brings the retail price point down and also brings the wholesale price point down and we're able to bank more dollars because there wasn't a third party between us and our retail customers.' Head Designer MidRes1

'Through trying to sell more, we focused very hard on postproduction even doing storage and dispatch for customers so we tried to effectively make ourselves more indispensable to your customers.' Managing Director LowRes2

Managing the level of integration was an approach that a number of firms utilised to create structures better suited to the operating environment. Vertical, forwards integration was a change both MidRes1 and LowRes2 used. MidRes1's managers describe how underperforming distributors and a need to bank more margin per unit drove them to vertically integrate forwards into distribution of their products to end users. LowRes2's Managing Director, in a bid to deliver more value to their customers began offering storage and dispatch services.

Several firms integrated horizontally during the GFC. MidRes7's managers describe acquiring a competing firm's manufacturing facility in another country to add capacity to production. MidRes3 and MidRes8's managers describe how they acquired or opened sales offices designed to extend the firms reach into new geographic markets.

Firms also made boundary decisions that saw them outsource components of the value chain. LowRes3's managers describe outsourcing as many skills as possible 
that the firm did not need to retain full time, in order to reduce costs. HighRes2 outsources all manufacturing for the same reason. MidRes3's CEO has moved to outsource more of the manufacturing process so that the firm becomes an assembler rather than a manufacturer.

Firms also invested in the development of existing assets. MidRes5's Managing Director discussed how the firm built a new facility with enough capacity to manage increasing volumes. The manager suggests that the firm chose to construct the new facility during the economic downturn in order to capitalise on the relatively lower costs of construction during this time. HighRes2's Managing Director describes how the firm invested in growing the R\&D team from a single engineer to twelve. MidRes6's managers described investing in capacity and volume in order to manage the expected growth in demand from entering new country markets.

Conversely, MidRes9 divested itself of an unprofitable contract manufacturing business after identifying that it no longer remained economic or fitted with the firm's strategy and vision of improving the lives of people with disabilities.

\section{Controlling Bottleneck Assets}

'We're probably about balanced. I suspect if we added more capacity...in fact, with our [Country 2] facility we're probably over capacity at the moment if you took the two sides into account. Operations Manager MidRes7

'....as an example one of our projects we had 22 injection moulds to make. Well that's like a fifth of what was made in New Zealand in that year so no one company can handle that. So we had to have all those injection moulds made in [Country 6]' Head Designer. HighRes2

'We're also looking at a new bottling line so that we have a more robust system both in terms of quality and if you've got two bottom lines if you have juice with one you're still able to produce on the other. At this stage they probably won't both be going at once; it's future proofing your production facility by investing more productive capacity.' Co-owner. MidRes6

'We always invested for efficiency given the size of our footprint here, space was always an issue so our footprint constrained us. So by investing in faster and smarter plant we could actually improve our efficiency.' Managing Director LowRes2 


\section{Controlling Bottleneck Assets Continued}

'As soon as we moved into that [Larger] building things became freed up and the turnover went up.' Manager MidRes8

The managers of firms that discussed managing bottleneck assets exclusively describe manufacturing as the source of their constraints. Firms made changes to their plant, systems and outsourcing practices to relieve these constraints.

Evidence suggests that making changes to manufacturing assets is a way firms looked to control bottlenecks. MidRes3's managers describe investing in a new bottling capacity. While MidRes7 mangers set in motion plans to do the same, investing in the acquisition of a new manufacturing plant to add capacity and relieve freight constraints. LowRes2 managed the constraining size of their facility by investing and reorganising production facilities to improve efficiency. MidRes8's managers describe how upon moving from a smaller facility to a larger one, the revenue of the firm improved by $50 \%$.

MidRes2 and LowRes2's managers describe how their investment in systems was designed to alleviate constraints. MidRes2's Managing Director invests in technology and systems that speed up production and minimise the need for human involvement in manufacturing. LowRes2's Managing Director describes that to relieve a bottleneck in transitioning from the design to manufacturing phase, the firm invested in software speed up the process.

HighRes2's Head Designer describes how due to constraints to manufacturing in New Zealand, the firm needed to outsource to its network of suppliers internationally to meet its demand for parts. MidRes1's designer describes how the firm outsources manufacturing so that it can change its facility quickly with little to no investment on its part, should it require capacity that is more productive. 


\section{Assessing Asset Appropriability}

'We try and protect our IP but as [Operations Manager] said they can grab a [Product], hand it over and analyse it.... So yeah, there is intellectual property that surrounds it. We don't allow people to come here and take photos of our manufacturing process at all. We try and protect that.' CFO MidRes7

'We sell a lot of our product to [Parent Company] but we also sell a significant amount to [their] competitors as well. That's an interesting relationship...we do deal with their competitors too so there's a certain amount of discreetness we'll say.' CFO MidRes9

'As a result, we build everything in-house, while they have huge means, they still have to buy my parts to build a [Product]... but that's the risk you take is that you are giving your products to your opposition.' Managing Director MidRes2

'That's right so someone would have to go to the same expense [of developing a machine] again...Y You could go to [Country 2]. The problem with [Country 2] is quality and your chain of supply and it's not too standard you've got to dump that or rework it so having the capacity to make it here gets rid of that issue.' Owner MidRes8

A number of firms discuss the risk of assets being appropriated by competitors. These concerns regard a number of asset types including products and intellectual property but also processes and equipment. Managers in MidRes7, MidRes9 and MidRes2 each describe how they struggle to keep their products out of the hands of competitors and identify the risk of reverse engineering as a means for their assets to be appropriated. As such they each utilise strategies, generally favouring secrecy, to mitigate these risks. The Owner of MidRes8 however, suggests that their risk of appropriation by international competitors is managed by the intricacies of the process, which involves integration of the supply chain to create products as well as a significant amount of troubleshooting to ensure products are produced with requisite quality.

\section{Reorganising Managing \& Capturing Cospecialisation Economies}

'So we've got all the fastest machines, all the latest technology the latest design tools and you've got this massive depth of knowledge - we are a production engineering company that makes fire engines as a product. We are not a fire engine manufacturing company.' Managing Director MidRes2

'Being in a niche area, having a unique set of products, establishing a brand that was a strong brand.' Co-owner MidRes6 


\title{
Reorganising Managing \& Capturing Cospecialisation Economies Continued
}

'We're trying to further outsource more of our processes and put more value into our designs which then means we don't have to do so much manufacturing.' CEO MidRes3

MidRes2's Managing Director describes how the firm uses its high technology facility, the skills to utilise that facility, and significant bank of knowledge of manufacturing to apply to its chosen sector. MidRes6's managers describe how the interplay between the firm's brand, product niche, and quality combine with the firm being based in New Zealand to derive particular value. The CEO also describes how the brand provides a 'roof' within which their in-house innovator can develop products that fit the brand. MidRes3's co-specialised assets are outlined by the managers when they describe them as driving value into the design of the products and outsourcing component manufacturing in order to manufacture less and assemble more.

\subsubsection{Selecting Decision making protocols}

\author{
Recognising Inflexion Points \\ 'They [Suppliers] were interesting because they were like a litmus test for what was going on, or like \\ a canary because we started to see from them things drop off before we saw other things drop off.' \\ CEO MidRes9
}

'We do notice that the dollar's that much stronger than the Euro so we get much more because we import our [Raw Materials] we get a better deal.' CEO MidRes6

'I think we are actually quite a good barometer of the economy because we've got a reasonably large number of customers... We can just about tell you, month by month, how the economy is going.' Co-owner MidRes6

'Actually that's a key point about the recession is that they change their quality. We changed because their quality...the pressure came on the manufacturer because the recession hit him. And so they drop their quality.' Managing Director MidRes1

A number of firms identified changes in their markets through observation of the GFC's effects on their customers and suppliers. MidRes6 considers its sales as a barometer of the economy. The Co-owner suggests their product is tied to consumers' disposable income; as such, orders from their customers are an indicator 
for market changes. MidRes1's managers both describe how the firm's customers didn't follow through with orders as agreed. MidRes8's managers suggest there are fewer customers for manufacturers in Wellington after difficult economic periods.

A number of firms appear to have identified indications of market changes from upstream in the supply chain, including MidRes9 and MidRes1. MidRes9's managers noticed that their suppliers' businesses dropped off before their own. The CEO described them as a 'litmus test' for their own business. MidRes 1 noticed an increase in quality issues from their manufacturer during the GFC. This precipitated a change in contract manufacturers three times.

A number of firms were alerted to changes in their markets through developments in finance and foreign exchange conditions. MidRes6's managers describe how the firm's purchasing power increased significantly during the crisis due to the appreciation of the New Zealand Dollar. The managers also note however, that exporting products became relatively harder due to the high cost of the New Zealand Dollar. LowRes2 struggled because international competition to their products became relatively more economical to customers for the same reason.

\section{Avoiding Decision Errors and Anticannibalisation Proclivities}

'Traceability: we can track any job, we can look at how much it costs us to do the job, where it is in the factory. Stock - automatic stock ordering, parts traceability and tracking, yeah everything. It does everything.' Managing Director MidRes2

'I make a point of going to see every single customer at least once a year where ever it is in the world. So I kind of don't have to interpret the information, I know exactly what is happening.' Managing Director HighRes2

'We have implemented our ISO quality standards throughout the business from our design process right through to manufacturing and assembly process that has been important to us it has been important to us for not just international credibility, but our mistakes are expensive and you make them twice it's inexcusable.' Head Designer HighRes2 
Few managers discussed incidences, processes or capabilities to avoid decision errors and anticannibalisation proclivities. MidRes2's Managing Director describes how the firm implemented a tracking system that monitors the production process. The system automatically tracks and controls the process automatically to reduce errors. HighRes2's Managing Director describes how he visits each of their customers at least once a year to ensure he doesn't have to interpret communications from customers. The Managing Director and Head Designer describe their ISO 9000 quality system as a driver of reduced errors in the firm.

\subsubsection{Building loyalty and commitment}

\section{Demonstrating Leadership}

'Every single manager has picked up additional responsibilities and I guess we're all trying to find our feet and working out how we all fit in together.' CFO MidRes7

'So that has been really successful - getting the right people, the right background, motivating them properly. I'm sure leadership had a part to play there. I'm very visible to all of them, very approachable.' Managing Director HighRes2

'Everyone was so anxious. They were more willing to be compliant and make change. We had quite a culture change...You'd say, "Look guys, we're here for a reason. The market's pretty crappy for us. We can either make these changes or we're going to go under."' CEO MidRes3

'....and he made the point that as a manager how you get through this in the next couple of years will really define you, which I found quite inspirational. So I mean our attitude was, well, going to fight this thing very hard.' Managing Director LowRes2

A number of firms showed modest evidence for demonstrating leadership. MidRes7's CFO describes how during a transition to move capacity to the newly acquired facility overseas, that managers at the firm took up extra responsibilities to ensure it went smoothly. HighRes2's Managing Director suggests his high visibility is a motivating factor to staff. MidRes3's CEO referred to how he led a culture change during the difficult financial period. He suggests he was left with a pliable and flexible staff culture in the firm after thinning out those who could not cope with the extent of changes. LowRes2's Managing Director described how he saw the difficult economic climate as defining as a manager. He made the decision to fight the GFC. LowRes4's 
CFO took an active approach in promoting and networking in order to develop the business.

\section{Effectively Communicating}

'I make a point of going to see every single customer at least once a year where ever it is in the world. So I kind of don't have to interpret the information, I know exactly what is happening, that made quite a big difference.' Managing Director HighRes2

Effectively communicating was another area of the framework that was under represented in the discussion with managers. HighRes2 was the only firm where any manager described a structured approach to communications. The Managing Director describes how at least once a year he visits each customer in person to ensure he understands their needs and issues.

\section{Recognising Noneconomic Factors, Values And Culture}

'Our purpose is to bring our technology and innovation to enhance the quality of life of people with disabilities.' CEO MidRes9

'It's about altering the culture. That's been rolled out and that's probably the link that's been missing... [it's] more about getting people involved and having teams take ownership of problems.' Innovation and Operations Manager MidRes7

'We're talking about a global company so there are regularly opportunities in other countries that come up. So there's the potential for people to go on to greater things if they want to.' Operations Manager MidRes7

'It's not about the process. It's only partly about the process. It's about altering the culture. That's been rolled out and that's probably the link that's been missing.' Operations Manger MidRes7

'Our purpose is to bring our technology and innovation to enhance the quality of life of people with disabilities.' CEO MidRes9

'We had quite a culture change, I suppose, during that period. People who couldn't cope just left or didn't like it so we were left with a core team of flexible staff; they're very pliable in that way.' CEO MidRes3

'We have sort of taken the view that actually we want to have certain core values and in our products we want to ensure quality, we want to have good environmental outcomes, we want to be careful about the types of inputs the go into the products.' Head Designer MidRes 1 
MidRes9's CEO and CFO describe the firm's vision of enhancing the lives of disabled people. MidRes7's managers discuss how the firm actively courts a positive and productive culture. It offers global development opportunities for staff. MidRes3's culture became one of flexibility and malleability after the loss of all but a core of staff. MidRes1 has environmental consciousness and philanthropic goals and principles inherent in the practices of the business. One of HighRes2's managers describes how they sought to build loyalty among staff by first focusing on recruiting high performance staff and rewarding them with shares in the business. He suggests the firm has low staff turnover of approximately two percent per annum.

\subsubsection{Transformation}

\subsubsection{Decentralisation and near decomposability}

\section{Adopting Loosely Coupled Structures}

'We've got... seven warehouses internationally and we want to start shipping to [Country 4], [Country 6] well what's the best location to put them in? So we are doing a project on that we are looking at building the [Country 2] warehouse at the moment.' Head Designer MidRes1

'We had some very close relationships with post production suppliers. For example, we have a [Provide Ancillary Services] - a lot of our competitors didn't have that which was one advantage we had.' Managing Director LowRes2

A relatively under-discussed class of capability, few managers made statements that regarded changes to create a more decentralised firm structure. MidRes1's managers describe how they have developed a decentralised firm structure which is headquartered in New Zealand, manufactures in another country and distributes both directly to consumers via warehousing in seven international locations and through dedicated distribution agents. LowRes2's Managing Director outlines how the firm integrated subcontracted ancillary services to provide further value to their clients. 


\section{Embracing Open Innovation}

'What I started doing more of was knocking on the [Customer] company doors to indicate that we had a resource here that was not being used - that was me - one engineer, we could actually develop something for you.' Head Designer HighRes2

'Then on the other side of things with our customers, people like [Customer], if we can develop a close relationship with them then we can not only give them what they want but refine it and they can give us ideas in how we could actually improve the product.' Co-owner MidRes6

'We're going to bring all our suppliers in and we're going to close the factory for half a day, have a few beers, get them all in and say, 'This is what we're doing. Is there anything we're not doing that we need to be doing that you can help us with to make this better?' Our suppliers get involved generally right at the outset.' CEO MidRes3

'This new product is a partnership with a [Food\} company from [Country 8]- they collect their used containers and we recycle those and turn them into our products.' Managing Director MidRes1

HighRes2 partners with its customers to co-design tailored solutions for products the client firms are bringing to market. This requires close integration during the development phase for both the drug and the delivery system. MidRes 6 engages with its customers to refine and even develop products that will appeal to end-users. The Managing Director from MidRes3 describes how the firm involves its suppliers both formally and informally during the process of development. The firm looks to draw on the knowledge of their suppliers when developing products. MidRes 1 partners with related firms for mutual benefit, but does not look for input from customers or suppliers.

\section{Developing Integration and Coordination Skills}

'I wanted us to shift for a long time from a manufacturing to an assembly process...it's been exceptionally difficult. I had some engineering changes here the last couple of years... then I wanted to say, 'How do we add value into a part?' and then I can get it produced somewhere else, bring it in and just plug and play.' CEO MidRes3

'So what we initially ended up with was an insanely complex set of options. Pricing structures, logistics, delivery, structures.... It's so complicated.... So we said, you know, we have to find a structure where we can continue to see the globe as our market and trade in all of these currencies, in all of these countries. So we might use the same structure to receive orders and reduce the number of ways in which we are fulfilling and simplifying.' Managing Director MidRes 1 
MidRes3 has looked to transition to an assembly process from manufacturing, instead coordinating manufacturing off-site at international locations. MidRes1's managers describe an integrated network of warehousing and logistics that it manages from New Zealand. It manages a diverse array of activities including manufacturing, logistics and various models of distribution.

\section{Cospecialisation}

'The brand can't exist without being New Zealand.... They're all one; the brand is it. That's our roof. You can't have a really good brand with a sub-par product.' CEO MidRes6

'We're trying to further outsource more of our processes and put more value into our designs which then means we don't have to do so much manufacturing.' CEO MidRes3

'.. yeah, well maybe productivity was the relationship between them. Because I talked about margin, and I talked about staffing discipline, I talked about technology - to bring that into the business and in a way, the overarching umbrella principle is productivity. So maximize margin per unit maximize activity per staff member.' Managing Director MidRes1

MidRes6 is active in managing their product and its quality to ensure it fits the brands values. The brand, the product and the firm's 'New Zealandness' is are critical to each other and the Co-owner and CEO manage the fit of the product portfolio to ensure they are aligned to create value. MidRes3 adds value to its designs in order to reduce the cost of components and production costs. MidRes1 had a productivity focus when managing its assets and processes.

\subsubsection{Governance}

\section{Achieving Incentive Alignment}

'...the key players have come into shares because the scheme gives them a sort of vested interest in the capital growth of the firm.' Managing Director HighRes2

'You've got to be sure whoever works for you is happy and you pay them enough.' CEO MidRes6

'While we are not obsessed with becoming super wealthy people our focus is on the dollar at the end.' Head Designer MidRes1

'He's doing a good job there and he is a joint venture partner, so he is our partner and his rewards from that would put them up for life.' CFO LowRes4 
The Managing Director of HighRes2 provides equity incentives to key players in his firm. MidRes 1 and MidRes6 actively manage staff incentives. MidRes6 ensures it pays market rates to staff while MidRes1 is active in managing its staff costs, opting to remove staff whose professions can be replaced by software. The managers of MidRes1 note that they are not obsessed with becoming wealthy so they run the company with that in mind. LowRes4's CFO describes how it incentivises its joint venture partners well in order to motivate performance.

\section{Minimising Agency Issues}

The key players have come into shares because the scheme gives them a sort of vested interest in the capital growth of the firm. Managing Director HighRes2

'So we have said all along that I don't want to go out for investment until we can prove that the business is... I don't want to give away $49 \%$ for $\$ 20,000$ considering how much time and effort we've put into it.' Head Designer MidRes1

'... of course we have the majority shareholding.' CFO LowRes4

The managers at HighRes2 outline how the firm's employee ownership scheme rewards high performing staff, effectively turning agents into principles in order to align interests. MidRes1's Head Designer describes how the owners aim to maintain ownership and fund the growth of the firm through lending until they can realise sufficient value from the sale of any shares. MidRes8's managers are preparing for the retirement of the owner and Managing Director. They have a succession plan in place with an eighteen-month timeline in order to ensure the management transition goes smoothly. LowRes4 retains the majority shareholding in their joint ventures to ensure they retain ultimate control over decisions. 


\section{Checking Strategic Malfeasance}

'I can't say how much, just how fundamental that has been...to ensure that people understand what we expect of each other in terms of how we behave. So [lt used to be] if someone who was an influential personality thought something was a good idea then a lot of money would go into it and it would have very little critique.' CEO MidRes9

'The first thing I did was cut back. We had some pretty average staff basically. First I replaced all the sales people.' Managing Director HighRes2

In MidRes9 the CEO refers to a status quo that was overcome during the GFC under which particularly influential individuals were capable of requisitioning and expending significant amounts of funding for projects that may have been poorly vetted. The Managing Director of HighRes2 notes that he is active in removing poorly performing staff from their roles.

\section{Blocking rent dissipation}

'I guess the thing with multi-nationals, even when I came on board, they have quite good processes in place and strong reporting requirements and the like.' CFO MidRes7

'[There Was] No governance in terms of innovation. A lot was spent.' CEO MidRes9

'We've changed the setup and because Andrew's taking over, he's my son, and he's taking over and he's probably got more energy in the building the thing up, l've reached a stage where l've probably reached a plateau'. Owner MidRes8

Few managers discussed changes to manage the dissipation of rents through governance capabilities. In MidRes7 the risk of managers subverting rents through power centralisation was manage through stringent reporting frameworks. While in MidRes9 these forms of controls were not in place and subsequently rents were dissipated through costly investment in failed innovations. In MidRes8, the exiting owner took steps to ensure his own performance was not a cost to performance by ensuring that management and governance were effectively transitioned. 


\title{
4.7.3.3 Knowledge Management
}

\author{
Learning \\ 'That [Supply Chain Disturbance] forced us to go through a process of learning and understanding \\ some of the research around not just the end user but others in the value chain back from them, \\ between us and the end user.' CEO MidRes9 \\ '... but you don't try to go a mile wide and an inch deep. That just doesn't work. \\ Q: Is that something that you've learned or is that... \\ A: $\quad$ It's something we've learned.' CEO LowRes3
}

'Any company that manufactures something will make mistakes and what you have to do is manage that process and we now do that extremely well. Those mistakes can come from suppliers supplying you with parts out of spec and right through to a product failing in the field. If something goes wrong with it, we manage that.'

'I think failure's a better teacher. [Another Manager] had various ventures that have come and gone and I think that's a very strong learning experience.' Co-owner MidRes6

'So the learning from the manufacturing is that wood is hard to make.' Managing Director MidRes1

Consistent across discussion of learning in these firms is that managers consider failure to be a teacher. Managers in MidRes 6 see past failures, both in the current firm and in other entrepreneurial undertakings, as a strong source of learning. MidRes1's head designer suggests the firm has learned how to bring product to market faster through iteration and experience.

\section{Knowledge Transfer}

'This year we spent money on a technical writer for eight months. Just trying to document all the little products and all the odds and sods that we've got. Trying to kind of capture a lot of that information into spec sheets.' Designer MidRes3

'The last months to developing a standard operating procedure... so I'm starting to write the policies down so that staff can answer the questions.' Managing Director MidRes1

'Because it's a small industry, it's a knowledge game and we have tended to have a fair bit of knowledge.' Manager MidRes8 


\section{Knowledge Transfer Continued}

'And over that time we've seen him probably every 2 months or so and we do that with a lot of different customers we help them with our own expertise solve all their problems because a lot of people don't have an understanding of springs and how they work.' Owner MidRes8

Managers in MidRes3 and MidRes1 suggest the firms have been active in codifying product specifications and standard operating procedures. MidRes8's managers describe how they look to bring their product and manufacturing knowledge to bear to develop products for its customers. This codification of knowledge enables the transfer of knowledge both within and outside the organisation by providing a framework that enables and facilitates its transition. This was achieved through the creation of standard operating and specification sheets but also informally, as in the case of MidRes8, where knowledge was bought to bear on a client's project at particular points in time.

\section{Knowhow Integration}

'So we've got all the fastest machines, all the latest technology, the latest design tools, and you've got this massive depth of knowledge - we are a production engineering company that makes [Product] as a product. We are not a [Product] manufacturing company.' Managing Director MidRes2

'We went through the [Government Funded Capability Development Scheme] that is a government funded process where we, with a government grant took a look at what we wanted to do and what we had to do to get there.' Head Designer HighRes2

'And the knowledge in-house because we've got the brand and the innovator in the house which is enormous because we don't have to wait for somebody to come with ideas. We just sit there and have lunch and ideas pour in.' CEO MidRes6

'Our drawing library, where all our intellectual property is, is very, very deep and strong so we can draw on a huge amount of knowledge we've built up and things we've captured properly over the last seven or eight years.' CEO MidRes3

The Managing Director of MidRes2 describes how the firm leverages knowledge of production processes to drive quality and technology into a particular sector. HighRes2 integrates design thinking into the development of their products. MidRes6 
keeps their innovator in-house enabling them to draw on his knowledge to develop and refine products. MidRes3's product knowledge is codified into a library with detailed knowledge that it can be recalled and reapplied as necessary.

\section{Achieving Intellectual Property Protection}

'So every situation is different. So essentially customers say: "we want to own the IP" that's the given from the outset, so we will come up with something unique but we want to be the manufacturer of that. 'Managing Director HighRes2

'We've spoken to our patent attorneys and they just said, 'The cost of trying to protect these is far too high.' So we've branded everything.' CEO MidRes3

'Our broader philosophy would be to not overdo the expenditure on intellectual property, because we made a conscious choice not to be defending it in court. So we use it as a preventive measure.' Managing Director MidRes1

'If they [Joint Venture Partners] invent anything when they are doing the moulding and stuff it's our property, that's ours, it's part of the contracts because we've given them the name and everything.' CFO LowRes4

Overall firms are pragmatic about how they manage and defend intellectual property. The cost of defending patents is a primary concern according to the managers interviewed. A number of firms found ways to avoid paying to defend intellectual property including keeping things secret as in MidRes7 and MidRes4 or building products to complement the intellectual property of larger firms that can afford to defend it as in the case of HighRes2. MidRes1 caps its investment in defence of intellectual property as well as choosing which markets in which to protect and defend its products.

MidRes4's managers take a different approach to managing intellectual property. The firm's Managing Director describes how the firm's processes are where the intellectual property value is derived. He suggests that as patenting their processes would require explicating the steps required; the firm tries to keep the details of the process secret. 


\subsubsection{Summary: Amalgamated Study}

The amalgamated case depicts the MidRes and LowRes firms that constituted the sample. These firms not only exhibited a range of performance but also demonstrated a significant range of dynamic capabilities. The themes identified in these firms were useful in the development of conclusions of the thesis and as such have been summarised here.

Sensing capabilities were present in nearly all firms. However, their application significantly varied between firms, with some undertaking searches for new technologies and their applications, while others retrenched from these activities in order to save costs. In particular, low resilience firms tended to discuss Processes to Direct Internal R\&D capabilities less often when compared to other firms.

Seizing capabilities showed a clear trend, with more resilient firms discussing these types of capabilities more often than less resilient ones. Resilient firms were consistently more active in developing new and existing business models and reorganising firm structures to suit the new operating environment. Meanwhile less resilient firms tended to retrench toward their core businesses.

Similar to the Seizing capabilities, indeed even more pronounced in some instances, Transformation was expressed in higher proportions in resilient firms when compared to less resilient ones. Governance and Knowledge Management capabilities are clear exemplars of this trend. However, Decentralisation and Cospecialisation capabilities were less discussed overall and the discussion of these capabilities was more evenly distributed across all firms.

The following table (Table 31) shows the heat maps for the firms in the amalgamated case. It depicts each firm's score, as a percentage of all firms, from the discussion of each type of dynamic capability. 
Table 31: Amalgamated Case Dynamic Capability Heat Maps

\begin{tabular}{|c|c|c|c|c|c|c|c|c|c|c|c|c|c|}
\hline Sensing & $\begin{array}{l}\text { HighRe } \\
\text { s2 }\end{array}$ & $\begin{array}{l}\text { MidRe } \\
\text { s1 }\end{array}$ & $\begin{array}{l}\text { MidRe } \\
\text { s2 }\end{array}$ & $\begin{array}{l}\text { MidRe } \\
\text { s3 }\end{array}$ & $\begin{array}{l}\text { MidRE } \\
\text { s4 }\end{array}$ & $\begin{array}{l}\text { MidRe } \\
\text { s5 }\end{array}$ & $\begin{array}{l}\text { MidRe } \\
\text { s6 }\end{array}$ & $\begin{array}{l}\text { MidRe } \\
\text { s7 }\end{array}$ & $\begin{array}{l}\text { MidRe } \\
\text { s8 }\end{array}$ & $\begin{array}{l}\text { MidRe } \\
\text { s9 }\end{array}$ & $\begin{array}{l}\text { LowR } \\
\text { es } 4\end{array}$ & $\begin{array}{l}\text { LowR } \\
\text { es3 }\end{array}$ & $\begin{array}{l}\text { LowR } \\
\text { es2 }\end{array}$ \\
\hline \multicolumn{14}{|c|}{ Percentage of Total Discussion } \\
\hline Processes to Direct Internal R\&D & 9.7 & 4.8 & 6.5 & 4.8 & 3.2 & 1.6 & 8.1 & 6.5 & 3.2 & 3.2 & 3.2 & 3.2 & 3.2 \\
\hline $\begin{array}{l}\text { Processes to Tap Exogenous } \\
\text { Science \& Technology }\end{array}$ & 14.3 & 4.8 & 0.0 & 0.0 & 4.8 & 0.0 & 14.3 & 14.3 & 0.0 & 0.0 & 4.8 & 9.5 & 0.0 \\
\hline $\begin{array}{l}\text { Processes to Tap Supplier and } \\
\text { Complementor Innovations }\end{array}$ & 12.5 & 3.1 & 6.3 & 0.0 & 0.0 & 9.4 & 12.5 & 9.4 & 3.1 & 12.5 & 0.0 & 12.5 & 0.0 \\
\hline $\begin{array}{l}\text { Processes to Identify Target Market } \\
\text { Segments, Changing Customer } \\
\text { Needs and Customer Innovation }\end{array}$ & 13.9 & 0.0 & 5.6 & 5.6 & 0.0 & 5.6 & 8.3 & 8.3 & 2.8 & 0.0 & 11.1 & 11.1 & 2.8 \\
\hline Seizing & $\begin{array}{l}\text { High } \\
\text { Res2 }\end{array}$ & $\begin{array}{l}\text { MidRe } \\
\text { s1 }\end{array}$ & $\begin{array}{l}\text { MidRe } \\
\quad \text { s2 }\end{array}$ & $\begin{array}{l}\text { MidRe } \\
\text { s3 }\end{array}$ & $\begin{array}{l}\text { MidRE } \\
\text { s4 }\end{array}$ & $\begin{array}{l}\text { MidRe } \\
\text { s5 }\end{array}$ & $\begin{array}{l}\text { MidRe } \\
\text { s6 }\end{array}$ & $\begin{array}{l}\text { MidRe } \\
\text { s7 }\end{array}$ & $\begin{array}{l}\text { MidRe } \\
\text { s8 }\end{array}$ & $\begin{array}{l}\text { MidRe } \\
\text { s9 }\end{array}$ & $\begin{array}{l}\text { LowR } \\
\text { es } 4\end{array}$ & $\begin{array}{l}\text { LowRe } \\
\text { s3 }\end{array}$ & $\begin{array}{l}\text { LowR } \\
\text { es2 }\end{array}$ \\
\hline
\end{tabular}

Delineating the Customer Solution \& Business Model

Selecting the Technology \&

Product Architecture

Selecting Revenue Architectures

Selecting Target Customers

Designing Mechanisms to Capture

Value

\begin{tabular}{|r|r|r|r|c|c|c|c|c|c|c|c|c|c|}
\hline 8.9 & 6.3 & 2.5 & 10.1 & 10.1 & 0.0 & 7.6 & 7.6 & 2.5 & 2.5 & 2.5 & 3.8 & 3.8 \\
\hline 8.5 & 11.9 & 1.7 & 8.5 & 6.8 & 0.0 & 6.8 & 1.7 & 11.9 & 3.4 & 1.7 & 5.1 & 5.1 \\
\hline 15.1 & 3.8 & 5.7 & 1.9 & 11.3 & 3.8 & 3.8 & 1.9 & 5.7 & 1.9 & 9.4 & 11.3 & 0.0 \\
\hline 5.8 & 3.8 & 2.9 & 12.5 & 5.8 & 5.8 & 5.8 & 1.9 & 5.8 & 5.8 & 0.0 & 1.9 & 2.9 \\
\hline
\end{tabular}


Table 31: Amalgamated Case Dynamic Capabilities Heat Maps Continued

\section{Selecting Enterprise Boundaries to manage Complements \& Control Platforms}

Calibrating Asset Specificity

Controlling Bottleneck Assets

Assessing Asset Appropriability

\begin{tabular}{|l|l|l|l|l|l|l|l|}
\hline 7.9 & 2.6 & 2.6 & 13.2 & 5.3 & 7.9 & 10.5 & 2.6 \\
\hline 4.5 & 0.0 & 0.0 & 0.0 & 9.1 & 0.0 & 4.5 & 18.2 \\
\hline 2.6 & 5.3 & 2.6 & 10.5 & 0.0 & 7.9 & 13.2 & 2.6 \\
\hline
\end{tabular}

\begin{tabular}{r|r|r|r|r}
\hline 5.3 & 5.3 & 2.6 & 5.3 & 2.6 \\
\hline 9.1 & 9.1 & 0.0 & 0.0 & 13.6 \\
\hline 5.3 & 5.3 & 2.6 & 0.0 & 2.6 \\
\hline
\end{tabular}

Reorganising Managing \& Capturing Cospecialisation Economies

Reorganising Managing \&

Capturing Cospecialisation

Economies

\begin{tabular}{ll|l|l|l|l|l|l|l|l|l|l|l|l|l}
0.0 & 6.9 & 6.9 & 3.4 & 10.3 & 3.4 & 6.9 & 6.9 & 3.4 & 3.4 & 0.0 & 0.0 & 3.4 \\
\hline
\end{tabular}

Selecting Decision Making Protocols

Recognising Inflexion Points

Avoiding Decision Errors \&

Anticannibalisation Proclivities

\begin{tabular}{|l|l|l|l|l|l|l|l|l|l|l|l|l|l|}
0.0 & 3.7 & 3.7 & 3.7 & 3.7 & 14.8 & 11.1 & 7.4 & 3.7 & 7.4 & 7.4 & 7.4 & 3.7 \\
\hline 30.0 & 0.0 & 0.0 & 0.0 & 10.0 & 0.0 & 0.0 & 0.0 & 10.0 & 0.0 & 0.0 & 0.0 & 0.0 \\
\hline
\end{tabular}


Table 31: Amalgamated Case Dynamic Capabilities Heat Maps Continued

Building Loyalty \& Commitment

Demonstrating Leadership

Effectively Communicating

Recognising Non-economic

Factors

Transformation

\begin{tabular}{|c|c|c|c|c|c|c|c|c|c|c|c|c|}
\hline \multicolumn{13}{|c|}{ Building Loyalty \& Commitment } \\
\hline 8.7 & 4.3 & 0.0 & 4.3 & 4.3 & 17.4 & 13.0 & 0.0 & 4.3 & 0.0 & 13.0 & 4.3 & 4.3 \\
\hline 22.2 & 0.0 & 0.0 & 11.1 & 0.0 & 0.0 & 44.4 & 0.0 & 0.0 & 0.0 & 0.0 & 0.0 & 0.0 \\
\hline 0.0 & 22.7 & 4.5 & 4.5 & 18.2 & 9.1 & 13.6 & 0.0 & 9.1 & 0.0 & 0.0 & 0.0 & 0.0 \\
\hline $\begin{array}{c}\text { HighR } \\
\text { es2 }\end{array}$ & $\begin{array}{c}\text { MidRe } \\
\text { s1 }\end{array}$ & $\begin{array}{c}\text { MidRe } \\
\text { s2 }\end{array}$ & $\begin{array}{c}\text { MidRe } \\
\text { s3 }\end{array}$ & $\begin{array}{c}\text { MidRE } \\
\text { s4 }\end{array}$ & $\begin{array}{l}\text { MidRe } \\
\text { s5 }\end{array}$ & $\begin{array}{c}\text { MidRe } \\
\text { s6 }\end{array}$ & $\begin{array}{c}\text { MidRe } \\
\text { s7 }\end{array}$ & $\begin{array}{c}\text { MidRe } \\
\text { s8 }\end{array}$ & $\begin{array}{c}\text { MidRe } \\
\text { s9 }\end{array}$ & $\begin{array}{c}\text { LowR } \\
\text { es } 4\end{array}$ & $\begin{array}{c}\text { LowR } \\
\text { es3 }\end{array}$ & $\begin{array}{c}\text { LowR } \\
\text { es2 }\end{array}$ \\
\hline
\end{tabular}

Percentage of Total Discussion

Decentralisation

Adopting Loosely Coupled

Structures

Embracing Open Innovation

Developing Integration and

Coordination Skills

\begin{tabular}{|c|c|c|c|c|c|c|c|c|c|c|c|c|c|}
\multicolumn{10}{c}{ Decentralisation } \\
\hline 0.0 & 11.9 & 0.0 & 11.9 & 2.4 & 7.1 & 7.1 & 0.0 & 9.5 & 4.8 & 7.1 & 4.8 & 2.4 \\
\hline 21.1 & 5.3 & 5.3 & 5.3 & 5.3 & 2.6 & 5.3 & 13.2 & 0.0 & 7.9 & 0.0 & 7.9 & 0.0 \\
\hline 5.1 & 7.7 & 10.3 & 7.7 & 15.4 & 5.1 & 10.3 & 0.0 & 5.1 & 7.7 & 7.7 & 0.0 & 0.0 \\
\hline
\end{tabular}

Cospecialisation

Managing Strategic Fit so that Asset

Combinations are Value Enhancing

\begin{tabular}{|l|l|l|l|l|l|}
\hline 0.0 & 11.5 & 7.7 & 3.8 & 11.5 & 0.0 \\
\hline
\end{tabular}

7.7

$15.4 \quad 11.5$

3.8

$0.0 \quad 0.0$ 
Table 31: Amalgamated Case Dynamic Capabilities Heat Maps Continued

\section{Governance}

Achieving Incentive Alignment

Minimising Agency Issues

Checking Strategic Malfeasance

Blocking Rent Dissipation

\begin{tabular}{|c|c|c|c|c|c|c|c|c|c|c|c|c|}
\hline 11.1 & 11.1 & 0.0 & 0.0 & 11.1 & 11.1 & 5.6 & 5.6 & 0.0 & 0.0 & 11.1 & 0.0 & 0.0 \\
\hline 5.3 & 5.3 & 5.3 & 0.0 & 15.8 & 5.3 & 15.8 & 0.0 & 5.3 & 5.3 & 10.5 & 0.0 & 0.0 \\
\hline 6.3 & 0.0 & 12.5 & 0.0 & 25.0 & 0.0 & 12.5 & 0.0 & 0.0 & 0.0 & 0.0 & 0.0 & 0.0 \\
\hline 4.5 & 9.1 & 13.6 & 9.1 & 18.2 & 0.0 & 0.0 & 0.0 & 9.1 & 9.1 & 4.5 & 0.0 & 9.1 \\
\hline
\end{tabular}

Knowledge Management

Learning

Knowledge Transfer

Knowhow Integration

Achieving Intellectual Property Protection

\begin{tabular}{|c|c|c|c|c|c|c|c|c|c|c|c|c|c|c|}
\hline 5.9 & 23.5 & 0.0 & 11.8 & 0.0 & 5.9 & 0.0 & 5.9 & 5.9 & 0.0 & 0.0 & 0.0 & 0.0 \\
\hline 2.9 & 5.7 & 11.4 & 2.9 & 17.1 & 2.9 & 17.1 & 5.7 & 2.9 & 5.7 & 0.0 & 2.9 & 0.0 \\
\hline 3.0 & 0.0 & 12.1 & 3.0 & 21.2 & 3.0 & 12.1 & 6.1 & 6.1 & 6.1 & 3.0 & 6.1 & 0.0 \\
\hline 19.0 & 19.0 & 4.8 & 9.5 & 9.5 & 0.0 & 14.3 & 0.0 & 9.5 & 0.0 & 4.8 & 4.8 & 0.0 \\
\hline
\end{tabular}




\subsection{Chapter Summary: Findings}

The findings chapter has provided a synthesised overview of the evidence that was collected and analysed in order to answer the research questions. The cases were structured to fit the dynamic capabilities framework (Teece, 2007). HighRes1, LowRes1 HighRes3 and HighRes4 were discussed in full. These cases were chosen as they represented the most and least resilient firms (HighRes1 and LowRes1) and particularly interesting stories of resilience (HighRes3 and HighRes4). The remainder of firms were amalgamated into a master case to represent the remainder of the findings from the seventeen surveyed firms; their results are shown in Table 31 a combined heat map. 


\section{Discussion}

\subsection{Chapter Introduction}

This chapter aligns the findings outlined in the previous chapter, with the resilience and dynamic capabilities literature. Divided into two parts, the chapter first discusses the insights from applying a dynamic capabilities framework for the examination of resilient action in firms. Part Two then conducts a structured discussion of a number of propositions that emerge from the integration of the literature and findings.

\subsection{Discussion Part 1: Reflections on Teece's Framework}

Teece's (2007) dynamic capabilities framework appears to provide a useful tool for examining the activities that contribute to the resilience of manufacturing firms. It offers a structured and encompassing view of the firm, its ecosystem, and the critical activities that enabled cause and effect relationships between action and outcome to become apparent in the data. Table 32 shows the difference in the percentage of discussion between the four most, and least, resilient firms. This highlights the differences in the areas of discussion between both cohorts of firm.

Table 32: Difference in proportion of references to dynamic capabilities in the most resilient compared to the least resilient firms.

\begin{tabular}{|c|c|c|c|}
\hline \multirow[b]{2}{*}{ Sensing } & \multicolumn{3}{|c|}{ Percentage of all discussion } \\
\hline & $\begin{array}{c}\text { Top } 4 \\
\text { Resilient } \\
\text { Firms }\end{array}$ & $\begin{array}{c}\text { Bottom } 4 \\
\text { Resilient } \\
\text { Firms }\end{array}$ & Difference \\
\hline Processes to Direct Internal R\&D & 46.8 & 11.3 & 35.5 \\
\hline Processes to Tap Exogenous Science \& Technology & 42.9 & 19.0 & 23.8 \\
\hline $\begin{array}{l}\text { Processes to Tap Supplier and Complementor } \\
\text { Innovations }\end{array}$ & 31.3 & 12.5 & 18.8 \\
\hline $\begin{array}{l}\text { Processes to Identify Target Market Segments, } \\
\text { Changing Customer Needs and Customer Innovation }\end{array}$ & 38.9 & 25.0 & 13.9 \\
\hline
\end{tabular}


Table 32: Difference in Proportion of References to Dynamic Capabilities in The Most Resilient Compared to The Least Resilient Firms Continued

\begin{tabular}{|c|c|c|c|}
\hline \multirow[b]{2}{*}{ Seizing } & \multicolumn{3}{|c|}{ Percentage of all discussion } \\
\hline & $\begin{array}{c}\text { Top } 4 \\
\text { Resilient } \\
\text { Firms }\end{array}$ & $\begin{array}{c}\text { Bottom } 4 \\
\text { Resilient } \\
\text { Firms }\end{array}$ & Difference \\
\hline \multicolumn{4}{|c|}{ Delineating the Customer Solution \& Business Model } \\
\hline Selecting the Technology \& Product Architecture & 36.7 & 13.9 & 22.8 \\
\hline Selecting Revenue Architectures & 35.6 & 11.9 & 23.7 \\
\hline Selecting Target Customers & 34.0 & 26.4 & 7.5 \\
\hline Designing Mechanisms to Capture Value & 39.4 & 10.6 & 28.8 \\
\hline
\end{tabular}

Selecting Enterprise Boundaries to Manage Complements \& Control Platforms

Calibrating Asset Specificity

Controlling Bottleneck Assets

Assessing Asset Appropriability

\begin{tabular}{|c|c|c|}
\hline 28.9 & 15.8 & 13.2 \\
\hline 36.4 & 13.6 & 22.7 \\
\hline 26.3 & 21.1 & 5.3 \\
\hline
\end{tabular}

Reorganising Managing \& Capturing Cospecialisation Economies

\begin{tabular}{|c|c|c|c|c|}
\hline $\begin{array}{l}\text { Reorganising Managing } \\
\text { Cospecialisation Economies }\end{array}$ & Capturing & 41.4 & 6.9 & 34.5 \\
\hline \multicolumn{5}{|c|}{ Selecting Decision Making Protocols } \\
\hline Recognising Inflexion Points & & 14.8 & 25.9 & -15.4 \\
\hline $\begin{array}{l}\text { Avoiding Decision Errors \& } \\
\text { Proclivities }\end{array}$ & Anticannibalisation & 80.0 & 0.0 & 80.0 \\
\hline \multicolumn{5}{|c|}{ Building Loyalty \& Commitment } \\
\hline Demonstrating Leadership & & 26.1 & 26.1 & 0.0 \\
\hline Effectively Communicating & & 44.4 & 0.0 & 44.4 \\
\hline Recognising Non-economic F & actors & 13.6 & 4.5 & 9.1 \\
\hline
\end{tabular}


Table 32: Difference in Proportion of References to Dynamic Capabilities in The Most Resilient Compared to The Least Resilient Firms Continued

\begin{tabular}{|c|c|c|c|}
\hline \multirow[b]{2}{*}{ Transformation } & \multicolumn{3}{|c|}{ Percentage of all discussion } \\
\hline & $\begin{array}{c}\text { Top } 4 \\
\text { Resilient } \\
\text { Firms }\end{array}$ & $\begin{array}{c}\text { Bottom } 4 \\
\text { Resilient } \\
\text { Firms }\end{array}$ & Difference \\
\hline \multicolumn{4}{|c|}{ Decentralisation } \\
\hline Adopting Loosely Coupled Structures & 23.8 & 21.4 & 2.4 \\
\hline Embracing Open Innovation & 42.1 & 7.9 & 34.2 \\
\hline Developing Integration and Coordination Skills & 20.5 & 10.3 & 10.3 \\
\hline \multicolumn{4}{|c|}{ Cospecialisation } \\
\hline $\begin{array}{l}\text { Managing Strategic Fit so that Asset } \\
\text { Combinations are Value Enhancing }\end{array}$ & 23.1 & 3.8 & 19.2 \\
\hline \multicolumn{4}{|c|}{ Governance } \\
\hline Achieving Incentive Alignment & 38.9 & 16.7 & 22.2 \\
\hline Minimising Agency Issues & 31.6 & 10.5 & 21.1 \\
\hline Checking Strategic Malfeasance & 50.0 & 0.0 & 50 \\
\hline Blocking Rent Dissipation & 14.3 & 14.3 & 0.0 \\
\hline \multicolumn{4}{|c|}{ Knowledge Management } \\
\hline Learning & 40.0 & 0.0 & 40 \\
\hline Knowledge Transfer & 25.7 & 2.9 & 22.9 \\
\hline Knowhow Integration & 21.2 & 9.1 & 12.1 \\
\hline Achieving Intellectual Property Protection & 23.8 & 9.5 & 14.3 \\
\hline
\end{tabular}

Sutcliffe and Vogus (2007) and Birkie et al. (2014) suggest that an appropriate theoretical framework through which to study resilience may be that of Dynamic Capabilities (Ambrosini \& Bowman, 2009; Helfat et al., 2007; Helfat \& Peteraf, 2009; Teece, 2007; Teece et al., 1997). One of the contributions of this thesis has been to 
investigate whether this is in fact the case through the application of Teece's operationalisation of the dynamic capabilities construct through the Sensing, Seizing, and Transforming framework.

Dynamic capabilities are positioned in the literature as capabilities that support the long term performance of firms (Eisenhardt \& Martin, 2000; Helfat et al., 2007; Helfat \& Peteraf, 2009; Teece, 2007). Evidence gathered by other authors suggests that dynamic capabilities do indeed contribute to performance, but with some mitigating variables, such as threshold levels of the capabilities and the mediating effect of the innovation performance - firm performance relationship (Bruni \& Verona, 2009; Grünbaum \& Stenger, 2014; Naldi, Wikström, \& Von Rimscha, 2014). In this study evidence emerged that supported these assertions, that is, firms that expressed more powerful and more variety of dynamic capabilities appear to be more resilient than those which express fewer, less diverse capabilities. Evidence also emerged that less resilient firms may have implemented these capabilities poorly when compared to more resilient firms.

In the process of categorising the capabilities expressed by firms within the structure of Teece's (2007) Sensing, Seizing and Transformation framework, some interesting insight into the types of actions that contribute to the resilience of firms during crises consistently emerged. Firm resilience is described by a number of authors as being the ability of firms to constantly renew and reorganise (Hamel \& Valikangas, 2003; Lengnick-Hall \& Beck, 2009; Webb \& Schlemmer, 2006) or 'processes and dynamics that create or retain resources' despite significant disturbance (Vogus \& Sutcliffe, 2007 , p. 3419). This is very similar to definitions of dynamic capabilities, which are positioned as the ability to build, integrate and reconfigure the firm's resources (Teece et al., 1997). Viewing resilience as the result of effective dynamic capabilities then, it would be expected that during a crisis, firms would show evidence of efforts to build, integrate or retain, renew and/or reorganise resources. The findings of this thesis 
suggest that resilient firms may be more active in these kinds of activities, and furthermore tend to fairly consistently express similar dynamic capabilities. The following quotes illustrate the types of processes that are exemplary of the capabilities the firms used to manage their resources during the GFC.

'Well we made a change in emphasis based on the conditions. We were looking to get efficiencies out of our process; so innovation was focused on finding ways to create those efficiencies. So removing international agents, new products and investing in our logistics and distribution were a major focus.' CEO HighRes1 (Designing Mechanisms to Capture Value)

'So we made a whole lot of... a lot of them were stupidly simple jigs that they allow people to work not hard, but smarter and far faster. So what happened now was instead of getting four or five breakers off the line in the day, we could now get twenty or thirty. Now you can start to sell. So our lead-time which used to be 32 weeks if you were lucky, started condensing down to 18 weeks and we were delivering on 18 weeks.' General Manager HighRes3 (Controlling Bottleneck Assets)

As can be seen in Table 32 (Page 192), the most resilient firms in the sample show a significantly higher proportion of the discussion of certain dynamic capabilities than the least resilient. Overall the resilient firms discussed dynamic capabilities more often than non-resilient firms. Teece's (2007) Sensing, Seizing and Transformation framework appears to describe the actions and processes firms use to find or invent a technology or opportunity, create business models and firms structures that allow it to exploit the opportunity, and to continually evolve and capture value from the new offering.

The sheer volume of collected and categorised statements that could reasonably be described as dynamic capabilities provides strong evidence that this frámework can be used as a tool through which to view and examine resilience. The finding that 196 
managers in resilient firms consistently discuss patterns of behaviour that characterise these kind of capabilities while resilient ones either do not, or do not discuss them consistently or as often, suggests that resilient firms are active in reorganising and creating new resources, business models, and structures around innovations designed to fit a dynamic environment. Non-resilient firms however, appear to express these capabilities less often and less consistently than resilient firms. Less resilient firms also displayed different capabilities than resilient ones. Resilient firms appear to develop multiple capabilities in parallel (Bingham, Heimeriks, Schijven, \& Gates, 2014).

The following section outlines the insight that has been gained from analysing the testimony of managers from a set of firms with a range of levels of resilience using the Sensing, Seizing and Transformation framework (Teece, 2007).

\subsubsection{Sensing}

Teece (2007) describes sensing capabilities as 'very much a scanning, creation, learning, and interpretive activity.' (p. 28) The aim of which is to identify and shape opportunities that the firm can later seize upon. The results of analysis show that overall, more resilient firms are more active at sensing for opportunities. In particular, managers from the four most resilient firms discussed actions and processes taken during the GFC that can be termed sensing capabilities. This appears to support Reinmoeller and van Baardwjik's (2005) finding of a relationship between the diversity of sources of ideas and resources for innovation and the performance of firms. These authors find that firms that increased spending on innovation, particularly during recessionary periods displayed resilience superior to other firms. Similarly, Muller, Valikangas and Merlyn (2005) suggest that resilience is benefited by discoveries, breakthroughs and opportunities the firms create from introspection and opportunism. 
However, sensing for opportunities does not appear to be exclusively the realm of resilient firms. Managers from a number of firms from the middle of the sample and below also discussed proportionately high numbers of certain sensing capabilities. These firms form a second peak of relatively high scores, suggesting that sensing alone is not sufficient to imbue a firm with resilience. This will be discussed in more detail in Proposition 2.

Figure 13: Sensing Totals

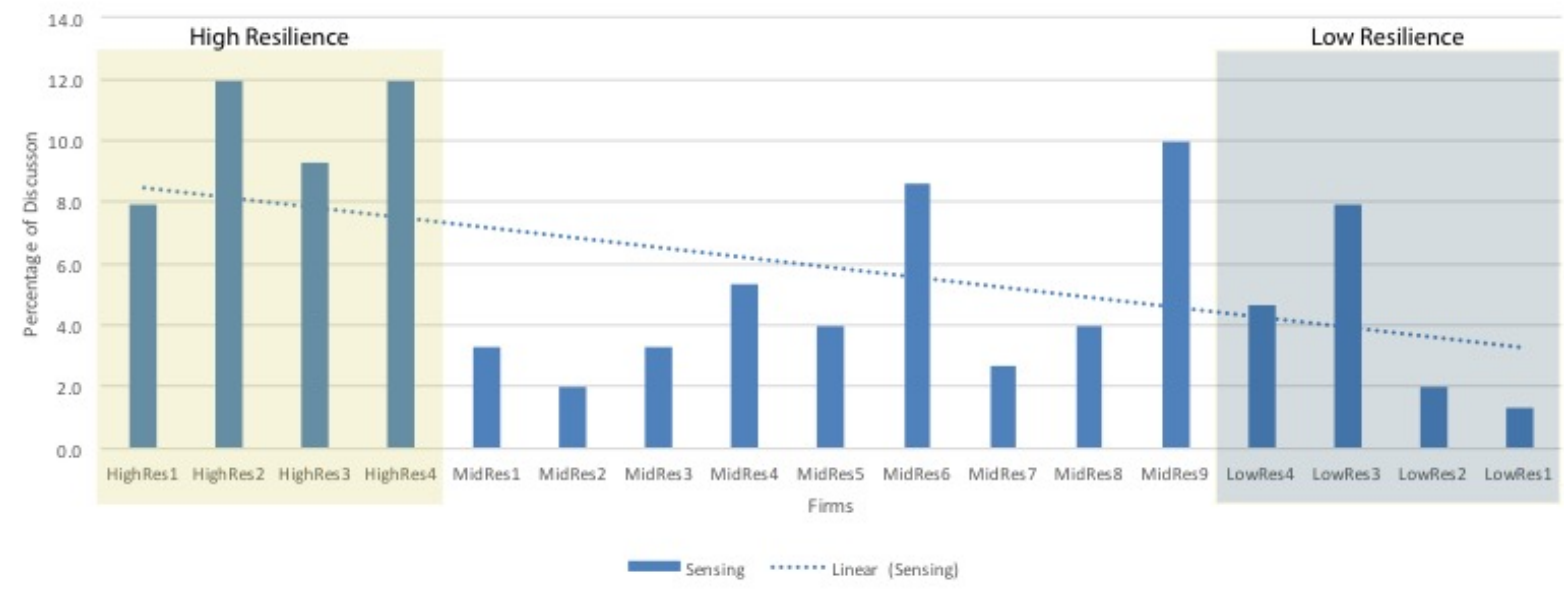

Despite this secondary peak, the overall trend for these types of capabilities is downward, towards the least resilient. This does suggest a relationship between sensing capabilities and resilience in firms (Figure 13).

\subsubsection{Sensing Summary}

Sensing capabilities regard the firm's ability to scan the environment for changes, technologies and opportunities (Teece, 2011). The findings suggest that resilient firms are active sensors, but in specific and targeted ways. Internal R\&D and to an extent external searches for technology were more present in resilient firms (Figure 13: Sensing Totals). 


\subsubsection{Seizing}

\subsubsection{Selecting Product Architectures and Business Models}

Chesborough (2010) and Chesborough and Rosenbloom (2002) discuss the role of the business model in extracting value from an innovation. They suggest that technology itself has no intrinsic value until a sufficiently structured business model exploits the features of the technology for profit. Resilient firms were significantly more likely to discuss capabilities that regard the development and evolution of business models. Not only are resilient firms more likely to have created, renewed, or reconfigured their business models, but more resilient firms are more likely to have had, or to have moved to, a business model that brings the firm closer to their clients and customers, lock them into the firms products, and thereby create more consistent and predictable flows of revenue.

HighRes1 utilises what their CFO described as the "Gillette Model" (Anderson, 2010) in which they provide a capital item for very little margin, in order to sell high margin consumables. Relatedly, both HighRes2 and 4 looked to integrate with their customers and develop bespoke solutions for the customer's products, locking the customer into the product for the effective distribution of their own products. HighRes3 reduced the cost of entry to its products by refurbishing both its own and competitor's products with new technology. The business models employed by these firms are in contrast to the typical manufacturing model employed by the less resilient firms in the study. The most resilient business models tended to be comprised of the capabilities discussed in the following paragraphs.

The resilient business models required that the firms make adjustments to their value chain and revenue structures (Chesbrough, 2010; Teece, 2007). In terms of selecting product architectures and business models, the most resilient firms manufactured 199 
products featuring technologies that they had developed themselves, through inhouse R\&D efforts. Although external searches for information were also utilised in the R\&D process, in resilient firms, these searches were on going and not focused on near commercialisation.

In designing revenue architectures, resilient firms were consistent in their efforts to improve the viability, consistency and diversity of revenues. The models these firms adopted were about aligning themselves with their customer needs and positioning products in such a way that the revenues from the products were tied to the consumer. In the cases of HighRes2 and HighRes4, these were often large international companies for whom sales were significantly de-risked, and had the expectation of global scale. Overall, the top four resilient firms looked to servitise (Raja, Bourne, Goffin, Çakkol, \& Martinez, 2013) their products by augmenting them with value-adding services or consumable components, this served to both increase and to create continuity of revenue while also improving customer experience.

Controlling bottlenecks appears to be a contributing capability of resilience. Resilient firms have invested in, or purchased capacity to improve throughput of bottleneck assets, or to capture gains in throughput by improving the precision and the bandwidth for volume in their existing assets. The only non-resilient firm that discussed this kind of capability put their efforts into increasing the speed of the transition between processes of manufacturing. 
Figure 14: Seizing Totals

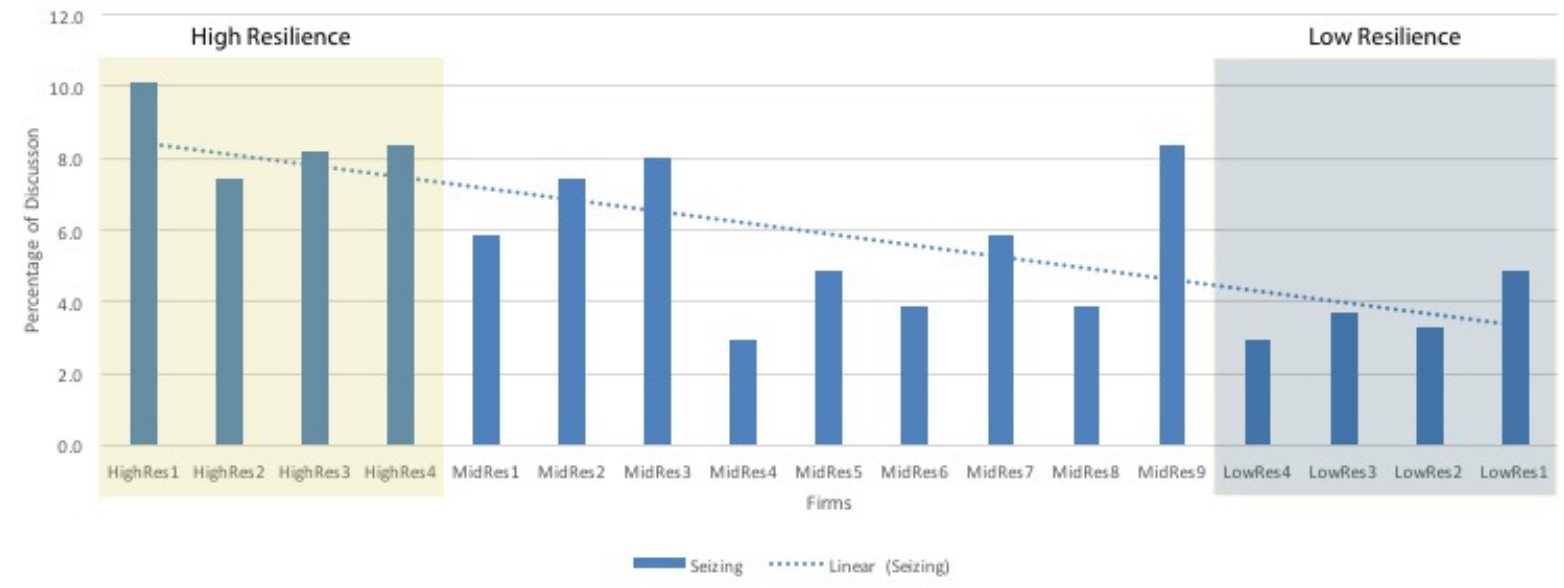

The results presented here show that resilient firms are active in discussing processes that resemble Seizing capabilities (Figure 14). The suggestion is that resilient firms are effective at designing business models, firm structures, and make decisions to capture value from an opportunity during a crisis.

Figure 15: Delineating the Customer Solution \& Business Model Totals

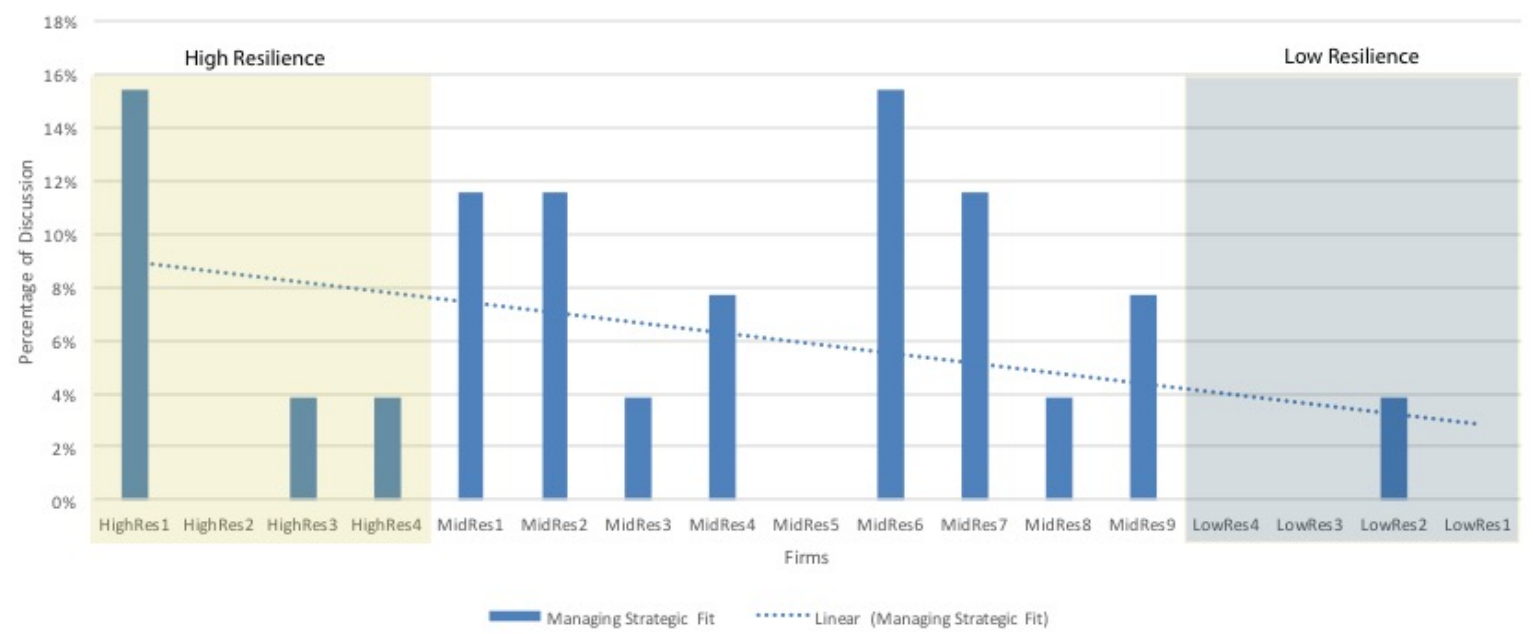

Chesbrough (2010) asserts that any technology has no intrinsic value and that the process of designing business models that effectively monetise an innovation are what imbue it with value. He goes on to say that a mediocre technology with an excellent business model may be more valuable than a great technology with a poor 
business model. Supporting this suggestion is the finding of this thesis that the business model of a firm appears to be a strong driver of its resilience (Figure 15). Hamel and Valikangas (2003) identify creating an appropriate business model as a challenge firms must overcome to create resilience.

Resilient firms were active in bringing their own researched and developed products and technologies to market. In selecting their technology platforms, resilient firms were careful in assessing prospective technology options for benefits. These were often defined in terms of the end user's own outcomes. Criteria such as cost, ease of use, ergonomics, and effectiveness were paramount, as was the technology's potential to create learning within the firm that could be applied in other areas. Less resilient firms conversely tended to move away from developing and designing their own products, adopting the existing platforms of others. That resilient firms focus their technology and product development around delivering value to the end user is a new insight generated by this study.

Teece (2007) suggests that the design and if necessary re-design of a firm's revenue structure is fundamental to the articulation of the business model and, as such, the core of its value proposition. Resilient firms made revenue model adjustments during the GFC that saw them move away from a commoditised product offering, towards a highly valued, high technology offering that was integrated into their customers' own businesses or lives through servitisation of products (Raja et al., 2013), where products are augmented through ancillary services. Customers become locked into the use of products due to their proprietary nature (in some cases bespoke to a customer's own products), or because knowledge asymmetries require customers to continue to employ the firm due to the risk of loss of product knowledge. Resilient revenue models appear to be designed to subvert the low demand of the GFC by creating demand (and hence revenue) through these lock-in approaches. Less resilient firms however, appear to continue to use a volume-centric approach to 
revenue. This would appear to fly in the face of the environmental conditions of historically low demand. Less resilient firms organised to produce in small runs or batch sizes as a response to the crisis, but smaller volumes and lower unit prices created strong pressure on their revenue models and represent a two-pronged reduction in profitability.

In selecting target customers, resilient firms appear to make extensions into new markets based on their similarity to their existing ones. Managers of resilient firms discussed how the firms targeted new customers using existing products and technologies. New markets were often identified geographically or by the opportunity to apply existing technologies. Resilient firms sold their traditional products in new geographic markets and into new sectors that had similar needs. They also applied structured decision framework to ensure product and market extensions were viable. For example, making extensions into areas that shared at least two of the criteria: the same client, same market or same technology. This ensured firms were banking on existing competencies.

Resilient firms were particularly active in designing mechanisms to capture value. Operational capabilities are those concerned with the efficiency of the firm (Teece, 2014b). However, in designing the value chain to retain the value of an innovation, resilient firms were driven to create efficiencies where possible. This included not only the vertical integration of firms but, also a continual focus on the development of operational efficiencies through resource development and alignment. This, in all cases, included moving to overseas locations to capitalise on the opportunities to reduce the transaction costs, both internal and external, of manufacturing and distributing products. Foss (2003) suggests that transaction costs provide a critical nexus for strategising. When these costs are positive, the opportunity to create, capture and protect value exists for firms. These outcomes are evident in the most resilient firms in the study. Each addressed transaction costs by integrating the 
distribution of their products into the value chain, extending and managing value chain components into countries where the costs of sourcing and manufacturing were lower, and improving the management of the value chain through implementing more accurate and sophisticated systems. In all cases, in resilient firms these systems were developed in-house, or purchased as bespoke packages in order to cater to the specific needs of the firm.

Resilient firms moved to setup manufacturing in low cost locations that were also closer to their key markets. This included outsourcing manufacturing activities to international providers and reducing reliance on local suppliers by sourcing from low cost locations. As well as reducing manufacturing costs, these firms made moves to self-distribute into other markets in order to capture value away from agents in the distribution and retail activities. Teece (2007) suggests that one of the factors driving success in the creation of a successful business model is a firm that understands their value chain, and how it can be organised to deliver in a cost effective and timely manner. Resilient firms appear to not only understand their value chains, but to be active in controlling what they understand to be crucial.

\subsubsection{Selecting Enterprise Boundaries to Manage Complements and Control Platforms}

Highly related to the business model design capabilities are those that relate to the setting of firm boundaries (Teece, 2007), where a boundary is the point in the value chain where transaction costs begin to be paid to external actors rather than exchanged within an internal economy. First, these decisions were designed to reduce the total value of external transaction costs, and second, to exert control over the supply chain. In reducing material costs and the costs of distribution, resilient firms were looking to capture and retain more of the margin of the final sale price of their products. When looking to exert control these firms were looking to, in turn, 
reduce the power of third party actors and to remove underperforming actors from the value chain.

These aims were achieved in a number of ways, including vertically integrating, reducing transaction costs, and outsourcing, reintegrating, or offshoring certain activities. Teece (1986), and Chesbrough and Teece (2002) outline how firms can organise their structure and boundaries to extract superior performance from innovations. These authors identify circumstances in which virtualisation (or outsourcing) capabilities can be beneficial in some firms and detrimental in others. They suggest that when superior capabilities to innovate exist outside the firm, it should 'go virtual' (p. 132). Conversely firms should look to retain manufacturing capabilities and processes to develop innovations in-house that they can perform better than the market. Lengnick-Hall et al. (2010) suggest dissolving organisational borders to improve resilience. Resilient firms made forward integration extensions into the distribution of their products towards end users. These changes were designed to improve the bottom line by banking the margin that would usually be appropriated by a third party distributor, but also to remove the variability and uncertainty that comes from selling through agents whose incentives to emphasize sales of a given brand's products is mediated by their portfolio of products from other firms. The majority of resilient firms integrated downstream toward their buyers, but some also moved to take control of the upstream supply chain. Less resilient firms did not make these vertical integration decisions. However, several less resilient firms did make horizontal integration moves. These changes did not appear to improve the firm's resilience, as they seem not to have alleviated any of the structural issues the firms encountered.

Resilient firms were active in assessing their access to capabilities. A number of these firms made decisions during the GFC either to outsource manufacturing processes, or to reduce the manufacturing burden to resemble an 'assembly' process. Other 
firms retained their manufacturing activities and either built new manufacturing capacity in lower cost locations, or worked to streamline and improve local manufacturing facilities. The most resilient firms appeared to be looking to increase their control over the value chain due to the risks of not having sourcing, or distribution, or manufacturing 'right' during a period of flat sales. Managers described the reason for outsourcing activities was to improve the flexibility they had to make changes to the scale of production. Similarly, efficiency, scale, and control were motivators for retaining activities in-house.

Manufacturing was scrutinised for its appropriability by competitors (Teece, 2007) more than any other activity. A number of firms employed secrecy and unique and highly technological processes to ensure that their assets, both physical and intangible, were protected from imitation.

A notable finding is that the decision to manufacture in-house, buy in premade components, and assemble, or outsource manufacturing was distributed across firms of all levels of resilience. The implication being that how these operational capabilities are accessed, as either in-house or purchased from the market, does not appear to affect the resilience of firms. Some resilient firms increased the scale of in-house manufacturing, banking on their capability to manufacture their products better than others. Meanwhile, others outsourced their manufacturing as one of the managers in these firms suggested, 'manufacturing is the hardest thing we do' (Managing Director HighRes4).

As such these firms became virtual manufacturers (Chesbrough \& Teece, 2002), designing and developing products through to commercialisation, outsourcing the manufacture and then distributing them to wholesalers or end users. It is notable however, that less resilient firms also made similar decisions to either retain and 
outsource manufacturing activities, further reinforcing the suggestion that these activities are not necessarily benefited by accessing the best capabilities, but that value for these firms is created elsewhere in the value chain. This is different to Teece (1986) and Chesbrough and Teece's suggestion that firms will gravitate towards the best capabilities. Instead (resilient) firms may look to focus control and energy into areas where they consider higher margins more achievable.

Overall the boundary decisions resilient firms chose to make were driven by the objectives of creating margin and productivity for these firms. Resilience literature offers little guidance on how firms should be structured, with the exception of Lengnick-Hall et al.'s (2010), who suggest that resilient firms dissolve their borders creating strong integration between themselves, customers, suppliers and complementors. This appears to be supported by the findings of this study with the caveat that borders should be dissolved in the areas that the firm can access superior capabilities in the environment and retain firm boundaries in those it cannot (Chesbrough \& Teece, 2002). This took the form of sourcing technologies and expertise from outside the firm and creating lasting links to those creators.

\subsubsection{Reorganising, Managing and Capturing Cospecialisation Economies}

Few firms discussed actions and processes that could be reasonably considered to fit Teece's (1986) concept of cospecialisation - defined as the ability of the assets of a firm to deliver unique value when combined. However, it could be argued that this is a difficult feature of firms to diagnose without explicit questioning which was not the nature of the approach. The questions posed to interviewees were based off resilience concepts and of those identified in the literature review, resource allocation and integration decisions do not feature prominently. However, the most resilient firms' managers describe benefiting both the top and bottom line of the firm by actively managing the interrelationships of their assets. Increases to productivity were 
unlocked by aligning manufacturing and distribution assets in specific locations, synergies in distribution were gained by acquiring distribution companies to move products more cheaply than before. The firm also looked to introduce new products into new markets and existing products into new markets. Leveraging their development and market development capabilities. The motivation was to create margin from the firm's value chain.

While this set of capabilities is only present in resilient firms, it is not as highly discussed in comparison with others. As such, it is difficult to identify whether it is a particularly strong contributor to resilience.

\subsubsection{Selecting Decision Making Protocols}

These capabilities provided an interesting view on the differences between resilient and non-resilient firms. Less resilient firms tended to discuss inflexion points (the points in time that they saw changes in their markets) more often than resilient ones did. Meanwhile, resilient firms were active in creating frameworks that structured information to enable better decision-making. These differences are shown in Table 33 on page 192.

Table 33: Selecting Decision Making Protocols Difference Between Top and Bottom Performing Firms

\begin{tabular}{|c|c|c|c|}
\hline Selecting Decision Making Protocols & 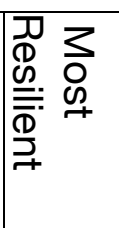 & 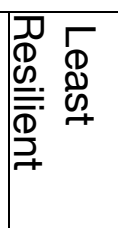 & 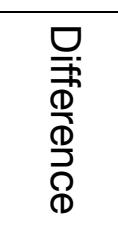 \\
\hline Recognising Inflexion Points & 14.8 & 25.9 & -15.4 \\
\hline Avoiding Decision Errors \& Anticannibalisation Proclivities & 80.0 & 0.0 & 80.0 \\
\hline
\end{tabular}


Lengnick-Hall and Beck (2009) describe resilient firms as having a complex and varied set of action alternatives that enable a firm to act in uncertain environments. Resilient firms were particularly active in creating decision frameworks that enabled them to make decisions more quickly and with outcomes that are more predictable. In such a manner these decision rules helped create these action alternatives by providing a type of pathway to outcomes that firms could use to validate the option set. These frameworks were both formal and informal in nature. With formal approaches to structuring information including accounting frameworks and documentation of standard operating procedures. While informal approaches included 'rule of thumb' type common sense criteria. Eisenhardt (1989b) outlines how firms that make decisions quickly often consider more information and generate more options when doing so and elicit better performance as a result. She also suggests that decisions create subtasks and actions that must also be performed effectively for the decision to be successful. Generally, resilient firms' decision-framing mechanisms were driven by conservativeness - that is not to overextend the firms into poorly understood terrain.

Hamel and Valikangaas (2003) suggest that firms need to be free from denial nostalgia and hubris as part of overcoming a 'cognitive challenge' to the creation of resilience. firms that make decisions using quantified and validated frameworks are potentially removing these biases from their decisions. Coutu (2002) suggests that when coping responses (sets of actions designed to manage a disturbance) are created using an appropriate understanding of the firm's environment, resilience results. These decision frameworks that structure information on the environment for example, the most resilient firm's constant currency reporting, potentially relay the environments' features to the managers to better inform their decisions.

Conversely in the case of the least resilient firm, despite assessing that their [Country 2] operation had to be shut down, the firm's overall performance and ability to recover 
from significant financial losses because of that, was a likely contributor to their lack of resilience. Their decision to close their operation showed that their post-decision actions were just as important as the decision being made and that the sub-decisions such as how to dismiss debt and employees were indicative of managers that had overcome the 'cognitive challenge'.

Meanwhile the least resilient firms were more active in discussing their inflexion points - the points at which their markets turned and became more difficult to operate within. It may be that this preponderance of discussion at the low end of resilience is indicative of managers in these firms post-hoc justification of the firms' poor performance, while more resilient firms simply do not consider the environment to be such a disruptive or hostile setting for business. Testimony from the managers in less resilient firms suggests that they have a tendency to lay the blame for poor performance on the environment. Their sentiment was that market forces created circumstances that were outside the manager's capacity to manage with the resources at their disposal.

\subsubsection{Building Loyalty and Commitment}

These capabilities were modestly represented in terms of total discussion. However, there were still very clear distinctions between the resilient and less resilient firms. (Table 34) 
Table 34: Building Loyalty and Commitment Differences Between Top and Bottom Performing Firms

\begin{tabular}{|c|c|c|c|}
\hline Building Loyalty \& Commitment & 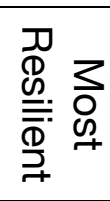 & 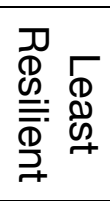 & 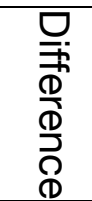 \\
\hline Demonstrating Leadership & 26.1 & 26.1 & 0.0 \\
\hline Effectively Communicating & 44.4 & 0.0 & 44.4 \\
\hline Recognising Non-economic Factors & 13.6 & 4.5 & 9.1 \\
\hline
\end{tabular}

The findings of this study suggest that leadership capabilities as well as other capabilities required to create loyalty and commitment in firms are at best consistently practiced across firms of all levels of resilience Teece (2007). Managers in resilient firms discuss their physical presence as motivators as being crucial to their success, while in less resilient firms, managers are seen to be 'walking the talk' to employees, reinforcing the firms' difficult financial status. Issues of firm culture were not central to the discussion in any cluster of firms.

Focusing on high quality communications however, was discussed in resilient firms. Because there was comparatively little evidence of these types of capability, 'presence of communications' was used as a proxy for 'effectiveness'. Lengnick-Hall et. al (2010) suggest that an organisational climate of open communication and collaboration are components of the preconditions for behavioural resilience, and that the outcome of this is an ability to combine originality and initiative to capitalise on an immediate situation. Seville (2006) also suggests that good communication is required for resilience, identifying communications with both internal and external stakeholders as key drivers. 


\subsubsection{Seizing Summary}

Seizing capabilities relate to a firm's ability to change in order to capture value from an identified technology or opportunity (Teece, 2007). The findings showed that certain seizing capabilities were consistently present in resilient firms and not nearly as consistently present in non-resilient firms (Figure 16). Structural changes and capabilities to change the value chain structure were evident in firms that are more resilient, in particular lengthening the firms reach towards customers was a consistent feature of resilient value chains.

Several other seizing capabilities including Reorganising, Managing \& Capturing Cospecialisation Economies; Assessing Asset Appropriability; and Demonstrating Leadership appear to be necessary but not sufficient to create resilience. This finding is discussed later in this chapter as Proposition 2.

Figure 16: Seizing Capabilities that Contribute to Resilience

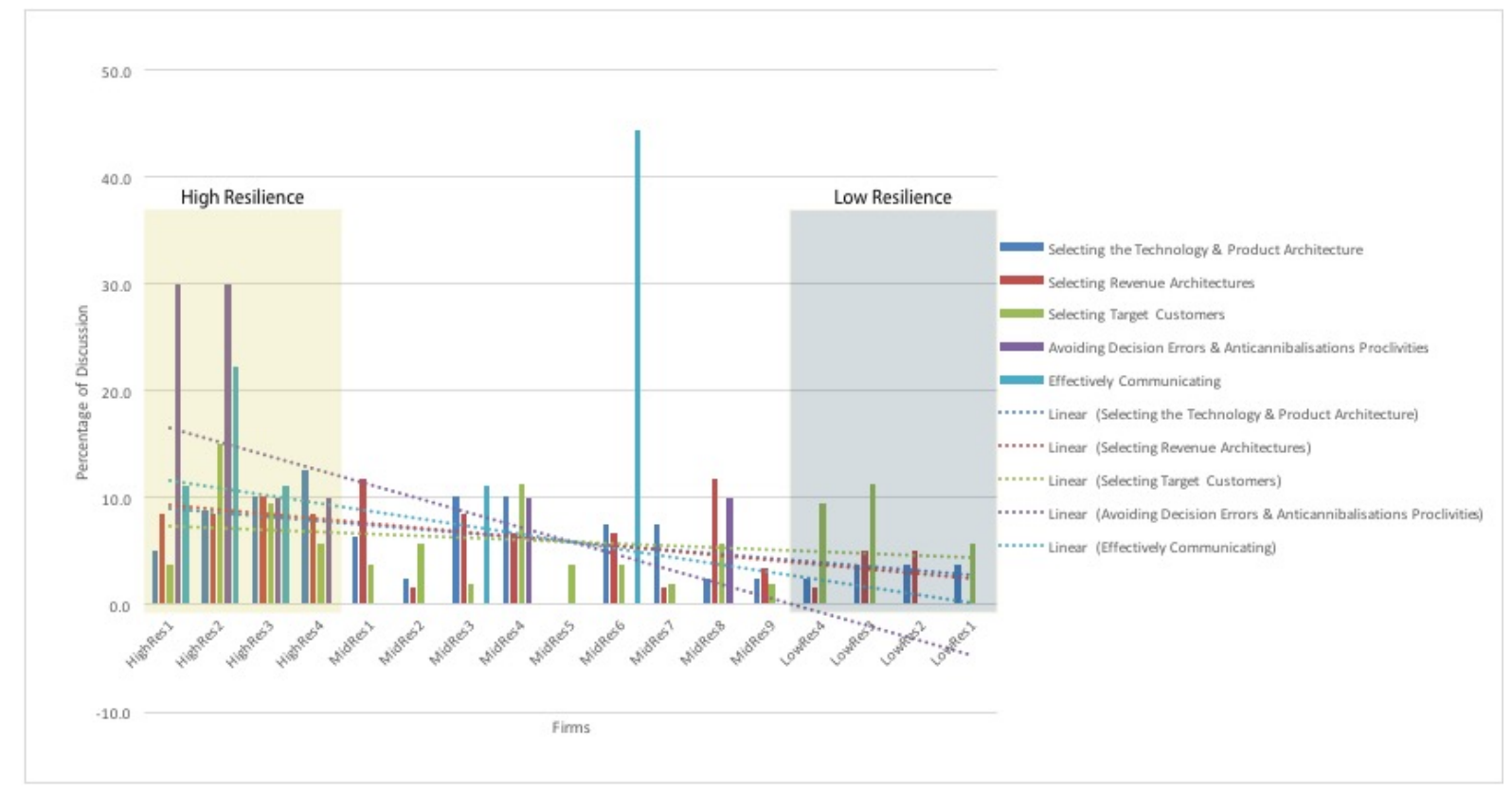




\subsubsection{Transformation}

\subsubsection{Decentralisation}

The decentralisation capabilities of a firm regards its ability to create quasiindependent profit centres (Teece, 2007). These capabilities were not evenly distributed, instead showing similar volumes of discussion across different levels of resilience for some and high levels of disparity in others.

Table 35: Decentralisation Differences Between Top And Bottom Performing Firms

\begin{tabular}{|c|c|c|c|}
\hline Decentralisation & 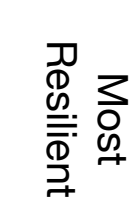 & 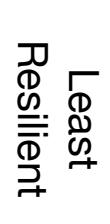 & $\begin{array}{l}\stackrel{\square}{D} \\
\stackrel{D}{D} \\
\mathbb{D} \\
\widetilde{D} \\
\mathbb{D}\end{array}$ \\
\hline Adopting Loosely Coupled Structures & 23.8 & 21.4 & 2.4 \\
\hline Embracing Open Innovation & 42.1 & 7.9 & 34.2 \\
\hline Developing Integration and Coordination Skills & 20.5 & 10.3 & 10.3 \\
\hline
\end{tabular}

As firms increase in size, the distance information must travel before decisions can be made increases in a centralised system, reducing flexibility and responsiveness (Teece, 2007). However, the testimony from managers in this study shows that decentralising their firms into quasi-independent profit centres was not a priority in resilient firms. The structure of subsystems and their coordination were discussed in firms from across the range of resilience, with a number of firms acquiring or developing satellite profit centres. Although these firms were actually increasing the centralisation of the firm's system as the satellite facilities were in all cases designed to funnel work back to the centre. Instances of true decentralisation - such as in the lowest resilience firm - lead to the obfuscation of the extent of disturbance and ultimately to one of the largest blows to the viability of the firm. In the instance of the least resilient firm, the decentralisation of decision making enabled a manager to hide 
the poor performance of his subsidiary, and as the multinational's largest operation, the loss of a substantial amount of the whole firm's annual profit. Ljungquist (2014) finds that excessive autonomy of a firm's subunits can hinder the transfer of knowledge and information across the firm. In other firms of low resilience, near total independence from their parent companies reinforce the finding that a particularly decentralised organisation may hinder resilience. These firms both struggled with growth and competition despite the freedom to make their own decisions during the GFC.

Open innovation, where firms utilise outside sources of information and pathways to market (Chesbrough, 2003), was highly employed in resilient firms in accessing sources of information outside their boundaries. This was approached by creating research arrangements with related organisations, with clients, customers, or with dedicated contracting outfits. Highly resilient firms show evidence for having engaged in open innovation practices. While firms with lower resilience also openly innovated, their approach tended to be ad hoc, with fewer long-term arrangements and more transactional instances of information and innovation sourcing. It is notable in these results, that sourcing innovations for new product development or process innovations was common, while sourcing pathways to markets was observed less

often. It seems that open innovation capabilities are valuable when employed consistently, forging strong, ongoing links to external sources of knowledge and ideas. Lengnick-Hall and Beck $(2005,2009)$ describe the feature of resilient firms as including functional habits that open up new sources of ideas and information during a disturbance. The open innovation model of information gathering would appear to be encompassed by this conception of a resilience response.

\subsubsection{Managing Strategic Fit and Cospecialisation}

As a key part of the reconfiguration of a firm's assets and resources, cospecialisation capabilities were highly represented in resilient firms. This suggests they were active 
in ensuring their strategic assets were working synergistically to create inimitable value for the firm.

Table 36: Managing Strategic Fit and Cospecialisation Differences Between Top And Bottom Performing Firms

\begin{tabular}{|c|c|c|c|}
\hline Cospecialisation & 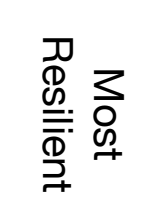 & 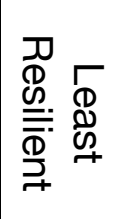 & 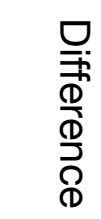 \\
\hline $\begin{array}{l}\text { Managing Strategic Fit so that Asset Combinations are } \\
\text { Value Enhancing }\end{array}$ & 23.1 & 3.8 & 19.2 \\
\hline
\end{tabular}

Ensuring that a firm's assets are part of a synergistic whole is the role of capabilities at the centre of managing strategic fit and cospecialisation (Teece, 2007). Entrepreneurs and managers can produce specialised value from the cospecialisation of assets. The data suggests that while most resilient firms discuss managing their assets for fit, so to do firms towards the centre of the resilience scale (Figure 17). Less resilient firms do not discuss this type of capability with notable frequencies. Resilient firms however, when discussing the fit of their assets exclusively describe how improving productivity and efficiency from the value chain was the unifying objective for efforts to manage strategic fit. 
Figure 17: Managing Strategic Fit so that Asset Combinations are Value Enhancing

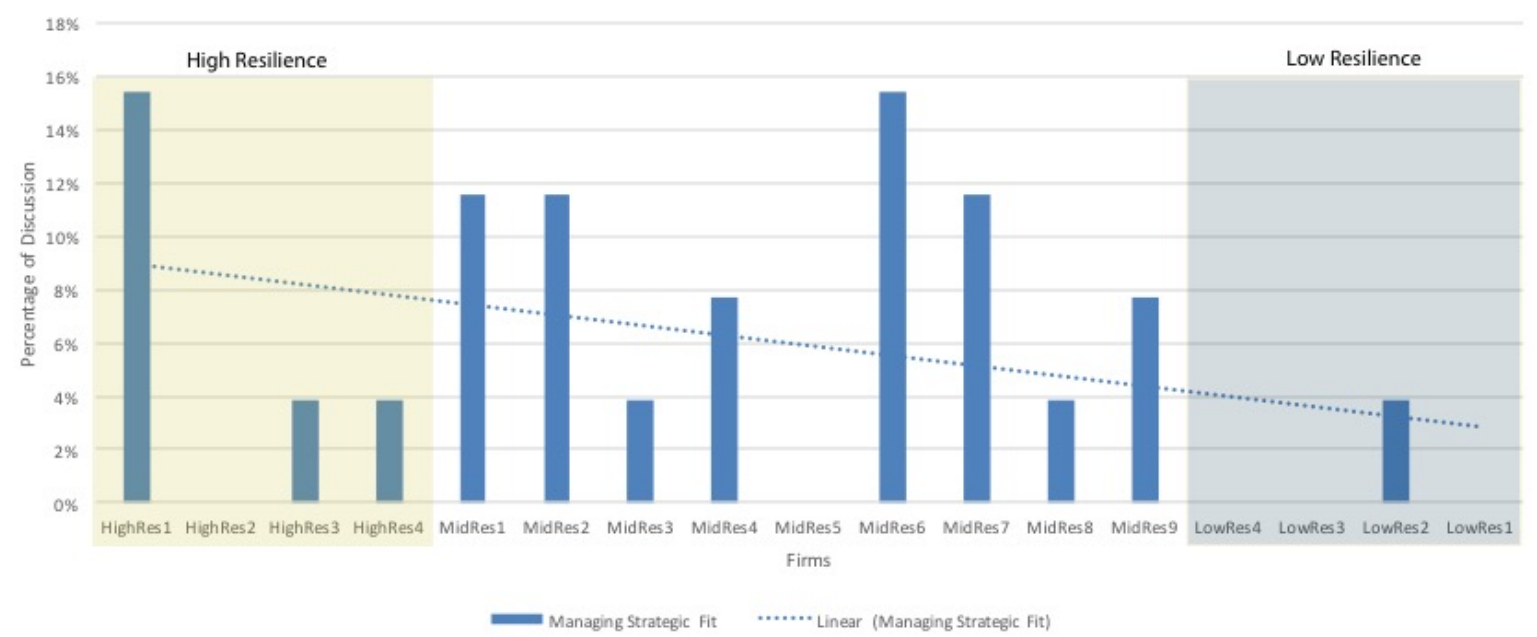

Managers in resilient firms discuss how productivity and efficiency, cost efficiency, and integration and control of the value chain were their goals for managing fit. However, mid-scoring firms also discuss these in similar terms. Ljungquist (2014) finds that unbalanced dynamic capabilities detract from efficiency. As the resilience of firms declines, their balance of dynamic capabilities also decreases, becoming more inconsistent in their application across the sensing, seizing and transformation framework. For these firms a lack of efficiency gained from efforts to manage strategic fit may have been affected by the unbalanced application of dynamic capabilities.

\subsubsection{Governance}

Governance capabilities were discussed consistently in resilient firms, while less resilient firms tended to discuss them both less often, but also in inconsistent amounts. Checking strategic malfeasance is particularly disparate between the clusters of firms. 
Table 37: Governance Capabilities Difference Between Top And Bottom Performing Firms

\begin{tabular}{|c|c|c|c|}
\hline Governance & 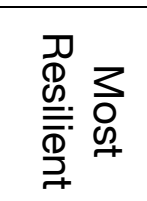 & 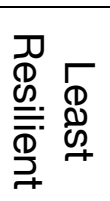 & 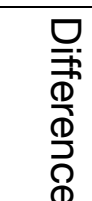 \\
\hline Achieving Incentive Alignment & 38.9 & 16.7 & 22.2 \\
\hline Minimising Agency Issues & 31.6 & 10.5 & 21.1 \\
\hline Checking Strategic Malfeasance & 50.0 & 0.0 & 50 \\
\hline Blocking Rent Dissipation & 14.3 & 14.3 & 0.0 \\
\hline
\end{tabular}

Managers in resilient firms were active in managing their boards and management in order to enable them to affect the changes they saw as necessary to create further change (Teece, 2007). Managers in these firms were active in petitioning and compromising with their Board of Directors to enable them to hedge more foreign exchange than allowed under existing covenants. One CEO removed the majority of an underperforming board and replaced them with higher performing individuals. The potential finding being that manager's interactions with the Board of Directors, the potential limits imposed upon them and the compromises made, were contributors to resilience. Contrasted with the unfettered autonomy of managers in less resilient firms, the implication was that poor management decision making went unchecked.

Resilient firms appear to be active in managing their governance structures through dynamic capabilities (Teece, 2007). While potentially undermining the job security of employees by removing underperforming staff, these firms were active in building relationships through leadership (Smart, Cameron, \& Ulrich, 1986), hiring highly qualified and experienced staff and providing equity incentives to staff for performance (Lengnick-Hall et al., 2010). Managers in less resilient firms discussed how a lack of incentives might have lead to poor performance in managers (for 
example LowRes1's [Country 2] manager who 'had no skin in the game'), although this is not a consistent finding across firms. Less resilient firms in the study however, often struggled to remove underperforming staff and managers in a timely manner. In none of the lower performing firms is there is discussion of reorganisation or renewal of governance structures.

\subsubsection{Knowledge Management}

In applying Teece's (2007) framework to the data, it is apparent that managers in resilient firms when discussing their resilience strategies, were more likely to describe their exemplary knowledge management dynamic capabilities than managers in less resilient firms.

Table 38: Knowledge Management Capabilities Differences Between Top And Bottom Performing Firms

\begin{tabular}{|c|c|c|c|}
\hline Knowledge Management & 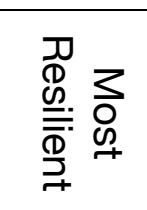 & 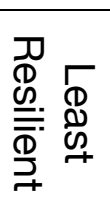 & 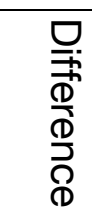 \\
\hline Learning & 40.0 & 0.0 & 40 \\
\hline Knowledge Transfer & 25.7 & 2.9 & 22.9 \\
\hline Knowhow Integration & 21.2 & 9.1 & 12.1 \\
\hline Achieving Intellectual Property Protection & 23.8 & 9.5 & 14.3 \\
\hline
\end{tabular}

Knowledge management dynamic capabilities are among the most consistently discussed across resilient firms, when compared with the less resilient. Resilient firms in the study were simply more active in managing their knowledge resources than firms with poorer performance. In fact the managers in the five lowest scoring firms did not discuss any capabilities that could have been described as learning, that is, 
the creation of new knowledge via experiential, vicarious, individual, or organisational processes (Teece, 2007). Learning in resilient firms is described in terms of the structuring and codification of experiences by managers and employees to ensure value is captured for its reuse in other situations. In resilient firms, these learnings were transferred and integrated across the organisations.

Managers of resilient firms discussed the development of standard operating procedures that were used to reduce the cost of performing processes multiple times. Firms codified knowledge to create 'banks' or repositories of this knowledge that they could rely on when it became more appropriate or valuable. Zollo (1998) found that codified processes are often valuable because they improve the capability of the firm to manage these processes better but also create 'know-why' as well as the knowhow to perform. That is to say, the process of codifying requires the understanding of motivations for actions and processes in order to extract optimum value from the procedure. The transfer and integration of knowhow across the firms was highly represented in the most resilient firms. These firms were active in their attempts to disseminate captured knowledge across the firm and to integrate it into practice.

\subsubsection{Transformation Summary}

Transformation capabilities were expressed in more resilient firms, although particular capabilities were clearly stronger contributors than others. Efforts made by firms to manage knowledge appeared to provide considerable benefits to their resilience, as did governance and managing strategic fit. This was particularly evident when comparing the most resilient with the least. Meanwhile, decentralisation capabilities were expressed by firms from across the sample. 


\subsubsection{Operationalising Teece's Dynamic Capabilities}

Existing research on dynamic capabilities has begun the process of creating analytic frames through which examples of strategy in practice can be (Barreto, 2010; Di Stefano et al., 2010; Eisenhardt \& Martin, 2000). Initial forays have so far employed Teece's (2007) conceptualisation at a high level, analysing for the presence of sensing, seizing or transformation capabilities (Naldi et al., 2014). This thesis has pursued a more granular approach by operationalizing at the lower, or more detailed, level of these capabilities (Teece, 2007).

One of the findings from employing this granularity as an approach it was observed that Teece's (2007) framework has some areas of significant overlap, not only within the sub-categorisation of capabilities, such as Governance, or Selecting decisionmaking protocols, or knowledge management, but also across these categories. This created two issues for analysing the data. First, there was a consistent difficulty in differentiating particular dynamic capabilities from each other. For example, Teece describes open innovation as:

'The open innovation model of Chesbrough (2003) also recognizes the benefits of relying on a distributed model of innovation where the enterprise reaches out beyond its own boundaries to access and integrate technology developed by others' (Teece, 2007, p. 1337).

But Teece also describes knowhow integration as:

'The combination of know-how within the enterprise, and between the enterprise and organizations external to it (e.g., other enterprises, universities), is important' (Teece, 2007, p. 1339). 
While these definitions appear reasonably distinct, operationalisation becomes difficult when considering the similar thematic principles inherent in the terms, and combinations of terms shared by both definitions. This is compounded by the fact that interviewees were not answering questions that asked about dynamic capabilities explicitly (a strength of the methodology in other ways). As such diagnosing the difference between evidence for a particular capability was at times problematic.

Secondly, and a related issue was that certain instances of testimony reoccurred consistently as evidence for different capabilities. For example, this quote from the CEO of the most resilient firm:

'We look to have two out of three of the following criteria when targeting a new area and that is: the [client], the same channel, or the same technology. That way we are safely banking on existing competencies.' CEO HighRes1

This short quote fits the operationalisation of a number of capabilities, including: processes to direct internal $R \& D$, selecting the product technology and architecture, avoiding decision errors and anticannibalisation proclivities, knowledge transfer, and knowhow integration. It succinctly sums up a directive for action that at once fits Teece's (2007) description of each these capabilities. This gives rise to the question, are these capabilities too closely related to be adequately differentiated? In which case it may be that a higher level of abstraction, that of the second tier of capabilities is more appropriate for study to avoid these overlaps; or does this instead suggest that the actions of managers in firms are simultaneously representative of multiple capabilities? This issue does not appear to have been discussed in other studies that examine dynamic capabilities. 
Within the scope of this study, the granularity of operationalisation was beneficial for a significant proportion of Teece's (2007) capabilities. The dynamic capabilities that regard a firm's capacity to drive internal R\&D processes, choose business models, value capture and revenue models, select decision protocols, and others, provide interesting and differentiated findings arising from the evidence provided by managers. As such, it may be that while certain processes are evidence for the simultaneity of expression of capability, others may be benefited by being combined or collapsed into more delineated categories. Governance, some knowledge management, and the cospecialisation capabilities are among those that may benefit from either further differentiation, or combining to create more distinction, and enabling more accurate and descriptive research outcomes.

\subsubsection{Summary of Reflections on Teece's Framework}

The dynamic capabilities framework used in the analysis for this thesis to categorise and examine the testimony of managers has proven a useful means of creating understanding of the types of change and activities that can create resilience in firms (Figure 18). The managers of resilient firms, while discussing other aspects of strategy, resources and related topics, were concerned with how their firm employed high-level capabilities to coordinate and manage the fit of resources other strategic variables (Helfat et al., 2007; Teece, 2014b; Teece et al., 1997). It was at an interesting finding to note that resilient firms tended to discuss actions from across the entire framework with considerable consistency. This application of the dynamic capabilities framework is an initial validation of Sutcliffe and Vogus' (2007) and Birkie et. al's (2014) suggestions that the actions of resilient firms is potentially well understood through the use of a dynamic capabilities framework. In doing so this thesis has provided an initial attempt at the alignment of these two strands of strategic management literature. 
Figure 18: References to total Sensing, Seizing and Transformation by Firm, in Order of Resilience

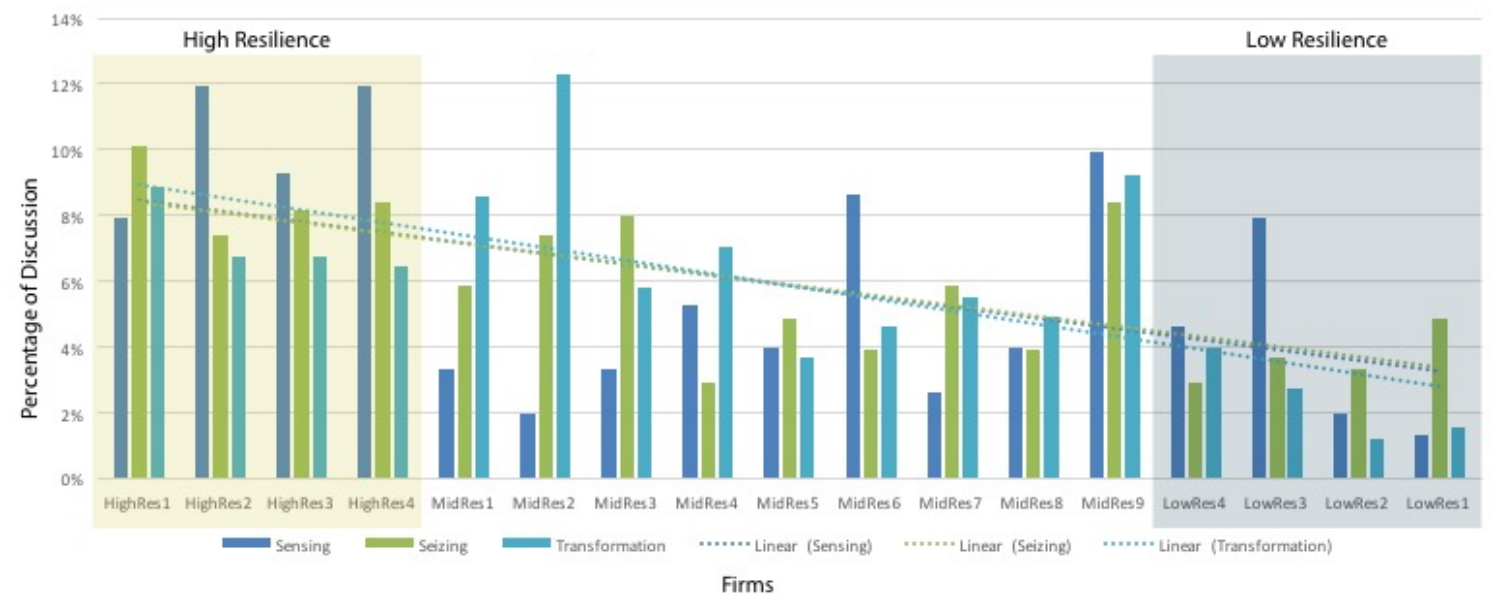

It is notable that the areas of the framework where resilient firms were more active in their discussion differed from those of less resilient firms (see Table 39 page 226). Resilient firms were more active in the capabilities that regard searching for, creating and retaining knowledge, creating business models, value chain and organisational structures, that are more efficient and create more consistent revenue streams. The following propositions discuss these findings in more detail. 


\subsection{Discussion Part 2: Propositions}

This section of the chapter describes four 'propositions' that have emerged as findings out of the analysis of data. It is necessary at this point to clarify the term proposition. Generally in research, a proposition is a 'potentially testable component of a theory' (Lynch, 2013, p. 11). In scientific research, a proposition would be developed into research questions and subsequent falsifiable hypotheses (Avan \& White, 2001). As such, a proposition is constituent to a theory and enables its further elaboration through research. In this case, the term proposition has been used as 'a statement or assertion that expresses a judgment' (Oxford University Press, 2010). The judgment(s) being asserted are those that have been identified in the process of analysis and have been reasonably derived. The use of this term is preferable to other categorisations of the developed findings as while being warranted assertions (such as the findings of post-positive research are considered to be), they also elaborate the theory of resilience, and each provides a framing of a potential research avenue in the future, satisfying in part some of the criteria of the research definition of the term.

\subsubsection{Proposition 1:}

Resilient firms have specific bundles of capabilities that make them so.

The discussion of Teece's (2007) framework has elucidated how, when viewed as dynamic capabilities, the data suggests that resilient firms employ both more, and more diverse dynamic capabilities when strategising for resilience. However, what is also apparent in the data is that particular bundles of capabilities are present across resilient firms. A bundle is used in this instance to refer to capabilities that are consistently expressed across firms in a given cluster, not any groupings derived from literature. These bundles were uncovered by comparing the presence and prevalence of these capabilities in resilient firms with their absence in non-resilient ones. These 
bundles include capabilities that could be considered both resilience creating, and failure preventing capabilities (McKee, Conant, Varadarajan, \& Mokwa, 1992). Resilience creating capabilities are those that appear, either in a bundle or individually, to provide better than average performance during a crisis. Failure preventing capabilities on the other hand appear to enable a firm to sustain performance, or to at least stave off failure from the effects of a crisis.

Resilient firms appear to display combinations of capabilities including:

- Processes to direct internal R\&D.

- Delineating the customer solution and business model.

- Selecting enterprise boundaries to manage complements and control platforms.

- Avoiding decision errors and anticannibalisation proclivities.

- Decentralisation.

- Governance, and.

- Knowledge management capabilities.

These capabilities are those that are consistently displayed by resilient firms, but are also not consistently present in either non-resilient or middling firms. In examining the data for patterns, similar themes emerge. Resilient firms expressed dynamic capabilities that created, exploited and retained knowledge within the firm and then (re)structured the firm to capture as much margin from the application of that knowledge in the creation of products. These capabilities, arranged by the difference in scores between high and low resilience firms are shown in Table 39. 
Table 39: Dynamic Capabilities Expressed by Most and Least Resilient Firms - Sorted by Difference

\begin{tabular}{|c|c|c|c|}
\hline Sensing & \multicolumn{3}{|c|}{ Transformation } \\
\hline Dynamic Capability & 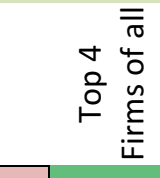 & 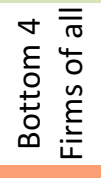 & 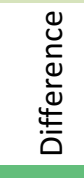 \\
\hline Avoiding Decision Errors \& Anticannibalisation Proclivities & 80.0 & 0.0 & 80.0 \\
\hline Checking Strategic Malfeasance & 50.0 & 0.0 & 50.0 \\
\hline Effectively Communicating & 44.4 & 0.0 & 44.4 \\
\hline Learning & 47.1 & 0.0 & 47.1 \\
\hline Processes to Direct Internal R\&D & 46.8 & 11.3 & 35.5 \\
\hline Reorganising Managing \& Capturing Cospecialisation Economies & 41.4 & 6.9 & 34.5 \\
\hline Embracing Open Innovation & 42.1 & 7.9 & 34.2 \\
\hline Designing Mechanisms to Capture Value & 39.4 & 10.6 & 28.8 \\
\hline Processes to Tap Exogenous Science \& Technology & 42.9 & 19.0 & 23.8 \\
\hline Selecting Revenue Architectures & 35.6 & 11.9 & 23.7 \\
\hline Knowledge Transfer & 25.7 & 2.9 & 22.9 \\
\hline Selecting the Technology \& Product Architecture & 36.7 & 13.9 & 22.8 \\
\hline Controlling Bottleneck Assets & 36.4 & 13.6 & 22.7 \\
\hline Achieving Incentive Alignment & 38.9 & 16.7 & 22.2 \\
\hline Minimising Agency Issues & 31.6 & 10.5 & 21.1 \\
\hline Managing Strategic Fit so that Asset Combinations are Value Enhancing & 23.1 & 3.8 & 19.2 \\
\hline Processes to Tap Supplier and Complementor Innovations & 31.3 & 12.5 & 18.8 \\
\hline Achieving Intellectual Property Protection & 23.8 & 9.5 & 14.3 \\
\hline $\begin{array}{l}\text { Processes to Identify Target Market Segments, Changing Customer Needs and } \\
\text { Customer Innovation }\end{array}$ & 38.9 & 25.0 & 13.9 \\
\hline Calibrating Asset Specificity & 28.9 & 15.8 & 13.2 \\
\hline Knowhow Integration & 21.2 & 9.1 & 12.1 \\
\hline Developing Integration and Coordination Skills & 20.5 & 10.3 & 10.3 \\
\hline Recognising Non-economic Factors & 13.6 & 4.5 & 9.1 \\
\hline Selecting Target Customers & 34.0 & 26.4 & 7.5 \\
\hline Assessing Asset Appropriability & 26.3 & 21.1 & 5.3 \\
\hline Blocking Rent Dissipation & 18.2 & 13.6 & 4.5 \\
\hline Adopting Loosely Coupled Structures & 23.8 & 21.4 & 2.4 \\
\hline Demonstrating Leadership & 26.1 & 26.1 & 0.0 \\
\hline Recognising Inflexion Points & 14.8 & 25.9 & -15.4 \\
\hline
\end{tabular}


Table 39 shows not only that resilient firms appear to express similar capabilities to each other, and that less resilient firms express different capabilities, The bundles of capabilities expressed by resilient firms span all of the categories of dynamic capabilities - Sensing, Seizing, Transformation, but notably they often do not include all of the capabilities that constitute a sub class of dynamic capabilities. For example, the capabilities that constitute the knowledge management category such as Learning are expressed more in highly resilient firms. Other knowledge management capabilities such as Knowhow integration occur further down the list - with a lower differential between high and low resilience firms.

These bundles reinforce the starting position of this thesis, that resilience is created by the application of dynamic capabilities during a crisis. The consistent bundles of dynamic capabilities present in resilient firms (and conversely not present in less resilient firms) support these findings.

The resilience literature offers a number of groupings of attributes that create resilience in firms. Authors phrase these in various ways, however, their approaches to describing them differ. Hamel and Valikangas (2003) describe resilient firms as having overcome a number of challenges. These are cognitive, behavioural, political and ideological challenges. Lengnick-Hall and Beck, (2009) and Lengnick-Hall, et al. (2010) also discuss cognitive and behavioural dimensions to resilience as well as adding a contextual dimension. Other authors also describe resilience as emerging from the alignment of attributes of firms (Bell, 2002). The proposition made here is that these authors' suggestions that firms need to align a particular group of attributes in order to be resilient appears to be bear out. Seville (2006) considers the adaptive capacity of firms as antecedent to resilience. The adaptive capacity - as the ability of the firm to enact environmentally appropriate change - would appear to be a strong match to the effective bundles of dynamic capabilities found here. 


\subsubsection{Summary of Proposition 1}

Overall, it appears that particular dynamic capabilities, either individually or as a bundle are present in resilient firms, or are not, or not in such significant proportions, in less-resilient ones. The most resilient firms are consistently active in searching for, or creating technologies and knowledge through sensing and knowledge management capabilities. They are also very active in evolving their business models and firm structures to capture more margin, efficiencies and revenue from their businesses. Managing the cospecialisation and strategic fit of the firms' assets was also a prevalent set of capabilities, these capabilities were strongly related to the way business models, and indeed firms, were structured in order to capture further value from particular unique combinations of assets.

Less resilient firms, however, were significantly less likely to express such combinations of dynamic capabilities. Instead, managers of these firms may have been emphatic regarding particular areas that could be considered dynamic capabilities, but these were often expressed in isolation, or in a punctuated fashion from across the framework.

\subsubsection{Proposition 2:}

Some dynamic capabilities can be necessary but not sufficient to create resilience

A running debate in the dynamic capabilities literature is the relationship between capabilities and competitive advantage. Zollo and Winter (Teece, 2007) suggest that dynamic capabilities create advantage when they are heterogeneously distributed across firms. Helfat et al. (2007) and Eisenhardt and Martin (2000) decouple dynamic capabilities from competitive advantage, suggesting there are mediating variables between the antecedent capabilities and the outcome of advantage. While dynamic capabilities are useful in the creation of resources, they do not necessarily result in 228 
ones that are uniquely valuable (Ambrosini \& Bowman, 2009). The technical and evolutionary fitness of the capabilities (Helfat \& Peteraf, 2009) are attributed with the effectiveness of those capabilities to create resources that lead to advantage. In a recent review of extant literature, Eriksson (2014) found that the link between dynamic capabilities and performance was still undefined.

In analysing the data here, a clear pattern emerged that suggested the presence of a set of capabilities that appear necessary but not sufficient to create resilience in a firm, invoking comparisons to the 'two-factor' hygiene theory (Herzberg, Mausner, \& Snyderman, 1993). The necessity but not sufficiency of dynamic capabilities has been alluded to in literature to date (Eisenhardt \& Martin, 2000; Villar, Alegre, \& Pla-Barber, 2014). The focus being on the mitigating variables (such as technical fitness of the capability or the actions of competitors). However, in the setting(s) studied here the suggestion emerging from the data is that particular capabilities may on their own never contribute sufficient value to create resilience in a crisis.

Varadarajan and others $(1992 ; 1985)$ describe two classes of competitive strategy variable; success producers and failure preventers that, based on the two-factor theory (Herzberg et al., 1993; Rajan, 1985) explain how various 'skills' can either produce success in firms by eliciting higher than average rents, or prevent failure. In failure prevention activities, no matter how much effort is applied, they will not produce success in a firm; merely stave off failure. The results of the analysis of data for this thesis show that there are certain dynamic capabilities while present in resilient firms, are also present in poorer performing firms. 
Figure 19: Dynamic Capabilities as Resilience Contributors or Necessary but not Sufficient

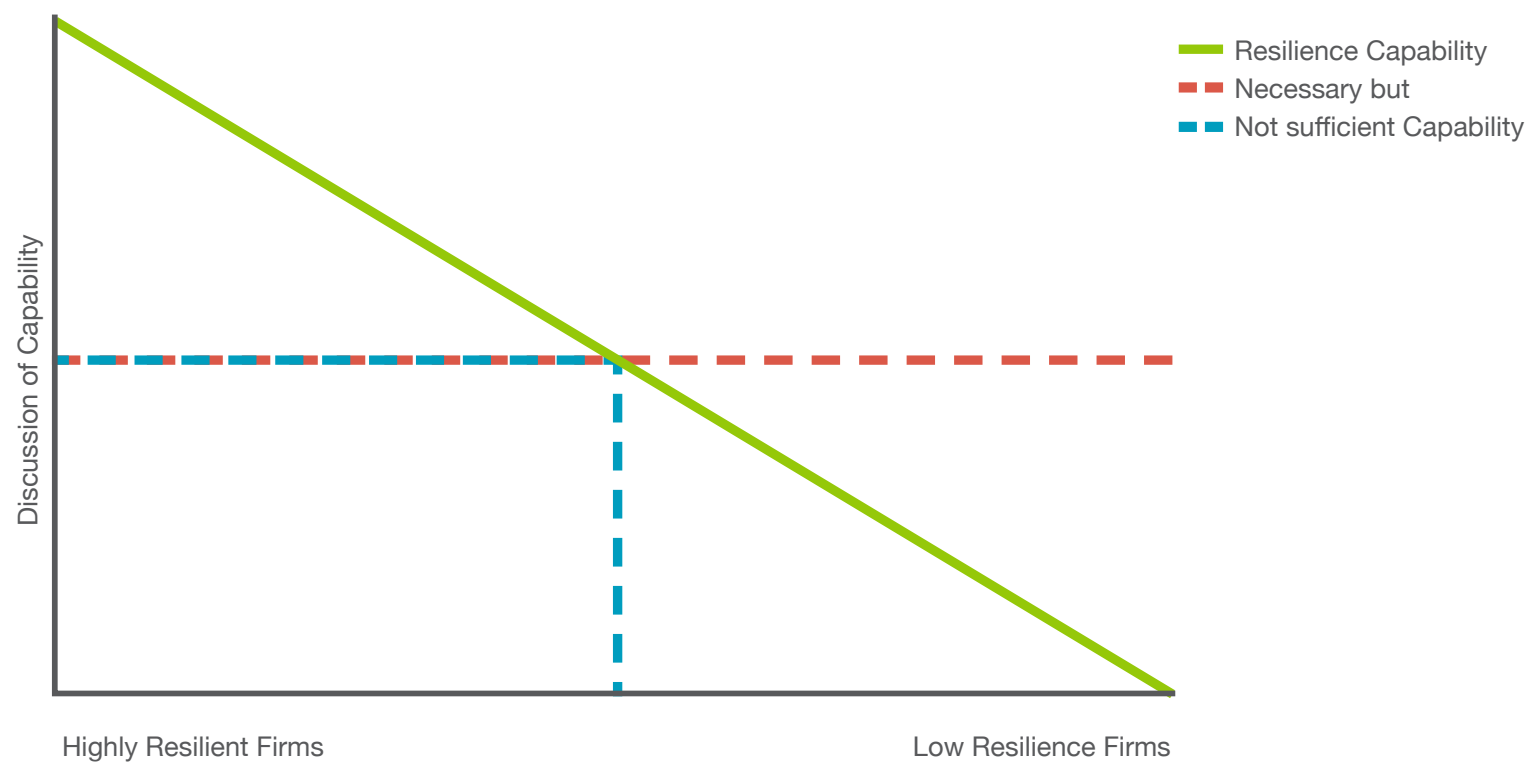

Figure 19 depicts how different capabilities (as sets of actions) might be present in firms of various performance levels. Resilience providing capabilities would be more often present in resilient firms. Detracting capabilities would be more often present in less resilient firms. Those capabilities that are necessary but not sufficient would be expected to be present in all firms, and, they may also be present in firms that are resilient through to middling firms.

The Resource-Based View of the firm (RBV), seeks to describe how a firm can create advantage though leveraging bundles of tangible or intangible resources that it has at its disposal (Barney, 1996; Peteraf, 1993; Wernerfelt, 1984). To sustain above average returns on these assets, they must fit all of the conditions of being Valuable, Rare, Inimitable and, Non-Substitutable (VRIN) (Barney, 1991; Barney, 1986; Dierickx \& Cool, 1989; R Rumelt, 1984). While in combination a resource with these attributes may provide unique value, each of these criteria are considered individually to be necessary but not sufficient to create sustainable advantage. Dynamic capabilities are often positioned within the RBV as one of the means that firms can use to create 
resources (Helfat \& Peteraf, 2009; Teece et al., 1997). As such, they are also distinctly separate from resources and are instead embedded in the processes that create them. Nonetheless, the finding that necessary but not sufficient capabilities may exist is a qualified link between these fields of theory.

The results of the analysis show that a number of dynamic capabilities may be necessary but not sufficient. These include: Processes to Identify Target Market Segments, Changing Customer Needs and Customer Innovation, Tap Supplier and Complementor Innovations, Building Loyalty and Commitment, Decentralisation and Near Decomposability, Cospecialisation, and Governance capabilities, from across the dynamic capabilities framework.

The capabilities to Tap Supplier and Complementor Innovations appear to have less relationship to resilience than other sensing capabilities (Figure 20). High and low scores from this capability class are distributed with less weight towards the resilient firms when compared to the internal R\&D and exogenous science and technology capabilities. The linear trend for the percentage of references shows a less than $2 \%$ average decline overall from resilient to non-resilient firms. In comparison the internal R\&D direction capabilities trend reduces by over $10 \%$ across the same scale. Capabilities to Tap Supplier and Complementor Innovations was an under-discussed area compared to other capability classes with little evidence to suggest particular approaches have any bearing on the resilience of firms. As such, this may have a lower evolutionary fitness than other capabilities in this sub-category of capabilities. Both resilient and non-resilient firms engaged with suppliers during the identification of opportunities. Again, resilient firms were more likely to have a formal approach working with suppliers and complementors. For example, one resilient firm had representatives of a client working on-site during a product development. 
Figure 20: Processes to Tap Supplier and Complementor Innovations

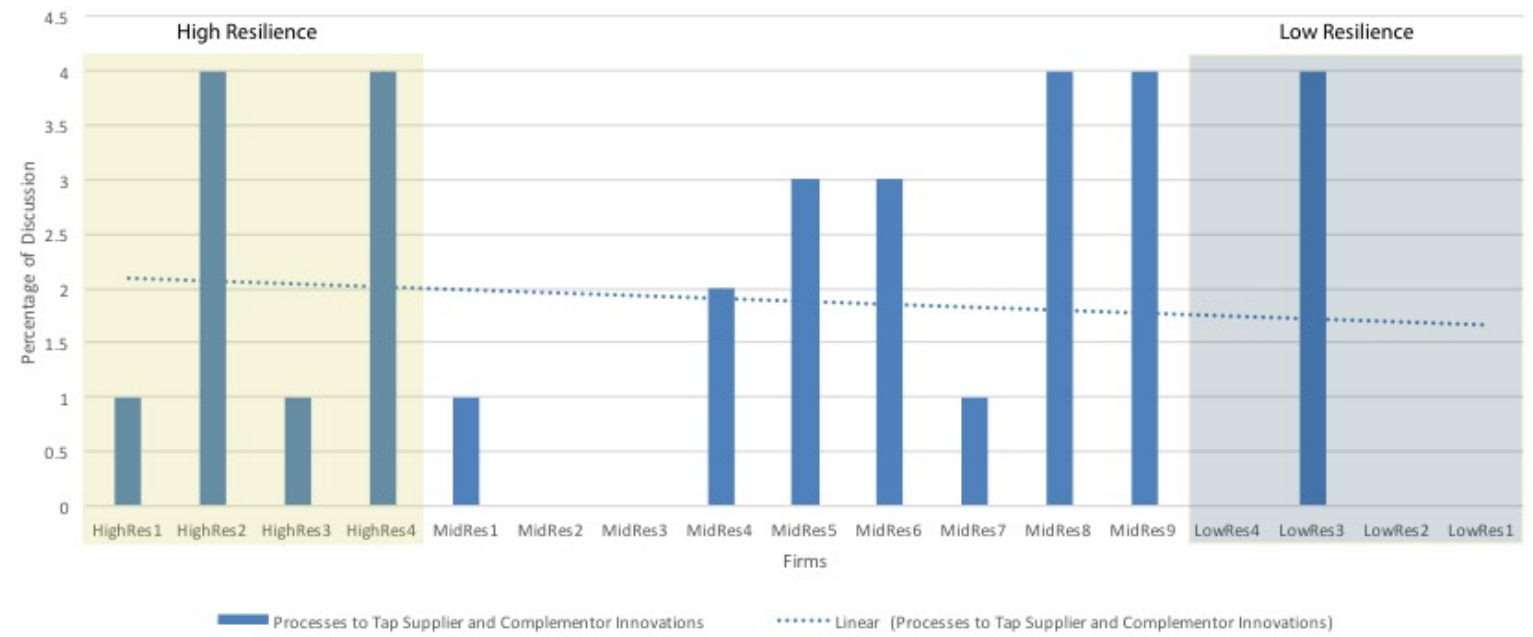

Evidence of processes to identify target market segments, changing customer needs and customer innovation capabilities were also inconsistently distributed across the firms when aligned across the objective resilience measures (Figure 21. While managers from resilient firms are slightly more likely to have discussed these processes, other firms also discuss them in similar volumes to resilient ones. In all instances, firms look to understand how customers use their products and what is valued and required of them. The potential implication is that understanding customer needs and their changes may be a failure preventer, rather than either a contributor or detractor of firm resilience. 
Figure 21: Processes to Identify Target Market Segments, Changing Customer Needs and Customer Innovation

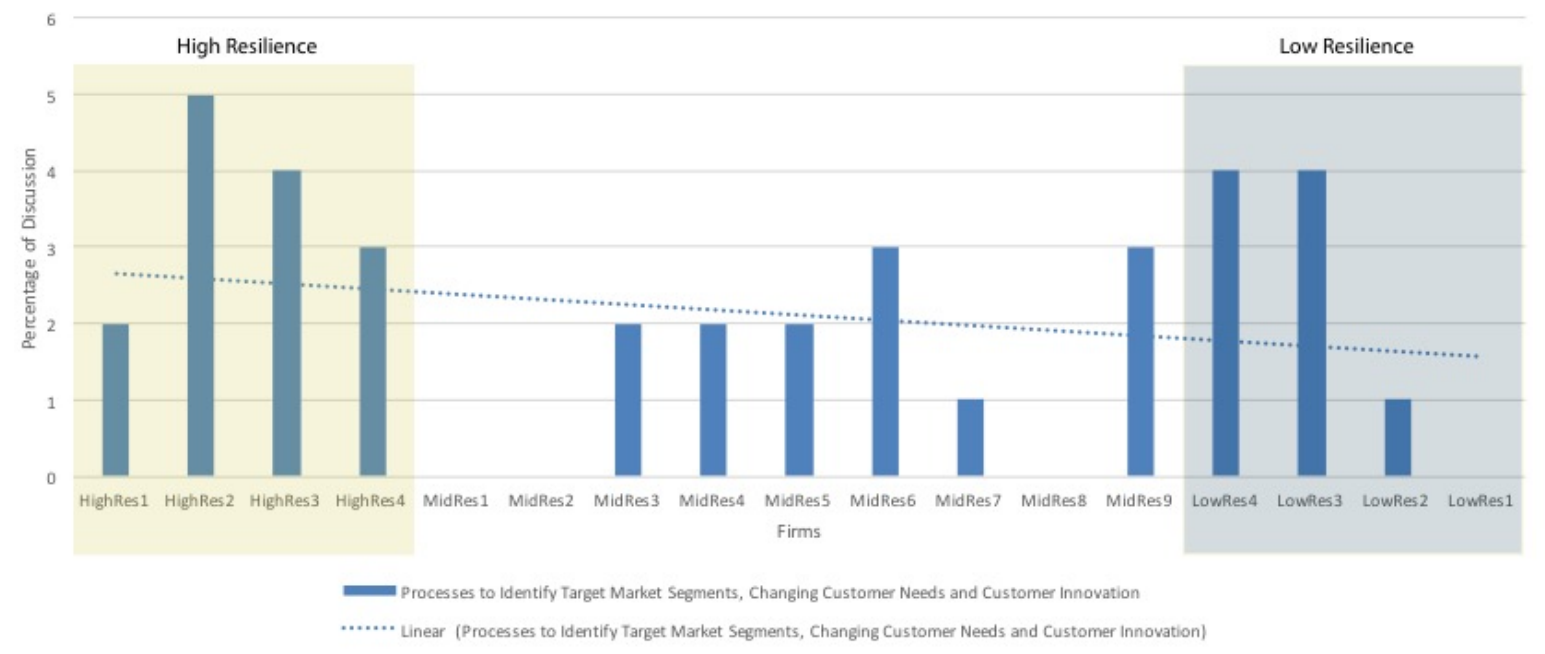

Demonstrating leadership is a seizing capability that regards managers' capabilities to make decisions with positive outcomes and to create loyalty (Teece, 2007). Managers from a range of firms discussed their efforts to ensure their leadership was visible to others and a positive influence on the firm. The presence of leadership capabilities was found in firms with a range of levels of resilience, including the poorest performers. Bell (2002) suggests that good leadership balances risk taking and risk containment, ensuring that innovation occurs but risk is mitigated. LengnickHall et al (2010) suggest that self-leadership is a feature of employees in resilient firms. However, this finding suggests that active management is more present in resilient firms diverging from Lengnick-Hall et al.'s suggestion.

Achieving Decentralisation and Near Decomposability are capabilities that relate to the organisation's ability to organise into semi-autonomous sub systems that can make decisions on their own, without having to adhere to hierarchical protocols (Teece, 2007). Teece suggests that adopting loosely coupled structures, openly innovating and developing integration and coordination skills, contribute to the firms' 
ability to decentralise effectively into quasi-independent profit centres. The identified resilience literature does not provide a view on the structure of firms.

A number of firms from across the sample opened or acquired facilities and satellite offices within New Zealand and overseas. The result was small, specific task oriented profit centres as decentralised offshoots of the group. However, because this was a process evident in firms from across the sample, it is possibly not a resilience imbuing strategy. Instead, the ability to create or acquire profit centres may simply be a prerequisite for subsistence during a crisis, according to these findings.

Open innovation was also consistently represented in testimony across a number of firms. While resilient firms still make up a substantial volume of the discussed open innovation capabilities, they are also discussed nonetheless in moderate to low resilience firms in meaningful amounts. However, open innovation was conducted differently in high and low resilience firms. As with other types of information sensing, resilient firms created lasting links with the sources of information in the form of research agreements and partnerships. Less resilient firms however, tend to approach these activities transactionally, looking to purchase the services or technologies of external agents on an as-needed basis.

Cospecialisation, as both a seizing (recognising, managing and capturing cospecialisation economies) and transformation (managing strategic fit so that asset combinations are value enhancing) capability was represented across a number of firms. Managers interviewed discussed combinations of their firm's assets as being particularly valuable. These managers described tangible assets being augmented by intangible assets, such as a firm's products being augmented by the firm's brand, or reducing costs through the combination of value chain assets. 
Building Loyalty and Commitment is a set of capabilities that relate to a firms capability to create those attributes in its human resources (Teece, 2007). While the effectively communicating capabilities were more prevalent in resilient firms, demonstrating leadership and recognising non-economic factors capabilities were consistently discussed by firms across the range of resilience. Leadership was expressed in a number of firms from across the sample as high visibility of managers and of managers being seen to do the right things given the circumstances. LengnickHall et al. (2010) suggest that creating a climate of open communication and collaboration is a contributor to resilience. These findings would add nuance to this in that rather than being a contributor to resilience, it is a foundational capability that is necessary for survival, rather than creates resilience.

Governance dynamic capabilities are those that relate to the creation of governance structures that improve the ability of the firm to perform (Teece, 2007). The resilient firms in the study were more active in managing their boards of directors in a manner that appeared to be consistent with the 'minimising agency issues' capabilities. These companies either changed their board members and chair people or were active in bargaining and compromising with them in order to create or retain particular freedoms to act.

Other governance capabilities however, were expressed across a range of firms, including achieving incentive alignment, checking strategic malfeasance, and blocking rent dissipation (Teece, 2007). Firms were active in aligning incentives to stakeholders including employees and board members, in the form of pay and stock but also to suppliers and customers in terms of the rates and prices they paid and offered. The firms were also active in ensuring that strategic malfeasance and rent dissipation were managed. Power brokers, silos and barriers to innovation both within and outside firms were removed. Excessive prices for supplies were managed through stringent cost comparison and competitive tendering, and the risk of bad 
debts and late payments and were reduced by retaining leverage over customers. Starr et al. (2003) describe how resilient firms have mapped and understood systemwide risk dependencies, while Carmeli and Markman (2011) identify attention to governance as critical to the resilience of firms. These governance actions appear to be consistent with this statement, however, as described, these capabilities appear to be necessary and not sufficient for resilience (McKee et al., 1992).

These findings add to the body of evidence suggesting that dynamic capabilities are decoupled from performance and advantage in firms by mediating variables (Easterby-Smith et al., 2009; Eisenhardt \& Martin, 2000; Eriksson, 2014; Helfat et al., 2007). Nuance is added to this theory given the resilience context. In extremely dynamic environments, despite their presence and application, certain capabilities may never provide performance, they may merely prevent failure (McKee et al., 1992).

The existing resilience literature does not discuss any set of actions, processes, or capabilities that are necessary but not sufficient to enable firms to cope with crises. Instead authors tended to focus on providing their view of what constitutes the prerequisites of resilience (cf. Bell, 2002; Carmeli \& Markman, 2011; Coutu, 2002; Hamel \& Valikangas, 2003; Lengnick-Hall \& Beck, 2009; Lengnick-Hall et al., 2010). As such, the contribution of necessary but not sufficient capabilities that underlie, but do not cause, resilience is new to the present literature.

\subsubsection{Summary of Proposition 2}

One of the findings of this thesis is that as well as capabilities that contribute to higher than average performance in firms during a crisis, there seems to be a bundle of capabilities that appear to prevent failure, enabling a firm to persist but not to perform highly. These include Processes to Identify Target Market Segments, Changing Customer Needs and Customer Innovation, Tap Supplier and Complementor 
Innovations Building Loyalty and Commitment, Decentralisation, and Near Decomposability, Cospecialisation, and Governance capabilities.

These capabilities refer to firms' ability to perform basic functions - identifying customers, knowing when those customers change their requirements or preferences, motivate staff to perform, setting up profit centres, getting assets to integrate to create value, and managing the firm appropriately.

The proposition of the existence of failure preventing capabilities augments the understanding of resilience by adding interesting nuance to the concept. While the types of capabilities proffered in proposition 1 may provide better than average performance, the capabilities that contribute the persistence component of resilience may be the failure preventing ones.

\subsubsection{Proposition 3:}

Capabilities that support efficiency and margin are among the most valuable in the creation of resilience.

Despite the proffered relationship between dynamic capabilities and long term firm performance (Grünbaum \& Stenger, 2014; Teece, 2007) their relationship to operational factors such as productivity, margin and profitability are mediated by the indirect effect of a firm's market strategy (Wang \& Ahmed, 2007). Bhamra et al. (2011) identify the efficient use of limited resources a key driver of resilience in firms. Similarly Sutcliffe and Vogus (2007) suggest that margin is vital to the resilience of firms. Evidence from both primary and secondary sources strongly suggested that during the GFC global demand for products in general was diminished (Bedford, 2008; Bellamy Foster \& Magdoff, 2009; Chor \& Manova, n.d.). With depressed sales, 
a number of the study firms acted to reconfigure their asset base to improve the bottom line contribution of their sustainable volumes of sales.

Teece (2014b) suggests that efficiency in firms is improved by operational capabilities that are themselves created by dynamic capabilities. The findings of this study are that resilient firms employed dynamic capabilities with the end goal of extracting margin-creating efficiencies from their value chain. That is, firms created, changed, and reconfigured their resources to create margin and efficiency. As such Teece's suggestion that dynamic capabilities are not themselves efficiency focused is born out by the findings of this study.

Managers in resilient firms discussed the reorganisation of their firm's assets to improve margin. New technologies that were created by resilient firms were designed to be lower cost to produce and with a higher margin to sell from the outset. The CEO of a highly resilient firm, was cognisant that their manufacturing business is structurally low margin, and as such looked to expand activities in the higher margin activity of contract research - already a part of their integrated product offering.

In examining the design of revenue models, firms clearly showed distinct gaps in the behaviours and capabilities between resilient firms when compared to non-resilient ones. The revenue models of resilient firms extended further up and down the value chain than others, and included a number of features, including servitisation of products, margin building, and retaining activities.

Business models, firm structures, and practices to create margin and improve the firms' bottom line were also discussed in resilient firms. This was achieved through increasing efficiency, but resilient firms also discussed techniques that locked customers into the use of the firm's products. 
Resilient firms often discussed how their approach to capturing margin was to integrate the distribution, wholesale and even retailing of their products to end users in order to bank the margin otherwise captured by a third party. A number of firms setup or acquired distribution channels. Some opted to remove distributors and retailers and offer products directly into particular markets.

Increasing diversity was used as a means to improve margins in resilient firms. Research dating back more than three decades continues to espouse the benefits of diversification (Palich, Cardinal, \& Miller, 2000; Rumelt, 1982). The Curvilinear model of diversification suggests that firms should diversify into related areas and that diversification into unrelated businesses reduces performance (Figure 22). LengnickHall, Beck and Lengnick-Hall (2010) suggest that resilient firms look to create a setting of diversity and adjustable integration during disturbances. Carmeli and Markman (2011) suggest that diversity of a firm's market capture strategy contributes resilience. The ecology and biodiversity literature clearly explicates the value of diversity and requisite variety to the resilience of ecosystem and other biological stability domains (Carpenter et al., 2001; Elmqvist et al., 2003; Folke et al., 2002; Ludwig, Walker, \& Holling, 1997). 
Figure 22: Curvilinear model of market diversity (Rumelt, 1982)

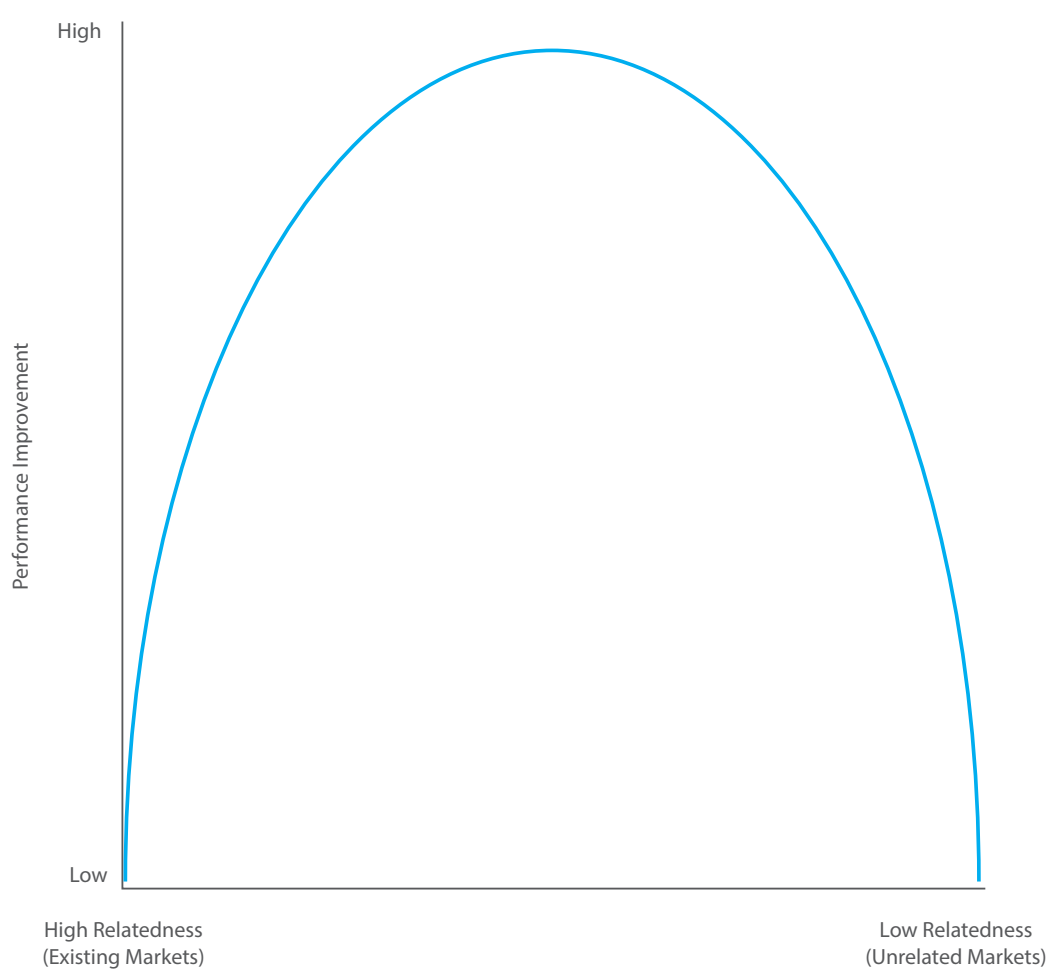

During the GFC, the managers in resilient firms emphasised the development of new products and markets where they considered higher margins to be achievable. These diversifications were across areas that firms could apply existing technologies or competencies. One resilient firm employed a strategy of extending existing products into new markets and new products into existing and new markets. Increasing its diversity along two axes. Another diversified its revenue by refurbishing older products with their new technology, including the products of competitors. Yet another resilient firm looked to diversify its markets in order to smooth the cyclicality of the seasonal markets it sells into, but also diversifying into new markets it sees as potential areas of related diversification. This firm also added its own brands of products as well as new categories of products during the GFC to increase the diversity of revenue. The application of these sensing and seizing capabilities 
provided the firms with access to new revenue streams from products and markets with higher margins as well as reduce the risk of the firms' current revenue streams.

Less resilient firms, however, do not refer to the issues of diversifying revenue with the exception of the least resilient. The firm having broadened out to take on almost any fit out work, even those outside its own industry. This lack of focus in the form of too much diversity may have contributed to the firm's lack of resilience. Existing resilience literature suggests diversity creating 'stratlets' or small forays into new areas are positive for resilience (Valikangas, 2004). However, these findings suggest there is perhaps more nuance to the creation of resilience through diversity. The most resilient firms made extensions of platform technologies into areas or markets with what they considered bankable similarities.

Quinn (1999) suggests that successful firms outsource because they can obtain higher value and more flexible, integrated services outside the firm, gain access to 'best in world' knowledge by engaging with providers, and achieve cross divisional coordination and shareholder value gains that they could not otherwise. EspinoRodríguez and Padrón-Robaina's (2006) review of research into outsourcing decisions provides a number of propositions outlining under which circumstances the literature would suggest a firm would choose to outsource an activity. They suggest that when an activity (manufacturing) is more homogenous, substitutable, imitable and less valuable, the more it will be outsourced. They go on to suggest that when activities do not form part of the firm's core competencies, that specialist providers can increase performance.

The make or buy dilemma was still a key decision for firms during the GFC. Resilient firms opted to vertically integrate their activities both up and downstream. The reasons given were generally regarding the firm's ability to a) control the activities in 
the value chain by removing risk and underperforming actors, and to b) improve the margin the firm could extract from the retail price of their products. This vertical integration was designed to augment the manufacturing of the firm, with managers at two firms moving to a simpler 'assembly' model rather than traditional manufacturing by sourcing more complete parts from suppliers. By taking control of the upstream supply chain, they ensured the quality of parts were sufficient to realise the improvements in efficiency and margin by not manufacturing themselves and reducing the reject rates in their own facilities. Figure 23 plots the firms in the sample and their relative position on the continuum of manufacturing in-house through to outsourcing manufacturing activities.

Figure 23: Resilience and the Continuum of Manufacturing Activities

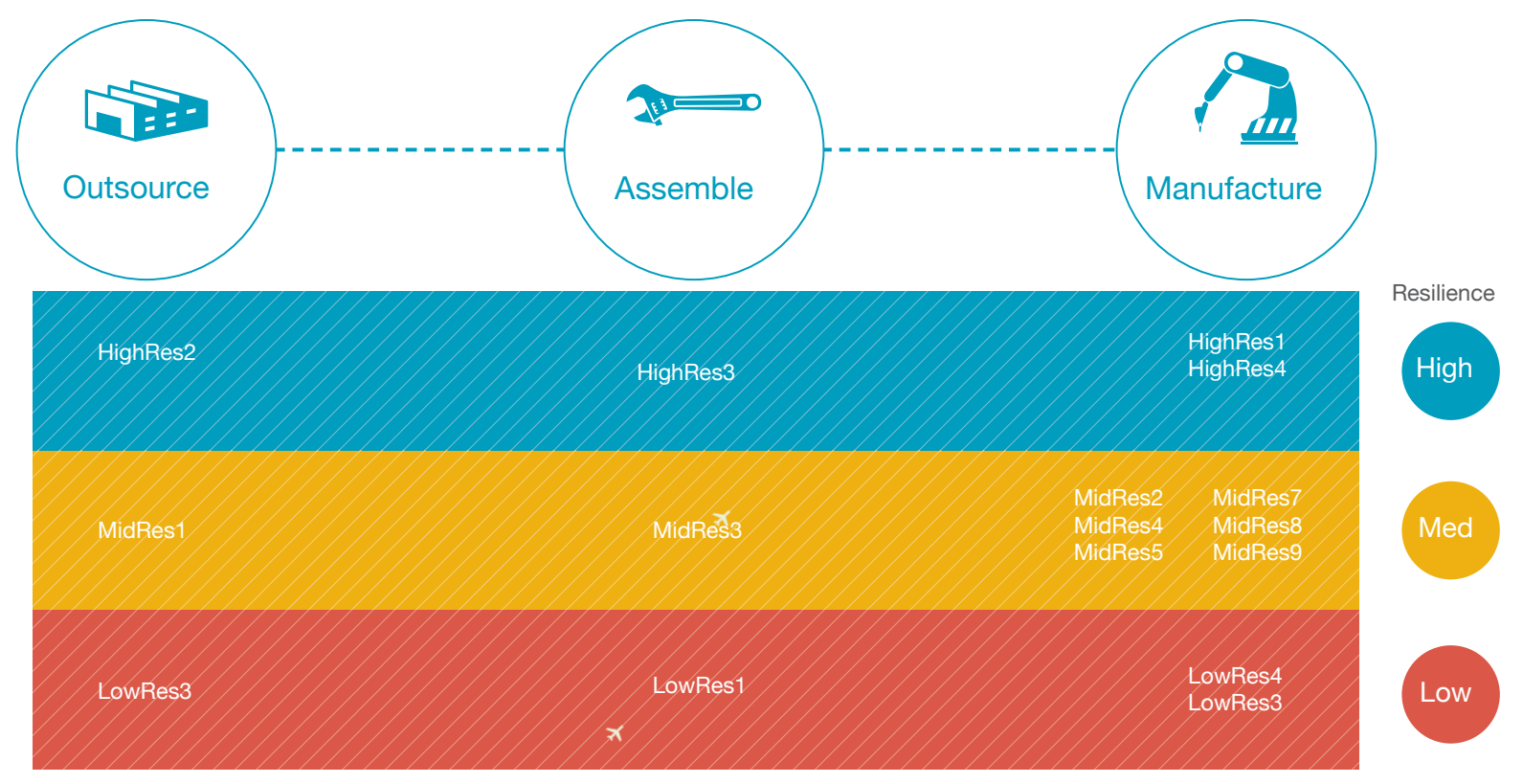

Other resilient firms integrated downstream, towards their consumers. This generally included taking control of the distribution of their products, from agents or distributors that the firms saw as underperforming, or that had poor motivation to do a good job. Resilient firms changed their value chain structure to integrate distribution activities; taking them back from third parties and developing their own distribution and retail 
channels. This was, in all cases, changed to retain the margin that distributors would generally claim and to improve the quality of the sales agents promoting the firms' products. Figure 24 shows how the value chain of resilient firms differs from that of less resilient firms, in terms of the activities they perform in-house or outsource, efficiency of the process and investment in R\&D.

Figure 24: Standard Value Chain Compared to Resilient Value Chain
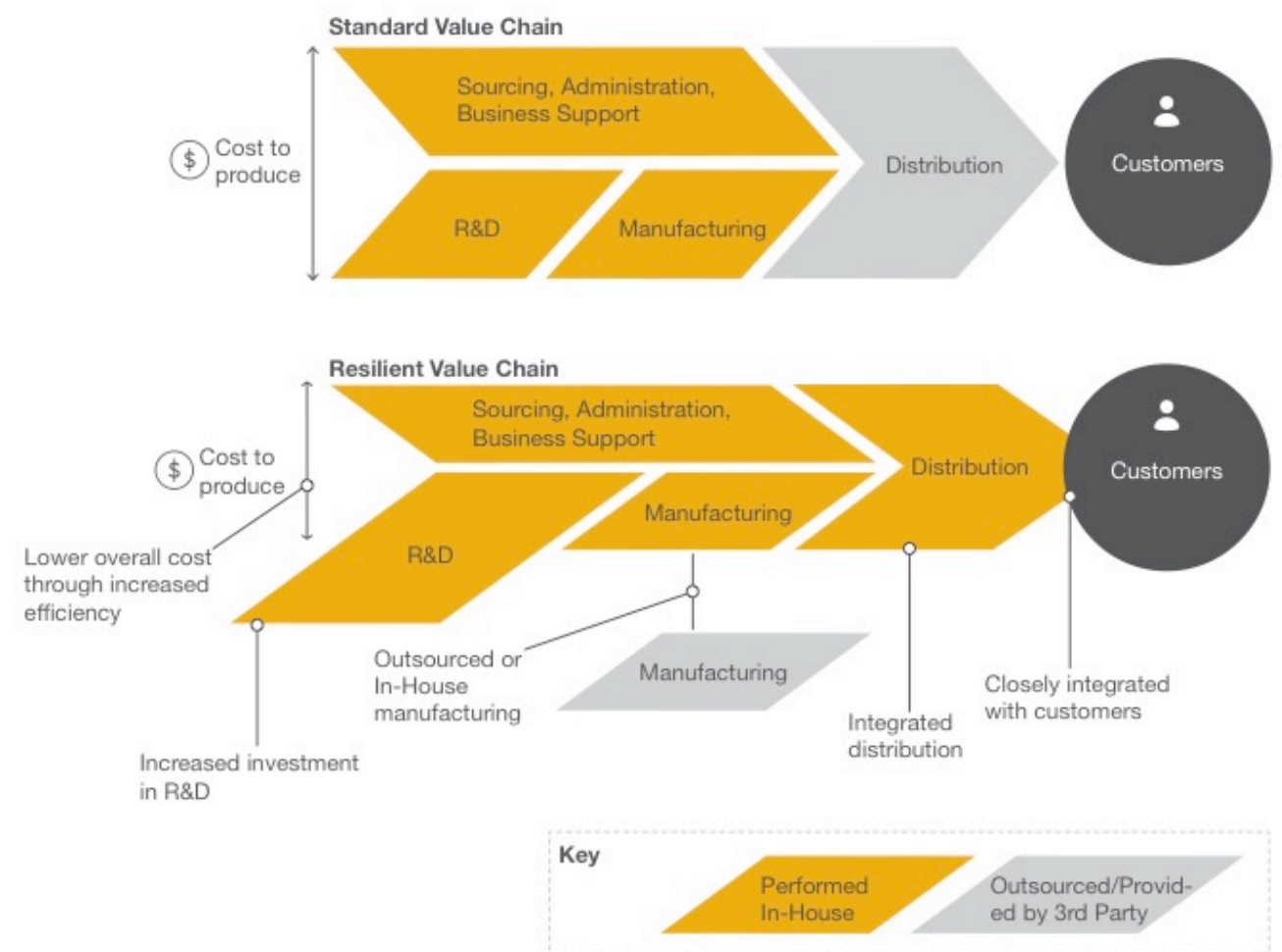

The findings show that despite a significant proportion of the sample performing the manufacturing function in-house, a high number of resilient firms sought to outsource or move to a less manufacturing intensive assembly model. The insight to be gained is that resilient firms do not consider that the manufacturing activity is 'core' to their business despite identifying as manufacturing firms. Secondly, that these firms may 
also consider the manufacturing activity to be homogeneous, substitutable, imitable, and not particularly valuable.

Relatedly, managers in resilient firms that outsource manufacturing describe it as being too difficult or too inflexible to perform in house. The technicalities of managing manufacturing and the lock-in of investing in plant reduced the firm's flexibility and options set. Certain managers also suggested that in order to scale their run size, they could not manufacture their own products due to issues of capacity. While the majority of firms choose to manufacture in-house, those that do not are spread consistently across the levels of resilience. This suggests that the manufacturing activity may be a hygiene factor (Rajan, 1985), necessary for survival but not sufficient to create performance or resilience.

\subsubsection{Summary of Proposition 3}

Dynamic capabilities do not in themselves create efficiency, instead they help to create operational capabilities that are efficient (Teece, 2007). While indirect, when dynamic capabilities are turned towards creating efficiency building operational capabilities, the result appears to contribute to the resilience of firms in dynamic environments. Wilhelm, Schlömer and Maurer (2015) find that dynamic capabilities can contribute to efficiency in the most dynamic environments where necessity of value capture offsets the cost of reconfiguring for efficiency. The finding of this thesis is that through reconfiguration and control of the value chain, resilient firms created efficiency and margin.

\subsubsection{Proposition 4:}

Capabilities that increase the 'volume' of knowledge, and improve the flow of, and access to, knowledge within a firm are among the most valuable for creating resilience. 
Figure 25 depicts the various knowledge management dynamic capabilities and their relationship to resilience in the studied firms.

Figure 25: Knowledge Management Dynamic Capabilities

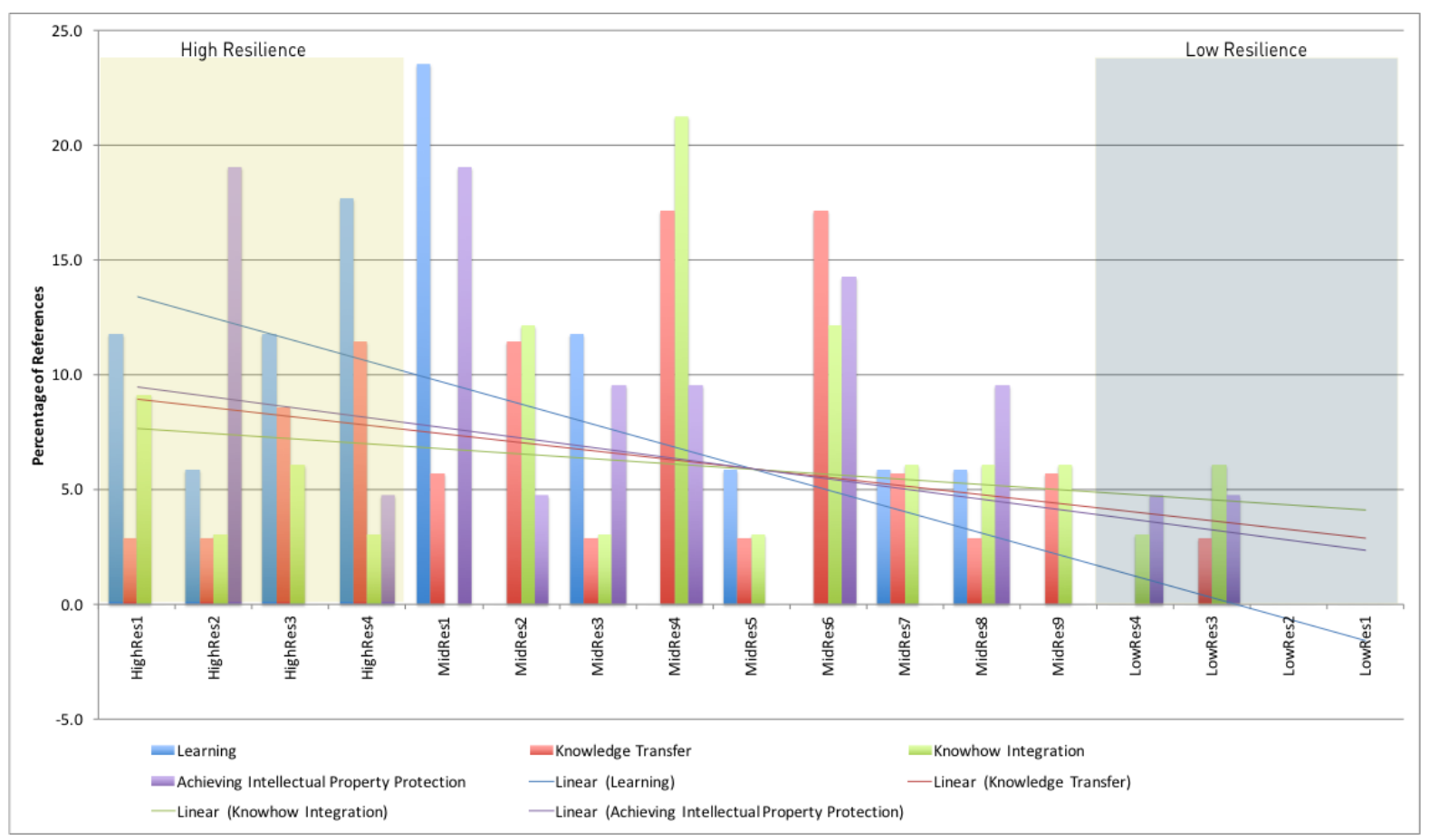

Existing resilience literature discusses concepts that are consistent with knowledge management processes. Hamel and Valikangaas (2003), Weick (1993), Lengnick-Hall et al. (2010) and Coutu (2002) discuss how scaffoldings that provide frameworks for action, training, metrics, and processes contribute to resilience. The findings of this thesis suggest that these authors have identified a crucial component in the resilience of firms.

As discussed previously in this chapter, the capabilities firms use to sense opportunities in their markets (Teece, 2007) are expressed in the most resilient firms in higher rates than in non-resilient ones. Reinmoeller and van Baardwijk (2005) describe how innovation, and in particular diversity and external sources of those 245 
innovations, create resilience in firms. The findings of this study corroborate their assertion that resilient firms invest more in innovation than others, and that they continue or even accelerate investment during crises. Resilient firms also actively engaged in open innovation processes (Chesbrough, 2003). Both related and unrelated fields were tapped to improve the development of resilient firm's own products and processes.

Table 40: Resilient compared to non-resilient firms percentage of discussion

\begin{tabular}{|c|c|c|c|}
\hline & $\begin{array}{c}\text { Top } 4 \\
\text { Firms (\% of } \\
\text { Discussion) }\end{array}$ & $\begin{array}{l}\text { Bottom } 4 \\
\text { Firms (\% of } \\
\text { Discussion) }\end{array}$ & Difference \\
\hline Processes to Direct Internal R\&D & 46.8 & 11.3 & 35.5 \\
\hline Processes to Tap Exogenous Science \& Technology & 42.9 & 19.0 & 23.8 \\
\hline $\begin{array}{l}\text { Processes to Tap Supplier and Complementor } \\
\text { Innovations }\end{array}$ & 31.3 & 12.5 & 18.8 \\
\hline $\begin{array}{l}\text { Processes to Identify Target Market Segments, } \\
\text { Changing Customer Needs and Customer } \\
\text { Innovation }\end{array}$ & 38.9 & 25.0 & 13.9 \\
\hline
\end{tabular}

When considering the four sub-types of sensing capability, several patterns emerge. Processes to sense opportunities from across the four subclasses of capabilities were particularly evident in the four most resilient firms. This suggests that in combination all four sensing capabilities are positive influences on resilience. However, less resilient firms also show evidence for all four, suggesting there is some nuance to how these types of processes are applied that contributes to their effectiveness. 
In particular, the capabilities associated with the creation of new technologies through internal R\&D or exogenous science and technology sources are discussed in significantly higher amounts in resilient firms than non-resilient ones. Sensing for changes in the firm's environment such as supplier and complementor innovations and target market changes are still more highly represented in resilient firms but not in the same proportions.

It would appear from these results that the Sensing capabilities that enable firms to identify and develop new knowledge and technologies are particularly valuable in the creation of resilience. In particular, processes to direct internal R\&D are referred to consistently by mangers of resilient firms than the other capabilities in this category. Each of the most resilient firms undertook significant R\&D as a matter of process developing proprietary technologies that were targeted to specific markets or large customers. In each of the most resilient firms, levels of investment in R\&D were increased during the GFC up to eighteen percent of revenue. These efforts were focused on bringing to market new products, based on the identified and developed platform technologies and that were higher in technology than those of their competitors.

These results are consistent with Reinmoeller and van Baardwjik's (2005) finding that resilient firms increased their investment in innovation over time and in particular, during recessionary periods. That resilient firms invest in R\&D as a matter of course, rather than situationally, aligns with Thomke et. al.'s (1998) suggestion that resilient firms embrace change, novelty and innovation as an inevitability, accepting that environmental change is constant and requires equally constant change in the organisation to match it. This is similar to the concept of requisite variety, which is consistently identified as crucial to the resilience of biological and ecological systems (Folke, 2006; Ludwig et al., 1997; Walker \& Salt, 2006). As such, resilient firms looked 
to deepen their R\&D efforts toward blue skies research as well as strengthening their ability to commercialise quickly and realise a return on investment in innovation.

Less resilient firms however, appear to perform R\&D more situationally; investing in development only when necessary to produce what is needed to survive. Managers in the least resilient firms discuss capabilities to direct internal R\&D in comparatively low levels to resilient firms. The evidence suggests that R\&D was performed in less resilient firms on an ad hoc basis, to create particular products or when clients and customers specifically request something. The result would appear to be piecemeal creation of implementable knowledge that does little to ensure a valuable pipeline of development. Muller, Valikangas and Merlin (2005) and Hamel and Valikangas (2003) suggest that firms need to create opportunities for themselves through 'introspective insights' and 'stratlets' that emerge from consistent investigation into the firm's own capabilities at different levels. These would appear to provide a complex and varied action inventory (Lengnick-Hall \& Beck, 2009) that the firm can use to create situationally appropriate innovations to create resilience. However, by conducting R\&D as a punctuated activity these opportunities are perhaps inconsistently and unreliably created. 
Figure 26: Processes to Direct Internal R\&D Totals

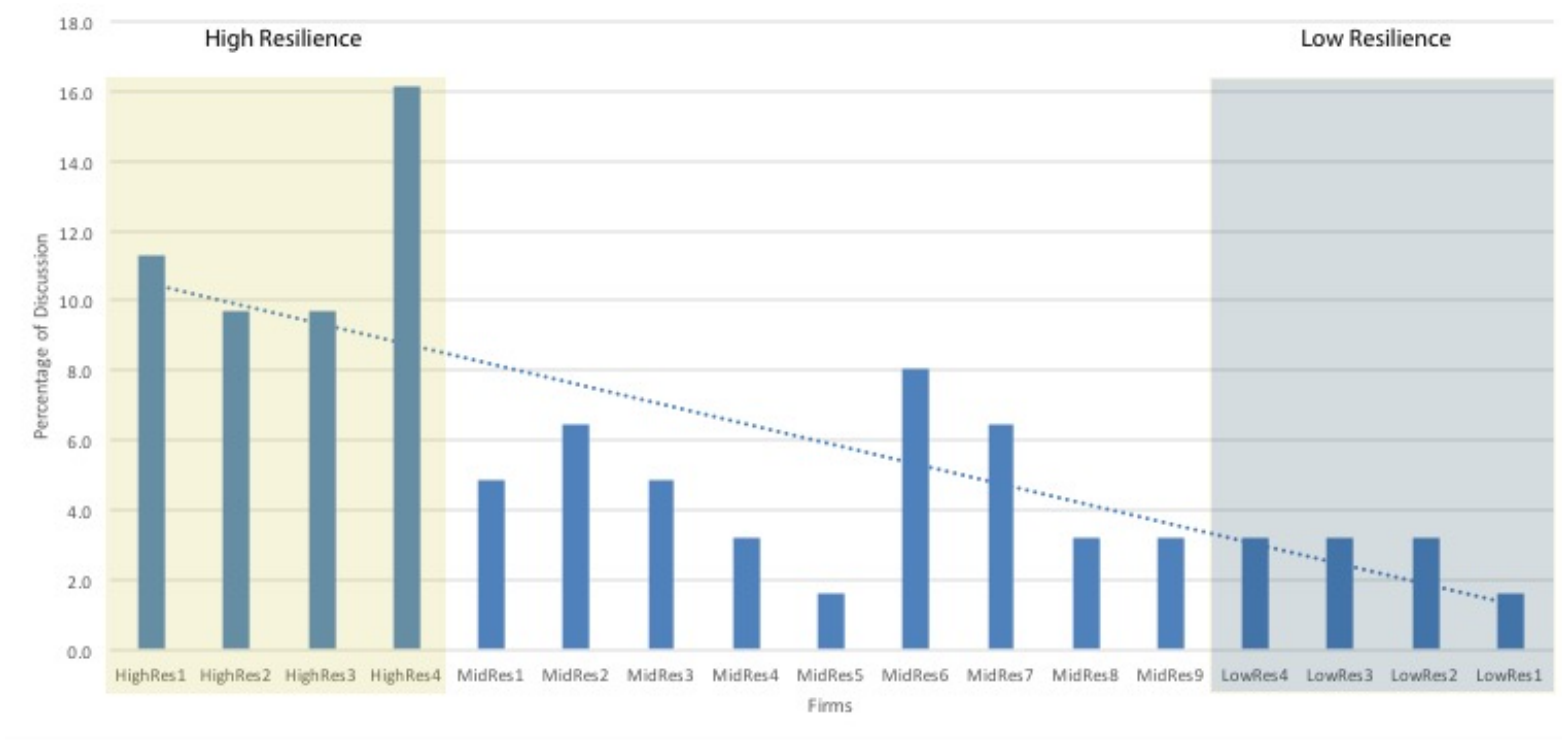

Of all the sensing capabilities, Processes to Direct Internal R\&D show the strongest positive relationship to the resilience of firms. While less resilient firms struggled to invest funds into R\&D, more resilient firms were actively pursuing new technologies, products, platforms and applications. The four most resilient firms were not only the highest scoring on the measures of this type of capability, the discussion of managers from these firms constituted nearly $50 \%$ of all references (Figure 26). The discussion from managers in resilient firms often regarded the level of investment the firms made into R\&D. Resilient firms increased the fixed proportion of revenue invested into R\&D, grew the size of research teams and created new facilities to perform R\&D in. Managers in the four most resilient firms also tended to suggest they had plans to continue increasing levels of investment in R\&D. The focus for these firms was on bringing new products to market, diversifying the application of existing platform technologies in new but related areas, and deepening R\&D efforts into areas without clear goals. Conversely, the four least resilient firms reduced or struggled to maintain pre-GFC levels of investment and were forced to bear the effects of this lack of development. Managers in these firms describe the outcomes of not performing 
sufficient R\&D as failing to: bring new products to market, enter any new markets, or add any new value to existing products.

The evidence for Processes to Tap Exogenous Science and Technology also exemplifies a potentially failure preventing capability. While managers from resilient firms were more likely to discuss the contribution of these types of capabilities to their strategy, several less resilient firms also discussed the means by which they engage in the external science and technology environment. The answers given by managers, reveals that lower resilience firms consistently purchase expertise from research institutions situationally and transactionally, on a one-off or case-by-case basis. Conversely the most resilient firms each engaged in more formalised research arrangements which enabled flows of information between organisations, in order to garner insights that were not easily or reasonably accessible through their internal R\&D processes.

As capabilities that look for sources of new knowledge both within and outside the firm, sensing capabilities appear to play a role in the resilience of firms (Figure 26). However, the sub-class of capability would appear to be a factor as would how those capabilities were implemented. Consistent, high proportions of revenue invested into R\&D activities to be carried out within the firm appear to have the largest positive effect (Reinmoeller \& van Baardwijk, 2005). Relatedly the objectives of R\&D that contribute resilience appear to be bringing new products to market and to extend the application of existing ones. This is evidenced by the testimony of managers in the resilient, but also by managers in non-resilient firms, who described their inability to invest in R\&D a constraint on their businesses. Levels of investment as a proportion of revenue appear then to contribute to the technical fitness of the capability (Helfat \& Peteraf, 2009). Engaging with developments in the research sector within the firms' field was also clearly beneficial, particularly if the research contributor was a potential customer. Other sensing capabilities are less strongly indicated as contributors. The 
impact of sensing through suppliers and complementors is indeterminate, while the impact of processes to identify target market segments, changing customer needs, and customer Innovation is also unclear but may be necessary but not sufficient in the creation of resilience in a firm (as outlined earlier in Proposition 2:).

\section{Open innovation}

Innovation that drew on external sources of knowledge (Chesbrough, 2003) was a consistent feature of the testimony of managers in resilient firms (Figure 27). This took the form of research agreements with other organisations either from within or outside the firm's own sector or area of expertise, and included the application of techniques from other organisations and fields to reduce cost, or time, or to improve competitiveness. While these types of dynamic capability were identified in this study as necessary but not sufficient due to their presence across a number of firms with various levels of resilience, they still serve to create knowledge in the firms. That knowledge appears valuable in the creation of resilience but that to source it in an open manner is itself not sufficient to do so, is an identified tension in the findings of this thesis. The effectiveness of these types of capabilities and their contribution to resilience potentially requires further investigation to understand this paradox.

Figure 27: Embracing Open Innovation Capabilities Relationship to Resilience

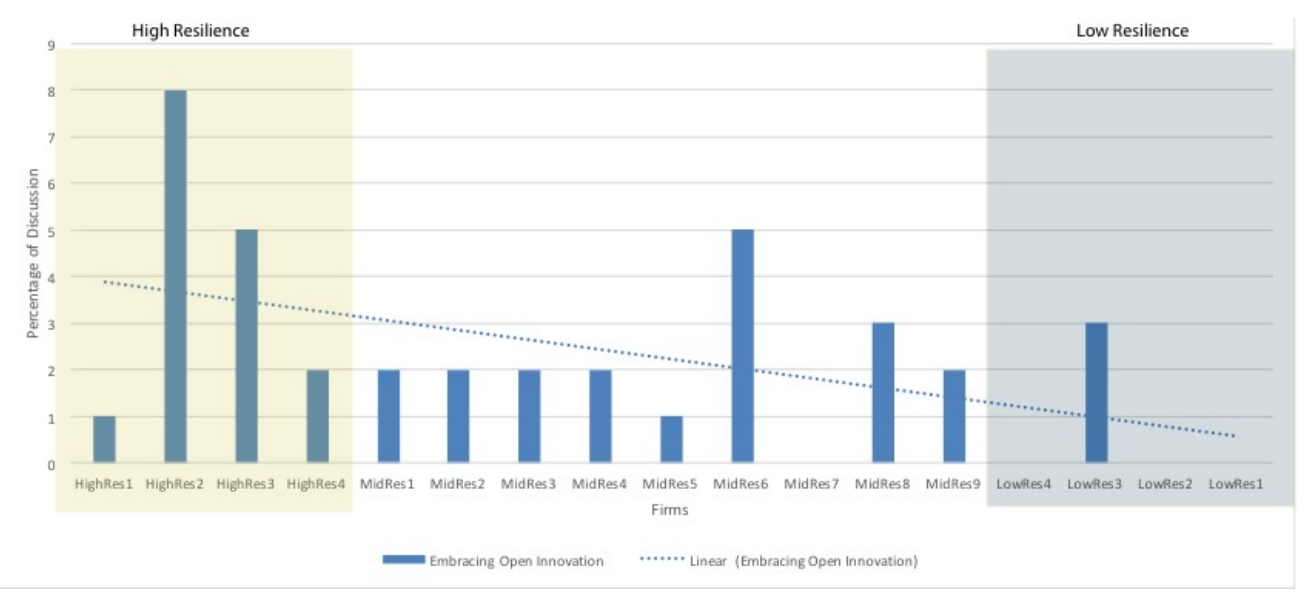


One potential explanation is the technical fitness of the capabilities employed (Helfat et al., 2007). Again, resilient firms were more likely to set up permanent relationships with external organisations to integrate external sources of knowledge (Chesbrough, 2003; Teece, 2007), while less resilient firms tended to act transactionally, buying in services and technologies on an 'as needed' basis. While the resilience literature is particularly emphatic about the value of innovation (Hamel \& Valikangas, 2003; Reinmoeller \& van Baardwijk, 2005; Valikangas, 2004), the finding offered here is that when innovating (in an open fashion at least) firms should look to consider it an ongoing rather than situational activity. This supports Reinmoeller and van Baardwijk's assertion that resilient firms innovate continually and invest in diverse innovation strategies.

\section{Codification}

A number of dynamic capabilities are expressed by firms through their efforts to capture, codify and utilise knowledge. Learning, knowledge transfer, integration, communication, and achieving intellectual property protection capabilities each rely on codification processes (Teece, 2007). Resilient firms were active in the codification of best practices, implicit knowledge, processes, and procedures in order to create knowledge-based resources that were uniquely valuable to the firm. These assets also contributed to the creation of frameworks enabling decisions to be made quickly and with limited information (Eisenhardt, 1989b). In a different publication Eisenhardt and Martin (2000) describe dynamic capabilities as best practices (Easterby-Smith et al., 2009). Zollo (1998) found that the codification of processes improved the performance of firms, in particular the codification of those that performed less often, such as post-merger integration activities. The value of codifying unusual processes fits comfortably within the dynamic capabilities literature, as authors strive to differentiate operational (everyday) capabilities from dynamic (uncommon) ones (Cepeda \& Vera, 2007; Teece, 2014b). Lengnick-Hall and Beck (2009) describe how resilient firms have a complex and varied action inventory - a wide range of actions 
and options they can rely on in dynamic environments. The codification of rarely used capabilities and processes would be a considerable contributor to this inventory (Zollo, 1998).

Codification also appears to be a valuable capability building exercise in itself as firms gain benefits from the process of codifying knowledge as well as from the 'manual' outcome as it produces 'know-why' as well as 'know-how' (Zollo \& Winter, 2002). As such, dynamic capabilities that create codified knowledge resources may be particularly valuable. Knowledge can constitute a resource in and of itself that contributes competitive advantage, and also an integrating factor for other resources - especially in dynamic environments (Omerzel \& Gulev, 2011). Second order dynamic capabilities are described as capabilities that help the firm create more specific dynamic capabilities (Schilke, 2014). These findings potentially suggest that codifying 'know-why' may be a second order capability, enabling firms to create and reconfigure resources through first order dynamic capabilities.

Creating decision frameworks, is discussed in several resilient firms as a way to avoid decision errors by creating a framework to assess decisions quickly with limited information (Eisenhardt, 1989b; Teece, 2007). Managers of resilient firms discussed how decisions were framed and the consistent mechanisms used to do so. These included constant currency accounting and experiential decision models. Managers in less resilient firms do not discuss these types of capabilities. Managers who discuss the creation of decision frameworks describe how their goal was to understand the decisions they had to make in the face of ambiguity and to ensure the firm did not overextend their resources and avoid poorly understood situations. Hamel and Valikangaas (2003) describe the need for resilient firms to be free from denial, bias and hubris, it would seem that appropriately structured decision frameworks provide the objective, albeit bound by the firms dominant logic (Bettis \& Wong, 2003), schema by which firms can avoid these pitfalls. 


\section{Learning, knowhow integration and knowledge transfer}

At the core of dynamic capabilities is the decision firms make between exploration (of new technologies; innovations) and exploitation (the development of business models around chosen technologies) (March, 1991). The allocation of resources towards either activity strongly affects a firm's ability to perform it successfully. Learning faster in exploration phases frees up more resources to exploit (Teece, 2007).

Developing, acquiring, and protecting intellectual property is a means resilient firms used to ensure others do not appropriate the outcomes of learning processes. These firms sought to protect their knowledge by patenting and registering designs to afford them legal protection. Notably, firms sought these protections in a targeted and pragmatic manner. Intellectual property was protected in markets and geographies that the firms deemed strategic and/or high risk. In particular, filings were made specific regions because of either their high value as markets or the risk of imitation. firms filed protection for these assets more as a deterrent, with most firms noting they either capped or selectively defended their intellectual property in courts. These insights are new to the resilience literature in that the value of intellectual property and the pragmatic approach to its defence have not been discussed to date.

\section{Effective communication}

Related to the management of knowledge assets were the effective communication capabilities in firms (Teece, 2007). These capabilities were particularly strongly represented in resilient firms, but not identified in the least. Lengnick-Hall et al. (2010) suggest resilient firms have created a climate of open communication. Openly communicating would appear to be a means firms can overcome barriers such as information and activity silos (also serving to check strategic malfeasance and block rent dissipation) and communication outside the firm's borders. This enables firms to 
understand developments in their industry and the drivers for their external stakeholders' actions.

\subsubsection{Summary of Proposition 4}

A particularly interesting finding was the strong emphasis resilient firms appear to place on knowledge, its acquisition, management, and integration. The distinct difference between resilient and non-resilient firms appears to be that resilient firms are perpetual innovators - building processes to continually learn, understand and create. While less resilient firms either struggled to commit sufficient funds to innovation processes, or undertook the search for new technologies, products and knowledge occasionally, in a punctuated fashion.

Resilient firms also worked to capture the knowledge they created in terms of processes, decisions, practices, and understanding. They sought to document, disseminate, and apply this knowledge across the organisation. Resilient firms also tended to discuss defence of this knowledge through intellectual property protection and secrecy ensuring that it was not appropriable by competitors.

\subsubsection{Summary of Propositions}

The propositions offered here are a set of rationalisations of the findings from the research. They represent discussions of the major, and particularly cogent emergent themes in the data. The first proposition, that resilient firms appear to exhibit a consistent bundle of dynamic capabilities is strongly evidenced in the way that these capabilities were observed as present in the most resilient firms but also by their lack of presence in less resilient firms. The bundle(s), including a mixture of sensing, seizing and transformation capabilities emphasise how resilient firms are active in creating new knowledge and technologies, adjusting firm and business model 
structures and processes to maximise the value that can be created from a new technology.

Proposition two identifies the possibility of particular dynamic capabilities that may be necessary, but not sufficient to create resilience in firms. These were identified as capabilities that, while present and resilient firms and may be considered to provide particular types of performance, they were also present in less resilient and middle performing firms.

The third proposition relates to the theme of resilient firms and their drive to create efficiency and margin during the GFC. Resilient firms moved to minimise waste in the production process and took over sections of the value chain where they believed they could capture more margin - such as in the supply of raw materials, the channels of distribution and retailing of products. Less resilient firms were not active in vertical integration changes, and did not appear to discuss efficiency and margin as key drivers of actions.

The final proposition is that resilient firms are active in pursuing, creating, capturing and leveraging knowledge assets. In particular Sensing and Transformation (knowledge management and open innovation) capabilities were used by resilient firms to gather strong portfolios of knowledge assets, including technologies, but also knowledge of processes and practices that were both common and uncommonly applied. The transfer and integration of these assets across the organisational system was also a focus for firms. 


\subsection{A Short Note On Control}

A further finding of the research was the strong, overarching theme of control that was so clearly exhibited by resilient firms. Dynamic environments are naturally unpredictable and often feature factors and forces that are outside the capacity of individual firms to influence (Chan \& Soong, 2011). Despite such operating conditions during the GFC, it was clear in the research that resilient firms, more so than other, less resilient firms, identified areas of their business, environment and ecosystem that they felt it was possible to exert control over in order to create certainty against the otherwise unpredictable environment. These areas can be generalised to the following categories: Control of actors and activities, control of costs and processes, control of technology and knowledge.

Resilient firms showed particular emphasis, over both middling and less resilient firms, in taking control over specific activities in the value chain. Resilient firms were consistent in their integration both up and downstream in efforts to shore up their supply of raw materials, and distribution and retail of finished products. These actions were motivated by the recognition that actors in the supply chain who were performing the supply, distribution and retail activities were underperforming as a result of the GFC and that security and efficiency in supply, margin, and sales growth could be realised by taking ownership and control of these activities.

Related to controlling actors and activities were efforts by resilient firms to control their costs. While it is acknowledged that dynamic capabilities do not directly contribute to efficiency (Teece, 2014b), they can be utilised to create operational capabilities which are focused on efficiency. Resilient firms were particularly active in controlling their cost structures - as set out in Proposition 3. The suggestion of the research is that resilient firms, unable to control the trend and volume of sales due to the effects of the GFC, instead aimed to manage the aspects of revenue and cost structure that were possible to affect (Teece, 2007). This was namely the cost of 
sourcing, the efficiency with which they manufactured their products and the margin they could retain of the final sales price of those products.

Another area that resilient firms were active in exerting control was over knowledge and technological assets. Knowledge management capabilities form the basis of Proposition 4 but it is notable that the efforts of resilient firms amounted to an emphasis on the creation, collection and subsequent control of knowledge, intellectual property and technology so that the value of these significant intangible assets was retained and leveraged to the fullest extent. Resilient firms created platform technologies and utilised intellectual property law and skilfully balanced the capability, capacity and propensity of other actors to protect those assets.

The Locus of Control is a psychological construct that refers to an individual's sense that their personal outcomes are the results of their own actions (Brockhaus, 1975). It has been used as a tool to understand how entrepreneurs may differ cognitively to non-entrepreneurs, with findings suggesting that entrepreneurs do indeed tend have high locus of control scores, and that such high scores tend to be associated with entrepreneurial success (Pillis \& Reardon, 2007). A parallel to be made between the entrepreneurial research field and resilience is that during the GFC firms were looking to make changes that they believed were within their capacity to control. Conversely, managers in less resilient firms tended to blame changes in their operating environment for their poor performance, suggesting they may have a weak locus of control. This is an area that may necessitate further investigation to examine its relationship to resilience.

\subsection{Chapter Summary: Discussion}

The utility of the dynamic capabilities framework for the study and explanation of the resilience of firms was explored. Then, four propositions regarding the emergent 258 
themes in resilient as compared to non-resilient firms were described. Proposition one suggests that resilient firms have particular bundles of capabilities that make them so. Proposition two proposes that some dynamic capabilities appear to be necessary but not sufficient to create resilience in firms. Capabilities that create efficiency and margin appear to be among the most valuable in the creation of resilience is proposition three. The fourth and final proposition is that capabilities that increase the 'volume' of knowledge, and improve the flow of, and access to, knowledge within a firm appear to be among the most valuable for creating resilience. The implications of these findings are discussed further in the concluding chapter. 


\section{Conclusion}

\subsection{Chapter Introduction}

This chapter elaborates on the implications of the findings of the research. Reiterating the aims of the thesis and the state of the current literature, the chapter compares findings with the expected results and then discusses the contribution of the findings is to research and practice.

\subsection{What is strategic resilience?}

Resilience is described by various authors as: a capacity for continuous reconstruction, or constant renewal and reorganisation, or the creation or renewal of resources, or innovation with respect to perpetuation (Hamel \& Valikangas, 2003; Lengnick-Hall \& Beck, 2009; Lengnick-Hall et al., 2010; Sutcliffe \& Vogus, 2003; Valikangas, 2004; Vogus \& Sutcliffe, 2007; Webb \& Schlemmer, 2006). Ultimately, the way these definitions describe resilience is as a means to enact change in an organisation when environmental disturbance makes retaining the status quo untenable. The literature is emphatic regarding the nature of this change: that it is born of cognition and made in the minds of managers (Beunza \& Stark, 2004; Coutu, 2002; Weick, 1993), or that it is the result of behaviours (Bourgeois, 1981). Routines, capabilities, competencies, slack, margin, capital, R\&D and ideology are all invoked as outlets for these thoughts and behaviours as a means to create performance in spite of significant environmental disturbance (Becker et al., 2005; Reinmoeller \& van Baardwijk, 2005).

Despite these initial theoretical forays into the discussion of resilience, a lack of empiricism has so far slowed development of the concept. This chapter summarises how this thesis has attempted to address this issue and contributes to the study of 
resilience in strategic management, dynamic capabilities theory and the wider field of management. It then identifies the relevance of the findings to practitioners and the potential avenues for future research.

This thesis takes the view that resilience should be viewed pragmatically that is; During a disturbance, the resilient firm has the ability to: perform by growing and achieving goals, maintain revenues, and expand or extend its asset base at better than average levels compared with other organisations.

This definition facilitated the identification of resilient, average performing and nonresilient firms, their actions and the differences between them, in this study.

\subsection{The aim of this thesis}

Utilising such a view of resilience, this thesis has sought to address identified gaps in extant literature by examining firms' actions during a crisis. This was achieved by investigating the strategies of seventeen firms in New Zealand's manufacturing sector during a significant environmental disturbance - the GFC. Rose (2004) suggests that for the development of the field of resilience it is important to identify the actions of resilient firms, especially those which violate expected norms. This thesis has set out to answer this call. By building a view of resilient action through the case of firms with varying levels of resilience, it was possible to identify those actions. By comparing these identified actions against the 'expected' ones as suggested by the conceptual model, divergent sets of actions were highlighted.

The data gathered and analysed provides a nuanced view of resilience that marries the existing strategic management literature with the emerging concept of resilience in the organisational context (Vogus \& Sutcliffe, 2007). In particular, the dynamic capabilities view (Easterby-Smith et al., 2009; Helfat et al., 2007; Teece \& Pisano, 
1994) has been used as a theoretical framework through which to examine the identified actions in resilient firms. This enhanced view of both resilience and dynamic capabilities forms the basis of the contribution of this thesis.

A focus on resilience in difficult contexts balances the emphasis in management theory on continual growth in more benign contexts. This helps to establish resilience as a more valid concept in management theory. The thesis also adds to the dynamic capabilities literature by employing it as a theoretical framework through which resilience can be observed. This augments its explanatory power as a model that can provide significant new insight into the relationship between dynamic capabilities and various firm performance measures.

In short, the new findings of this thesis are that resilient firms appeared to employ more, and more varied, dynamic capabilities than less resilient firms. More specifically, resilience appears to be related to a firm's ability to create, rebuild, or reconfigure their resources to create performance in dynamic environments. However, despite resilience being thought of as unique to individual firms, the types of capability expressed were fairly consistent across resilient firms. Capabilities that favour sensing for opportunities, business models that bring customers closer to the business, and the creation of heterogeneous knowledge assets are among the most valuable for the creation of resilience.

\subsection{Research Questions, Findings and Contribution}

The central contribution of this thesis is the empirical findings regarding the capabilities that provide resilience to firms in dynamic environments. The following discussion outlines how the findings answer the research questions, which were examined in the context of New Zealand's manufacturing sector during the GFC. 


\subsubsection{What contributes to resilience in firms?}

The literature review in this thesis resulted in a model that outlines the attributes that resilient organisations would be expected to have. Through the analysis of interview data and by ranking the firms using using objective measures of resilience, the attributes of the model that was supported by the evidence was determined. Figure 28 offers a summary of these findings.

Figure 28: Evidence supporting and refuting resilience concepts identified

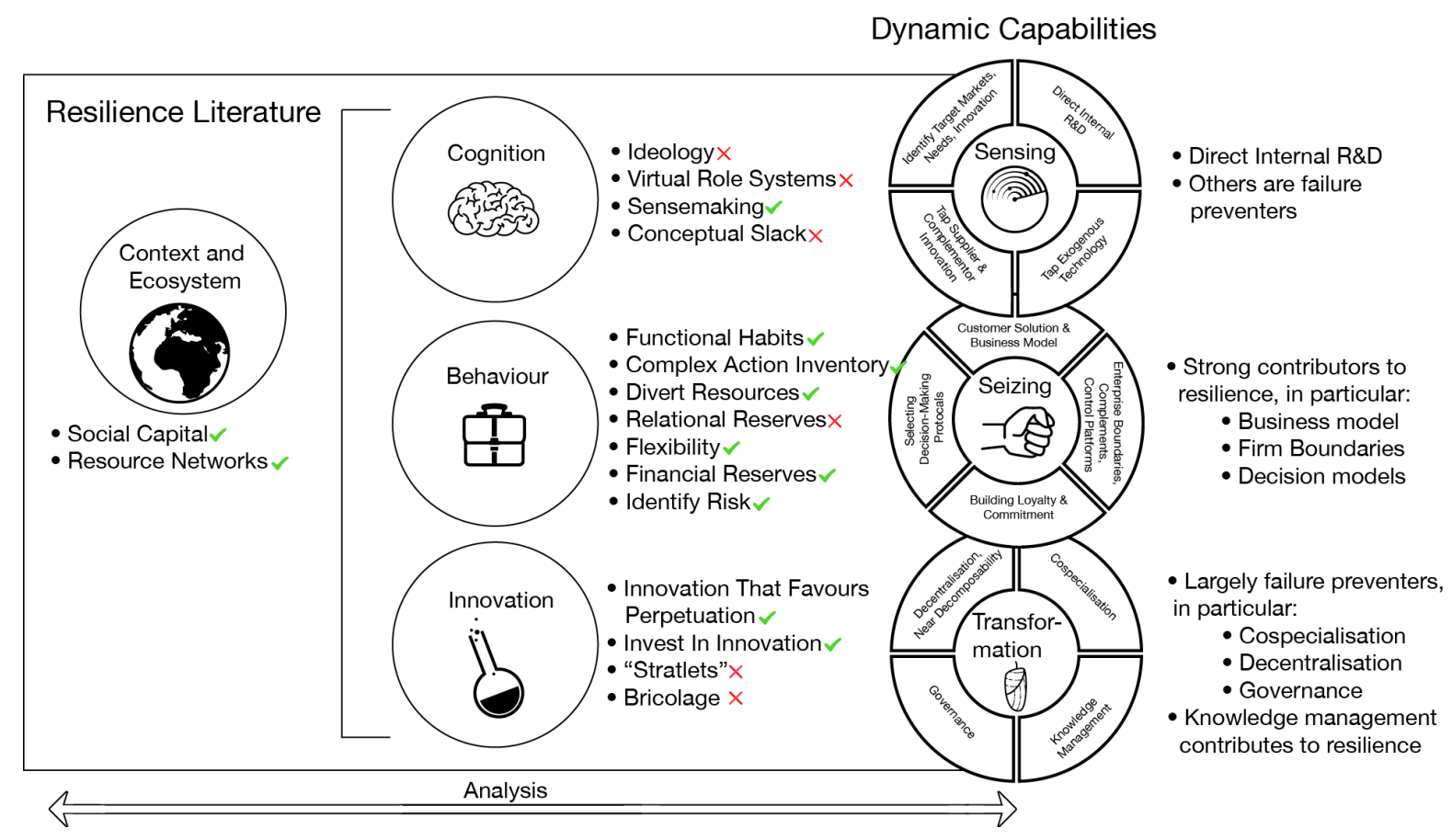

The existing resilience literature outlines factors that fall broadly into the categories of: contextual, cognition, behaviour, and innovation (Coutu, 2002; Gittell, 2005; Hamel \& Valikangas, 2003; Lengnick-Hall \& Beck, 2009; Lengnick-Hall et al., 2010; Reinmoeller \& van Baardwijk, 2005; Valikangas, 2004; Weick, 1993). While a number of these characteristics were identified in resilient firms, several were not, including Ideology, virtual role systems, conceptual slack, and relational reserves. For firms in this study Stratlets and bricolage appeared to be oppositional to behaviours in 
resilient firms, which preferred to make large investments in platform technologies developed in a deliberate and considered manner in order to address identified customer needs or new or existing markets. Table 42 below outlines the literature's asserted concepts and the findings of this thesis. 
Table 41: Core Resilience Concepts Identified In Literature

\begin{tabular}{|c|c|c|c|}
\hline \multicolumn{4}{|c|}{ Core resilience concepts } \\
\hline Response & Description & Key References & Findings \\
\hline $\begin{array}{l}\text { Diversity of } \\
\text { Innovation } \\
\text { Strategy, Strategic } \\
\text { innovation, } \\
\text { Adaptive change }\end{array}$ & $\begin{array}{l}\text { Small bets on many technologies (stratlets), } \\
\text { strategic exploration, creating new approaches } \\
\text { to replace those rendered ineffective }\end{array}$ & $\begin{array}{l}\text { Valikangas (2004), } \\
\text { Reinmoeller \& van } \\
\text { Baardwijk (2005), Muller } \\
\text { et al. (2005), Lengnick- } \\
\text { Hall \& Beck (2009), } \\
\text { Lengnick-Hall et al. } \\
\text { (2010), }\end{array}$ & $\begin{array}{l}\text { NOT CONFIRMED } \\
\text { Instead firms made large bets on platform technologies } \\
\text { that are used to extend into related markets }\end{array}$ \\
\hline Bricolage & $\begin{array}{l}\text { Institutionalised innovation, making do with } \\
\text { what is at hand. Improvisation. }\end{array}$ & $\begin{array}{l}\text { Coutu (2002), Weick } \\
\text { (1993) }\end{array}$ & $\begin{array}{c}\text { PARTIALLY CONFIRMED } \\
\text { Resilient firms are institutionalised innovators. } \\
\text { However, this innovation is well funded and } \\
\text { increasingly well invested, rather than improvised from } \\
\text { available resources }\end{array}$ \\
\hline R\&D/Innovation & $\begin{array}{l}\text { Investment in R\&D, internal and external } \\
\text { searches for information }\end{array}$ & $\begin{array}{l}\text { Reinmoeller \& van } \\
\text { Baardwijk (2005) }\end{array}$ & $\begin{array}{l}\text { CONFIRMED } \\
\text { Increasing R\&D investment during a crisis and a } \\
\text { balance of internal and external sources of innovation } \\
\text { were present in resilient firms }\end{array}$ \\
\hline Strategic Flexibility & $\begin{array}{l}\text { The relationship between competitive position } \\
\text { and responsiveness of supply chain }\end{array}$ & $\begin{array}{l}\text { Sheffi \& Rice (2005), } \\
\text { Sheffi (2005) }\end{array}$ & $\begin{array}{l}\text { PARTIALLY CONFIRMED } \\
\text { Resilient firms discuss their position as being defensive } \\
\text { in their market and made supply chain decisions that } \\
\text { enabled them to be flexible to change }\end{array}$ \\
\hline
\end{tabular}


Table 41: Core Resilience Concepts Identified In Literature Continued

\begin{tabular}{|c|c|c|c|}
\hline $\begin{array}{l}\text { Renewal, } \\
\text { Reconstruction }\end{array}$ & $\begin{array}{l}\text { Resilient organisations have the capability to } \\
\text { renew and reconstruct themselves to manage } \\
\text { disturbance and to perpetuate }\end{array}$ & $\begin{array}{l}\text { Webb \& Schlemmer } \\
\text { (2006) Hamel \& } \\
\text { Valikangas (2003) }\end{array}$ & $\begin{array}{l}\text { CONFIRMED } \\
\text { The presence of dynamic capabilities in resilient firms } \\
\text { suggests their ability to create, renew and reconfigure } \\
\text { resources during a crisis creates resilience }\end{array}$ \\
\hline Margin & $\begin{array}{l}\text { High margins enable a firm to ride out } \\
\text { disruptions on lower volumes of sales }\end{array}$ & $\begin{array}{l}\text { Sutcliffe \& Vogus } \\
\text { (2003), Sheffi \& Rice } \\
\text { (2005) }\end{array}$ & $\begin{array}{l}\text { CONFIRMED } \\
\text { Resilient firms reorganised to create margin that } \\
\text { enabled them to capture more bottom line when sales } \\
\text { volumes were depressed }\end{array}$ \\
\hline Slack & $\begin{array}{l}\text { Redundancy (Supply chain), Reserves } \\
\text { (financial, relational) }\end{array}$ & $\begin{array}{l}\text { Gittell et al. (2006), } \\
\text { Sheffi \& Rice (2005), } \\
\text { Ernst \& Young (2010) }\end{array}$ & $\begin{array}{c}\text { PARTIALLY CONFIRMED } \\
\text { Supply chain and financial reserves were not } \\
\text { discussed by resilient firms, while relational reserves } \\
\text { were present in the leadership, and non-economic } \\
\text { dynamic capabilities }\end{array}$ \\
\hline $\begin{array}{l}\text { Governance and } \\
\text { capture strategy }\end{array}$ & $\begin{array}{c}\text { Capture new markets, assimilate, dominate } \\
\text { and defend new markets }\end{array}$ & $\begin{array}{l}\text { Carmeli \& Markman } \\
\qquad(2011)\end{array}$ & $\begin{array}{l}\text { CONFIRMED } \\
\text { Resilient firms made related extensions into new } \\
\text { markets. New markets were defensible due to the } \\
\text { commonalities with firms' existing markets }\end{array}$ \\
\hline Business Model & $\begin{array}{c}\text { How an organisation captures, retains and } \\
\text { delivers value }\end{array}$ & $\begin{array}{l}\text { Hamel \& Valikangas } \\
\qquad(2003)\end{array}$ & $\begin{array}{l}\text { CONFIRMED } \\
\text { Resilient firms were active in creating business models } \\
\text { that bought them closer to consumers and created } \\
\text { more consistent flows of revenue }\end{array}$ \\
\hline
\end{tabular}


Table 41: Core Resilience Concepts Identified In Literature Continued

\begin{tabular}{|c|c|c|c|}
\hline Sense-making, & $\begin{array}{c}\text { Attributing meaning to experience. Freedom } \\
\text { from bias, denial and nostalgia, awareness of } \\
\text { the environment }\end{array}$ & $\begin{array}{c}\text { Ceick (1993), Hamel \& } \\
\text { Valikangas (2003), } \\
\text { Lengnick-Hall \& Beck } \\
\text { (2005), Coutu (2002) }\end{array}$ & $\begin{array}{c}\text { Capturing and codifying knowledge, creating decision } \\
\text { models and documenting processes to understand } \\
\text { and enable informed action was present in resilient } \\
\text { firms }\end{array}$ \\
\hline Ideology & Mission, vision, values & $\begin{array}{c}\text { Coutu (2002), Hamel \& } \\
\text { Valikangas (2003) }\end{array}$ & NoT CONFIRMED \\
\hline $\begin{array}{c}\text { Connectivity, } \\
\text { social capital, } \\
\text { resource networks firms did not discuss their ideologies as } \\
\text { driving action }\end{array}$ & $\begin{array}{c}\text { Number of connections to other organisations, } \\
\text { trust inherent in those connections, access to } \\
\text { resources others do not have }\end{array}$ & $\begin{array}{c}\text { Lengnick-Hall \& Beck } \\
\text { (2005) }\end{array}$ & $\begin{array}{c}\text { Certain firms discussed their relationships to other } \\
\text { organisations and access to resources but the } \\
\text { evidence is inconsistent and indeterminate }\end{array}$ \\
\hline
\end{tabular}




\subsection{New findings of this thesis that contribute to resilience}

This thesis has made a number of findings that are new to the strategic management literature. This includes extending and elaborating the theory regarding the resilience, and resilience strategies, of firms but also to the dynamic capabilities field of theory. These findings are discussed here.

\subsubsection{Theoretical Contribution}

The stock of resilience literature date offers a range of characteristics that would be reasonably expected to improve or create resilience in firms (Coutu, 2002; Hamel \& Valikangas, 2003; Sheffi, 2005; Sheffi \& Rice, 2005; Valikangas, 2004; Vogus \& Sutcliffe, 2007). These were aggregated into a conceptual model in the Literature Review; Table 39 outlines these theorised attributes. A key theoretical contribution is the confirmation, partial confirmation, and disconfirmation of these in the context of this study (New Zealand's manufacturing sector). In providing clarity on factors of resilience that are effective, or not effective, this thesis has utilised a logic (that of dynamic capabilities) that reconciles why these may or may not be effectual attributes.

The dynamic capabilities theory has also been extended through the identification of necessary but not sufficient capabilities as mediating the capability/advantage relationship (Helfat \& Peteraf, 2009). Dynamic capabilities theory has also been augmented through the identification of knowledge and efficiency-creating capabilities as particularly valuable in the creation of resilience in firms.

\subsubsection{Research \& Development and Innovation}

One area in particular that the existing literature identifies as key to resilience is the ability to innovate. Firms that innovate improve their adaptive capacity (Thomke et al., 
1998), create breakthroughs and opportunities (Hamel \& Valikangas, 2003; LengnickHall \& Beck, 2009; Muller et al., 2005), and renew and create resources (Coutu, 2002). The findings of this thesis show that firms that innovate consistently and across their value chain in both product and process are among the most resilient. Adding nuance to this insight is that resilience appears to be garnered by firms that participate in (particularly inbound) open innovation (Henry William Chesbrough, 2003), engaging with external experts and providers to contribute to the creation of new technologies. These resilient firms also proactive in protecting their proprietary products and platforms through design registrations, patents and continually advancing their technologies. This amounted to a focus on control over technology and its acquisition and protection. Resilient firms will tap sources for technology consistently and then ensure they can protect it to extract as much value as possible. This view of resilience extends the existing literature from an acknowledgement of the value of innovation, to a more explicit focus on the type of innovations (new platform technologies, efficiency in processes) and sources of innovation (creation and investment in new R\&D capacity, external sources), and its protection through legal means.

\subsubsection{Knowledge management}

Related to the above contribution, is the finding that resilient firms actively accumulate and manage their knowledge assets. The resilience literature does not identify knowledge management as a central tenet of resiliency in firms. As such, these findings provide an extension to current understanding. Resilient firms captured the outcomes of innovation, and research and development processes, as well as the benefits of standard operating procedures, and codification of internal best practices. These firms were looking to control the flows of knowledge through the firm in order to create decision frameworks that were more robust and provided a more accurate and encompassing view of the environment. Eisenhardt (1989b), and Dean and Sharman (1996) identify the value of decision frameworks in dynamic environments. 
However, value of the capability to capture the and apply knowledge across the firm elaborates our understanding of how knowledge assets enhance resilience.

\subsubsection{Business model and firm structure}

Business models are a relatively newly defined concept, emerging from a new generation of internet based businesses whose approach to creating and delivering value is fundamentally different to the physically bound manufacturing organisations of the previous century (Chesbrough \& Rosenbloom, 2002). The business model identifies the firm's value proposition, market segments, value chain and cost structure, profit potential, value network, and competitive strategy. These defining aspects of an organisation's core proposition and function were identified by Hamel and Valikangas (2003) as necessitating innovation to earn resilience. These authors do not however, provide a view on what a resilient business model may entail. The findings of this thesis suggest that resilient firms significantly altered their business models. The findings show that resilient firms were more likely to have, or to transition to, a business model that bought them closer to their customers and clients. This was often achieved by integrating distribution activities into the value chain, or by omitting the retail channel altogether and selling direct to clients.

Manufacturing business models where firms fabricate and then pass products to an intermediary or distributor were abandoned by all of the most resilient firms in the study and retained by the least. Instead, more resilient firms looked to become as integrated with their clients and customers as possible. This served to increase the firm's control over the final product, its implementation, and use. As well, resilient firms looked to provide ancillary services to augment their products and lock customers into further use and improve customer satisfaction (Raja et al., 2013), but also increasing the firms' certainty of revenue. This approach was designed to gain 
control over the sales channel as well as to capture the margin that would normally be assumed by a third party distributor or retailer.

Outsourcing, firm boundary, and make-or-buy decisions were also not addressed by the extant literature on resilience. However, the findings of this thesis suggest that for resilient firms at least, these issues were front of mind and central to their response to crises. Resilient firms made decisions either to significantly increase investment in their ability to manufacture by expanding or developing new facilities, or to move to outsource to improve flexibility, reduce risk, and dynamically scale capacity.

\subsubsection{Efficiency and Margin}

A further contribution to the literature was the focus of resilient firms on improving margins. Discussions of the efficiency paradigm (Morgan, Strong, \& McGuinness, 2003) in extant resilience literature is mixed with some authors suggesting that efficiency and margin is key to resilient firms (Sutcliffe \& Vogus, 2003). Conversely, other authors suggest that an excessive focus on efficiency creates brittleness in a system (Folke et al., 2002; Sheffi, 2005). This thesis finds however, that within the context studied, a drive for efficiency was unequivocally of benefit to resilient firms. This was potentially driven by the particular crisis faced by firms - a sudden and significant reduction in demand. Resilient firms made steps to capture a higher percentage of margin from these lower sales volumes in order to retain bottom line and in some cases improve it.

\subsection{Research Questions Asked and Answered}

This thesis identified a number of research questions, based on the identified gaps in the resilience literature. Tables 40,41 and 42 identify those questions, and identify 
what the literature would suggest the answer to the question(s) would be expected to be, and compares and contrasts this position with the findings of this research.

Table 42: Research questions, position of literature and findings of this thesis

\begin{tabular}{|c|c|}
\hline $\begin{array}{l}\text { Research } \\
\text { Question }\end{array}$ & Thesis Contribution \\
\hline \multirow{6}{*}{$\begin{array}{l}\text { What } \\
\text { contributes to } \\
\text { resilience in } \\
\text { firms? }\end{array}$} & $\begin{array}{l}\text { Contrary to literature, resilient firms made large bets on platform technologies } \\
\text { that they used to extend safely into new markets and applications. Not only are } \\
\text { they platforms, but they are specifically identified and heavily invested in as the } \\
\text { future platforms for the firm; 'Stratlets' and Bricolage were not present. }\end{array}$ \\
\hline & $\begin{array}{c}\text { Certain types of renewal, change and innovation were present in resilient firms. } \\
R \& D \text {, business models, and knowledge management were focuses for change } \\
\text { and development in firms. Change that removed barriers between firms and } \\
\text { other firms, upstream suppliers and customers, and improved efficiency were } \\
\text { most effective. }\end{array}$ \\
\hline & $\begin{array}{l}\text { Contributes the view that resilience is born of strategic action and the decisions } \\
\text { of managers. The resilience of human resources was not strongly evidenced. }\end{array}$ \\
\hline & $\begin{array}{l}\text { Efficiency was a major focus for resilient firms. Removing cost and } \\
\text { internalising/outsourcing activities for efficiency was apparent across resilient } \\
\text { firms. Productivity was often an overarching driver of action in resilient firms and } \\
\text { the efficiency of the value chain was at the forefront of manager's decisions. }\end{array}$ \\
\hline & $\begin{array}{l}\text { Firms that were active in sourcing and structuring information from their } \\
\text { environment tended to be more resilient. The reduction of barriers between } \\
\text { others in the ecosystem, Decision tools and standard operating procedures } \\
\text { were created by resilient firms to enable action based on imperfect information } \\
\text { and improve response times and quality. }\end{array}$ \\
\hline & $\begin{array}{l}\text { Firms exhibit consistent resilience strategies. This includes understanding } \\
\text { where the business suffers risk and addressing it through business model, } \\
\text { structural, integrative and knowledge changes. }\end{array}$ \\
\hline
\end{tabular}


Table 43: Research questions, position of literature and findings of this thesis

\begin{tabular}{|c|c|}
\hline $\begin{array}{l}\text { Research } \\
\text { Question }\end{array}$ & Thesis Contribution \\
\hline \multirow{2}{*}{$\begin{array}{l}\text { Do dynamic } \\
\text { capabilities } \\
\text { play a role in } \\
\text { the resilience } \\
\text { of firms? }\end{array}$} & $\begin{array}{l}\text { The dynamic capabilities literature provides a framework through which to view } \\
\text { resilient action. Categorising the actions of firms through Teece's (2007) } \\
\text { framework provides a useful means of creating insight into the types of } \\
\text { capabilities that create resilience. The study would appear to show that using } \\
\text { this view, resilient firms exhibit a reasonably consistent bundle of capabilities. }\end{array}$ \\
\hline & $\begin{array}{l}\text { The dynamic capabilities view deals with the change, renewal, and } \\
\text { reconfiguration of resources, with a number of the antecedents, core concepts, } \\
\text { and outcomes of resilience strongly aligned. The thesis provides an initial foray } \\
\text { into empirically linking the two areas by identifying dynamic capabilities that } \\
\text { appear to have contributed to the resilience of firms in crisis. }\end{array}$ \\
\hline
\end{tabular}

Table 44: Research questions, position of literature and findings of this thesis

\begin{tabular}{|c|c|c|}
\hline $\begin{array}{c}\text { Research } \\
\text { Question }\end{array}$ & Thesis Contribution \\
\hline $\begin{array}{c}\text { What are the } \\
\text { capabilities } \\
\text { that create } \\
\text { resilience? }\end{array}$ & $\begin{array}{c}\text { The thesis finds that Sensing capabilities, in particular R\&D, and business model } \\
\text { structure and boundary changes, and knowledge management capabilities are } \\
\text { among the strongest contributors to resilience. Some capabilities appear to be } \\
\text { necessary but not sufficient to create resilience. These include decentralisation, } \\
\text { cospecialisation, leadership and minimising agency issues. This provides a view } \\
\text { of how dynamic capabilities may be decoupled from competitive advantage. }\end{array}$ \\
\hline
\end{tabular}

\subsection{Broader Contributions to Literature}

\subsubsection{Dynamic Capabilities}

Both Sutcliffe and Vogus (2007) and Birkie et al. (2014) suggest that the dynamic capabilities literature has the potential to describe the resilience (or resilient action) of firms. The research described in this thesis has begun to elucidate what in particular these capabilities provide to resilience and has also contributed to the understanding of dynamic capabilities relationship with firm performance. 
The dynamic capabilities literature has transitioned from a highly theoretical perspective of the firm and the relationship of its actions to performance, into a well evidenced and substantially predictive theory (Ambrosini \& Bowman, 2009; Augier \& Teece, 2009; Bingham et al., 2014; Bruni \& Verona, 2009; Vogel \& Güttel, 2012; Zahra \& George, 2002). This study has applied the dynamic capabilities framework (Teece, 2007) in a new empirical setting (New Zealand's manufacturing sector) and as a means to investigate a new concept (resilience strategies) to improve the understanding of both.

The findings of this thesis - that the Sensing, Seizing, and Transformation (Teece, 2007) framework can be used to provide insight into how resilient firms might behave - is a contribution to this dynamic capabilities theory. That business model, firm boundary and structure, and knowledge management capabilities, among others occurred consistently, in resilient firms adds evidence of dynamic capabilities link to performance.

In operationalising and implementing the dynamic capabilities framework (Teece, 2007, 2011) for research, a number of implications for literature apparent. One particularly significant implication was finding that a number of the dynamic capabilities as set out by Teece were highly interrelated, not only in terms of their definition but also their application within firms. A prime example of this is how strongly knowledge permeates the framework. Actions to acquire and accumulate, index, and apply knowledge provided evidence for multiple dynamic capabilities and such instances identified in a number of firms. There were strong overlaps across capabilities and firms. This leads to the conclusion that dynamic capabilities are not mutually exclusive and linear in application and potentially highly valuable when applied in parallel. 


\subsubsection{Necessary but not sufficient capabilities}

The presence of capabilities that appear to be necessary but not sufficient to create resilience is also a contribution to the dynamic capabilities literature. To date there has been disagreement regarding the relationship between dynamic capabilities firm performance and competitive advantage (Easterby-Smith et al., 2009). Teece et al. (1997) effectively suggest there is a correspondence between dynamic capabilities and competitive advantage in that these capabilities are said to be foundational to advantage. Others suggest the relationship between dynamic capabilities and performance is mediated by other variables (Helfat et al., 2007; Schilke, 2014; Zollo \& Winter, 2002). This thesis contributes to this debate by identifying that certain dynamic capabilities may not be sufficient to create advantage, and that only when combined with other dynamic capabilities that are more causative of advantage will firms see benefit from them. This finding supports Zollo and Winters' (2002) more agnostic view of dynamic capabilities, which is that they are created and employed 'in pursuit of improved effectiveness' (p. 340). More specifically, these findings suggest that dynamic capabilities are partially decoupled from competitive advantage and instead provide performance through the creation of new and reconfigured assets that are more suitable to a dynamic environment (Teece, 2014b).

The finding that certain dynamic capabilities may only be valuable in combination with others also provides nuance to the existing understanding of the phenomena. That is, a dynamic capabilities' relationship to performance is possibly less direct and more complicated than previously theorised. Existing conceptions regarding mediating variables (Helfat et al., 2007; Schilke, 2014; Zollo \& Winter, 2002), and technical and evolutionary fitness (Easterby-Smith et al., 2009; Helfat et al., 2007; Helfat \& Peteraf, 2009) as predictors or drivers of the effectiveness of dynamic capabilities are potentially not sufficiently explanatory of the relationship between capabilities and advantage. Instead, the findings point to the potential requirement for 'threshold levels' of dynamic capabilities, or capabilities that perform at a 
particular level of effectiveness The contribution that the relationship between strategy, capabilities and advantage is more nuanced than previously believed is also an invitation for further research.

\subsection{Implications for Practice}

This thesis describes a foray into the understanding of resilience in New Zealand's manufacturing sector, in the particular setting of the GFC. The results have been structured using an academic framework to provide insight into specific fields of study rather than to practice. However, despite this there are several findings that practitioners could find informative.

One of the findings of this thesis was that the most resilient firms displayed dynamic capabilities consistently from across the framework. As such, managers should consider how their firms can develop such numerous and well balanced capabilities. Dynamic capabilities are idiosyncratic and path dependent (Teece, 2011). As such their genesis is embedded in a firms history (Kleiner, 2013). Mangers looking to create strong dynamic capabilities in the future, should be looking to position todays' resources for tomorrows' operating environment. As dynamic capabilities are used to identify and assess opportunities, mobilise to capture value from those opportunities, and continuously renew them (Augier \& Teece, 2009; Teece, 2007), managers need to implement processes to perform such activities.

Sensing capabilities are about spotting opportunities. To do so effectively managers need to build and test hypotheses regarding the market and technological evolution of their environment (Teece, 2007). Then, in the Seizing process, to capture value from the hypothesised future, the firm must secure access to capital and human resources, motivate and incentivise employees, and create strong internal and external relationships. Over time, the firm must manage the fit of its resources through 
Transformation capabilities in order to soften rigidities and continually evolve and renew. Each of these stages of process requires development of certain resources. $s$

Teece (2011) discusses the importance of developing intangible assets - in particular knowledge assets. Dynamic capabilities are focused on the creation of these resources due to their heterogeneity, inimitability, inherent value and usefulness. However, these types of assets are not naturally occurring and as such their development is dependent on the actions of managers (Kleiner, 2013). Given the findings of this thesis - that knowledge-focused dynamic capabilities and their resultant resources were particularly valuable to firms, managers should emphasize the creation of this type of asset in their own businesses. This may take the form of investments in R\&D in order to create new technologies and platforms, development of intellectual property, and forging links to other organisations to access and internalise their capability to develop knowledge.

The make or buy decision is an on-going and cyclical discussion for firms (Chesbrough \& Teece, 2002). This thesis finds that in this context for manufacturing firms, outsourcing, minimising or performing manufacturing in-house appears to make little difference to the performance of firms. Instead, the efficiency of the process and control that the firm can exert over certain other aspects of the value chain appears to have more impact on performance. Firms in the study appeared to elicit superior performance benefits when they actively managed sourcing and distribution activities. In essence, how raw materials are bought into the firm and how finished products are distributed makes more difference to the resilience of firms than the (supposed) core activity of manufacturing. These actions were performed with the unifying goal of creating efficiency and retaining margin. Managers may be well served by consideration of the process of manufacturing as a whole, rather than being overly concerned with such make or buy decisions. 
Resilient firms vertically integrated both up and downstream during the GFC. The drive within these firms was to create efficiency and to capture margin that would otherwise have accrued to a third party. Efficiency was gained within the extended value chain by collecting and disseminating internally developed best practices. Standard operating procedures, documentation and other processes that that drove efficiency and reduced the ambiguity of courses of action were also expressed in resilient firms. These practices are of potential benefit to practicing managers.

Related to this lengthening of value chains both up and downstream, resilient firms also displayed servitisation or near servitisation of their product offering, ancillary services or adopting business models that created ongoing streams of revenue. The 'Gillette model', described as the sale of a capital item at low margin and then proprietary consumables at a high level of profitability as a means to stabilise and maintain a firm's streams of revenue was an example (Raja et al., 2013).

\subsection{Future Research}

As exploratory research, the results of this thesis have exposed a number of avenues for further study. First, an opportunity exists to apply the extended resilience framework into other sectors. While the manufacturing sector provided a valuable setting to perform this exploratory research, service or other intangible product sectors would provide a valuable extension to the understanding of resilience. It may be that in the manufacturing sector particular dynamic capabilities are useful for creating resilience, but in other sectors the capabilities that are important may differ.

This study examined the resilience of firms to the GFC and its effects on manufacturing businesses in New Zealand. This has provided a number of insights into resilience in this context, however the question of 'resilience of what, to what?' (Carpenter et al., 2001, p. 1) is central to the discussion and indeed to further 
development of theory. As such, future research should look to understand how the type of environmental challenge affects the required resilience attributes and processes that produce performance and advantage during differing crises.

A study with a larger, more representative sample size may provide results and findings more applicable to both research and practice through the potential to generalise the findings (Oliver, 2006). By quantitatively studying resilience, the wide scale testing for the presence of the identified resilience constructs would be possible and the process of theory elaboration can move to confirmation (Yin, 2010).

Some of the strongest results in this study were around the business models, structures, and knowledge assets that resilient firms utilise and possess over less resilient ones. Further in-depth studies into these areas would provide deeper insight into the features of these capabilities that add to the resilience field of theory.

The concept of managerial control, which was identified as a recurrent theme across the most resilient firms, would also be an area with potential for further research. Exploring the perspective and actions of managers for the strength of locus of control would potentially provide another valuable perspective on the managerial actions that create resilience in firms.

This thesis provides new insights into the value of dynamic capabilities for the resilience of firms. Another potential avenue for future research is that of examining the longevity of capabilities developed as part of a response to a crisis or environmental contingency that prompts such changes. Dynamic capabilities are described as persistent and not ad hoc (Zollo \& Winter, 2002). This provides two potential avenues for research. First, studies could examine how dynamic capabilities that provide resilience (such as Sensing, Business-model and Knowledge 279 
management capabilities) are initially developed. Secondly, how long do the capabilities developed from such necessities persist and what is their relevance and value to firms in a post-crisis environment?

\subsection{Limitations to Research}

Despite providing findings that can be considered new to the field of strategic management, dynamic capabilities and resilience research, the approach, methodology and setting of the study suffer from some inherent limitations (Creswell, 2009; Miles \& Huberman, 1994).

A consistent (and reasonable) criticism of qualitative research is the lack of generalizability of results (Miles \& Huberman, 1994; Yin, 2010). Generalizability is the extent to which the results can be applied across a population similar to those the data were gathered from. Because of the generally small sample sizes in qualitative research, the statistical relevance of the sample is significantly diminished. This study was designed to gather rich data in order to uncover resilient actions of firms within a particular setting and as such qualitative techniques were an appropriate means through which to examine this phenomenon (Guba \& Lincoln, 1994). While this was a valuable approach in this instance, the findings of this study may not be assumed to apply across other manufacturing firms in different contexts, or indeed across other sectors.

Relatedly, the context of the manufacturing sector is also a limitation of the research that affects the extension of findings to other industry sectors. As all industry sectors are naturally unique in their structure, products, business models and more, the transferability of findings across sectors is difficult (Yin, 2010). For example, the findings from firms that manufacture products may have less bearing on services firms. 
Also affecting the generalisability of the findings is the context under study (Berg \& Lune, 2011). The sample was selected from firms within the New Zealand manufacturing sector and as such may not be generalizable to other countries or sectors due to the inherent and unique attributes of this context (for example: a small first-world economy, with its relative geographical isolation). Extension of findings and theory into other contexts is likely to be limited by these factors (Yin, 2010).

The nature of the disturbance is also a limitation to this study. The GFC was a widespread, significant economic crisis that embodied myriad effects on nations, sectors and firms. However, it is important to note that other types of disturbance could not only result in different effects to firms, but would also necessitate different resilience responses.

Another acknowledged limitation is that the data gathered was based on the retrospective recollection of the managers of firms. The risk is that post-hoc rationalisation raises opportunities for managers to justify actions that were a priori less rational or even unrelated to their own actions (Hassett \& Paavilainen-Mäntymäki, 2013). This is particularly pertinent in instances where the performance of management during difficult circumstances was the focus of investigation. The risk is that selective or unintentional bias affects responses of managers in order to protect their own egos is an acknowledged risk in this type of research (Yin, 2010). This was minimised by conducting multiple interviews in each firm to provide opportunity to verify the statements made by managers. The validity of claims is strengthened by the verification of testimony through multiple perspectives on the same issues as well as the use of secondary data (Graebner \& Eisenhardt, 2007; Yin, 2002). Using comparisons between resilient and less resilient firms also provides verification through elimination of generic practice across all firms. 
The study of resilience is complicated by the difficulties in operationalizing the concept. The approach was to compare high performing firms with lower performing ones in order to diagnose the differences in behaviour that appeared significant. However, it is worth noting that an ideal comparison in this instance would be of high performing (and resilience) firms, and firms that failed and are no longer operational. This would have provided the widest possible spread of performance for comparison. However, the difficulties in identifying, contacting and studying failed and dissolved firms made this impractical. It is noteworthy that several of the poor performing firms in the sample failed after the research was conducted.

The final identified limitation is the temporally bounded nature of the data gathering phase (Hassett \& Paavilainen-Mäntymäki, 2013). The interviews were gathered across an eight month period during the largest financial crisis in recent history (Blankenburg \& Palma, 2009). Each interview, and hence case, was surveyed at a particular point in time, in a rapidly evolving and dynamic environment. Collection of data regarding change in demographic variables provides a view across time of selected variables but are also limited by the time this data was collected and the information available to managers.

\subsection{Concluding Statements}

The opportunity to study the resilience of firms has yielded interesting results that were at times surprising. While the focus on efficiency and innovation were reasonably expected responses to a financial crisis, the emphasis (and apparent effectiveness) of knowledge management capabilities, business model and vertical integration changes were unexpected, but fascinating findings. The most resilient firms looked to exert control over select aspects of their operations, both within and outside their boundaries to counter the effects of the GFC. 
The concept of resilience still requires significant attention and development in academia. This thesis has aimed to extend the current stock of literature by identifying the presence, or lack of presence, of resilience concepts in firms and by extending the understanding of resilience by identifying new findings from evidence.

The application of dynamic capabilities as an empirical framework through which to view the resilience of the firm is a novel approach at the time of writing. That resilient firms have and employ particular bundles of these capabilities suggests that a firm's ability to change to meet disturbances occurs across numerous facets. The finding that some capabilities are necessary but not sufficient to create resilience suggests that threshold levels of capabilities may be required for a successful resilience response to a crisis.

Resiliency in firms has been identified as a key trait for success in a modern business context. Despite this, in academic and practitioner discussion, resilience receives little attention. This may be due to difficulties in operationalising it, the various definitions that can be employed and the nebulous nature of the antecedents, prerequisites, and outcomes of resilience due to its highly contextual nature. These issues are not insurmountable, however, and this thesis has aimed to contribute by building on the existing conceptual development that the literature has provided. It may also be that system-wide change in order to position the firm for unforeseen, ambiguous disturbances is difficult to prioritise and invest in. Despite any barriers to discussion, operationalisation, or implementation, resilience remains an increasingly important issue in management for scholars and practitioners alike. 


\section{References}

Aaker, D. A., \& Mascarenhas, B. (1984). The need for strategic flexibility. Journal of Business Strategy, 5(2), 74-82. http://doi.org/10.1108/eb039060

AC Nielsen. (2010, October 9). The State of the Global Consumer: Spending Trends | Nielsen Wire. Retrieved February 2, 2012, from http://blog.nielsen.com/nielsenwire/consumer/the-state-of-the-global-consumerspending-trends/

Adams, R. M. (1978). Strategies of Maximization, Stability, and Resilience in Mesopotamian Society, Settlement, and Agriculture. Proceedings of the American Philosophical Society, 122(5), 329-335.

Adger, W. N. (2000). Social and ecological resilience: are they related? Progress in Human Geography, 24(3), 347-364. http://doi.org/10.1191/030913200701540465

Aizenman, J., \& Jinjarak, Y. (2009). Current account patterns and national real estate markets. Journal of Urban Economics, 66(2), 75-89.

Ali, S., Peters, L. D., He, H., \& Lettice, F. (2010). Market based organisational learning, dynamic, and substantive capabilities: An integrative framework. Journal of Strategic Marketing, $18(5)$, $363-377$. http://doi.org/http://dx.doi.org.helicon.vuw.ac.nz/10.1080/0965254X.2010.497846

Allison, H. E., \& Hobbs, R. J. (2004). Resilience, adaptive capacity, and the lock-in trap of the Western Australian agricultural region. Ecology and Society, 9(1). Retrieved from http://researchrepository.murdoch.edu.au/540/

Ambrosini, V., \& Bowman, C. (2009). What are dynamic capabilities and are they a useful construct in strategic management? International Journal of Management Reviews, 11(1), 29-49. http://doi.org/10.1111/j.1468-2370.2008.00251.x

Anderson, C. (2010). Free: How Today's Smartest Businesses Profit by Giving Something for Nothing (1 edition). New York, N.Y.: Hyperion.

Anthony, E. J., \& Cohler, B. J. (1987). The Invulnerable Child (1st ed.). The Guilford Press.

Arksey, H., \& Knight, P. (1999). Interviewing for social scientists: an introductory resource with examples. SAGE. 
Ash, J., \& Newth, D. (2007). Optimizing complex networks for resilience against cascading failure. Physica A: Statistical Mechanics and Its Applications, 380, 673-683. http://doi.org/10.1016/j.physa.2006.12.058

Augier, M., \& Teece, D. J. (2009). Dynamic Capabilities and the Role of Managers in Business Strategy and Economic Performance. ORGANIZATION SCIENCE, 20(2), 410-421. http://doi.org/10.1287/orsc.1090.0424

Avan, B. I., \& White, F. (2001). The proposition: an insight into research. JPMA. The Journal of the Pakistan Medical Association, 51(1), 49-53.

Backus, D., \& Cooley, T. (2012, November 1). Global "Imbalances" and the Crisis. The Wall Street Journal. Retrieved from http://online.wsj.com/article/SB10001424052748703652104574652230174885724.ht $\mathrm{ml}$

Baker, T., \& Nelson, R. E. (2005). Creating Something from Nothing: Resource Construction through Entrepreneurial Bricolage. Administrative Science Quarterly, 50(3), 329 -366. http://doi.org/10.2189/asqu.2005.50.3.329

Barbaro, M., \& Uchitelle, L. (2008, January 14). Americans Cut Back Sharply on Spending. The New York Times. Retrieved from http://www.nytimes.com/2008/01/14/business/14spend.html

Barney, J. (1991). Firm Resources and Sustained Competitive Advantage. Journal of Management, 17(1), 99-120. http://doi.org/10.1177/014920639101700108

Barney, J. B. (1986). Strategic Factor Markets: Expectations, Luck, and Business Strategy. Management Science, 32(10), 1231-1241. http://doi.org/10.1287/mnsc.32.10.1231

Barney, J. B. (1996). The Resource-Based Theory of the Firm. ORGANIZATION SCIENCE, 7(5), 469. http://doi.org/10.1287/orsc.7.5.469

Barreto, I. (2010). Dynamic Capabilities: A Review of Past Research and an Agenda for the Future. Journal of Management, 36(1), 256-280. http://doi.org/10.1177/0149206309350776

Beard, C. (2015, April 16). Autum tinge - PMI. Retrieved from http://www.businessnz.org.nz/resources/surveys-and-statistics/pmi/2015/autum-tingepmi 
Becker, M. C. (2004). Organizational routines: a review of the literature. Industrial and Corporate Change, 13(4), 643 -678. http://doi.org/10.1093/icc/dth026

Becker, M. C., Lazaric, N., Nelson, R. R., \& Winter, S. G. (2005). Applying organizational routines in understanding organizational change. Industrial and Corporate Change, 14(5), 775 -791. http://doi.org/10.1093/icc/dth071

Beckert, J. (2012). Agency, Entrepreneurs and Institutional Change: The Role of Strategic Choice and Institutionalized Practices in Organizations. (B. G. Peters \& J. Pierre, Eds.) (Vol. 1: Developing Institutional Theory). Los Angeles: Sage.

Bedford, P. (2008). The global financial crisis and its transmission to New Zealand - an external balance sheet analysis. Reserve Bank of New Zealand: Bulletin, 71(4), 18-28.

Bellamy Foster, J., \& Magdoff, F. (2009). The Great Financial Crisis: Causes and Consequences (1st ed.). New York: Monthly Review Press.

Bell, M. A. (2002). The Five Principles of Organizational Resilience. Gartner.

Bengtsson, J., Angelstam, P., Elmqvist, T., Emanuelsson, U., Folke, C., Ihse, M., ... Nyström, M. (2003). Reserves, resilience and dynamic landscapes. Ambio, 32(6), 389-396.

Benjamin, R., Gladman, B., \& Randell, B. (1998). Protecting IT Systems from Cyber Crime. The Computer Journal, 41(7), 429 -443. http://doi.org/10.1093/comjn1/41.7.429

Berg, B. L., \& Lune, H. (2011). Qualitative Research Methods for the Social Sciences (8 edition). Boston: Pearson.

Berkes, F., Colding, J., \& Folke, C. (2002). Navigating Social-Ecological Systems: Building Resilience for Complexity and Change (1st ed.). Cambridge University Press.

Berkes, F., \& Folke, C. (1992). A systems perspective on the interrelations between natural, human-made and cultural capital. Ecological Economics, 5(1), 1-8. http://doi.org/10.1016/0921-8009(92)90017-M

Bernanke, B. S. (2010, March). Monetary Policy and the Housing Bubble. Presented at the The Annual Meeting of the American Economic Association, Atlanta, Georgia.

Bettis, R. A., \& Wong, S.-S. (2003). Dominant Logic, Knowledge Creation and Managerial Choice. In M. Easterby-Smith \& M. A. Lyles (Eds.), The Blackwell handbook of organizational learning and knowledge management. Wiley-Blackwell. 
Beunza, D., \& Stark, D. (2004). Survival and Sensemaking: Organizational Resilience in a Wall Street Trading Room After 9/11. SSRN eLibrary. Retrieved from http://papers.ssrn.com/sol3/papers.cfm?abstract_id=563315

Bhamra, R., Dani, S., \& Burnard, K. (2011). Resilience: the concept, a literature review and future directions. International Journal of Production Research, 49(18), 5375-5393. http://doi.org/10.1080/00207543.2011.563826

Biklen, S. K., \& Casella, R. (2007). A Practical Guide to the Qualitative Dissertation (1st ed., Vol. 1). New York, N.Y.: Teachers College Press.

Bingham, C. B., Heimeriks, K. H., Schijven, M., \& Gates, S. (2014). Concurrent learning:How firms develop multiple dynamic capabilities in parallel. Strategic Management Journal, n/a-n/a. http://doi.org/10.1002/smj.2347

Birkie, S. E., Trucco, P., \& Kaulio, M. (2014). Disentangling core functions of operational resilience: a critical review of extant literature. International Journal of Supply Chain and Operations Resilience, 1(1), 76-103. http://doi.org/10.1504/IJSCOR.2014.065461

Blankenburg, S., \& Palma, J. G. (2009). Introduction: the global financial crisis. Cambridge Journal of Economics, 33(4), 531 -538. http://doi.org/10.1093/cje/bep038

Block, J. (1950). An experimental investigation of the construct of ego-control (Doctoral Dissertation). Stanford University.

Block, J. (1993). Ego-Resilience through Time. Retrieved from http://www.eric.ed.gov/ERICWebPortal/contentdelivery/servlet/ERICServlet?accno= ED356879

Block, J., \& Kremen, A. M. (1996). IQ and Ego-Resiliency: Conceptual and Empirical Connections and Separateness. Journal of Personality and Social Psychology, 70(2), 349-361.

Bodin, P., \& Wiman, B. L. B. (2004). Resilience and other stability concepts in ecology: notes on their origin, validity and usefulness 1. The ESS Bulletin, 2(2), 33-44.

Boin, A., \& van Eeten, M. J. G. (2013). The Resilient Organization. Public Management Review, 15(3), 429-445. http://doi.org/10.1080/14719037.2013.769856

Bolig, R., \& Weddle, K. D. (1988). Resiliency and Hospitalization of Children. Children's Health Care, 16(4), 255. http://doi.org/10.1207/s15326888chc1604_2 
Bollard, A., \& Ng, T. (2009). Coping with global financial and economic stresses. Reserve Bank of New Zealand Bulletin, 72, 34-45.

Borland, J. H. (1990). Postpositivist Inquiry: Implications of the "New Philosophy of Science" for the Field of the Education of the Gifted. Gifted Child Quarterly, 34(4), 161 -167. http://doi.org/10.1177/001698629003400406

Bourgeois, L. J. (1981). On the Measurement of Organizational Slack. The Academy of Management Review, 6(1), 29-39.

Bowman, C., \& Ambrosini, V. (2003). How the Resource-based and the Dynamic Capability Views of the Firm Inform Corporate-level Strategy. British Journal of Management, 14(4), 289-303.

Brand, F. S., \& Jax, K. (2007). Ecology and Society - Vol. 12, No. 1 (2007). Ecology and Society, 12(1). Retrieved from http://www.ecologyandsociety.org/articles/2029.html

Breznik, L., \& Lahovnik, M. (2014). Renewing the resource base in line with the dynamic capabilities view: a key to sustained competitive advantage in the IT industry. Journal for East European Management Studies, 19(4), 453-485.

British Petroleum. (2011). BP Statistical Review of World Energy (p. 49). British Petroleum.

Brockhaus, R. H. (1975). I-E Locus of Control Scores as Predictors of Entrepreneurial Intentions. Academy of Management Proceedings, 1975(1), 433-435. http://doi.org/10.5465/AMBPP.1975.4990354

Bruni, D. S., \& Verona, G. (2009). Dynamic Marketing Capabilities in Science-based Firms: an Exploratory Investigation of the Pharmaceutical Industry. British Journal of Management, 20, S101-S117. http://doi.org/10.1111/j.1467-8551.2008.00615.x

Calantone, R. J., Cavusgil, S. T., \& Zhao, Y. (2002). Learning orientation, firm innovation capability, and firm performance. Industrial Marketing Management, 31(6), 515-524. http://doi.org/10.1016/S0019-8501(01)00203-6

Captial Economics Limited. (2012). Increase in Real Value Added (p. 1). Wellington: The New Zealand Initiative.

Carmassi, J., Gros, D., \& Micossi, S. (2009). The Global Financial Crisis: Causes and Cures. JCMS: Journal of Common Market Studies, 47(5), 977-996. http://doi.org/10.1111/j.1468-5965.2009.02031.x 
Carmeli, A., \& Markman, G. D. (2011). Capture, governance, and resilience: strategy implications from the history of Rome. Strategic Management Journal, 32(3), 322-341. http://doi.org/10.1002/smj.880

Carpenter, S. A., Walker, B., Anderies, J. M., \& Abel, N. (2001). From Metaphor to Measurement: Resilience of What to What? Ecosystems, 4(8), 765-781.

Cepeda, G., \& Vera, D. (2007). Dynamic capabilities and operational capabilities: A knowledge management perspective. Journal of Business Research, 60(5), 426-437. http://doi.org/10.1016/j.jbusres.2007.01.013

Chan, D. L. H., \& Soong, S. C. (2011). Strategic repositioning in a dynamic environment. Library Management, $\quad 32(1 / 2), \quad 22-36$. http://doi.org/http://dx.doi.org.helicon.vuw.ac.nz/10.1108/01435121111102557

Chesbrough, H. (2010). Business Model Innovation: Opportunities and Barriers. Long Range Planning, 43(2-3), 354-363. http://doi.org/10.1016/j.lrp.2009.07.010

Chesbrough, H., \& Rosenbloom, R. S. (2002). The role of the business model in capturing value from innovation: evidence from Xerox Corporation's technology spin-off companies. Ind Corp Change, 11(3), 529-555. http://doi.org/10.1093/icc/11.3.529

Chesbrough, H. W. (2003). Open Innovation: The New Imperative for Creating and Profiting from Technology. Harvard Business Press.

Chesbrough, H. W., \& Teece, D. J. (2002). Organizing for Innovation: When Is Virtual Virtuous? Harvard Business Review, 80(8), 127-135.

Chor, D., \& Manova, K. (n.d.). Off the cliff and back? Credit conditions and international trade during the global financial crisis. Journal of International Economics. http://doi.org/10.1016/j.jinteco.2011.04.001

Colebatch, T. (2009, October 27). We failed the GFC test. The Sydney Morning Herald. Sydney. Retrieved from http://www.smh.com.au/federal-politics/political-opinion/we-failedthe-gfc-test-20091026-hglk.html

Comfort, L. K., Boin, A., \& Demchak, C. C. (2010a). Designing Resilience: Preparing for Extreme Events. University of Pittsburgh Pre.

Comfort, L. K., Boin, A., \& Demchak, C. C. (2010b). Designing Resilience: Preparing for Extreme Events. University of Pittsburgh Pre. 
Comfort, L. K., Sungu, Y., Johnson, D., \& Dunn, M. (2001). Complex Systems in Crisis: Anticipation and Resilience in Dynamic Environments. Journal of Contingencies and Crisis Management, 9(3), 144-158. http://doi.org/10.1111/1468-5973.00164

Coutu, D. L. (2002). How resilience works. Harvard Business Review, 80(5), 46-50, 52, 55 passim.

Creswell, J. W. (2009). Research design: qualitative, quantitative, and mixed methods approaches. Sage Publications.

Crotty, J. (2009). Structural causes of the global financial crisis: a critical assessment of the "new financial architecture." Cambridge Journal of Economics, 33(4), 563 -580. http://doi.org/10.1093/cje/bep023

Crouch, M., \& McKenzie, H. (2006). The logic of small samples in interview-based qualitative research. Social Science Information, 45(4), 483-499. http://doi.org/10.1177/0539018406069584

Damanpour, F. (1991). Organizational Innovation: A Meta-Analysis of Effects of Determinants and Moderators. The Academy of Management Journal, 34(3), 555-590. http://doi.org/10.2307/256406

DeAngelis, D. L. (1980). Energy flow, nutrient cycling, and ecosystem resilience. Ecology, 61(4), 764-771. http://doi.org/10.2307/1936746

Dean, J. W., \& Sharfman, M. P. (1996). Does Decision Process Matter? A Study Of Strategic Decision-making Effectiveness. Academy of Management Journal, 39(2), 368-392. http://doi.org/10.2307/256784

Denzin, N. K. (1989). Interpretive interactionism. SAGE.

Dierickx, I., \& Cool, K. (1989). Asset Stock Accumulation and Sustainability of Competitive Advantage. Management Science, 35(12), 1504-1511.

Di Stefano, G., Peteraf, M., \& Verona, G. (2010). Dynamic capabilities deconstructed: a bibliographic investigation into the origins, development, and future directions of the research domain. Industrial and Corporate Change, 19(4), 1187-1204. http://doi.org/10.1093/icc/dtq027

Dosi, G., Nelson, R. R., \& Winter, S. G. (2000). The nature and dynamics of organizational capabilities. Oxford University Press. 
Drabble, E. (1907). On the size of the cells of Pleurococcus and Saccharomyces in solutions of a neutral salt. Biochemical Journal, 2(5-6), 221.

Dun \& Bradstreet. (2012). Global Business Failures Report. Dun \& Bradstreet.

Easterby-Smith, M., Lyles, M. A., \& Peteraf, M. A. (2009). Dynamic Capabilities: Current Debates and Future Directions. British Journal of Management, 20, S1-S8. http://doi.org/10.1111/j.1467-8551.2008.00609.x

Economic and Social Commission for Western Asia. (2009). The impact of the global financial crisis on the world oil market and its implications for the GCC countries. Economic and Social Commission for Western Asia.

Eisenhardt, K. M. (1989a). Building Theories from Case Study Research. The Academy of Management Review, 14(4), 532-550. http://doi.org/10.2307/258557

Eisenhardt, K. M. (1989b). Making Fast Strategic Decisions in High-Velocity Environments. The Academy of Management Journal, 32(3), 543-576. http://doi.org/10.2307/256434

Eisenhardt, K. M., \& Martin, J. A. (2000). Dynamic Capabilities: What Are They? Strategic Management Journal, 21(10/11), 1105-1121.

Elliot, L. (2011, August 7). Global financial crisis: five key stages 2007-2011 | Business | The Guardian. $\quad$ Retrieved $\quad$ August 22, 2011, from http://www.guardian.co.uk/business/2011/aug/07/global-financial-crisis-key-stages

Elmqvist, T., Folke, C., Nystrom, M., Peterson, G., Bengtsson, J., Walker, B., \& Jon Norberg. (2003). Response Diversity, Ecosystem Change, and Resilience. Frontiers in Ecology and the Environment, 1(9), 488-494.

Eriksson, T. (2014). Processes, antecedents and outcomes of dynamic capabilities. Scandinavian Journal of Management, 30(1), 65-82. http://doi.org/10.1016/j.scaman.2013.05.001

Ernst \& Young. (2010). “Beyond Borders: Ernst \& Young Global Biotechnology Report 2009” (p. 116). Zurich/Boston: Ernst \& Young. Retrieved from http://www.ey.com/CH/en/Newsroom/News-releases/20090505-Beyond-BordersErnst---Young-Global-Biotechnology-Report-2009-Global-financial-crisisprofoundly-strains-biotechnology-business-model 
Espino-RodrÃ-guez, T. F., \& PadrÃ $\tilde{A}^{3}$ n-Robaina, Vã-. (2006). A review of outsourcing from the resource-based view of the firm. International Journal of Management Reviews, 8(1), 49-70. http://doi.org/10.1111/j.1468-2370.2006.00120.x

Fahey, L., \& Christensen, H. K. (1986). Evaluating the Research on Strategy Content. Journal of Management, 12(2), 167 -183. http://doi.org/10.1177/014920638601200203

Farrell, M. (2011, September 16). Europe's default risk: CDS bets - Sep. 15, 2011 [New]. Retrieved September 26, 2011, from http://money.cnn.com/2011/09/15/markets/europe_default_risk/index.htm

Fink, A. S. (2000). The Role of the Researcher in the Qualitative Research Process. A Potential Barrier to Archiving Qualitative Data. Forum Qualitative Sozialforschung / Forum: Qualitative Social Research, 1(3). Retrieved from http://www.qualitativeresearch.net/index.php/fqs/article/view/1021

Flick, U., von Kardorff, E., \& Steinke, I. (Eds.). (2004). A Companion to Qualitative Research. (B. Jenner, Trans.) (1st ed.). Hamburg: SAGE Publications Inc.

Folke, C. (2006). Resilience: The emergence of a perspective for social-ecological systems analyses. Global Environmental Change, 16(3), 253-267. http://doi.org/10.1016/j.gloenvcha.2006.04.002

Folke, C., Carpenter, S., Walker, B., Scheffer, M., Elmqvist, T., Gunderson, L., \& Holling, C. S. (2004). Regime shifts, resilience, and biodiversity in ecosystem management. Annual Review of Ecology, Evolution, and Systematics, 35(1), 557-581. http://doi.org/10.1146/annurev.ecolsys.35.021103.105711

Folke, C., Steve Carpenter, Thomas Elmqvist, Lance Gunderson, CS Holling, \& Brian Walker. (2002). Resilience and Sustainable Development: Building Adaptive Capacity in a World of Transformations. Royal Swedish Academy of Sciences. Retrieved from http://www.bioone.org/perlserv/?request=get-document\&doi=10.1639\%2F00447447\%282002\%29031\%5B0437\%3ARASDBA\%5D2.0.CO\%3B2

Foss, N. J. (2003). The Strategic Management and Transaction Cost Nexus: Past Debates, Central Questions, and Future Research Possibilities. Strategic Organization, 1(2), 139-169. http://doi.org/10.1177/1476127003001002304

Franken, H., Le Fort, G., \& Parrado, E. (2004). Business Cycle Responses and Resilience of the Chilean Economy During the Last Fifty Years. International Monetary Fund. 
Fratzscher, M. (2011). Capital flows, push versus pull factors and the global financial crisis (Working Paper Series No. 20111364). European Central Bank. Retrieved from http://www.ecb.europa.eu/pub/pdf/scpwps/ecbwp1364.pdf

Fuglsang, L., \& Sørensen, F. (2011). The balance between bricolage and innovation: management dilemmas in sustainable public innovation. The Service Industries Journal, 31, 581-595. http://doi.org/10.1080/02642069.2010.504302

Furman, G. C. (1990, April). Abduction or induction? The semantics of data analysis in qualitative research. Presented at the Annual Meeting of the American Educational Research Association, Boston.

Garud, R., \& Karnøe, P. (2003). Bricolage versus breakthrough: distributed and embedded agency in technology entrepreneurship. Research Policy, 32(2), 277-300. http://doi.org/10.1016/S0048-7333(02)00100-2

German, B. (2009, October 13). The Other Peak Oil: Demand from Developed World Falling. Scientific American.

Gill, P., Stewart, K., Treasure, E., \& Chadwick, B. (2008). Methods of data collection in qualitative research: interviews and focus groups. British Dental Journal, 204(6), 291295. http://doi.org/10.1038/bdj.2008.192

Gioia, D. A., \& Chittipeddi, K. (1991). Sensemaking and sensegiving in strategic change initiation. Strategic Management Journal, 12(6), 433-448. http://doi.org/10.1002/smj.4250120604

Gittell, J. H. (2005). The Southwest Airlines way: using the power of relationships to achieve high performance. McGraw-Hill Professional.

Gittell, J. H., Cameron, K., Lim, S., \& Rivas, V. (2006). Relationships, Layoffs, and Organizational Resilience. The Journal of Applied Behavioral Science, 42(3), 300 -329. http://doi.org/10.1177/0021886306286466

Gittell, J. H., Nordenflycht, A. V., \& Kochan, T. A. (2003). Mutual Gains or Zero Sum? Labor Relations and Firm Performance in the Airline Industry. SSRN eLibrary. Retrieved from http://papers.ssrn.com/sol3/papers.cfm?abstract_id=395447

Given, L. (2008). The SAGE Encyclopedia of Qualitative Research Methods. 2455 Teller Road, Thousand Oaks California 91320 United States: SAGE Publications, Inc. 
Retrieved from http://srmo.sagepub.com/view/sage-encyc-qualitative-researchmethods/n99.xml

Glantz, M. D., \& Johnson, J. L. (1999). Resilience and development: positive life adaptations. Springer.

Goldman, D. (2008, November 26). Consumer spending drops 1\%. CNN Money. Washington DC.

Gopalakrishnan, S., \& Damanpour, F. (1994). Patterns of generation and adoption of innovation in organizations: Contingency models of innovation attributes. Journal of Engineering and Technology Management, 11(2), 95-116. http://doi.org/10.1016/0923-4748(94)90001-9

Graebner, M. E., \& Eisenhardt, K. M. (2007). Theory Building From Cases: Opportunities and Challenges. Academy of Management Journal, 50(1), 25-32. http://doi.org/10.2307/20159839

Gray, D. E. (2009). Doing Research in the Real World (Second Edition). Sage Publications Ltd.

Grünbaum, N. N., \& Stenger, M. (2014). Dynamic Capabilities: Do They Lead to Innovation Performance and Profitability? (SSRN Scholarly Paper No. ID 2466939). Rochester, NY: Social Science Research Network. Retrieved from http://papers.ssrn.com/abstract $=2466939$

Guba, E. G., \& Lincoln, Y. S. (1994). Competing Paradigms in Qualitative Research. In N. K. Denzin \& Y. S. Lincoln (Eds.), Handbook of qualitative research (pp. 105 - 117). Sage Publications.

Guest, G., Bunce, A., \& Johnson, L. (2006). How Many Interviews Are Enough? An Experiment with Data Saturation and Variability. Field Methods, 18(1), 59-82. http://doi.org/10.1177/1525822X05279903

Gunderson, L. H., \& Holling, C. S. (2001). Panarchy: Understanding Transformations in Human and Natural Systems (1st ed.). Island Press.

Hamel, G., \& Valikangas, L. (2003). The Quest for Resilience. Harvard Business Review, 81(9), 53-63. 
Harrison, G. W. (1979). Stability under Environmental Stress: Resistance, Resilience, Persistence, and Variability. The American Naturalist, 113(5), 659-669.

Hassett, M. E., \& Paavilainen-Mäntymäki, E. (2013). Handbook of Longitudinal Research Methods in Organisation and Business Studies. Northampton, MA: Edward Elgar Pub.

Hays, D. G., \& Singh, A. A. (2011). Qualitative Inquiry in Clinical and Educational Settings. Guilford Press.

Helfat, C. E., Finkelstein, S., \& Mitchell, W. (2007). Dynamic capabilities: understanding strategic change in organizations. Wiley-Blackwell.

Helfat, C. E., \& Peteraf, M. A. (2009). Understanding dynamic capabilities: progress along a developmental path. Strategic Organization, 7(1), 91-102. http://doi.org/10.1177/1476127008100133

Herzberg, F., Mausner, B., \& Snyderman, B. B. (1993). The Motivation to Work (Reprint edition). New Brunswick, N.J., U.S.A: Transaction Publishers.

Hesse-Biber, S. N., \& Leavy, P. (2010). The Practice of Qualitative Research. SAGE.

Holling, C. S. (1973). Resilience and Stability of Ecological Systems. Annual Review of Ecology and Systematics, 4, 1-23.

Holling, C. S. (1996). Engineering Resilience versus Ecological Resilience. In Engineering Within Ecological Constraints. National Academy Press. Retrieved from http://books.google.co.nz/books?hl=en\&lr=\&id=QE4ydbFti7AC\&oi=fnd\&pg=PA31 $\& d q=$ engineering + resilience\&ots=28xMsqpGvt\&sig=YZzfXUS_qLLlfkE3NRMj7Y GvleY\#v=onepage \&q=engineering\%20resilience $\& \mathrm{f}=$ false

Hollis, J. (1996). Supply chain re-engineering: the experience of Littlewoods chain stores. Supply Chain Management: An International Journal, 1(1), 5-10. http://doi.org/10.1108/13598549610799022

Hosking, R. (2012, November 9). Worse to come yet for manufacturing. The National Business Review. Auckland. Retrieved from http://www.nbr.co.nz/article/manufacturing-stillflat-\%E2\%80\%93-and-theres-worse-come-rh-p-128072

Huber, G. P., \& Power, D. J. (1985). Retrospective Reports of Strategic-Level Managers: Guidelines for Increasing Their Accuracy. Strategic Management Journal, 6(2), 171180. 
Hulsen, K. K. (1896). Specific gravity, resilience and strength of bone. St Petersburg: Bull. Biol. Lab.

International Monetary Fund. (2012, May 1). IMF Primary Commodity Prices. Retrieved February 1, 2012, from http://www.imf.org/external/np/res/commod/index.aspx

Jamrog, J. J., McCann, J. E. I., Lee, J. M., Morrison, C. L., Selsky, J. W., \& Vickers, M. (2006). Agility and resilience in the face of continuous change: a global study of current trends and future possibilities, 2006-2016. New York: American Management Association.

Johnson, D., Meyer, M. E., Berkowitz, J. M., Miller, V., \& Ethington, C. T. (1997). Testing Two Contrasting Structural Models of Innovativeness in a Contractual Network. Human Communication Research, 24(2), 320-348. http://doi.org/10.1111/j.14682958.1997.tb00417.x

Kaplan, R. S., \& Norton, D. P. (1996). The Balanced Scorecard: Translating Strategy Into Action. Harvard Business Press.

Kavoussi, B. (2012, July 25). The Recession Killed This Many Small Businesses. The Huffington Post. Retrieved from http://www.huffingtonpost.com/2012/07/25/us-lostmore-than-170000-small-businesses-2008-2010_n_1702358.html

Kendra, J. M., \& Wachtendorf, T. (2003). Elements of Resilience After the World Trade Center Disaster: Reconstituting New York City's Emergency Operations Centre. Disasters, 27(1), 37-53. http://doi.org/10.1111/1467-7717.00218

Keupp, M. M., Palmié, M., \& Gassmann, O. (2011). The Strategic Management of Innovation: A Systematic Review and Paths for Future Research. International Journal of Management Reviews. http://doi.org/10.1111/j.1468-2370.2011.00321.x

King, M. (2010, January). Speech at the University of Exeter. University of Exeter.

Kleiner, A. (2013, November). The Dynamic Capabilities of David Teece. Retrieved February 15, 2016, from http://www.strategy-business.com/article/00225?gko=d24f3

Kneale, K. (2009, December 2). You're Probably Doing Your Layoffs All Wrong - Forbes.com. Forbes. Retrieved from http://www.forbes.com/2009/02/12/layoffs-workforceplanning-leadership-management_0212_kneale.html

Kolko, J. (2010). Design strategy, product management, education \& writing. MIT's Design Issues, 26(1). 
Kowalski, A. (2012, February 1). Consumer Spending Stalls as Americans Lift Savings: Economy. BusinessWeek: Homepage. Retrieved from http://www.businessweek.com/news/2012-02-01/consumer-spending-stalls-asamericans-lift-savings-economy.html

Krauss, C. (2008, October 14). Commodity Prices Tumble. The New York Times. Retrieved from http://www.nytimes.com/2008/10/14/business/economy/14commodities.html

Kruger, C. (2008, May 3). More aboard for Citi. The Sydney Morning Herald. Sydney. Retrieved from http://www.smh.com.au/business/more-aboard-for-citi-200803041wvs.html

Lau, R. S. M. (1996). Strategic flexibility: a new reality for world-class manufacturing. Advanced Management Journal, 61(2), 5.

Lengnick-Hall, C. A., \& Beck, T. E. (2005). Adaptive Fit Versus Robust Transformation: How Organizations Respond to Environmental Change. Journal of Management, 31(5), 738 -757. http://doi.org/10.1177/0149206305279367

Lengnick-Hall, C. A., \& Beck, T. E. (2009). Resilience Capacity and Strategic Agility: Prerequisites for Thriving in a Dynamic Environment. College of Business, University of Texas at San Antonio. Retrieved from http://ideas.repec.org/p/tsa/wpaper/0059.html

Lengnick-Hall, C. A., Beck, T. E., \& Lengnick-Hall, M. L. (2010). Developing a capacity for organizational resilience through strategic human resource management. Human Resource Management Review, In Press, Corrected Proof. http://doi.org/10.1016/j.hrmr.2010.07.001

Leonard-Barton, D. (1992). Core Capabilities and Core Rigidities: A Paradox in Managing New Product Development. Strategic Management Journal, 13, 111-125.

Letourneau, N., \& Allen, M. (1999). Post-positivistic critical multiplism: a beginning dialogue. Journal of Advanced Nursing, 30(3), 623-630. http://doi.org/10.1046/j.13652648.1999.01133.x

Lévi-Strauss, C. (1996). The savage mind: (la pensée sauvage). Oxford University Press.

Lincoln, Y. S., \& Guba, E. G. (1985). Naturalistic inquiry. SAGE.

Ljungquist, U. (2014). Unbalanced dynamic capabilities as obstacles of organisational efficiency: Implementation issues in innovative technology adoption. Innovation: 
Management, $\quad$ Policy $\quad \& \quad$ Practice, $\quad 16(1), \quad 82-95$. http://doi.org/10.5172/impp.2014.16.1.82

Long, C., \& Vickers-Koch, M. (1995). Using core capabilities to create competitive advantage. Organizational Dynamics, 24(1), 7-22. http://doi.org/10.1016/0090-2616(95)90032-2 Longstaff, P. H. (2005). Security, Resilience, and Communication in Unpredictable Environments such as Terrorism, Natural Disasters and Complex Technology. Programme for Information Resources Policy, Harvard University. Retrieved from www.pirp.harvard.edu

Longstaff, P. H., Velu, R., \& Obar, J. (2004). Resilience for Industries in Unpredictable Environments: You Ought To Be Like Movies. Programme for Information Resources Policy, Harvard University. Retrieved from www.pirp.harvard.edu

Ludwig, D., Walker, B., \& Holling, C. S. (1997). Conservation Ecology: Sustainability, Stability, and Resilience. Conservation Ecology, 1(1), 7.

Lynch, S. M. (2013). Overview of the Research Process. In Using Statistics in Social Research (pp. 5-15). Springer New York. Retrieved from http://link.springer.com/chapter/10.1007/978-1-4614-8573-5_2

MacArthur, R. (1955). Fluctuations of Animal Populations and a Measure of Community Stability. Ecology, 36(3), 533. http://doi.org/10.2307/1929601

Magnani, L. (2001). Abduction, reason, and science: processes of discovery and explanation. New York: Kluwer Academic/Plenum Publishers.

Makhlouf, G. (2013, July). Some Lessons from the Global Financial Crisis. Presented at the The Trans-Tasman Business Forum, Auckland.

March, J. G. (1991). Exploration and Exploitation in Organizational Learning. Organization Science, 2(1), 71-87. http://doi.org/10.1287/orsc.2.1.71

Marshall, C., \& Rossman, G. B. (2010). Designing Qualitative Research (Fifth Edition edition). Los Angeles: SAGE Publications, Inc.

Marshall, J. (1981). Making sense as a personal process. In P. Reason \& J. Rowan (Eds.), Human Inquiry: A Sourcebook of New Paradigm Research (1st ed.). John Wiley \& Sons. 
Mason, M. (2010). Sample Size and Saturation in PhD Studies Using Qualitative Interviews. Forum Qualitative Sozialforschung / Forum: Qualitative Social Research, 11(3). Retrieved from http://www.qualitative-research.net/index.php/fqs/article/view/1428

Maxwell, J. C. (1865). A Dynamical Theory of the Electromagnetic Field. Philosophical Transactions of the Royal Society of London, 155, 459-512.

McKee, D. O., Conant, J. S., Varadarajan, P. R., \& Mokwa, M. P. (1992). Success-producer and failure-preventer marketing skills: A social learning theory interpretation. Journal of the Academy of Marketing Science, 20(1), 17-26. http://doi.org/10.1007/BF02723472

Merrouche, O., \& Nier, E. (2010). What Caused the Global Financial Crisis? - Evidence on the Drivers of Financial Imbalances 1999 - 2007. International Monetary Fund.

Meyer, A. D. (1982). Adapting to Environmental Jolts. Administrative Science Quarterly, 27(4), 515-537. http://doi.org/10.2307/2392528

Meyer, M. W., \& Zucker, P. L. G. (1989). Permanently Failing Organizations. Sage Publications, Inc.

Miles, M. B., \& Huberman, A. M. (1994). Qualitative Data Analysis: An Expanded Sourcebook (2nd ed.). Sage Publications, Inc.

Montgomery, C. A., Wernerfelt, B., \& Balakrishnan, S. (1989). Strategy content and the research process: A critique and commentary. Strategic Management Journal, 10(2), 189-197. http://doi.org/10.1002/smj.4250100208

Muller, A., Välikangas, L., \& Merlyn, P. (2005). Metrics for innovation: guidelines for developing a customized suite of innovation metrics. Strategy \& Leadership, 33(1), 3745. http://doi.org/10.1108/10878570510572590

Muller, M. (1997). Institutional Resilience in a Changing World Economy? The Case of the German Bankking and Chemical Industries. British Journal of Industrial Relations, 35(4), 609-626. http://doi.org/10.1111/1467-8543.00071

Munasinghe, M. (1993). Environmental economics and sustainable development. World Bank Publications. 
Nag, R., Hambrick, D. C., \& Chen, M. (2007). What is strategic management, really? Inductive derivation of a consensus definition of the field. Strategic Management Journal, 28(9), 935-955. http://doi.org/10.1002/smj.615

Naldi, L., Wikström, P., \& Von Rimscha, M. (2014). Dynamic Capabilities and Performance. International Studies of Management and Organization, 44(4), 63-82. http://doi.org/10.2753/IMO0020-8825440404

Narayanan, V. K., Colwell, K., \& Douglas, F. L. (2009). Building Organizational and Scientific Platforms in the Pharmaceutical Industry: A Process Perspective on the Development of Dynamic Capabilities. British Journal of Management, 20, S25-S40. http://doi.org/10.1111/j.1467-8551.2008.00611.x

Newey, L. R., \& Zahra, S. A. (2009). The Evolving Firm: How Dynamic and Operating Capabilities Interact to Enable Entrepreneurship. British Journal of Management, 20, S81-S100. http://doi.org/10.1111/j.1467-8551.2008.00614.x

New Zealand Treasury. (2010, January). Special Topic: Recession and recovery in the OECD - The Treasury - New Zealand. Retrieved September 23, 2011, from http://www.treasury.govt.nz/economy/mei/jan10/03.htm

Ng, T. (2013). Organizational Resilience and Adversity Quotient of Singapore Companies. In International Proceedings of Economics Development and Research (Vol. 65, pp. 8185). Singapore, Singapore: IACSIT Press. Retrieved from http://search.proquest.com.helicon.vuw.ac.nz/docview/1522270243?pqorigsite $=$ summon

Obstfeld, M., \& Rogoff, K. (2005). The Unsustainable US Current Account Position Revisited (CEPR Discussion Papers No. 5416). C.E.P.R. Discussion Papers. Retrieved from http://www.cepr.org/pubs/dps/DP5416.asp

Oliver, P. (2006). The SAGE Dictionary of Social Research Methods (1st ed., Vol. 1). 1 Oliver's Yard, 55 City Road, London England EC1Y 1SP United Kingdom: SAGE Publications, Ltd. Retrieved from http://srmo.sagepub.com/view/the-sage-dictionaryof-social-research-methods/SAGE.xml

Omerzel, D. G., \& Gulev, R. E. (2011). Knowledge Resources and Competitive Advantage. Managing Global Transitions, 9(4), 335-354. 
Oppenheim, A. (1994). Questionnaire Design, Interviewing and Attitude Measurement. Journal of Community \& Applied Social Psychology, 4(5), 371-372. http://doi.org/10.1002/casp.2450040506

Ovans, A. (2015). What Resilience Means, and Why It Matters. Retrieved July 8, 2015, from https://hbr.org/2015/01/what-resilience-means-and-why-it-matters

Oxford University Press. (2010). Oxford English Dictionary. Oxford: Oxford University Press.

Palich, L. E., Cardinal, L. B., \& Miller, C. C. (2000). Curvilinearity in the diversificationperformance linkage: An examination of over three decades... Strategic Management Journal, 21(2), 155.

Patton, M. Q. (2001). Qualitative Research \& Evaluation Methods (3rd ed.). Sage Publications, Inc.

Pehrsson, T., Ghannad, N., Pehrsson, A., Abt, T., Chen, S., Erath, F., \& Hammarstig, T. (2015). Dynamic capabilities and performance in foreign markets: Developments within international new ventures. Journal of International Entrepreneurship, 13(1), 28-48. http://doi.org/http://dx.doi.org.helicon.vuw.ac.nz/10.1007/s10843-014-0139-z

Pendry, D. (2009, February 27). Three Top Economists Agree 2009 Worst Financial Crisis Since Great Depression; Risks Increase if Right Steps are Not Taken | Reuters. Business Wire. $\quad$ Cambridge. $\quad$ Retrieved from http://www.reuters.com/article/2009/02/27/idUS193520+27-Feb-2009+BW20090227

Perrow, C. (1984). Normal accidents: living with high-risk technologies. Princeton University Press.

Peteraf, M. A. (1993). The cornerstones of competitive advantage: A resource-based view. Strategic Management Journal, 14(3), 179-191. http://doi.org/10.1002/smj.4250140303

Petricevic, O. (2013). Architecture of firm dynamic capabilities across inter-organizational activities: Explaining innovativeness in the context of nanotechnology (Ph.D.). Georgia State University, United States -- Georgia. Retrieved from http://search.proquest.com.helicon.vuw.ac.nz/docview/1353675206/abstract/2CE34F4 8EC48A5PQ/1?accountid=14782

Pettigrew, A. M., Thomas, H., \& Whittington, R. (2001). Handbook of Strategy and Management. SAGE. 
Pfeffer, J., \& Sutton, R. I. (2006). Hard Facts, Dangerous Half-Truths And Total Nonsense: Profiting From Evidence-Based Management (1st ed.). Harvard Business Press.

Phillips, D. C., \& Burbules, N. C. (2000). Postpositivism and educational research. Rowman \& Littlefield.

Pickett, S. T. A., Cadenasso, M. L., \& Grove, J. M. (2004). Resilient cities: meaning, models, and metaphor for integrating the ecological, socio-economic, and planning realms. Landscape and Urban Planning, 69(4), 369-384. http://doi.org/10.1016/j.landurbplan.2003.10.035

Pillis, E. de, \& Reardon, K. K. (2007). The influence of personality traits and persuasive messages on entrepreneurial intention: A cross-cultural comparison. Career Development International, $12(4)$ $382-396$. http://doi.org/10.1108/13620430710756762

Portes, A. (1998). Social Capital: Its Origins and Applications in Modern Sociology. Annual Review of Sociology, 24, 1-24.

Prahalad, C. K., \& Hamel, G. (1990). The Core Competence of the Corporation. Harvard Business Review, 68(3), 78-91.

Pryor, N. (2012, October 12). Manufacturing crisis “disastrous.” Stuff.co.nz. New Zealand. Retrieved from http://www.stuff.co.nz/business/industries/7808109/Manufacturingcrisis-disastrous

Quinn, R. E. (1999). Strategic Outsourcing: Leveraging Knowledge Capabilities. Sloan Management Review, 40(4), 105.

Rajagopalan, N., \& Spreitzer, G. M. (1997). Toward a Theory of Strategic Change: A MultiLens Perspective and Integrative Framework. Academy of Management Review, 22(1), 48-79. http://doi.org/10.5465/AMR.1997.9707180259

Raja, J. Z., Bourne, D., Goffin, K., Çakkol, M., \& Martinez, V. (2013). Achieving Customer Satisfaction through Integrated Products and Services: An Exploratory Study. Journal of Product Innovation Management, 30(6), 1128-1144. http://doi.org/10.1111/jpim.12050

Rajan, V. P. (1985). A Two-factor Classification of Competitive Strategy Variables: Summary. Strategic Management Journal (pre-1986), 6(4), 357. 
Redl, F. (1969). Adolecscents - Just how do they react? In G. Coplen \& S. Debovci (Eds.), Adolescence: psychosocial perspectives. Basic Books.

Reinmoeller, P., \& van Baardwijk, N. (2005). The link between Diversity and Resilience. Sloan Management Review, 7.

Robert E. Morgan, Carolyn A. Strong, \& Tony McGuinness. (2003). Product-market positioning and prospector strategy. European Journal of Marketing, 37(10), 14091439. http://doi.org/10.1108/03090560310487176

Robson, C. (2002). Real World Research: A Resource for Social Scientists and PractitionerResearchers (2 edition). Oxford, UK; Madden, Mass: Wiley-Blackwell.

Rohan, M. J., \& Zanna, M. P. (n.d.). Values and Ideologies, 458-478. http://doi.org/10.1002/9780470998519.ch21

Rose, A. (2004). Defining and measuring economic resilience to disasters. Disaster Prevention and Management, 13(4), 307-314. http://doi.org/10.1108/09653560410556528

Rouse, M. J., \& Daellenbach, U. S. (1999). Rethinking research methods for the resource-based perspective: Isolating sources of sustainable... Strategic Management Journal, 20(5), 487.

Rudd, K. (2009, February 1). The Global Financial Crisis. The Monthly. Retrieved from http://www.themonthly.com.au/issue/2009/february/1319602475/kevin-rudd/globalfinancial-crisis

Rumelt, R. (1984). Towards a Strategic Theory of the Firm. In R. Lamb (Ed.), Resources, firms, and strategies: a reader in the resource-based perspective. Oxford University Press.

Rumelt, R. (2011). Good Strategy Bad Strategy: The Difference and Why It Matters. Crown Business.

Rumelt, R. P. (1982). Diversification strategy and profitability. Strategic Management Journal, 3(4), 359-369. http://doi.org/10.1002/smj.4250030407

Sabherwal, R., Hirschheim, R., \& Goles, T. (2001). The Dynamics of Alignment: Insights from a Punctuated Equilibrium Model. Organization Science, 12(2), 179-197.

Saldana, J. (2009). The Coding Manual for Qualitative Researchers. Sage Publications Ltd. 
Salenborg, E., Stålered, T., Sandberg, S., \& Hultén, B. (2013). Recession-proofing: A case study of how Small and Medium-sized Enterprises remain resilient during times of recession.

Sambamurthy, V., Bharadwaj, A., \& Grover, V. (2003). Shaping Agility through Digital Options: Reconceptualizing the Role of Information Technology in Contemporary Firms. Management Information Systems Quarterly, 27(2). Retrieved from http://aisel.aisnet.org/misq/vol27/iss2/5

Schilke, O. (2014). Second-Order Dynamic Capabilities: How Do They Matter? Academy of Management Perspectives, 28(4), 368-380. http://doi.org/10.5465/amp.2013.0093

Schwartz, N. D. (2009, March 20). Rapid Declines in Manufacturing Spread Global Anxiety. The New York Times. $\quad$ Retrieved from http://www.nytimes.com/2009/03/20/business/worldbusiness/20shrink.html

Seidman, I. (1997). Interviewing as Qualitative Research (2 Sub). Teachers College Press.

Senyard, J. M., Baker, T., Davidson, P., \& Steffens, P. (2010). Entrepreneurial Bricolage And Firm Performance: Moderating Effects Of Firm Change And Innovativeness (pp. 610). Presented at the Academy of Management, Montreal, Canada.

Seville, E. (2006). Resilience: what does it mean for an organisation? Retrieved from http://www.theicor.org/art/present/art/ARBC00019.pdf

Sheffi, Y. (2005). The Resilient Enterprise: Overcoming Vulnerability for Competitive Advantage (illustrated edition). The MIT Press.

Sheffi, Y., \& Rice, J. B. (2005). A Supply Chain View of the Resilient Enterprise. MIT Sloan Management Review, 47(1), 41.

Sirmon, D. G., \& Hitt, M. A. (2009). Contingencies within dynamic managerial capabilities: Interdependent effects of resource investment and deployment on firm performance. Strategic Management Journal, 30(13), 1375-1394. http://doi.org/http://dx.doi.org.helicon.vuw.ac.nz/10.1002/smj.791

Slade, M. (2009, March 10). Company failures soar by 40pc. New Zealand Herald. Retrieved from

http://www.nzherald.co.nz/business/news/article.cfm?c_id=3\&objectid=10560781 
Smart, J. C., Cameron, K. S., \& Ulrich, D. O. (Eds.). (1986). Transformational Leadership in Colleges and Universities. In Higher education: handbook of theory and research (1 st ed.). Springer.

Starr, R., Newfrock, J., \& Delurey, M. (2003). Enterprise Resilience: Managing Risk in the Networked Economy. Strategy+Business, (30), 12.

Statistics New Zealand. (2010a). A guide to unemployment statisics. Wellington: Statistics New Zealand.

Statistics New Zealand. (2010b). Business Operations Survey: 2010 - Statistics New Zealand - Technical Notes. Retrieved June 11, 2011, from http://www.stats.govt.nz/browse_for_stats/businesses/business_growth_and_innovati on/BusinessOperationsSurvey_HOTP2010/Technical\%20Notes.aspx

Statistics New Zealand. (2010c). Overseas Merchandise Trade: October 2010. Wellington: Statistics New Zealand.

Statistics New Zealand. (2012a). Business Demography Tables. Wellington: Statistics New Zealand.

Statistics New Zealand. (2012b, October 9). Economic Survey of Manufacturing: June 2012 quarter - Statistics New Zealand. Retrieved October 30, 2012, from http://www.stats.govt.nz/browse_for_stats/industry_sectors/manufacturing_and_prod uction/EconomicSurveyofManufacturing_HOTPJun12qtr.aspx

Stephenson, A., Seville, E., Vargo, J., \& Roger, D. (2010). Benchmark Resilience: A study of the resilience of organisatoins in the Auckland Region (p. 49). Auckland: Resilient Organisations.

Strauss, A. C., \& Corbin, J. M. (1998). Basics of Qualitative Research: Second Edition: Techniques and Procedures for Developing Grounded Theory (2nd ed.). Sage Publications, Inc.

Sutcliffe, K. M., \& Vogus, T. J. (2003). Organizing for resilience. In J. E. Dutton, R. E. Quinn, \& K. S. Cameron (Eds.), Positive Organizational Scholarship: Foundations of a New Discipline (1st ed.). Berrett-Koehler Publishers.

Taylor, J. B. (2007). Housing and Monetary Policy. National Bureau of Economic Research Working Paper Series, No. 13682. Retrieved from http://www.nber.org/papers/w13682 
Teece, D. J. (1980). Economies of scope and the scope of the enterprise. Journal of Economic Behavior \& Organization, 1(3), 223-247. http://doi.org/10.1016/0167-2681(80)900025

Teece, D. J. (1986). Profiting from technological innovation: Implications for integration, collaboration, licensing and public policy. Research Policy, 15(6), 285-305. http://doi.org/10.1016/0048-7333(86)90027-2

Teece, D. J. (2007). Explicating dynamic capabilities: the nature and microfoundations of (sustainable) enterprise performance. Strategic Management Journal, 28(13), 13191350. http://doi.org/10.1002/smj.640

Teece, D. J. (2011). Dynamic Capabilities: A Guide for Managers. Ivey Busines Journal, March/April.

Teece, D. J. (2014a). A dynamic capabilities-based entrepreneurial theory of the multinational enterprise. Journal of International Business Studies, 45(1), 8-37. http://doi.org/10.1057/jibs.2013.54

Teece, D. J. (2014b). The Foundations of Enterprise Performance: Dynamic and Ordinary Capabilities in an (economic) Theory of Firms. Academy of Management Perspectives, 28(4), 328-352. http://doi.org/10.5465/amp.2013.0116

Teece, D. J., \& Pisano, G. (1994). The Dynamic Capabilities of Firms: an Introduction. Ind Corp Change, 3(3), 537-a-556. http://doi.org/10.1093/icc/3.3.537-a

Teece, D. J., Pisano, G., \& Shuen, A. (1997). Dynamic capabilities and strategic management. Strategic Management Journal, 18(7), 509-533. http://doi.org/10.1002/(SICI)10970266(199708)18:7<509::AID-SMJ882>3.0.CO;2-Z

The Economist. (2011, September 10). Global business failures; The Economist, 400(8750). Retrieved from http://search.proquest.com.helicon.vuw.ac.nz/docview/888378692

The World Bank. (2012, January 18). Data \& Research - Turbulent Year Ahead for Global Economy. $\quad$ Retrieved $\quad$ February 1, 2012, from http://econ.worldbank.org/WBSITE/EXTERNAL/EXTDEC/0,,contentMDK:2308842 9 pagePK:64165401 piPK:64165026 theSitePK:469372,00.html

Thomke, S., von Hippel, E., \& Franke, R. (1998). Modes of experimentation: an innovation process--and competitive--variable. Research Policy, 27(3), 315-332. http://doi.org/10.1016/S0048-7333(98)00041-9 
Tsai, W., \& Ghoshal, S. (1998). Social Capital and Value Creation: The Role of Intrafirm Networks. The Academy of Management Journal, 41(4), 464-476. http://doi.org/10.2307/257085

Valikangas, L. (2004, May 24). Four Steps to Corporate Resilience. Strategy+Business, 4.

Van de Ven, A. H., \& Poole, M. S. (1995). Explaining Development and Change in Organizations. Academy of Management Review, 20(3), 510-540. http://doi.org/10.5465/AMR.1995.9508080329

Verdinelli, S., \& Scagnoli, N. I. (2013). Data Display in Qualitative Research. Retrieved from https://www.ideals.illinois.edu/handle/2142/45262

Villar, C., Alegre, J., \& Pla-Barber, J. (2014). Exploring the role of knowledge management practices on exports: A dynamic capabilities view. International Business Review, $23(1), 38-44$.

Vogel, R., \& Güttel, W. H. (2012). The Dynamic Capability View in Strategic Management: A Bibliometric Review: DCV in Strategic Management. International Journal of Management Reviews, n/a-n/a. http://doi.org/10.1111/ijmr.12000

Vogus, T. J., \& Sutcliffe, K. M. (2007). Organizational resilience: Towards a theory and research agenda. In IEEE International Conference on Systems, Man and Cybernetics, 2007. ISIC (pp. 3418-3422). IEEE. http://doi.org/10.1109/ICSMC.2007.4414160

Walker, B., Holling, C. S., Carpenter, S., \& Kinzig, A. (2004). Resilience, Adaptability and Transformability in Social--ecological Systems. Ecology and Society, 9(2), 5.

Walker, B., \& Salt, D. (2006). Resilience Thinking: Sustaining Ecosystems and People in a Changing World. Island Press.

Wang, C. L., \& Ahmed, P. K. (2007). Dynamic capabilities: A review and research agenda. International Journal of Management Reviews, 9(1), 31-51. http://doi.org/10.1111/j.1468-2370.2007.00201.x

Webb, B., \& Schlemmer, F. (2006). Resilience as a Source of Competitive Advantage for Small Information Technology Companies. In B. Donnellan, T. J. Larsen, L. Levine, \& J. I. DeGross (Eds.), The Transfer and Diffusion of Information Technology for Organizational Resilience. Boston: Kluwer Academic Publishers. Retrieved from http://gx4ej7nu5f.scholar.serialssolutions.com/?sid=google\&auinit=B\&aulast=Webb 
\&atitle $=$ Resilience + as $+a+$ source + of + competitive + advantage + for + small + information + technology+companies\&id=doi:10.1007/0-387-34410-1_12

Weick, K. E. (1993). The Collapse of Sensemaking in Organizations: The Mann Gulch Disaster. Administrative Science Quarterly, 38(4), 628-652.

Weick, K. E. (1995). Sensemaking in organizations. SAGE.

Weir, J. (2012, October 11). Manufacturing orders hit three-year low. Stuff.co.nz. New Zealand. Retrieved from http:/www.stuff.co.nz/business/industries/7802456/Manufacturingorders-hit-three-year-low

Wernerfelt, B. (1984). A Resource-Based View of the Firm. Strategic Management Journal, 5(2), 171-180.

White, W. R. (2009). Should monetary policy “lean or clean”? (Globalization and Monetary Policy Institute Working Paper). Federal Reserve Bank of Dallas. Retrieved from http://ideas.repec.org/p/fip/feddgw/34.html

Wilhelm, H., Schlömer, M., \& Maurer, I. (2015). How Dynamic Capabilities Affect the Effectiveness and Efficiency of Operating Routines under High and Low Levels of Environmental Dynamism. British Journal of Management, n/a-n/a. http://doi.org/10.1111/1467-8551.12085

Yin, R. K. (2002). Case Study Research: Design and Methods, Third Edition, Applied Social Research Methods Series, Vol 5 (3rd ed.). Sage Publications, Inc.

Yin, R. K. (2010). Qualitative Research from Start to Finish (1st ed.). The Guilford Press.

Zahra, S. A., \& George, G. (2002). The Net-Enabled Business Innovation Cycle and the Evolution of Dynamic Capabilities. Information Systems Research, 13(2), 147-150. http://doi.org/10.1287/isre.13.2.147.90

Zahra, S. A., Sapienza, H. J., \& Davidsson, P. (2006). Entrepreneurship and Dynamic Capabilities: A Review, Model and Research Agenda*. Journal of Management Studies, 43(4), 917-955. http://doi.org/10.1111/j.1467-6486.2006.00616.x

Zajac, E. J., Kraatz, M. S., \& Bresser, R. K. F. (2000). Modeling the dynamics of strategic fit: a normative approach to strategic change. Strategic Management Journal, 21(4), 429453. http://doi.org/10.1002/(SICI)1097-0266(200004)21:4<429::AIDSMJ81>3.0.CO;2-\# 
Zollo, M. (1998). Knowledge codification, process routinization, and the creation of organizational capabilities: Post-acquisition management in the United States banking industry (Ph.D.). University of Pennsylvania, United States -- Pennsylvania. Retrieved from

http://search.proquest.com.helicon.vuw.ac.nz/docview/304477993/abstract?accountid $=14782$

Zollo, M., \& Winter, S. G. (2002). Deliberate Learning and the Evolution of Dynamic Capabilities. Organization $\quad$ Science, 339-351. http://doi.org/10.1287/orsc.13.3.339.2780 
Appendix 1: Alignment Between Identified Resilience and Dynamic Capabilities Concepts

\begin{tabular}{|c|c|c|c|}
\hline \multicolumn{2}{|c|}{ Resilience } & \multicolumn{2}{|c|}{ Dynamic Capabilities } \\
\hline References & Concept & Concept & References \\
\hline $\begin{array}{c}\text { Webb \& } \\
\text { Schlemmer } \\
\text { (2006) }\end{array}$ & $\begin{array}{c}\text { Renew, } \\
\text { Reorganise }\end{array}$ & $\begin{array}{l}\text { Reconfigure, } \\
\text { create, extend, } \\
\text { modify }\end{array}$ & $\begin{array}{l}\text { Sutcliffe \& Vogus } \\
\text { (2007), } \\
\text { Teece (2007, 2011) } \\
\text { Helfat et al. (2007) }\end{array}$ \\
\hline $\begin{array}{c}\text { Hamel \& } \\
\text { Valikangaas } \\
\text { (2003), Weick } \\
\text { (1993), Coutu } \\
\text { (2002), Lengnick- } \\
\text { Hall \& Beck } \\
\text { (2005) }\end{array}$ & Processes & $\begin{array}{c}\text { Processes to } \\
\text { select innovations }\end{array}$ & $\begin{array}{l}\text { Zollo \& Winter } \\
\text { (2002), Teece } \\
\text { (2007, 2011), } \\
\text { Eisenhardt \& } \\
\text { Martin (2000) }\end{array}$ \\
\hline $\begin{array}{l}\text { Sheffi \& Rice } \\
\text { (2005) }\end{array}$ & Flexibility & $\begin{array}{l}\text { Competitive } \\
\text { Flexibility }\end{array}$ & $\begin{array}{c}\text { Teece, Pisano \& } \\
\text { Shuen (1997) }\end{array}$ \\
\hline $\begin{array}{l}\text { Sheffi \& Rice } \\
\text { (2005) }\end{array}$ & Prior Knowledge & $\begin{array}{c}\text { Knowledge, know- } \\
\text { how, }\end{array}$ & $\begin{array}{c}\text { Teece (2007), } \\
\text { Zollo \& Winter } \\
\text { (2002) }\end{array}$ \\
\hline $\begin{array}{c}\text { Reinmoeller \& } \\
\text { van Baardwijk } \\
\text { (2005) }\end{array}$ & Innovation & $\begin{array}{l}\text { Innovation } \\
\text { Capability }\end{array}$ & $\begin{array}{c}\text { Lawson \& } \\
\text { Samson (2001), } \\
\text { Verona \& Ravasi } \\
(2003)\end{array}$ \\
\hline $\begin{array}{c}\text { Lengnick-Hall \& } \\
\text { Beck (2005), } \\
\text { Weick (1993) }\end{array}$ & $\begin{array}{c}\text { Routines, } \\
\text { Functional Habits }\end{array}$ & Routines & $\begin{array}{c}\text { Eisenhardt \& } \\
\text { Martin (2000), } \\
\text { Winter (2003), } \\
\text { Teece \& Pisano } \\
\text { (1997), Zott (2003) }\end{array}$ \\
\hline
\end{tabular}




\begin{tabular}{|c|c|c|c|}
\hline $\begin{array}{c}\text { Sutcliffe \& Vogus } \\
\text { (2007) }\end{array}$ & Margin & $\begin{array}{l}\text { Value Capture } \\
\text { Mechanisms/Capt } \\
\text { uring Co- } \\
\text { specialisation } \\
\text { Economies }\end{array}$ & Teece $(2007,2011)$ \\
\hline $\begin{array}{c}\text { Lengnick-Hall \& } \\
\text { Beck (2005), } \\
\text { (1993), Coutu } \\
\text { (2002), Beunza \& } \\
\text { Stark (2004) } \\
\text { Weick (1993) }\end{array}$ & Sense Making & Sensing & Teece $(2007,2011)$ \\
\hline $\begin{array}{c}\text { Lengnick-Hall \& } \\
\text { Beck (2005), } \\
\text { Coutu (2002), } \\
\text { Hamel \& } \\
\text { Valikangaas } \\
\text { (2003) }\end{array}$ & $\begin{array}{l}\text { Ideology and } \\
\text { Values }\end{array}$ & $\begin{array}{l}\text { Values, Culture } \\
\text { and Non- } \\
\text { Economic Factors }\end{array}$ & Teece $(2007,2011)$ \\
\hline $\begin{array}{l}\text { Lengnick-Hall \& } \\
\text { Beck (2005) }\end{array}$ & Social Capital & Social Capital & $\begin{array}{c}\text { Blyler \& Coff } \\
\quad(2003), \\
\text { Subramaniam \& } \\
\text { Youndt (2005) }\end{array}$ \\
\hline $\begin{array}{c}\text { Hamel \& } \\
\text { Valikangaas } \\
(2003)\end{array}$ & Business Model & Business Model & Teece $(2007,2011)$ \\
\hline $\begin{array}{l}\text { Jamrog, McCann, } \\
\text { Lee, Morrison, } \\
\text { Selsky, \& Vickers } \\
\text { (2006), Lengnick- } \\
\text { Hall \& Beck } \\
\text { (2009), McCann \& } \\
\text { Lee (2009) }\end{array}$ & Agility & Agility & $\begin{array}{c}\text { Zahra, Sapienza \& } \\
\text { Davidsson (2006), } \\
\text { Sambamurthy, } \\
\text { Bharadwaj, \& } \\
\text { Grover (2003) }\end{array}$ \\
\hline
\end{tabular}




\section{Appendix 2: Interview Schedule}

1. Can you describe your firm for me please?

2. How were things for your firm before the global financial crisis?

3. So when did the crisis become noticeable to you?

4. When was it at its worst?

5. What were the differences in this period from the year(s) before?

6. What was the biggest or most fundamental problem/issue you faced in this period?

7. What was it like at that peak? What were its effects on your business?

8. How did you adapt your business to function during this period?

9. Can you outline your firm's objectives during the Global Financial Crisis?

10. Is there a relationship between these objectives?

11. Can you describe for me your product and market strategy from before the crisis?

12. Then what was your product and market strategy during the crisis?

13. So what were the real changes to this part of your strategy?

14. Did your firm have any advantages over others before the crisis? What were they?

15. How about during the crisis? did you maintain those same advantages? Or did it/they change? What did it/they change to? 
16. How did your firm compare to others in your industry during the crisis?

17. What were the big changes (if any) you saw in your environment during the crisis?

18. What did you do to address those changes?

19. Were they or do you expect them, to be permanent?

20. What was your approach to investment pre-crisis? What did your channel your investment funds to?

21. And then during the crisis what did you invest in?

22. Tell me about that change in investment what were you hoping to achieve?

23. Before the crisis, what were the crucial aspects or components of your firm that allowed you to compete?

24. What were the crucial aspects of your firm, which allowed you to compete during the crisis?

25. Can you tell me about those changes? What was significant about them to you?

26. Before the crisis, what was your firm's focus for innovation activities?

27. And then how did that change during the crisis?

28. What areas did you focus your innovation efforts in? (Product/Process/Market)

29. Before the Crisis, what were the goals of your innovation process?

30. Then during the crisis, what were you seeking to do with your innovations? 
31. Were any changes your firm made during this period particularly successful?

32. Were any less successful than you expected? Why?

33. How about the rate of innovation? Can you tell me about before and during the crisis? What drove that (if any) change in efforts?

34. Did you resurrect any previously abandoned innovations during the crisis?

35. Do you involve customers or suppliers in the innovation process typically? How about during the crisis? 


\section{Financial Questionnaire}

Completion of this questionnaire implies consent to participation

- What was your company's Book Value per Share in 2009?

- What was your company's Return on Assets in 2009?

- What was your company's price to sales ratio in 2009 ?

- What were your company's earnings per share in 2009 ?

- What is your company's market capitalisation value?

- How much did your company spend (in dollars) on innovation in 2009?

- What was your company's change in sales for 2009 when compared with $2008 ?$

- What was your company's free cash flow in 2009 ?

- How much did your company spend (in dollars) on innovation per employee in 2009 ?

- In 2009 how much did your company spend on research and development as a percentage of the total cost of product development? 


\title{
Appendix 4: Initial Contact Information Letter
}

\author{
18 October 2012
}

Address

Dear (Firm/Manager to Whom It May Concern)

Recently I was interviewing members of another manufacturing firm and your name and that of [Company] was mentioned as potentially being very relevant to my $\mathrm{PhD}$ research project.

The project focuses on highly resilient firms in your industry and understanding how your competitive and innovation strategies enabled you to operate during the recent Global Financial Crisis. Your firm has been identified as potentially being able to provide extremely valuable insight in this area.

As such, I was hoping I might be able to conduct a few short interviews with some members your firm's management. In agreeing to be interviewed, there is no cost to you or your organisation except that of your time. Interviews should take approximately one hour each at most.

Example interview questions include:

- Can you outline your firm's objectives during the Global Financial Crisis?

- Did your firm have any advantages over others before the crisis?

- What were the big changes (if any) you saw in your environment during the crisis?

Please note, all information you provide is confidential. No identifiable features of individuals or firms will be presented in any of the final products of this research, according to Victoria University's Human Ethics Committee guidelines. Further details of the study are in the attached information sheet.

If you are interested in kindly donating your time, please reply to this email indicating the best means of contacting you in order to set up an interview. Should you have any questions, please do not hesitate to contact me or my supervisor Sally Davenport, either by email or phone. I am happy to clarify any details of the study.

This project receives its funding from Industrial Research Limited. My Supervisor Sally Davenport and I thank you for your consideration. 
Sincerely

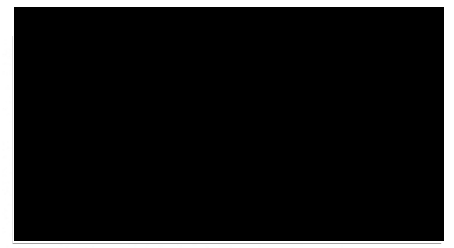

Simon Collins

PhD Researcher

Victoria Management School

Phone: XX XXX XXX

Email: X@XXX.X

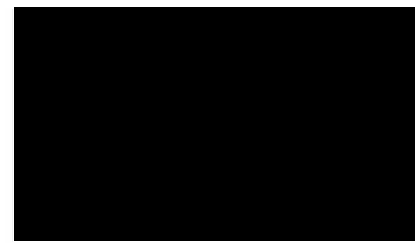

Sally Davenport

Professor of Management

Victoria Management School

Phone: XX XXX XXX

Email: X@XXX.X 